LUIS MIGUEL TEOFANES BENDEZÚ HERNÁNDEZ

\title{
DESENVOLVIMENTO DE UM PROGRAMA COMPUTACIONAL PARA BALANCEAMENTO DE REDES DE DISTRIBUIÇÃO DE AR
}

\author{
Dissertação apresentada à Escola \\ Politécnica da Universidade de São Paulo \\ como requisito para obtenção do título de \\ Mestre em Engenharia.
}

SÃO PAULO

2010 
LUIS MIGUEL TEOFANES BENDEZÚ HERNÁNDEZ

\title{
DESENVOLVIMENTO DE UM PROGRAMA COMPUTACIONAL PARA BALANCEAMENTO DE REDES DE DISTRIBUIÇÃO DE AR
}

\author{
Dissertação apresentada à Escola \\ Politécnica da Universidade de São Paulo \\ como requisito para obtenção do título de \\ Mestre em Engenharia. \\ Área de concentração: \\ Engenharia Mecânica.
}

Orientador:

Prof. Dr. Antonio Luis de Campos Mariani

SÃO PAULO

2010 
Este exemplar foi revisado e alterado em relação à versão original, sob responsabilidade única do autor e com a anuência de seu orientador.

São Paulo, 23 de março de 2010.

Assinatura do autor

Assinatura do orientador

FICHA CATALOGRÁFICA

Bendezu Hernandez, Luis Miguel Teofanes

Desenvolvimento de um programa computacional para balanceamento de redes de distribuição de ar / L.M.T. Bendezu Hernandez. -- ed.rev. -- São Paulo, 2010.

$125 \mathrm{p}$.

Dissertação (Mestrado) - Escola Politécnica da Universidade de São Paulo. Departamento de Engenharia Mecânica.

1. Escoamento (Simulação) 2. Simulação (Modelagem computacional) 3. Ar condicionado (Eficiência) I. Universidade de São Paulo. Escola Politécnica. Departamento de Engenharia Mecânica II. t. 


\section{RESUMO}

O balanceamento de uma rede de distribuição de ar consiste em estabelecer as vazões corretas nos elementos terminais conforme previsto no projeto. A revisão bibliográfica apontou que o balanceamento aplicado à distribuição de ar passou a ser considerado no final dos anos de 1960. A aplicação de modelos matemáticos com a simulação do escoamento do ar nos dutos das redes tem início no final dos anos 80. No presente trabalho o objetivo foi estudar metodologia para simulação e balanceamento de redes de distribuição de ar, implementando-a em um programa de computador. Foram estudados diferentes métodos para realizar 0 balanceamento: método proporcional, método T e o método direto. Foi adotado o direto, em que as vazões são impostas e as diferenças de pressão determinadas para escoamentos em caminhos em paralelo. Mediante o uso de conceitos que fazem analogia entre a fluido-dinâmica e a eletricidade, foi desenvolvido um algoritmo e elaborado um programa de computador. O aplicativo desenvolvido possui 6 etapas principais: caracterização da rede, perda distribuída, perda localizada, perda total, simulação do escoamento e comparação de caminhos. A partir de um estudo de caso, o programa foi testado simulando uma rede de distribuição. Esta mesma rede teve seu balanceamento avaliado por cálculos em planilha eletrônica. Os resultados do estudo de caso com os valores de pressão para todos os trechos da rede, assim como as diferenças de pressão que definem a magnitude do balanceamento foram comparados e estão coincidentes dentro da margem esperada.

Palavras-chave: Redes de distribuição de ar. Programa para simulação de escoamento. Ar condicionado. Qualidade do ar interno. 


\begin{abstract}
S
The balancing of a net air distribution consists in establishment the correct flowrate in the terminals elements according the design. The bibliographic review show that the balancing applied in air distribution are consider at the 60`s. In the end of the 8012019s the mathematics models beginning applied to air flow simulation in ducts. In the present work the objective is studies the methodology to simulation and balancing air distribution nets using software. Different methods are studies to apply in balance: proportional method, T method and direct method. The direct method is adopted, which the flowrate is fixed and the pressure difference is obtained for the parallel paths. Using fluid-dynamics and electrical analogy concepts an algorithm was developed and a software was prepared. The applicatory developed was divided in 6 main stages: net characterization, continuous losses, local losses, total losses, flow simulation and path comparing. Using a case study the software was tested and the distribution net was simulating. This same net was balancing evaluated by a computational spreadsheet. The case study results present the values of pressure for the sections of the net, and the pressure differences to obtained the balancing. This values was consider coincident with the expected.
\end{abstract}

Keywords: Balancing. Air net distribution. Software flow simulation. Air conditioning. Indoor air quality. 


\section{INTRODUÇÃO}

\subsection{BREVE HISTÓRICO}

Até o final da década de 1950, praticamente não haviam empresas exclusivamente especializadas em Teste, Ajuste, e Balanceamento (TAB) para sistemas de ar condicionado, e faltavam os conhecimentos necessários exigidos para um adequado balanceamento, (LAWSON; GERDON, 1994). As atividades de teste e balanceamento de redes de distribuição de ar eram desordenadas e mal executadas, indicando que havia necessidade de treinar pessoal para realizar estas tarefas. Em conseqüência deste contexto e da necessidade de ampliar o conhecimento neste campo foram fundadas associações independentes e propostos métodos para o balanceamento.

Segundo Lawson (1994), historicamente verifica-se que foram criadas algumas entidades relacionadas ao balanceamento de redes. Em 1965 foi fundado, por um pequeno grupo de engenheiros independentes, o Associated Air Balance Council (AABC) para realizar testes e balanceamento, e em 1976 foi criado o National Enviromental Balancing Bureau (NEBB). A partir de então passam a ser publicadas regulamentações, orientações e manuais sobre o processo de TAB. Exemplos importantes destas publicações relacionadas às instituições são:

- American Society of Heating, Refrigerating, and Air Conditioning Engineer (ASHRAE): Em 1988 publica a Norma 111 para teste e balanceamento "Practices for Measurement, Testing, Adjusting, and Balancing of Building Heating, Ventilation, Air-Conditioning and Refrigeration System".

- Associated Air Balance Council (AABC): Em 1989 edita, "National Standards for Testing and Balancing Heating, Ventilating, and Air Conditioning Systems".

- National Environmental Balancing Bureau (NEBB): Em 1991 publica "Procedural Standards for Testing, Adjusting, Balancing of Environmental Systems".

- Sheet Metal and Air Conditioning Contractors National Association (SMACNA): Em 1993 edita "HVAC Systems - Testing, Adjusting, and Balancing manual". 
No início o TAB desenvolveu-se como uma ciência prática e não uma ciência que utiliza equações e modelos matemáticos. Assim, nos primeiros trabalhos de balanceamento a proposta era medir a vazão de ar e realizar ajustes seqüenciais nos registros até obter o valor especificado no projeto. Este procedimento era repetido para todos os dispositivos da rede de distribuição de ar na edificação, até que toda ela estivesse balanceada.

Em determinados tipos de redes de distribuição de ar as técnicas utilizadas no processo de balanceamento não conduziam à obtenção da vazão, ou seja, o processo não convergia.

\subsection{COLOCAÇÂO DO PROBLEMA}

Atualmente com as recomendações para 0 processo de teste $\mathrm{e}$ balanceamento, têm-se procedimentos definidos, instrumentos e requisitos para realizar o trabalho. Mas ainda há problemas importantes, um deles é a falta de conhecimento do pessoal que trabalha na parte dos testes, que adota o processo de tentativa e erro sem uma metodologia adequada. Em geral não são utilizados métodos e modelos matemáticos para fazer a simulação da rede de distribuição de ar, ou para obter-se previamente valores que modifiquem as resistências nos caminhos do ar, viabilizando o balanceamento. $O$ ideal é que o balanceamento seja realizado como etapa do projeto.

$O$ presente trabalho adota 0 balanceamento como etapa seguinte ao dimensionamento da rede de dutos, sendo colocada como meta a obtenção dos valores de diferencial de pressão relacionados com as vazões de projeto usando um programa de computador desenvolvido e especifico para este fim.

\subsection{MOTIVAÇÃO}

Tendo em vista que nenhum dos métodos de dimensionamento conduz, na maioria das aplicações, à obtenção das vazões de projeto, torna-se necessário adotar o balanceamento da rede de distribuição de ar para que as vazões resultem coincidentes, dentro de uma margem, (SMALL, 2002). Esta margem é definida como, a diferença admitida entre a vazão de projeto e obtida após o balanceamento, e é normalmente de $\pm 5 \%$ de acordo com o proposto pela ASHRAE (1997). 
Este balanceamento deve ser aplicado, entre outros locais, em instalações comerciais, em edifícios de escritórios, e instalações hospitalares, onde os parâmetros que definem condições de conforto e salubridade nos ambientes são importantes tanto para os diferentes tipos de ocupantes, como profissionais ou pacientes em tratamento de saúde.

Segundo Shilei, Neng e Guohui (2005), nas áreas atendidas pelos sistemas de ar condicionado, devido ao aumento de exigências de conforto térmico pelas pessoas na zona de ocupação, o consumo de energia pelos edifícios também foi incrementado. Por isso o balanceamento também é importante para assegurar que $o$ sistema de ar condicionado esteja fornecendo o conforto pleno para o ocupante a um custo de energia mais baixo possível.

\subsection{ESCOPO DO TRABALHO}

O trabalho foi desenvolvido adotando a seqüência de seis passos detalhados a seguir:

\subsubsection{Levantamento bibliográfico}

O desenvolvimento deste trabalho iniciou-se com o levantamento bibliográfico para o estudo da distribuição de ar através do uso de redes de dutos. Foram encontrados artigos, livros, revistas, manuais e com o uso do sistema informatizado ocorreu $\mathrm{o}$ acesso às bases de livros e jornais virtuais. Nesta bibliografia destacaramse artigos publicados em periódicos e nos Transactions da ASHRAE.

\subsubsection{Estudos dos métodos de dimensionamento, simulação e balanceamento}

Nas referências adotadas foram encontrados diversos métodos para determinar as perdas de pressão nas redes de distribuição de ar e realizar o dimensionamento e balanceamento.

Estes foram apresentados no capitulo três, deste trabalho, no item Revisão Bibliográfica. A literatura pesquisada indica o método da perda unitária constante para o processo de dimensionamento de redes, que pode ter associado a si procedimentos que auxiliarão o balanceamento. 


\subsubsection{Desenvolvimento de algoritmo}

Para realizar a simulação de um sistema de redes de dutos foi desenvolvido um algoritmo dividido em 6 etapas: Caracterização da rede, Perdas distribuídas, Perdas localizadas, Perdas totais, Simulação da rede e Comparação de caminhos.

$\mathrm{Na}$ etapa de caracterização da rede são adotados procedimentos para que seja feita a identificação dos elementos da rede de distribuição de ar prédimensionada de modo a facilitar o cadastro no programa. Na etapa de Perda distribuída, são organizados os parâmetros do escoamento e dados preliminares. $\mathrm{Na}$ terceira etapa, identificada como Perdas localizadas são organizados os coeficientes de perda dos acessórios. Na etapa de Perda total são determinados valores resultantes da soma das perdas distribuídas e localizadas para cada trecho da rede. $\mathrm{Na}$ quinta etapa são mostrados todos os fundamentos da modelagem para Simulação da rede, considerando as vazões de projeto e os diferentes caminhos para o escoamento do ar. E finalmente, na última etapa denominada Comparação de caminhos, são adotados critérios para analisar os pares de caminhos em paralelo, e definição de necessidades de balanceamento.

\subsubsection{Escolha de editor base para programação}

Neste passo foi escolhido um editor de programação, com objetivo de estabelecer uma boa interface com o usuário. No início o editor adotado foi o MatLab 2006. Com ele foram feitos testes calculando coeficientes de perda de pressão para trechos de uma rede, sendo que a determinação destes foi realizada mediante equação matricial aplicada a cada trecho. O uso do aplicativo trouxe dificuldades na geração de um programa executável. Isto ocorreu, pois seu uso requer o pacote Simulink, e esta junção não possibilitava a obtenção adequada do executável de modo funcional.

Outro editor estudado foi o Visual Basic 6.0 que contém centenas de instruções, funções e características especiais, além de possibilitar o uso de telas e imagens tais como menus, caixas de diálogo, botões e objetos auxiliando o registro de redes de distribuição de ar. 
Este aplicativo possibilita gerar um programa executável de modo que o usuário não precise ter o aplicativo instalado. Assim pelos motivos expostos foi escolhida esta linguagem, sendo que ela também oferece uma boa interface entre $o$ programa e o usuário.

\subsubsection{Desenvolvimento do Programa}

A implantação do algoritmo para uso através de meios computacionais foi realizada com o desenvolvimento de um programa. Este foi estruturado em Visual Basic e possui 3 partes principais: "Identificação do Projeto", "Inserção de Dados e Cálculos" e "Tabelas de Dados e Resultados".

Na primeira parte é identificado o nome do projeto e nome do usuário a ser cadastrado no Programa.

A segunda parte se encontra dividida em 6 etapas: Caracterização da rede, Perdas distribuídas, Perdas localizadas, Perdas totais, Simulação da rede e Comparação de caminhos. Nestas são inseridos os dados e são simulados os possíveis caminhos percorridos pelo ar.

A terceira parte esta dividida em 4 tabelas: Tabela de caracterização da rede, Tabela de perdas distribuídas, Tabela de perdas localizadas e Tabela de perdas totais. Esta realiza o registro das informações cadastradas e calculadas em arquivos de banco de dados estruturados em Microsoft Access ${ }^{\circledR}$.

\subsubsection{Estudo de caso e aplicação do programa}

Com o objetivo de avaliar o desempenho do programa desenvolvido foram adotadas redes de distribuição de ar, pré-dimensionadas sugeridas por diferentes fontes, como Handbook of Fundamentals - ASHRAE, 1993; HVAC Systems Duct Design - SMACNA, 1990; Bolliger Jr. Mariani A. L.C - Programa SMACNA, 2002; NETSAL \& Associates.- T-Method Duct System Simulator, 1993.

Dois delas foram escolhidos para ser apresentadas neste trabalho como estudo de casos. A instalação da rede de distribuição de ar considerada está proposta no HVAC SYSTEMS DUCT DESIGN - SMACNA, 1990 o outro é proposto pelo Programa SMACNA, 2002. Sendo avaliados todos os trechos com o programa. 


\section{OBJETIVOS}

O principal objetivo deste trabalho é estudar e apresentar uma metodologia para realizar o balanceamento de redes de distribuição de ar, implementado-a em um programa de computador.

Para alcançar o objetivo central são definidas metas secundárias e etapas a seguir relacionadas. Em primeiro lugar faz-se a definição de um algoritmo para simular o escoamento do ar em uma rede pré-dimensionada. Em seguida é feita a escolha do aplicativo que serve como base para o desenvolvimento de um programa executável que receba as informações da rede de dutos e do escoamento. Este deve realizar os cálculos e apresentar os resultados necessários para 0 balanceamento.

O programa desenvolvido deve avaliar redes de distribuição de ar em fase de projeto ou pertencentes a instalações já existentes, e que exijam a realização do TAB. Assim a ferramenta desenvolvida deve facilitar o processo de balanceamento, auxiliando ao engenheiro de projeto ou o profissional de TAB reduzindo o tempo na execução das suas atividades.

A implantação dos resultados obtidos com o balanceamento da rede deve garantir os objetivos da instalação de condicionamento de ar, como por exemplo, colaborar com a obtenção da Qualidade do Ar Interior (QAI) para os ocupantes especialmente com a obtenção de vazões corretas em cada difusor, e velocidade adequada na zona de ocupação. Este equilíbrio entre projeto e execução deve também atender a níveis racionais de uso de energia. 


\section{REVISÃO BIBLIOGRÁFICA}

Foi feito o levantamento da literatura mediante o uso de banco de dados bibliográficos da USP, Sibinet e outras fontes onde se viabilizou artigos sobre o estudo de técnicas de distribuição de ar, redes de dutos, modelos de equacionamento para o dimensionamento e balanceamento.

\subsection{DISTRIBUIÇÃO DE AR}

O desenvolvimento deste trabalho iniciou com o levantamento bibliográfico para o estudo da distribuição de ar através do uso de redes de dutos. Essa distribuição de ar deve produzir fluxos, isto é, movimentos que auxiliem os efeitos de misturar massas de ar, remover e adicionar calor, reter partículas em filtros, garantindo as condições estabelecidas para parâmetros definidos no projeto do sistema. Em última instância ela tem a função de proporcionar uma vazão que será fornecida a cada elemento terminal da rede para a obtenção do conforto térmico em ambientes climatizados.

Segundo Creder (1996), o ar depois de impulsionado pelo ventilador segue através do sistema de dutos, e é distribuído no ambiente condicionado por meio de grelhas e difusores. Por isso, de acordo com Stoecker e Jones (1985), o projetista deve selecionar convenientemente a localização e o tipo dos acessórios para a insuflação, como também a localização das grelhas de retorno.

Ainda segundo Costa (1998), nas instalações de ventilação mecânica o ar de insuflação deve ser distribuído uniformemente sobre as superfícies do local, devendo ser evitadas as correntes de ar desagradáveis, por isso a velocidade do ar na zona de ocupação deve ficar compreendida de acordo aos limites recomendados pela Associação Brasileira de Normas Técnicas (ABNT).

A norma NBR 16401 - Parte 2: Instalações de Ar Condicionado - Sistemas Centrais e Unitários (2008) apresenta os limites para a velocidade de ar, indicando que para sistemas convencionais ela não deve superar $0,20 \mathrm{~m} / \mathrm{s}$ na zona de ocupação. Os valores para a velocidade de ar devem ser limitados de modo a não provocar desconforto aos ocupantes, e os limites podem ser ajustados em função do tipo de sistema de tratamento e da estação do ano. A distribuição do ar estabelece a 
velocidade na zona de ocupação conforme discutem Alexandre (2006) e Bolliger Jr. e Mariani (2002).

Os sistemas de ar condicionado podem ser classificados como de expansão direta ou indireta. Nos sistemas de menor capacidade de refrigeração que operam por expansão direta, como Splits e aparelhos de janela, em geral não há utilização de dutos para distribuição de ar. Nos equipamentos chamados de Self containeds a distribuição de ar é tradicionalmente feita através de dutos com difusores distribuídos pelo teto.

Nos sistemas com expansão indireta, que adotam resfriadores (chillers) e unidades de tratamento de ar (fan coils) a distribuição do ar é, em geral, feita também por rede de dutos no teto ou pelo piso (plenum). Para ambas alternativas, equipamentos com expansão direta ou indireta, também é possível realizar a distribuição do ar lateralmente.

Com bases nas considerações anteriores dois tipos de distribuição de ar que permitem intervenções foram identificados, e serão a seguir analisadas.

\subsubsection{Distribuição de ar pelo teto}

Os estudos de Howell (1999) mostram que em um sistema de distribuição pelo teto, o ar é introduzido por meio de difusores colocados na parte superior do ambiente e seu objetivo é fornecer fluxos que tenham suficiente alcance para cobrir uma região do ambiente, como mostra a figura 3.1.

Atualmente este é o processo de distribuição de ar mais adotado, em virtude de sua alta capacidade de indução e de sua aplicabilidade tanto para inverno como para o verão. O adequado dimensionamento e balanceamento dos dutos da rede garantirão que o ar tenha a movimentação desejada. 


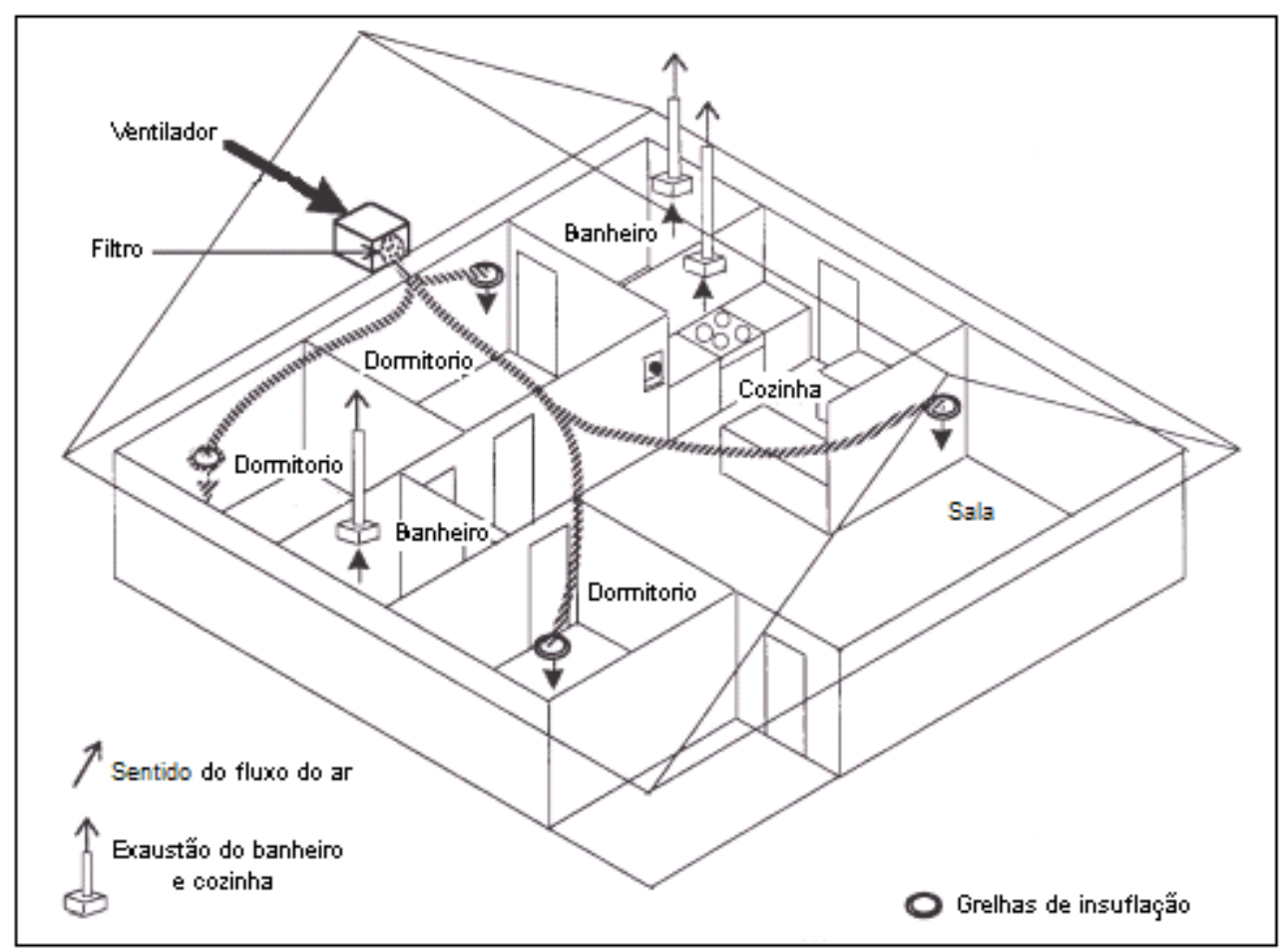

Figura 3.1 - Exemplo de distribuição de ar pelo teto (Adaptado de: Energy Star, 2000)

Os sistemas de distribuição de ar pelo teto podem ser de vazão de ar constante (VAC), ou de vazão de ar variável (VAV).

Os sistemas de vazão de ar constante (VAC) têm esse nome por que mantêm a vazão do ar fornecido para cada espaço condicionado constante e conta com o controle de temperatura para satisfazer as exigências de carga térmica nos diferentes espaços condicionados.

Do ponto de vista do balanceamento os sistemas de vazão de ar constante (VAC) são mais fáceis de dimensionar e de balancear.

Nos sistemas de vazão de ar variável (VAV), o procedimento de balanceamento deve ser adotado para a condição de máxima vazão nas caixas de controle.

Há casos particulares, nos quais pode haver necessidade de verificação do balanceamento para condições críticas que alteram significativamente a distribuição do ar encontrada para a situação de registros e caixas VAV totalmente abertas. 


\subsubsection{Distribuição de ar pelo piso}

O sistema de distribuição de ar pelo piso (Underfloor Air Distribution) representado na figura 3.2, é feito mediante o uso de dutos, ou através de um plenum formado pelo piso elevado, onde estão instalados os difusores, e pela laje, no qual o ar proveniente do fan-coil é descarregado. Este sistema pode ser de vazão de ar constante (VAC) ou de vazão de ar variável (VAV), com o uso de variador de freqüência no ventilador. (LEITE, 2003).

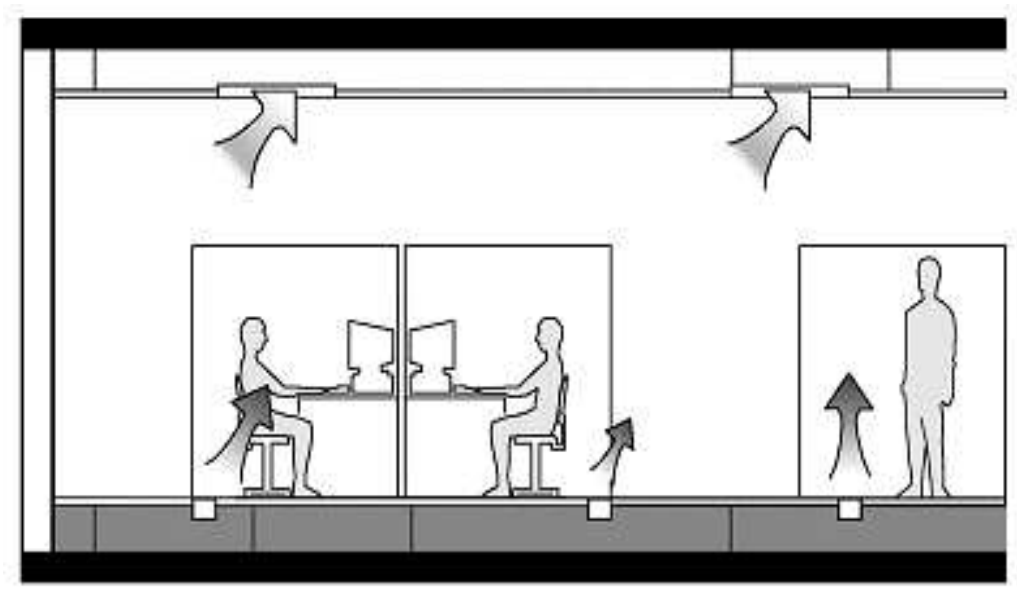

Figura 3.2 - Distribuição de ar pelo piso (ASHRAE Fundamentals Handbook, 2001).

\subsection{EQUACIONAMENTOS PARA DETERMINAR PERDAS DE PRESSÃO}

Nas redes de distribuição e circulação de ar sempre ocorrem perdas quando existe movimentação deste fluido. As perdas ocorrem por atrito viscoso e podem ser agravadas em função do comportamento do escoamento e dos obstáculos impostos ao mesmo. Essas perdas podem ser avaliadas através da variação da pressão total entre dois pontos ou seções distintas do sistema. (BOLLIGER JR., MARIANI, 2002).

De forma geral as perdas em um trecho compreendido entre duas seções e percorrido por uma vazão mássica $(\dot{\mathrm{m}})$ podem ser classificadas em duas grandes categorias: Perdas distribuídas e Perdas Localizadas. 


\subsubsection{Perdas distribuídas}

A perda de pressão distribuída é aquela que ocorre em trechos de dutos retilíneos com seção transversal constante. Ela contabiliza os efeitos do atrito viscoso presente no escoamento do fluido no trecho. A expressão utilizada para determinar o cálculo de perdas distribuídas em dutos foi proposta por "Darcy Weisbach".

$$
\Delta p_{d}=\frac{f \cdot L}{D_{h}} \cdot \frac{V^{2}}{2} \cdot \rho
$$

Onde as variáveis são:

$\Delta \mathrm{p}_{\mathrm{d}}=$ Perda de pressão distribuída

$\mathrm{f}=$ Coeficiente de atrito ou coeficiente de perda distribuída

$\mathrm{L}=$ Comprimento do trecho de duto considerado

$D_{\mathrm{h}}=$ Diâmetro hidráulico

$\rho=$ Massa específica

$V=$ Velocidade média na seção do escoamento

As considerações para aplicação do equacionamento apresentado são:

a) Hipóteses adotadas:

- Escoamento com fluido incompressível ( $\rho=c t e)$

- Propriedades físicas do fluido constante no trecho considerado (escoamento isotérmico)

- Trechos de dutos retos com seção constante, e por conseqüência com mesma velocidade.

b) Determinação do coeficiente de perda distribuída (f):

O coeficiente de perda distribuída, ou de atrito f, é um parâmetro adimensional, portanto independe do sistema de unidades utilizado, porém depende de dois outros adimensionais, rugosidade relativa $\left(\varepsilon / D_{h}\right)$ e número de Reynolds $(R e)$, a seguir detalhados. 
A rugosidade relativa $\left(\varepsilon / D_{h}\right)$ é dada pela relação entre a rugosidade $(\varepsilon)$ e o diâmetro hidráulico $\left(D_{h}\right)$. Sendo $\varepsilon$ a rugosidade da superfície interna do duto (em m ou $\mathrm{mm}$ ) e seu valor é obtido através de tabelas existentes nos manuais ou como dado de fabricante do conduto, em função do material e tempo de uso.

A tabela 3.1 apresenta alguns exemplos de dados para rugosidade de diversos materiais.

$$
\frac{\varepsilon}{D_{h}}
$$

Tabela 3.1 - Rugosidade de superfícies (Stoecker, 1985)

\begin{tabular}{|c|c|}
\hline Material & Rugosidade $\boldsymbol{\varepsilon}(\mathbf{m})$ \\
\hline Aço & $0,0009-0,009$ \\
\hline Concreto & $0,0003-0,003$ \\
\hline Ferro fundido & 0,00026 \\
\hline Chapa metálica & 0,00015 \\
\hline Aço comercial & 0,000046 \\
\hline Tubo estirado & 0,0000015 \\
\hline
\end{tabular}

O diâmetro hidráulico $\left(D_{h}\right)$ é definido pela expressão:

$$
D_{h}=\frac{4 . S}{P_{m}}
$$

Com $S$ = área da seção transversal do trecho do duto em questão.

$\mathrm{P}_{\mathrm{m}}=$ Perímetro molhado: área da seção transversal molhada.

O número de Reynolds $(R e)$ é definido pela relação da equação (4).

$$
R e=\frac{\rho \cdot V \cdot D_{h}}{\mu}
$$


Nesta expressão $\boldsymbol{\mu}$ é a viscosidade dinâmica do fluido à temperatura do escoamento. Na tabela 3.2 são apresentados valores para viscosidade e massa específica do ar seco em função da temperatura.

Tabela 3.2: - Propriedades do ar seco à pressão atmosférica ao nível do mar (Stoecker, 1985)

\begin{tabular}{|c|c|c|}
\hline $\begin{array}{c}\text { Temperatura } \\
\left({ }^{(} \mathbf{C}\right)\end{array}$ & $\begin{array}{c}\text { Viscosidade }(\boldsymbol{\mu}) \\
\text { Pa.s }\end{array}$ & $\begin{array}{c}\text { Massa Específica }(\boldsymbol{\rho}) \\
\mathbf{k g} / \mathbf{m}^{3}\end{array}$ \\
\hline-10 & $1,6768 * 10^{-5}$ & 1,3414 \\
\hline 0 & $1,7238 * 10^{-5}$ & 1,2922 \\
\hline 10 & $1,7708 * 10^{-5}$ & 1,2467 \\
\hline 20 & $1,8178 * 10^{-5}$ & 1,2041 \\
\hline 30 & $1,8648 * 10^{-5}$ & 1,1644 \\
\hline 40 & $1,9118 * 10^{-5}$ & 1,1272 \\
\hline 50 & $1,9588 * 10^{-5}$ & 1,0924 \\
\hline
\end{tabular}

Assim, a partir dos parâmetros apresentados a determinação do valor de $\mathbf{f}$ pode ser feita através de gráficos como o diagrama de Moody, ou através das equações 5,6 ou 7.

No diagrama de Moody pode-se obter o valor de $\mathbf{f}$, a partir dos parâmetros de entrada $(R e)$ e $\left(\varepsilon / D_{h}\right)$, conforme apresentado na figura 3.3

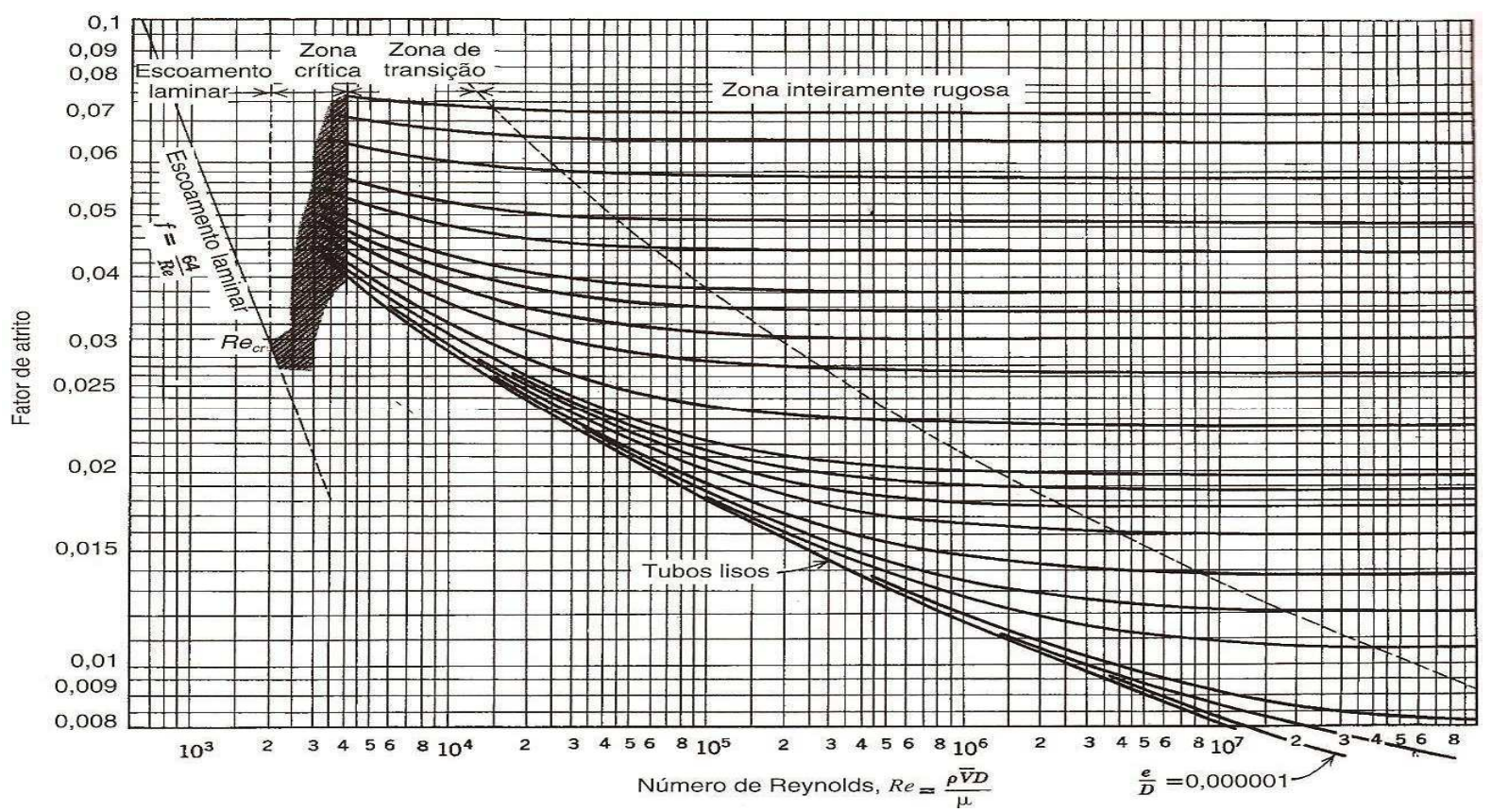

Figura 3.3 - Diagrama de Moody (Fox e MacDonald, 1995). 
Pode-se obter o coeficiente de perda de carga distribuída $\mathbf{f}$ através das equações, (5), (6), (7) em função do regime de escoamento.

Para escoamento em regime laminar $(R e \leq 2400)$, ele depende apenas do número de Reynolds $(R e)$ e é expresso por uma relação linear conforme fórmula de "Hagen - Poiseuille":

$$
f=\frac{64}{R e}
$$

Para escoamento em regime turbulento ( $R e \geq 2700$ ), há diversas equações em que o fator de atrito depende do número de Reynolds $(R e)$ e da rugosidade relativa $\left(\varepsilon / D_{h}\right)$. As equações (6) e (7) são duas alternativas possíveis para o cálculo de f e são atribuídas a Altshul e Colebrook respectivamente. São válidas e possuem resultados com diferenças menores que $5 \%$ para a faixa de número de Reynolds usualmente encontrados nos dutos de ar condicionado e ventilação, que está entre $4 \times 10^{3}$ e $2 \times 10^{5}$.

$$
\begin{gathered}
f=0,11 \cdot\left[\frac{\varepsilon}{D_{h}}+\frac{68}{\operatorname{Re}}\right]^{0,25} \\
\frac{1}{\sqrt{f}}=-2 \cdot \log _{10}\left[\frac{0,27 \cdot \varepsilon}{D_{h}}+\frac{2,51}{\operatorname{Re} \cdot \sqrt{f}}\right]
\end{gathered}
$$

\subsubsection{Perdas localizadas}

Segundo White (2002), para qualquer sistema de tubulações, além das perdas distribuídas por atrito viscoso, deve-se determinar perdas adicionais chamadas perdas localizadas, devidas a:

- Entrada e saída de tubos.

- Expansões ou contrações bruscas e graduais

- Curvas, cotovelos, tês e outros acessórios.

- Válvulas, abertas ou parcialmente fechadas. 
Em geral as perdas localizadas são medidas experimentalmente e correlacionadas com os parâmetros do escoamento, com a geometria da singularidade e com as propriedades do fluido.

Um exemplo de singularidade muito comum nas redes de distribuição de ar são as contrações e expansões de seção como mostram as figuras 3.4 e 3.5 respectivamente, onde o escoamento se dirige do ponto 1 para o ponto 2 .

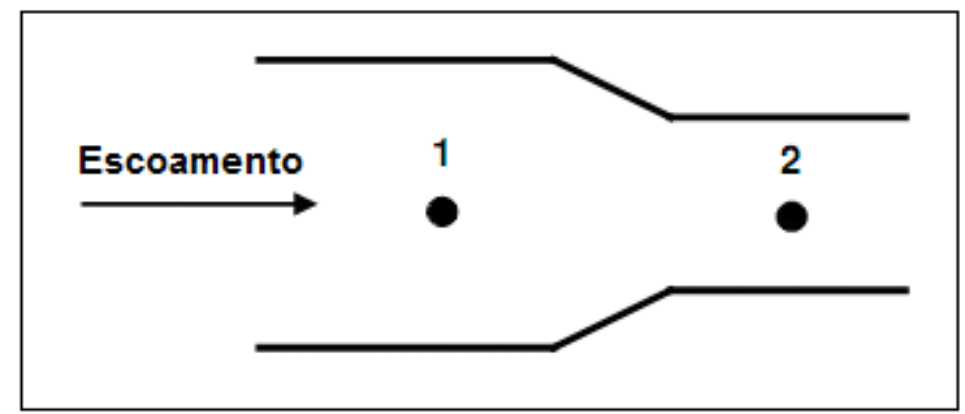

Figura 3.4 - Seção com contração (White, 2002)

A equação para o cálculo da perda singular está dada a seguir:

$$
\Delta \mathrm{p}_{\mathrm{L}}=\text { K. } . \cdot \frac{\left(\mathrm{V}_{2}\right)^{2}}{2}
$$

Na qual K é o coeficiente de perda de carga localizada

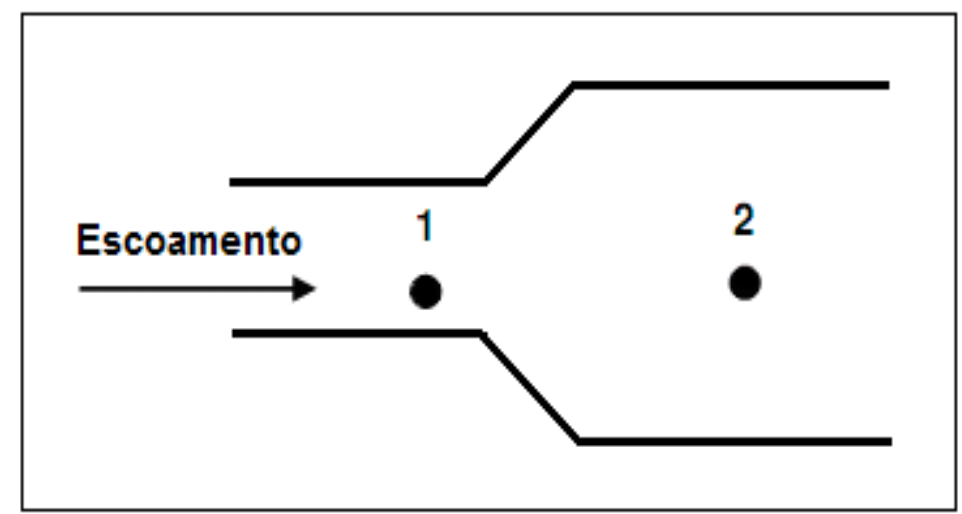

Figura 3.5 - Seção com expansão (White, 2002)

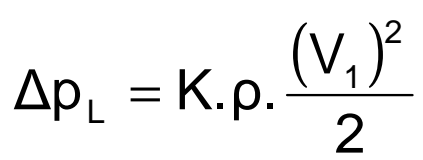


$\mathrm{O}$ coeficiente $\mathrm{K}$ depende do tipo de singularidade. Um exemplo de valores de K para contrações ou expansões bruscas e graduais pode ser observado a partir do gráfico e da tabela apresentados na figura 3.6.

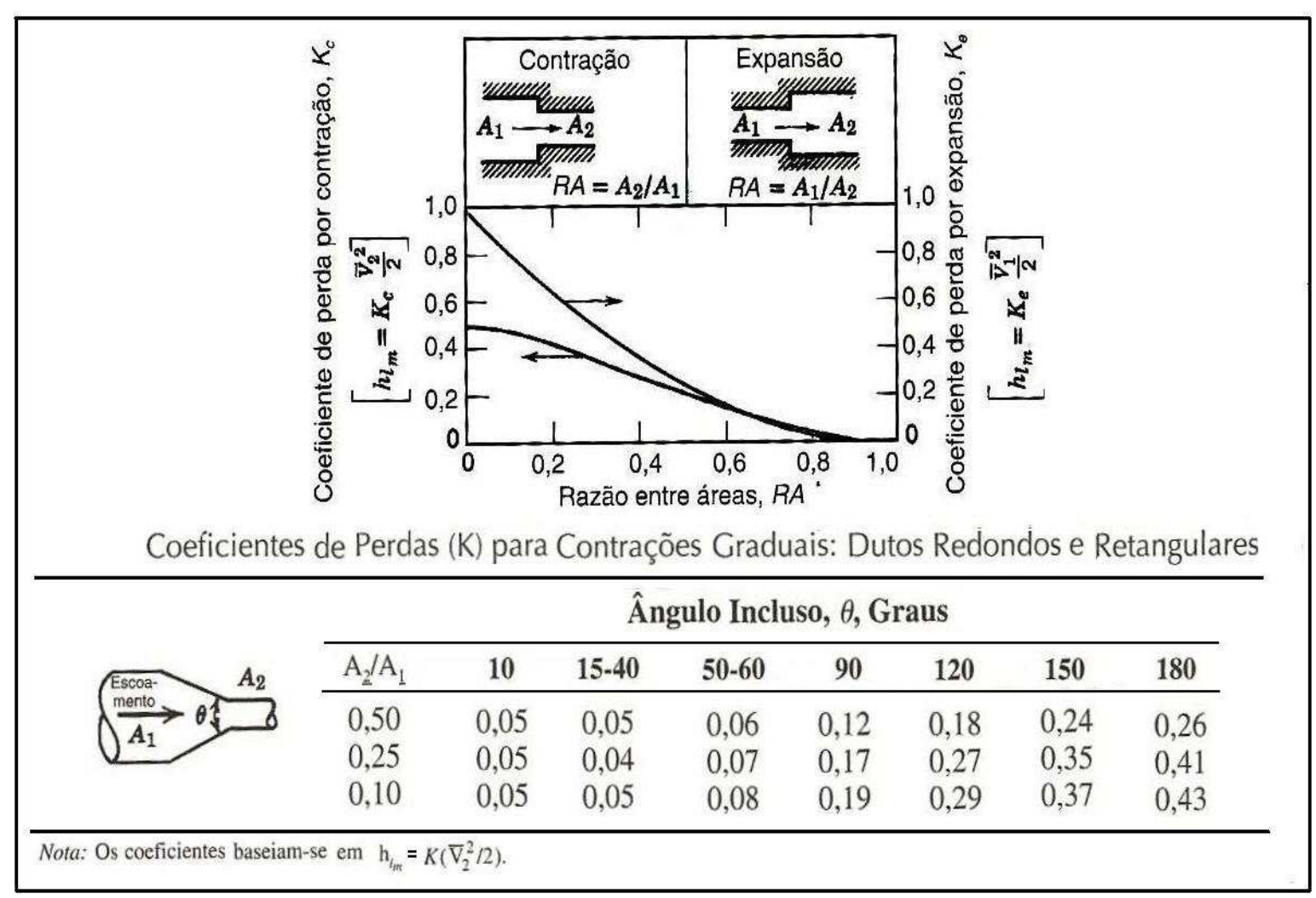

Figura 3.6 - Coeficientes de perda para contrações e expansões

(Fox e MacDonald, 1995).

\subsection{MODELOS PARA ANÁLISE DE REDES DE DUTOS}

De acordo com Bolliger Jr. e Mariani (2002), para resolver as equações aplicadas a redes de condutos que contêm dois ou mais trechos, pode-se estabelecer modelos que auxiliem nos cálculos e simulações destes. Há semelhanças entre esses modelos e as equações que são adotadas para tratar os circuitos elétricos.

\subsubsection{Analogia elétrica aplicada a redes de distribuição de ar}

Uma analogia entre a fluido-dinâmica e a eletricidade pode ser estabelecida de acordo com a tabela 3.3. 
Tabela 3.3 - Analogia entre grandezas em sistemas fluido-dinâmicos e elétricos (Bolliger Jr. e Mariani, 2002).

\begin{tabular}{|c|c|}
\hline $\begin{array}{c}\text { Sistema Fluido- } \\
\text { dinâmico }\end{array}$ & Sistema Elétrico \\
\hline$\Delta \mathrm{p}$ & $\Delta \mathrm{V}$ \\
\hline$\dot{\mathrm{m}}$ & $\mathrm{I}$ \\
\hline
\end{tabular}

As grandezas são:

$\Delta \mathrm{p}=$ Perda de pressão entre dois pontos.

$\Delta \mathrm{V}=$ Diferencial de potencial elétrico entre dois pontos.

$\dot{\mathrm{m}}$ = Vazão mássica .

I = Intensidade de corrente elétrica.

A analogia entre o escoamento de fluido e o fluxo de corrente elétrica pode ser representada através das leis de Kirchoff da eletricidade aplicadas a situações fluido-dinâmicas, a seguir descritas.

\section{$\underline{1^{a} \text { Lei de Kirchoff }}$}

Esta primeira lei, que está relacionada com o princípio da continuidade, indica que em um nó a soma das vazões mássicas de entrada é igual à soma das vazões mássicas de saída. Um exemplo da aplicação desta lei está apresentado na figura 3.7.

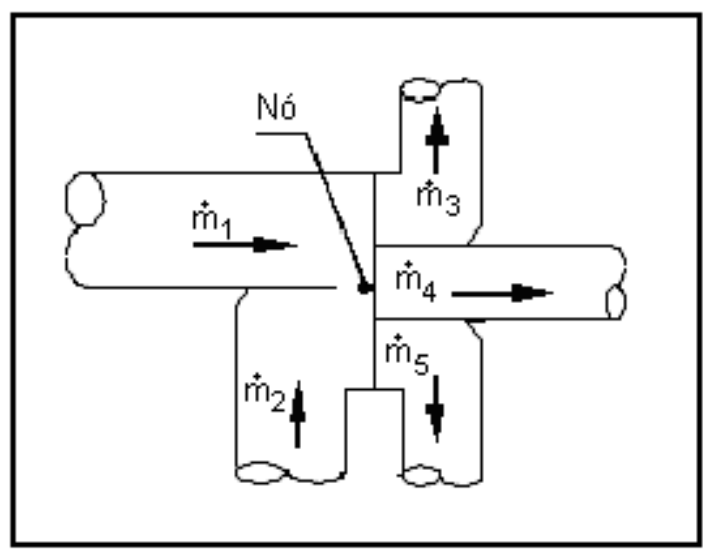

Figura 3.7 - Vazões mássicas de entrada e saída de um nó da rede. (Bolliger Jr. e Mariani, 2002). 
O equacionamento estabelecido para o exemplo é:

$$
\dot{m}_{1}+\dot{m}_{2}=\dot{m}_{3}+\dot{m}_{4}+\dot{m}_{5}
$$

Genericamente para regime permanente, esta lei pode ser dada por:

$$
\left(\sum_{i=1}^{n} \dot{m} i\right)_{\text {entrada }}=\left(\sum_{j=1}^{K} \dot{m} j\right)_{\text {saida }}
$$

\section{$\underline{2^{\underline{a}} \text { Lei de Kirchoff }}$}

Esta segunda lei é similar à aplicação da equação da energia entre duas seções comuns a trechos de dutos em paralelo. Neste caso as perdas de pressão se igualam nestes trechos. Na figura 3.8, há um exemplo, no qual a perda de pressão entre os pontos A e B é o mesmo pelos dois caminhos possíveis, tanto através do trecho principal com um trocador de calor, quanto através do circuito de by-pass onde há um registro.

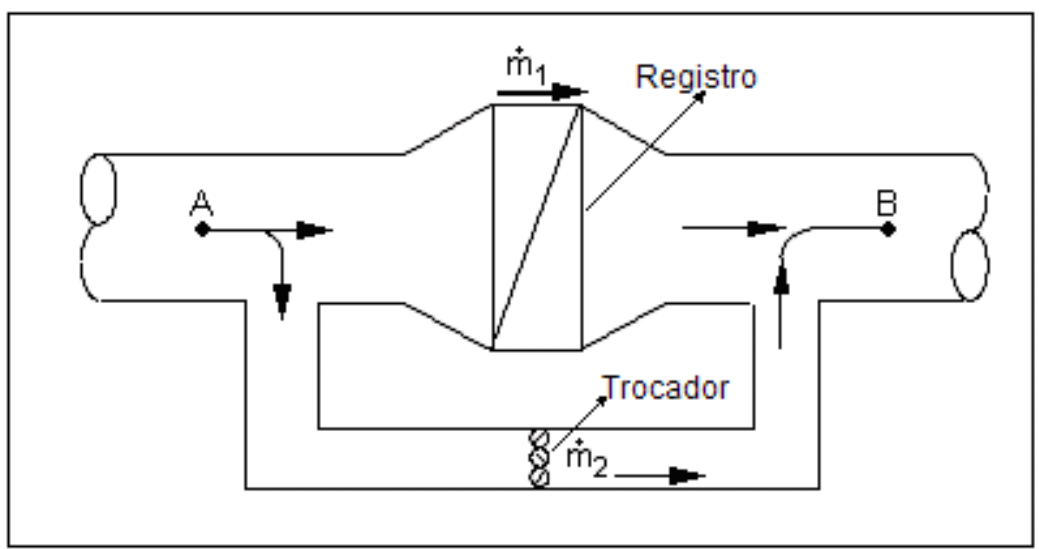

Figura 3.8 - Trechos da rede dispostos em paralelo (Bolliger Jr. e Mariani, 2002)

O equacionamento estabelecido no exemplo da figura 3.8 é:

$$
\left(\Delta \mathrm{p}_{\mathrm{A}-\mathrm{B}}\right)_{\text {trocador }}=\left(\Delta \mathrm{p}_{\mathrm{A}-\mathrm{B}}\right)_{\text {registro }}
$$

Equação geral para trechos em paralelo:

$$
\left(\Delta \mathrm{p}_{\mathrm{A}-\mathrm{B}}\right)_{\text {caminho } 1}=\left(\Delta \mathrm{p}_{\mathrm{A}-\mathrm{B}}\right)_{\text {caminho } 2}=\left(\Delta \mathrm{p}_{\mathrm{A}-\mathrm{B}}\right)_{\text {caminho } \mathrm{n}}
$$


$\mathrm{Na}$ modelagem de redes de condutos que são analisadas para fins de balanceamento devem ser aplicadas as leis de Kirchoff e estabelecidos os equacionamentos a partir das mesmas.

\subsubsection{Resistência fluido-dinâmica}

O conceito de "resistência fluido-dinâmica" é análogo ao de resistência elétrica e é inerente às características geométricas e do regime do escoamento não se identificando com as perdas de pressão correspondentes, sendo as vazões mássicas conseqüentes da diferença de pressão e das resistências fluido-dinâmicas, ou seja:

$$
\dot{m}=f(\Delta p, R) \text { ou } \Delta p=f(R, \dot{m})
$$

A relação entre a vazão mássica e a perda de pressão através de um elemento de um circuito, na sua forma mais geral, é obtida pela expressão:

$$
\Delta \mathrm{p}=\mathrm{R} \cdot \dot{\mathrm{m}}^{2}+\mathrm{R}_{1} \cdot \dot{\mathrm{m}}
$$

Se o regime for totalmente turbulento tem-se que $R_{1}$ é nulo e a equação (15) se reduz a:

$$
\Delta \mathrm{p}=\mathrm{R} \cdot \mathrm{m}^{2}
$$

A figura 3.9 ilustra esta situação:

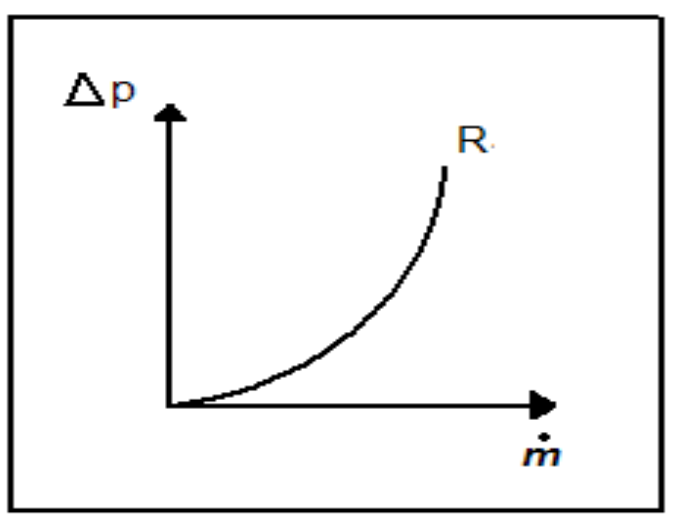

Figura 3.9 - Comportamento típico da perda de pressão em função da vazão mássica para regime turbulento (Bolliger Jr. e Mariani, 2002) 
A resistência $\mathrm{R}$ se identifica como a constante da parábola e é associada aos componentes dos sistemas HVAC, tais como:

- Serpentina.

- Filtros.

- Registros.

- Difusores.

- Dutos, etc.

Para regime laminar a resistência $R$ é nula e há dependência linear entre $\Delta p$ e $\dot{m}$, relacionada pela resistência $R_{1}$, conforme equação (17) e figura 3.10.

$$
\Delta \mathrm{p}=\mathrm{R}_{1} \cdot \dot{\mathrm{m}}
$$

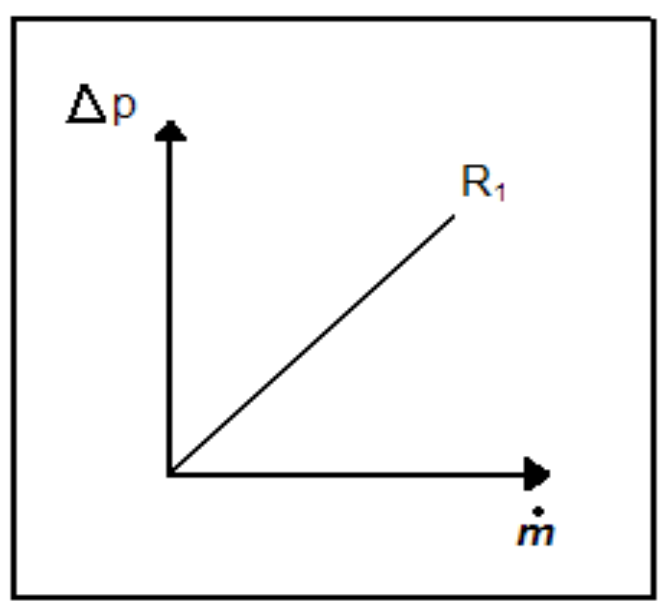

Figura 3.10 - Comportamento típico da perda de pressão em função da vazão mássica para regime laminar (Bolliger Jr. e Mariani, 2002) 


\subsubsection{Relação entre resistência com o coeficiente de perda}

Tomando as equações (1) e (8) que permitem calcular respectivamente as perdas distribuídas e localizadas, isolando o termo comum da pressão dinâmica, pode-se utilizar um coeficiente de perda $\mathbf{C}$ genérico, e obter a relação dada pela equação (18):

$$
\begin{aligned}
& \Delta p_{d}=\frac{f \cdot L}{D_{h}} \cdot \rho \frac{V^{2}}{2} \\
& \Delta p_{L}=K \cdot \rho \frac{V^{2}}{2} \\
& \Delta p=C \cdot \rho \frac{V^{2}}{2}
\end{aligned}
$$

Em regime de escoamento turbulento a equação (16) pode ser reescrita em termos de velocidade para poder ser comparada com a equação (18) e obter-se uma relação entre o coeficiente de perda $\mathbf{C}$ e a resistência fluido-dinâmica $\mathbf{R}$.

$$
\begin{gathered}
\Delta p=R \cdot m^{2}=R \cdot \rho^{2} \cdot V^{2} \cdot S^{2}=C \cdot \rho \cdot \frac{V^{2}}{2} \\
\therefore R=\frac{C}{2 \cdot \rho \cdot S^{2}}
\end{gathered}
$$

Para regime de escoamento laminar a equação (17) também pode ser reescrita em termos de velocidade para poder ser comparada com a equação (18) de modo a obter-se uma relação entre o coeficiente de perda $\mathbf{C}$ e a resistência fluido-dinâmica $\mathbf{R}$.

$$
\Delta p=R_{1} \cdot m=R_{1} \cdot \rho \cdot V \cdot S=C \cdot \rho \cdot \frac{V^{2}}{2}
$$




$$
\therefore \mathrm{R}_{1}=\frac{\mathrm{C}}{\mathrm{S}}
$$

\subsubsection{Disposição dos trechos em uma rede de distribuição de ar}

Nas redes de distribuição de ar são encontrados trechos com condutos em série e em paralelo. White (2002) apresenta propostas para estabelecer os equacionamentos nos casos de sistemas com múltiplos condutos que relacionam as vazões e as perdas, conforme pode ser visto nos tópicos seguintes.

\section{Condutos em série}

É um conjunto de dois ou mais condutos posicionados seqüencialmente onde a mesma vazão passa por todos eles. A figura 3.11 mostra um esquema com três condutos em série.

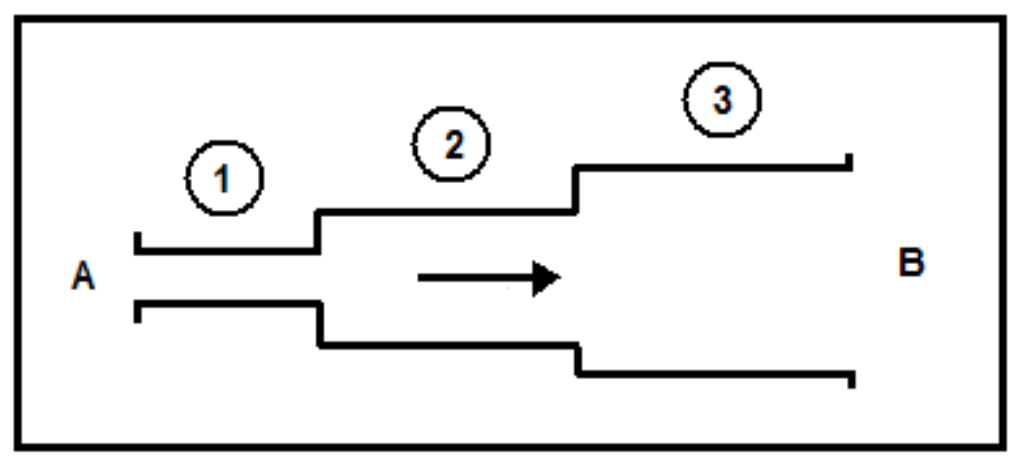

Figura 3.11 - Condutos em série (White, 2002)

Considerando três condutos em série pode-se equacionar as vazões que os atravessam por:

$$
\mathrm{Q}_{\mathrm{A}-\mathrm{B}}=\mathrm{Q}_{1}=\mathrm{Q}_{2}=\mathrm{Q}_{3}=\text { constante }
$$

Outra propriedade de condutos em série indica que a perda total através do conjunto é igual à soma das perdas em cada conduto. 


$$
\Delta \mathrm{p}_{\mathrm{A}-\mathrm{B}}=\Delta \mathrm{p}_{1}+\Delta \mathrm{p}_{2}+\Delta \mathrm{p}_{3}
$$

As perdas distribuídas e localizadas em cada duto devem ser somadas para obter-se a perda total entre os extremos $A$ e $B$ do conjunto, conforme a equação (25).

$$
\Delta p_{A-B}=\left(\frac{f_{1} \cdot L_{1}}{D_{1}}+\sum K_{1}\right) \frac{V_{1}^{2} \cdot \rho}{2}+\left(\frac{f_{2} \cdot L_{2}}{D_{2}}+\sum K_{2}\right) \frac{V_{2}^{2} \cdot \rho}{2}+\left(\frac{f_{3} \cdot L_{3}}{D_{3}}+\sum K_{3}\right) \frac{V_{3}^{2} \cdot \rho}{2}
$$

\section{Condutos em paralelo}

Os condutos são considerados em paralelo quando o início e o final de cada um deles está conectado a seções comuns a todos. Neste caso a vazão total na seção comum inicial iguala-se à da seção final, e pode ser determinada como a soma das vazões que atravessam cada conduto. A figura 3.12 mostra uma instalação de três condutos em paralelo.

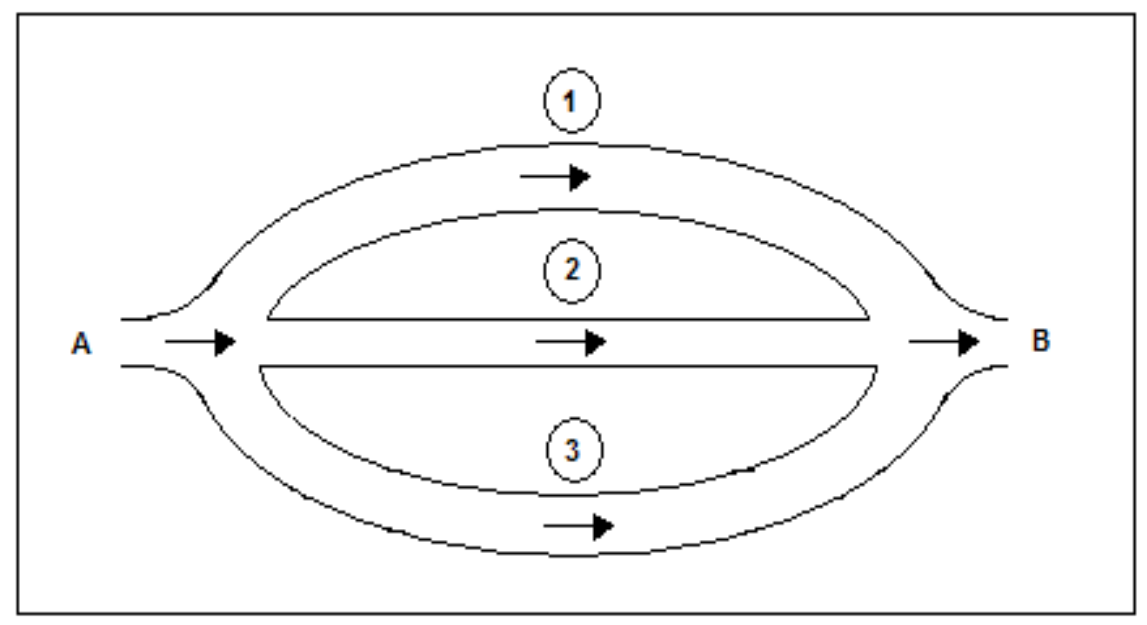

Figura 3.12 - Condutos em paralelo (White, 2002)

Pode-se equacionar as vazões que atravessam o conjunto de três condutos em paralelo da seguinte forma:

$$
\mathrm{Q}_{\mathrm{A}-\mathrm{B}}=\mathrm{Q}_{1}+\mathrm{Q}_{2}+\mathrm{Q}_{3}
$$


Outra propriedade de condutos em paralelo indica que a perda total através do conjunto é igual à perda que ocorre em cada um deles.

$$
\Delta p_{A-B}=\Delta p_{1}=\Delta p_{2}=\Delta p_{3}
$$

Tomando as perdas distribuídas e localizadas em cada duto, pode-se reescrever a equação (27) como:

$$
\Delta \mathrm{p}_{\mathrm{A}-\mathrm{B}}=\left(\frac{\mathrm{f}_{1} \cdot \mathrm{L}_{1}}{\mathrm{D}_{1}}+\sum \mathrm{K}_{1}\right) \cdot \frac{\mathrm{V}_{1}^{2} \cdot \rho}{2}=\left(\frac{\mathrm{f}_{2} \cdot \mathrm{L}_{2}}{\mathrm{D}_{2}}+\sum \mathrm{K}_{2}\right) \cdot \frac{\mathrm{V}_{2}^{2} \cdot \rho}{2}=\left(\frac{\mathrm{f}_{3} \cdot \mathrm{L}_{3}}{\mathrm{D}_{3}}+\sum \mathrm{K}_{3}\right) \cdot \frac{\mathrm{V}_{3}^{2} \cdot \rho}{2}
$$

\subsubsection{Resistência em sistemas onde o regime de escoamento em cada componente é turbulento}

\section{Trecho de componentes em série}

Percorridos pela mesma vazão mássica conforme figura 3.13

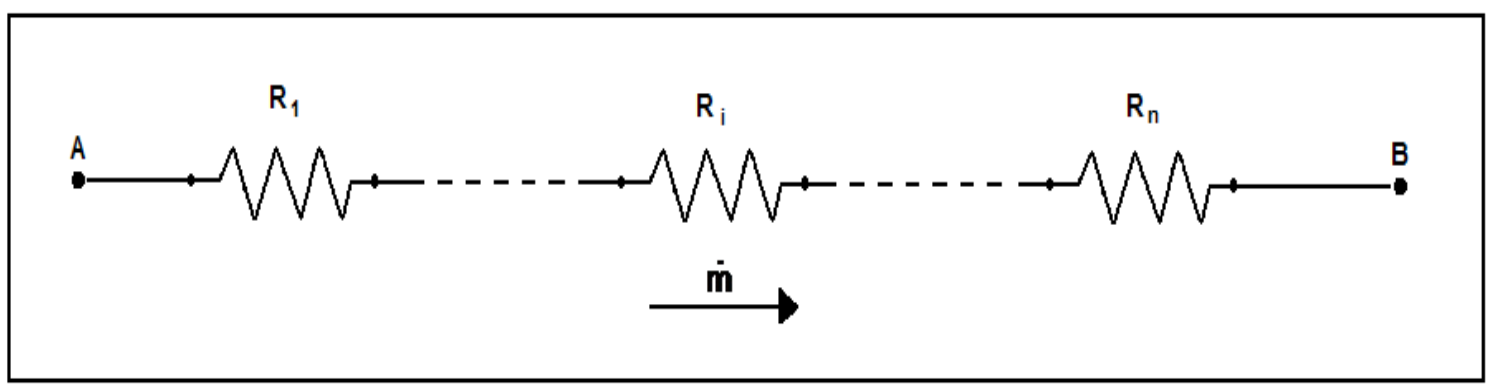

Figura 3.13 - Trechos com componentes em série

(Bolliger Jr. e Mariani, 2002)

$$
\begin{gathered}
\Delta \mathrm{p}_{\mathrm{A}-\mathrm{B}}=\Delta \mathrm{p}_{1}+\Delta \mathrm{p}_{2}+\ldots+\Delta \mathrm{p}_{\mathrm{i}}+\ldots+\Delta \mathrm{p}_{\mathrm{n}} \\
\Delta \mathrm{p}_{\mathrm{i}}=\mathrm{R}_{\mathrm{i}} \cdot \dot{\mathrm{m}}^{2} \\
\Delta \mathrm{p}_{\mathrm{A}-\mathrm{B}}=\mathrm{R}_{\text {eq }} \cdot \dot{\mathrm{m}}^{2}
\end{gathered}
$$




$$
\begin{gathered}
\therefore \Delta \mathrm{p}_{\mathrm{A}-\mathrm{B}}=\sum \Delta \mathrm{p}_{\mathrm{i}}=\sum \mathrm{R}_{\mathrm{i}} \cdot \dot{\mathrm{m}}^{2}=\dot{\mathrm{m}}^{2} \cdot \sum \mathrm{R}_{\mathrm{i}} \\
\therefore \Delta \mathrm{p}_{\mathrm{A}-\mathrm{B}}=\mathrm{R}_{\text {eq }} \cdot \dot{\mathrm{m}}^{2}=\dot{\mathrm{m}}^{2} \cdot \sum \mathrm{R}_{\mathrm{i}}
\end{gathered}
$$

e por tanto

$$
\mathrm{R}_{\text {eq }}=\sum \mathrm{R}_{\mathrm{i}}=\sum \frac{\mathrm{C}_{\mathrm{i}}}{2 \mathrm{~S}_{\mathrm{i}}{ }^{2} \rho_{\mathrm{i}}}
$$

Pode-se concluir que nos trechos de componentes em série a resistência associada ao trecho é a soma das resistências dos componentes.

\section{Trecho de componentes em paralelo}

De acordo com as leis de Kirchoff e da figura 3.14.

$$
\begin{aligned}
& \dot{m}=\dot{m}_{1}+\dot{m}_{2}+\ldots+\dot{m}_{i}+\ldots+\dot{m}_{n} \\
& \Delta \mathrm{p}_{\mathrm{A}-\mathrm{B}}=\Delta \mathrm{p}_{1}=\Delta \mathrm{p}_{2}=\ldots=\Delta \mathrm{p}_{\mathrm{i}}=\ldots=\Delta \mathrm{p}_{\mathrm{n}}=\Delta \mathrm{p} \\
& \Delta_{\mathrm{i}}=\mathrm{R}_{\mathrm{i}} \dot{\mathrm{m}}_{\mathrm{i}}^{2} \\
& \mathrm{p} \\
& \underset{p}{\Delta}=\mathrm{R}_{\mathrm{q}}^{\mathrm{e}}{ }^{*} \dot{\mathrm{m}}^{2} \rightarrow \dot{\mathrm{m}}=\frac{\sqrt{\Delta}}{\sqrt{\mathrm{R}_{\substack{\mathrm{q} \\
\mathrm{q}}}}}
\end{aligned}
$$




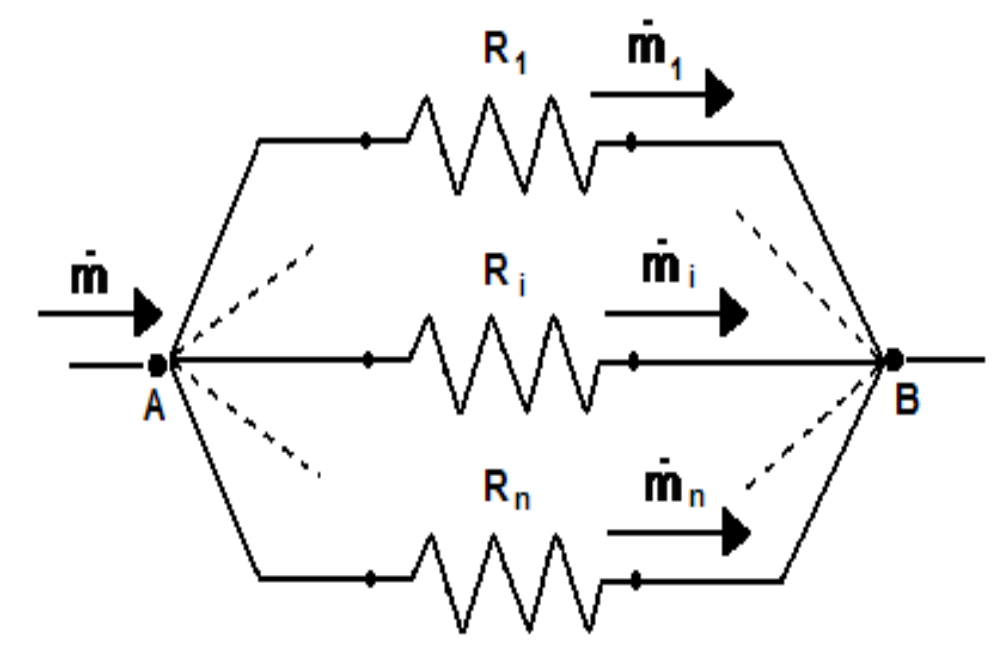

Figura 3.14 - Trechos com componentes em paralelo (Bolliger Jr. e Mariani, 2002)

Pode-se concluir que nos trechos de componentes em paralelo a resistência equivalente associada ao trecho é dada por:

$$
\mathrm{R}_{\mathrm{eq}}=\frac{1}{\left(\sum \frac{1}{\mathrm{R}_{\mathrm{i}}}\right)^{2}}
$$

\subsection{REDES DE DISTRIBUIÇÃO DE AR E SEU DIMENSIONAMENTO}

Segundo Stoecker (1985), um sistema de redes de dutos consiste em trechos, cotovelos, ramificações de entrada e de saída, difusores, etc. No dimensionamento de sistemas de dutos, existem perdas de pressão introduzidas por filtros e trocadores de calor que devem ser também consideradas. As principais exigências para os dutos são:

- Conduzir as vazões de ar especificadas aos locais apropriados.

- Menor custo do ponto de vista de fabricação, de instalação e de operação dos ventiladores.

- Ocupar o menor espaço possível do edifício.

- Não transmitir nem gerar ruído inadequado. 
Segundo Besant e Asiedu (2000), as redes de distribuição de ar devem ser dimensionadas para gerarem níveis baixos de ruído. Nos casos em que a principal fonte de ruído é o ventilador de insuflação, ou de retorno (se houver), os dutos podem ter a função de absorver o ruído gerado.

Em ambientes ocupados por pessoas, onde o objetivo é o conforto humano, a rede de distribuição do ar tem como finalidade central colaborar na garantia da qualidade do ar interno. Em ambientes com outros objetivos ela possui relevante importância, por exemplo, para as áreas industriais, e em ambientes hospitalares, nos quais a prioridade é respectivamente atender requisitos associados à fabricação de produtos, e garantia de salubridade.

Essas redes de dutos podem possuir diferentes características, em função dos parâmetros que definem a movimentação do ar: pressão, velocidade, vazão, etc. $O$ projeto de sistemas de dutos envolve uma série de decisões que devem ser tomadas de maneira metódica e racional para garantir dimensões razoáveis com velocidades do ar adequadas. (STOECKER, 1985).

Os métodos para o dimensionamento de redes de dutos são:

- Velocidade Constante.

- Redução de Velocidade.

- Recuperação de Pressão Estática.

- Perda Unitária Constante.

- Trecho de Seção Constante.

Suas características serão apresentadas a seguir:

\subsubsection{Método da velocidade constante}

Segundo Bolliger Jr. e Mariani (2002), o método de velocidade constante consiste em dimensionar o duto de forma a manter uma vazão com a velocidade constante. Não havendo problemas de ruído pode ser utilizado como vantagem de economia de chapa, com captores especiais a serem adotados antes das mudanças de direção a $90^{\circ}$. 
Neste método as velocidades do ar nos dutos e nos difusores são especificadas previamente, determinando assim a perda de carga. Com isso podese determinar um ventilador adequado que satisfaça a perda de carga máxima com a vazão do sistema. Os valores recomendáveis de velocidades variam em função da aplicação. Deve-se ter presente que velocidades altas provocarão perdas de carga altas e por tanto um custo operacional alto do ventilador como também se podem ter problemas de ruído.

\subsubsection{Método da redução de velocidade}

Yamane e Saito (1986) indicam que este método é o mais simples e mais direto. O método de redução de velocidade é semelhante ao método de velocidade constante, mas envolve diferentes velocidades para diferentes tamanhos de dutos, com a redução de velocidade, no sentido do fluxo de ar.

Para o dimensionamento dos trechos este método não se prende a nenhuma condição especifica como em outros casos, podendo as velocidades resultar de forma aleatória dentro das disponibilidades de espaço e de ruído, o que pode apresentar problemas de balanceamento das vazões de projeto. Pode haver também necessidade de dispositivos especiais que dispensam a geração de pressão estática para a distribuição à 90․ Com exceção de casos de dutos simples, ou para situações em que o projetista possui muita prática, este método não é muito adequado, nem recomendável.

\subsubsection{Método da recuperação de pressão estática}

O método de recuperação estática propõe que a redução de velocidade (no sentido do ar) de um trecho para outro cause um ganho de pressão estática no trecho seguinte igual à perda de pressão estática no mesmo trecho, de modo a manter aproximadamente constante o nível estático em todos os nós da rede.

Estudos de Howell et al. (1999), diz que o método é especialmente adaptado para velocidades altas, e em instalações com trechos de grandes comprimentos. Este método é vantajoso uma vez que as pressões na rede, o controle do dimensionamento dos dutos e as velocidades são conhecidos. 


\subsubsection{Método da perda unitária constante}

Segundo Bolliger Jr. e Mariani (2002), este método propõe que, escolhida a velocidade máxima no trecho da rede próximo ao ventilador, duto principal, a velocidade de projeto deste mesmo trecho permite determinar a perda unitária de pressão (perda de pressão por unidade de comprimento). O dimensionamento dos demais trechos é feito conservando a mesma perda unitária inicialmente determinada. De acordo com Stoecker (1985), com este método se obtém um melhor resultado para o dimensionamento das redes de dutos. Os passos para a aplicação do método são:

- Determinar vazões mássicas para cada trecho.

- Introduzir a velocidade máxima no primeiro trecho, considerar como variável de interação dos demais trechos.

- Calcular as velocidades mássicas obtidas pelos produtos das velocidades volumétricas padrões, pela massa específica do local de ar.

- Obter as áreas das seções correspondentes (das vazões e velocidades mássicas), para dutos de seção retangular ou circular $\left(D_{h}\right)$.

- Calcular o número de Reynolds para cada trecho.

- Calcular o coeficiente de atrito (f) para cada trecho.

- Determinar as pressões dinâmicas correspondentes.

- Determinar as perdas unitárias de pressão.

\subsubsection{Método dos trechos de seção constante}

Este método dimensiona o tronco de seção constante com a vazão mais elevada. Quanto maior for à velocidade correspondente ao trecho, maior a dificuldade de balanceamento do duto nas vazões de projeto.

\subsection{BALANCEAMENTO EM REDES DE DISTRIBUIÇÃO DE AR}

\subsubsection{Primórdios e evolução}

Os sistemas de distribuição de ar como são conhecidos hoje, não foram instalados até depois da segunda guerra mundial, obtendo-se a calefação por meio 
de vapor de água e a ventilação era obtida por meios mecânicos. O trabalho de Bevirt (1994) resume que nesse tempo muitos dos trabalhos de teste e balanceamento foram insatisfatórios, criando a necessidade de treinamento do pessoal relacionado com o balanceamento, fornecendo assim a capacidade para realizar os trabalhos em sistemas de distribuição de ar.

Segundo Lawson (1994), até finais da década dos anos 50, não existiam empresas dedicadas exclusivamente a teste e balanceamento de sistemas de distribuição de ar, e o balanceamento era realizado por empresas que faziam instalações de calefação, ventilação e ar condicionado, carecendo da experiência necessária para a obtenção do TAB. Como conseqüência desta necessidade foram criadas empresas para realização destes procedimentos, e a evolução destas companhias nos Estados Unidos da América do Norte está relacionada à sua organização em instituições como a Associated Air Balance Council (AABC) fundada em 1965, e ao National Environmental Balancing Bureau (NEBB) criado em 1976.

Para Lawson e Gerdon (1994), no início da prática do balanceamento foi necessário estabelecer técnicas para a medição de vazão do ar distribuído através das redes, para em seguida posicionar registros manualmente. Um dos pontos críticos neste processo era a obtenção com exatidão dos valores de vazão, conforme discute Mariani (2000). O procedimento adotado nesta época era principalmente realizado em campo, através da repetição da medição seguida de ajuste com a finalidade de atingir o balanceamento em cada área.

A tendência de realizar o balanceamento depois da instalação estar concluída era reforçada pela consideração adotada por profissionais de projeto, de que alguns métodos de dimensionamento utilizados para rede de dutos conduziam ao "autobalanceamento". Sendo que o método "Recuperação de pressão estática" era citado como o mais eficaz para atingir este objetivo. Em seu artigo "Fallacy of the static regain duct design method" os professores Tsal e Behls (1988) criticam este paradigma que supõe o balanceamento resultante do dimensionamento.

A discussão apresentada por Tsal e Behls no seu dois artigos (1988a, 1988b), aprofundada em projeto de pesquisa patrocinado pela ASHRAE, levou à proposta de realizar-se a análise do balanceamento como etapa de projeto da rede.

Surge a proposta do Método "T" apresentada por Tsal, Belhs e Mangel (1990) para realizar a simulação de redes de distribuição de ar e suas conseqüências, 
como otimização e análise econômica (TSAL, BEHLS, 1988b), e avaliação de vazamentos (TSAL, BEHLS e VARVAK, 1988a e 1988b).

No final dos anos 80 e na década de 1990, a exigência de melhor qualidade na avaliação de desempenho das instalações de ar condicionado e ventilação influenciou a evolução dos estudos, análises e procedimentos adotados para realização do TAB.

Conforme Mariani (1998), Alexandre (1999) e Howard III (1999), dois fatores passaram a influenciar a exigência de balanceamento adequado para as instalações: garantia da Qualidade do Ar Interior (QAI) e otimização do uso de energia.

Em seu artigo Nolfo (2001) preocupa-se em valorizar o TAB descrevendo uma seqüência de passos para efetuar o balanceamento em instalações existentes. $O$ primeiro passo é o teste para determinação do estado de operação dos equipamentos, seguido do ajuste dos dispositivos de controle da vazão de ar em busca do balanceamento, de modo a obter os valores propostos pelo projeto.

Segundo Gerdon (1996) o balanceamento na indústria de calefação, ventilação e ar condicionado desenvolveu-se como ciência prática e não uma ciência definida por equações matemáticas. Ele indica que o objetivo das empresas que atuam em balanceamento é testar e avaliar a capacidade de todos os equipamentos da instalação e dos dispositivos de controle da vazão de ar. O autor enfatiza que estas empresas usualmente realizam ajustes de modo empírico para tentar atingir as condições de projeto.

O trabalho de Sun (1996) discute a importância da unidade de tratamento de ar atender sua finalidade de resfriar ou esquentar 0 ar para satisfazer as necessidades térmicas dos ocupantes com taxas de renovação do ar adequadas. Recordando que $\mathrm{o}$ ar fornecido aos ambientes retorna ao equipamento para ser resfriado ou aquecido, e ser misturado ao ar externo que irá proporcionar uma ventilação adequada e com qualidade na zona de ocupação. $O$ autor discute alternativas para a saída da parcela do ar que será renovado considerando possibilidades para o descarte através de banheiros e de outras áreas onde ocorre à circulação de ar. A figura 3.15 mostra o esquema de um sistema de tratamento de ar que exige balanceamento da distribuição de ar nos ambientes integrado com a operação dos equipamentos de exaustão de áreas adjacentes e com o efeito de pressurização. $O$ balanceamento deve considerar que a vazão em massa do ar de 
retorno é igual à vazão insuflada menos a soma das vazões de exaustão e a quantidade de ar necessária para pressurização.

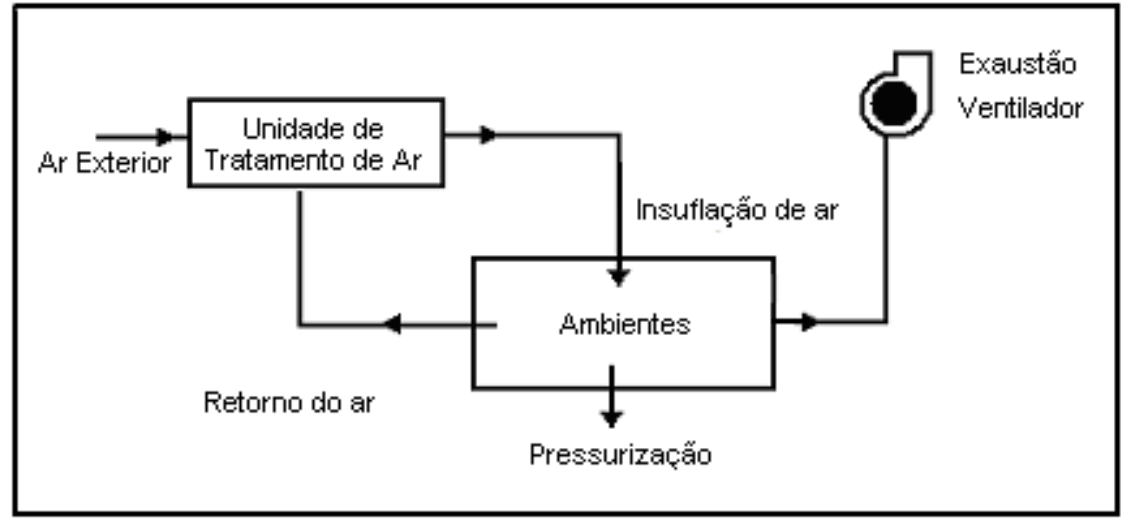

Figura 3.15 - Balanceamento na unidade de tratamento de ar (Adaptado de Sun, 1996)

Ao final do processo de balanceamento obtêm-se as vazões resultantes em cada equipamento de movimentação de ar. Pode ocorrer que a atuação sobre os registros para ajustes estabeleça valores de vazões proporcionais nos terminais, porém a vazão total pode ser menor que a de projeto, e assim surge a necessidade de aumentá-la. Duas possibilidades podem ser consideradas: troca do equipamento de ventilação ou aumento da rotação do ventilador.

\subsubsection{Redes de dutos e balanceamento}

A distribuição de ar por uma rede de dutos é muito importante para que uma instalação de ar condicionado opere com qualidade garantindo que a quantidade adequada de ar chegue a cada região dos ambientes. Diversos autores discutem a importância do balanceamento das redes de distribuição de ar.

A SMACNA (1990) analisando os métodos de dimensionamento conclui que, na maioria das aplicações, nenhum dos métodos conduz diretamente ao balanceamento da rede de distribuição de ar. Assim, torna-se necessário realizar o balanceamento destas para que as vazões resultem coincidentes com os valores de projeto, dentro de uma margem. A margem, isto é, a diferença admitida entre a vazão de projeto e a obtida após o balanceamento, é normalmente de $\pm 5 \%$ de acordo com o proposto pela ASHRAE (1997).

O trabalho de Besant e Asiedu (2000) recomenda a utilização do método $\mathrm{T}$, que será explicado no tópico 3.5.4.2, para auxiliar o dimensionamento e o 
balanceamento das redes de dutos. Este pode ser aplicado utilizando-se um programa de computador que facilita a obtenção dos resultados em menor tempo, sendo atraente na execução e avaliação dos projetos.

Segundo Brooks (1995), além do dimensionamento dos dutos, sua fabricação e instalação são muitos importantes. Alguns itens como avaliação do espaço ocupado por eles, custo e balanceamento devem ser considerados no pré-projeto. $O$ autor destaca que um dimensionamento muito deficiente da rede de dutos, sem balanceamento, pode resultar em condições que exigirão do ventilador, o fornecimento de maior pressão, incrementando a quantidade de energia utilizada.

\subsubsection{Medição de vazão para o balanceamento}

Conforme foi afirmado, um dos pontos críticos para a realização do balanceamento em uma rede existente é medir com exatidão os valores de vazão de ar em cada trecho da instalação. Ainda que a faixa de tolerância $( \pm 5 \%)$ para os valores de vazão medidos não seja muito pequena, dependendo dos locais, padrões de escoamento e instrumentação disponíveis pode-se obter incertezas acima de $20 \%$ nos resultados (MARIANI, 1998).

Assim, a experiência reunida nas publicações das instituições já citadas como, AABC, ASHRAE, NEBB e SMACNA, apresentam um conjunto de técnicas e orientações para realizar medições de vazão em dutos e acessórios terminais de redes. Algumas destas técnicas e instrumentos são apresentados nos próximos itens.

\subsubsection{Medições em seções transversais de dutos}

Em geral faz-se a determinação da vazão na seção transversal do duto a partir do valor da velocidade média e da área desta seção. O desafio está na determinação da velocidade média, pois a distribuição de velocidades pode não ser uniforme.

Para determinar a velocidade média utiliza-se usualmente um instrumento que avalia a velocidade local, em um ponto, como o Tubo de Pitot, e é preciso definir uma técnica e posições para realizar as medições. Alternativas para dutos com 
seção transversal retangular são apresentadas em dois exemplos a seguir, conforme sugestões da SMACNA, e do AABC.

A proposta da SMACNA (1993), que é indicada para perfis de velocidades uniformes é $\mathrm{o}$ método de áreas iguais. A figura 3.16 representa a posição onde 0 instrumento deve ser colocado.

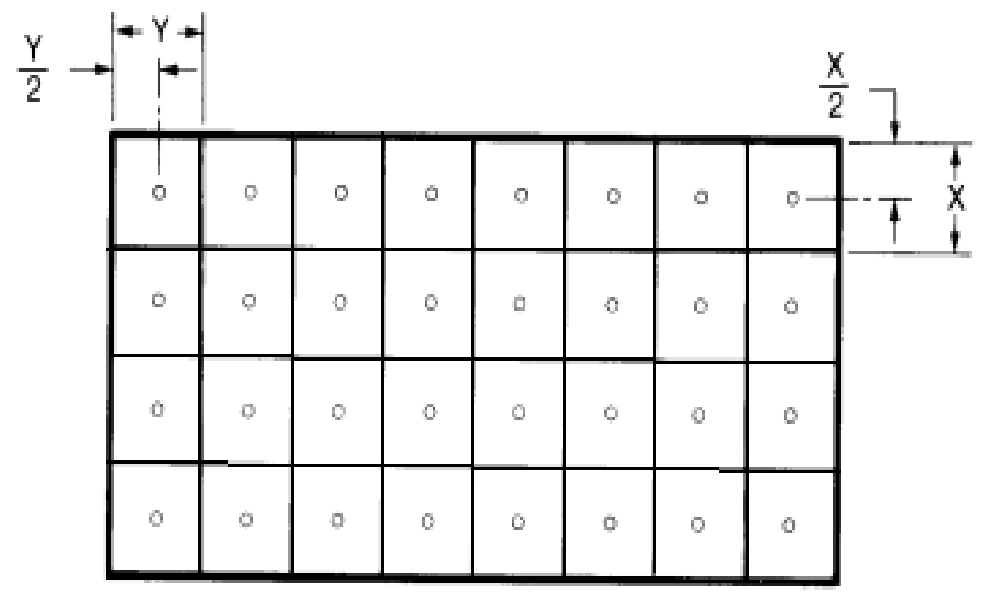

Figura 3.16 - Exemplo da determinação dos pontos de medição (SMACNA, 1993)

Uma alternativa proposta pela $A A B C$ (1989) pode ser utilizada para obter medições com maior exatidão, em testes com perfil de velocidades com significativas variações de valores, especificamente nos pontos próximos às paredes do duto. A figura 3.17 mostra um exemplo deste método.

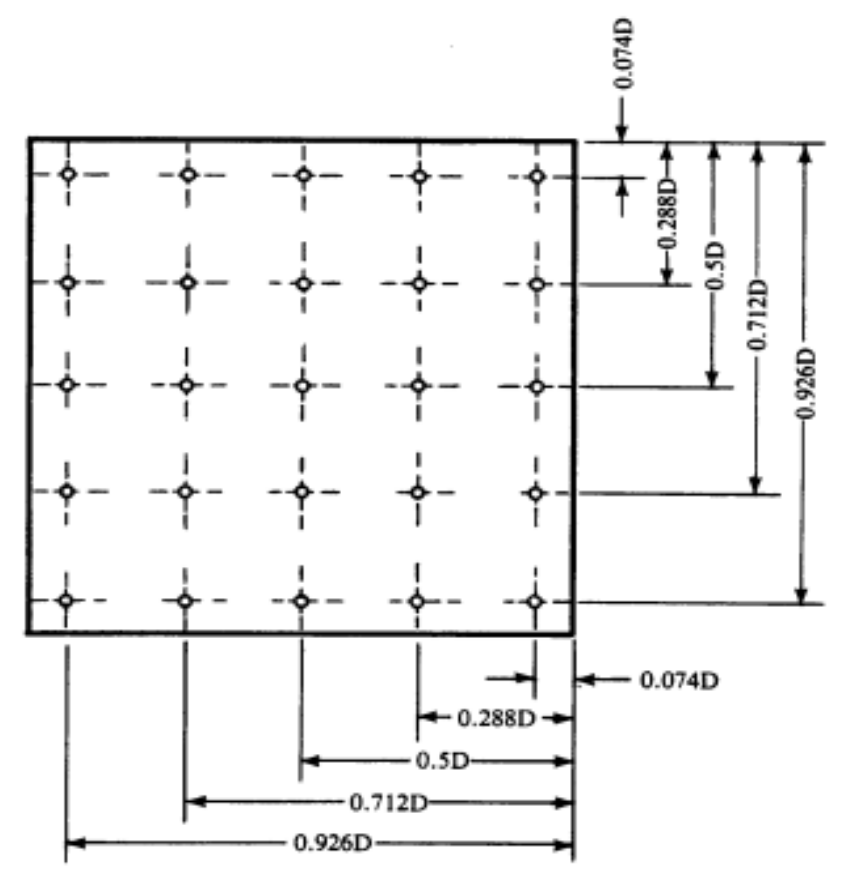

Figura 3.17 - Exemplo da determinação dos pontos de medição (AABC, 1989) 
A velocidade local $\mathrm{v}_{\mathrm{i}}$, medida com um tubo de Pitot, em um ponto determinado da seção transversal do duto, conforme exemplos citados anteriormente é calculada pela equação:

$$
v_{i}=\sqrt{\frac{2 \cdot p_{\operatorname{din}}}{\rho}}
$$

Nesta equação a variável $p_{\text {din }}$ representa a pressão dinâmica tomada no tubo de Pitot.

Por sua vez, a velocidade média é calculada através da média das velocidades locais, conforme a equação (41) e não podem ser adotados valores de pressão dinâmica média.

$$
\mathrm{V}=\frac{1}{\mathrm{n}} \cdot \sum_{\mathrm{i}=1}^{\mathrm{n}} \mathrm{v}_{\mathrm{i}}
$$

Por fim, o cálculo da vazão volumétrica é realizado através da equação (42) que utiliza a velocidade média (V) e a área da seção do duto (S).

$$
\mathrm{Q}=\mathrm{V} . \mathrm{S}
$$

\subsubsection{Medições em elementos terminais}

A medição de vazão em acessórios terminais também pode trazer sérias dificuldades para a execução do balanceamento em campo. Dependendo da instrumentação e das técnicas utilizadas os resultados podem ter pouca exatidão e baixa repetitividade, conforme destacam Bolliger Jr. e Mariani (2002). Considerandose os difusores e grelhas como os elementos terminais mais utilizados, uma das propostas é realizar a medição da velocidade em uma seção próxima à sua saída; ou entrada. Posiciona-se um medidor de velocidade local, que pode ser um anemômetro de fio quente, ou de pás rotativas, ou um velômetro ou um Tubo de 
Pitot, e são medidos diversos valores para a obtenção do valor médio da velocidade. A determinação da área correspondente à velocidade média estimada é o principal fator que dificulta a obtenção de bons resultados de vazão.

A evolução das técnicas e instrumentos para medidas de vazão resultou no medidor de vazão tipo coifa, também chamado de "Balometer". Este instrumento possui uma coifa que acoplada ao elemento terminal confina o escoamento e possibilita boa medição da vazão.

\subsubsection{Métodos para obtenção do balanceamento}

\subsubsection{Método proporcional para aplicação em campo}

Segundo a SMACNA (2003), este método é freqüentemente executado em campo para regular sistemas de distribuição de ar ou de água. O método utiliza um coeficiente de vazão, $\mathbf{C}_{\mathbf{q}}$, que relaciona o valor medido no processo com o dado de projeto, conforme apresentado na equação (43).

$$
\mathrm{C}_{\mathrm{q}}=\frac{\text { Vazão Medida }}{\text { Vazão de Projeto }}
$$

O procedimento para aplicação deste método é o seguinte:

- O sistema deve estar balanceado na condição de máxima vazão, isto é este deve ser medido utilizando todos os registros completamente abertos.

- As vazões medidas nos terminais são utilizadas para determinar valores de $\mathrm{C}_{\mathrm{q}}$, comparando-as com as vazões de projeto. $\mathrm{O}$ terminal com menor $\mathrm{C}_{\mathrm{q}}$ é escolhido como referência e permanece com seu regulador aberto.

- A vazão no elemento terminal com o segundo menor $C_{q}$, é ajustado para que ele tenha mesmo $C_{q}$ que a saída com menor valor.

- A vazão no terminal com o terceiro mais baixo valor de $C_{q}$,é ajustado para que ele tenha mesmo $C_{q}$ que os terminais já ajustados, primeiro e segundo.

- Este procedimento é repetido até que todos os terminais atinjam igual $\mathrm{C}_{\mathrm{q}}$.

Para uma rede que possua vários semi-troncos ligados a um mesmo tronco principal, e cada semi-tronco tenha seus diferentes ramais, o balanceamento deve 
ser feito gradualmente. Primeiramente comparando os ramais entre $\mathrm{si}$, depois comparando os semi-troncos e finalmente fazendo a regulagem final no tronco principal. Em situações em que o coeficiente de vazão final seja menor que um, ou seja, as vazões resultantes menores que as vazões de projeto, é necessário investir em soluções que permitam aumentar a vazão do sistema.

\subsubsection{Método T - simulação da rede com determinação das vazões}

Segundo Tsal, Behls e Mangel (1990), este método trata-se de uma ferramenta auxiliar para dimensionamento cujo objetivo também é o balanceamento dos sistemas de distribuição de ar. Este método, que poder ser implantado através de um aplicativo computacional, é um recurso que possibilita ao projetista redimensionar e balancear uma rede a partir dos resultados obtidos para um préprojeto preliminar.

O método propõe a simulação de uma rede de distribuição de ar utilizando como estratégia a analogia elétrica $e$ as leis de Kirchoff para prever 0 comportamento do escoamento na rede e fazer a determinação das vazões resultantes em cada trecho, e nos elementos terminais, realizando iterações sucessivas. Estes resultados são apresentados em termos percentuais dos valores propostos no projeto.

Ele foi implantando em um aplicativo computacional, o programa T-Duct, e comercializado em versões preliminares através da empresa NETSAL \& Associates. Com o falecimento do Professor Robert Tsal o desenvolvimento e fornecimento do programa foram descontinuados.

No processo de simulação da rede realizado com o aplicativo, versão 2.0 os resultados principais são os valores de vazão apresentados em termos porcentuais, comparativamente aos valores de projeto.

Para obter-se o balanceamento é necessário introduzir modificações de dimensões, de acessórios, ou posição dos reguladores até obter valores de vazão adequados. Este procedimento de tentativas seguidas deve ser repetido pelo número de vezes que for necessário para obterem-se vazões próximas às de projeto, com a margem desejada. 
3.5.4.3 Método direto - simulação da rede com determinação das pressões de balanceamento

Este método, proposto por Bolliger Jr. e Mariani (2002), utiliza fundamentos similares aos adotados pelo método $\mathrm{T}$, isto é correlacionar o sistema fluido-dinâmico com a eletricidade, analisando as redes de distribuição de ar com o emprego da analogia elétrica e aplicando as Leis de Kirchoff.

Ele propõe que seja realizada a simulação do escoamento nos trechos da rede de dutos impondo que os valores de vazão de projeto se estabeleçam. Para esta condição são determinadas as perdas de pressão correspondentes aos vários caminhos que devem ser percorridos pelo fluido. A comparação das perdas de pressão nos caminhos em paralelo feita a partir de cada junção de dutos, identificada por nó, deve resultar na pressão de balanceamento. Ou seja, o processo deve progredir do ambiente para o ventilador, tanto na insuflação como no retorno, e fazer a determinação dos níveis de pressão total hipotéticos em cada um dos nós pelos dois caminhos possíveis. A diferença entre os valores, se houver, é a pressão exigida para o balanceamento. Note-se que para facilitar a aplicação do método, na estratégia de formatação da rede cada junção divergente deve dividir-se a partir de uma entrada em apenas duas saídas. E da mesma forma as junções convergentes devem ter duas entradas e uma saída.

Diferentes possibilidades podem ser adotadas para fazer o balanceamento. Em uma delas o caminho, que apresentou na simulação a menor perda de pressão, irá receber um regulador, ou poderá se redimensionado, reduzindo de suas dimensões. Outra possibilidade é redimensionar o ramal que apresentou maior perda de pressão, ampliando suas dimensões, ou modificando acessórios de algum trecho neste caminho.

O cálculo dos reguladores é possível, e pode ser feito como, por exemplo, definindo-se a posição da abertura de registros instalados no caminho de menor perda. Utilizando os resultados da diferença de pressão determinada para o balanceamento, a ser consumida neste trecho e informações de um fabricante de registros, ou de um manual que apresente valores do coeficiente de perda em função da posição de abertura, dada suas dimensões.

Este método também pode ser adotado para gerar um aplicativo computacional, como está proposto neste trabalho. 


\section{MODELAGEM E ALGORITMO PARA SIMULAÇÃO DE REDES DE DISTRIBUIÇÃO DE AR}

A revisão bibliográfica apontou alternativas de modelos para realizar balanceamento de redes de distribuição de ar. Duas podem ser consideradas adequadas para estabelecer um algoritmo e desenvolver um aplicativo computacional que torne prático o uso do método. Os dois modelos são: o Método T e o Método Direto.

A principal diferença entre eles é que o primeiro, método $\mathrm{T}$ realiza a simulação das redes de escoamento de fluidos considerando que para os caminhos em paralelo as diferenças de pressão resultantes são as mesmas, e faz iterações para determinar qual a vazão resultante em cada caminho. Em seguida, compara as vazões obtidas com as de projeto, obtendo as necessidades de balanceamento. No método direto, ocorre também a simulação da movimentação dos fluidos, sendo imposta a vazão em cada trecho, e por conseqüência nos caminhos em paralelo, para os quais a diferença entre as pressões calculadas para cada caminho é o valor exigido para o balanceamento.

A escolha entre as alternativas recaiu sobre o "Método Direto" por ser um método prático e direto na obtenção das diferenças de pressão de balanceamento e indica rapidamente os caminhos críticos que precisam de intervenção. Este foi implementado através de programa de computador específico e também testado através de cálculos em planilhas eletrônicas. Para implementar o modelo proposto pelo método direto foi desenvolvido um algoritmo organizado em seis etapas. Em cada uma delas, para realizar os cálculos associados ao fluxo do ar, foi considerada a analogia elétrica já citada, seus princípios e leis. As etapas estabelecidas foram denominadas como:

- Parâmetros Característicos da Rede.

- Perda de Pressão Distribuída.

- Perda de Pressão Localizada.

- Perda de Pressão Total.

- Simulação da Rede.

- Comparação de Caminhos. 
Algumas premissas importantes adotadas no desenvolvimento do algoritmo foram: utilizar valores em termos de vazões em massa, de velocidade mássica, tornando os cálculos independentes de variações da massa específica. A entrada de dados no algoritmo pede todas as propriedades físicas do fluido em cada trecho da rede. Desta forma a simulação do escoamento pode ser feita para fluidos que tenham alteradas suas condições de temperatura, como também para diferentes fluidos. Existem pontos comuns entre o Método Direto e o Método T, e por isso para o desenvolvimento do algoritmo com a lógica do Método Direto, foram utilizados diversos conceitos propostos pelo Método T, conforme será visto nos itens seguintes.

\subsection{PARÂMETROS CARACTERÍSTICOS DA REDE}

Na primeira etapa do algoritmo é feita a identificação dos trechos, dos nós e por conseqüência dos caminhos que o escoamento de ar percorre desde o equipamento de condicionamento de ar até os ambientes, como também no retorno, na tomada de ar externo, e eventualmente, se houver, no escape para o exterior.

Para estabelecer a lógica que define as interligações entre trechos e nós, como também com o ventilador, e com o meio exterior à rede são adotadas definições e regras semelhantes às propostas por Tsal (1990) em seu método. O objetivo deste procedimento é facilitar o cadastro da rede de distribuição de ar prédimensionada no programa de computador desenvolvido a partir deste algoritmo.

As definições propostas por Tsal (1990) são:

- O trecho é definido como sendo o duto que se encontra entre dois nós ou entre um nó e um elemento terminal, difusor ou grelha, ou ainda entre um nó e o ventilador no quais as seções transversais nos trechos têm em comum, vazão mássica do ar, massa específica do ar, forma e dimensões.

- Os nós são identificados como os pontos extremos de um trecho ou pela junção de dois trechos. Pode também ser adotado quando se tem um acessório de transição, por exemplo, mudança de seção, entre dois trechos.

- Os caminhos são definidos por uma seqüência de trechos em série percorridos pelo escoamento de ar a partir de um nó. 
As regras propostas por Tsal (1990) são:

- Organizar a rede de distribuição de ar com estrutura similar à de uma árvore genealógica, em que um trecho pai pode ter no máximo dois trechos filhos. Se tiver dois, um deles será o filho reto e o outro o filho ramal.

- Os trechos recebem numeração ao invés dos nós.

- A numeração dos trechos é feita no sentido do ambiente para o ventilador, independentemente do sentido de movimentação do ar, como mostra a figura 4.1 .

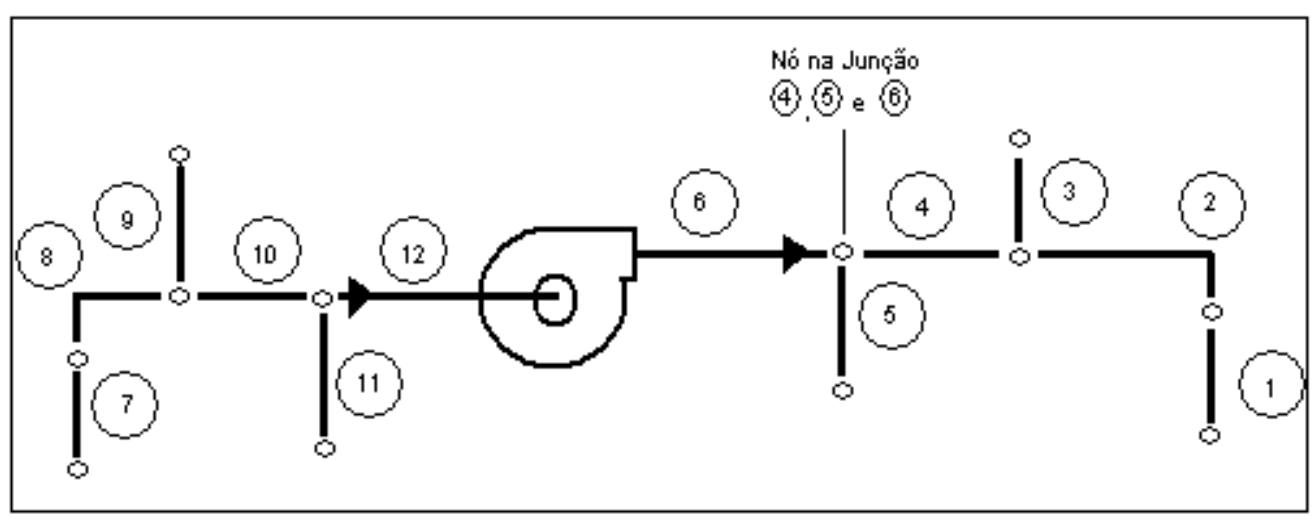

Figura 4.1 - Numeração dos trechos

- Os trechos de maior vazão em cada junção correspondem a números maiores que os afluentes ou efluentes que têm menor vazão.

- A ordem em que são colocados os nós é no sentido do ambiente para o ventilador, independentemente do sentido de movimentação de ar, um exemplo está mostrado na figura 4.2.

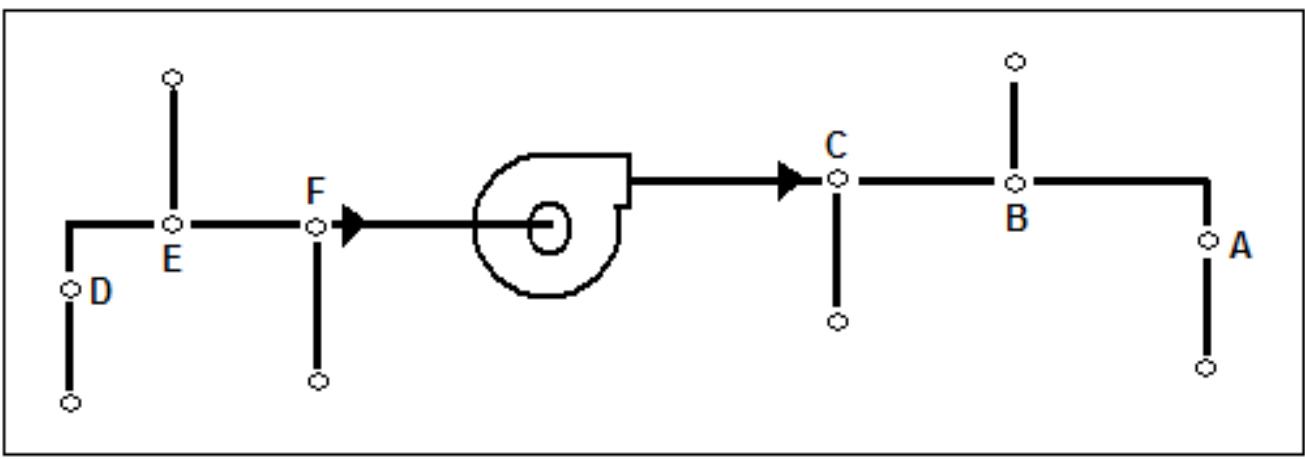

Figura 4.2 - Identificação dos nós 
- Em um nó o trecho que tem a mesma direção do trecho comum é chamado reto e o outro,se houver, é chamado de ramal como mostra o exemplo de uma junção divergente da figura 4.3.

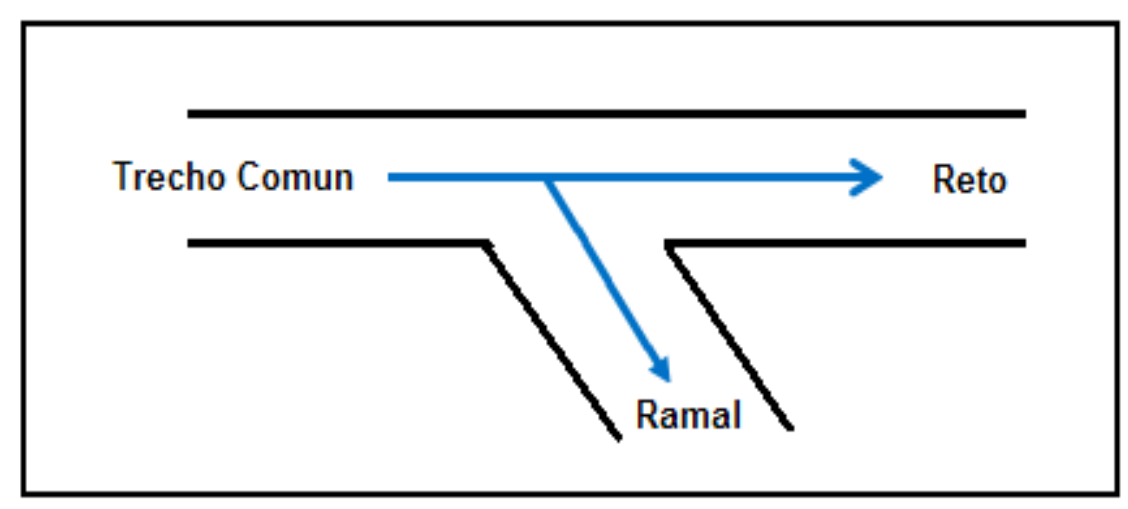

Figura 4.3 - Identificação dos trechos em junção divergente

- Quando houver mais de três trechos interligados em um nó, deve-se criar um trecho de comprimento desprezível como é ilustrado na figura 4.4, de modo a obter junções que integrem no máximo 3 trechos. Surge então um novo nó, e um trecho fictício que não causa perda.

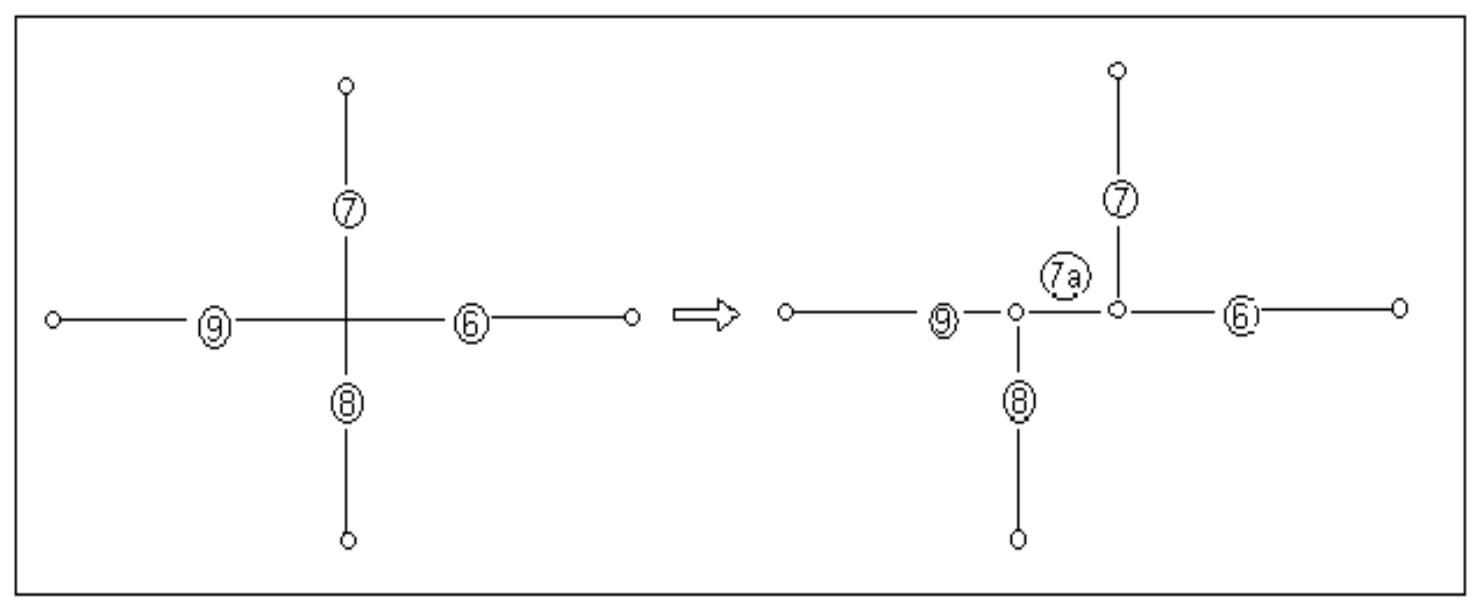

Figura 4.4 - Adaptação para nós com mais de 3 trechos interligados

Além do cadastro dos trechos e nós da rede oferecendo como resultado a disposição dos trechos, nesta etapa são inseridos os dados dimensionais dos dutos que compõe cada trecho, considerando duas geometrias para as seções transversais, retangular e circular. 


\subsection{PERDA DE PRESSÃO DISTRIBUÍDA}

A seguinte etapa do algoritmo tem como meta calcular as perdas distribuídas para cada um dos trechos da rede. As premissas para determinação destas perdas são:

- É preciso organizar e obter os seguintes parâmetros de projeto relativos em cada trecho: o comprimento e a rugosidade do duto, a vazão volumétrica do fluido, e suas respectivas massa específica e viscosidade cinemática.

- Os valores de vazão volumétrica devem estar referidos à sua condição de massa específica de cada trecho para permitir a determinação das vazões em massa e velocidade de massa.

Com os valores adotados para o ar em cada um dos trechos são calculados a vazão mássica, velocidade mássica, pressão dinâmica, número de Reynolds, coeficiente de perda distribuída, e a perda distribuída utilizando as equações a seguir:

- Vazão mássica (m் :

$$
\dot{\mathrm{m}}=\mathrm{Q} \cdot \mathrm{\rho}
$$

sendo:

$$
\begin{aligned}
& Q=\text { Vazão de projeto } \\
& \rho=\text { Massa especifica }
\end{aligned}
$$

- Velocidade mássica $(G)$ :

$$
\mathrm{G}=\frac{\dot{\mathrm{m}}}{\mathrm{S}}
$$

sendo:

$$
\mathrm{S}=\text { Área do duto retangular }
$$


- Pressão dinâmica (Pdin):

$$
\underset{\mathrm{i}}{\mathrm{d}}=\frac{\mathrm{G}^{2}}{2 \rho}
$$

- Número de Reynolds (Re):

$$
\mathrm{R}_{\mathrm{e}}^{\mathrm{G}}=\frac{\mathrm{G}}{v \cdot \rho}
$$

sendo:

$$
\begin{aligned}
& \text { Dh = Diâmetro hidráulico } \\
& \mathrm{v}=\text { Viscosidade cinemática }
\end{aligned}
$$

- Coeficiente de perda distribuída (f):

$$
f=0,11 \cdot\left(\frac{\varepsilon}{D_{h}}+\frac{68}{\operatorname{Re}}\right)^{0,25}
$$

sendo:

$$
\varepsilon=\text { Rugosidade }
$$

- Perda de pressão distribuída $\left(\Delta \mathrm{P}_{\mathrm{d}}\right)$ :

$$
\Delta P_{d}=\frac{f^{*} L}{D} * \underset{d}{\mathrm{i}}
$$

sendo:

$$
\mathrm{L}=\text { Comprimento do trecho }
$$


Convém lembrar que os valores de vazão de projeto para o sistema de ar condicionado, nos casos mais comuns, podem ser estabelecidos de acordo uma dos dois requisitos:

- Carga Térmica: vazão mássica necessária para manter as condições termoigrométricas, garantindo conforto e salubridade para os ocupantes dos ambientes internos.

- Filtragem: atender necessidades de filtragem em ambientes que possuem exigências em termos de contaminação.

\subsection{PERDA DE PRESSÃO LOCALIZADA}

O outro cálculo de perdas que é preciso ser realizado no algoritmo é relativo às localizadas, que em geral são preponderantes às distribuídas, conforme afirmam Bolliger Jr. e Mariani (2002). Estas perdas, que ocorrem quando se tem uma mudança de direção do escoamento, mudança da área da seção transversal do duto ou com a presença de algum elemento que interfira no escoamento, exigirá levantamento de coeficientes ou de valores absolutos para seu cálculo.

Os coeficientes de acessórios de redes de distribuição de ar, como junções, joelhos, transições, registros, são determinados experimentalmente e tabelados em manuais, como o da SMACNA (1990) ou o da ASHRAE (1997).

Como referência, para o caso de junções, foi adotado que os coeficientes de perdas dos trechos filhos devem ser associados às pressões dinâmicas calculadas com as velocidades destes no cálculo da perda.

A equação (50) é utilizada no cálculo da perda localizada em cada acessório, partindo de um coeficiente $\mathrm{Ci}$.

$$
\Delta \mathrm{P}_{\mathrm{L}_{\mathrm{i}}}=\mathrm{C}_{\mathrm{i}} * \mathrm{P}
$$

sendo: $\quad \Delta \mathrm{P}_{\mathrm{Li}}=$ Perda de pressão localizada no acessório

$\mathrm{C}_{\mathrm{i}}=$ Coeficiente de perda relativo ao acessório

Valores de perdas para acessórios específicos $\left(\Delta \mathbf{p}_{\mathrm{ace}}\right)$, como difusores, são determinados pelos fabricantes e publicados em seus catálogos técnicos. Estes 
estão referidos à condição padrão do ar cuja massa específica é $\rho=1,204 \mathrm{~kg} / \mathrm{m}^{3}$ e devem ser um dado de entrada que será acumulado com as outras perdas localizadas.

As perdas localizadas são totalizadas somando aquelas calculadas $\left(\Delta \mathbf{P}_{\mathbf{L i}}\right)$ com valores fornecidos diretamente por fabricantes $\left(\Delta \mathbf{p}_{\mathrm{ace}}\right)$.

$$
\Delta \mathrm{P}_{\mathrm{L}}=\underset{\substack{\mathrm{C} \\ \mathrm{e}}}{\Delta \mathrm{P}_{\mathrm{a}}}+\sum_{i} \Delta \mathrm{P}_{\mathrm{L}_{\mathrm{i}}}
$$

\subsection{PERDAS DE PRESSÃO TOTAL}

Com os resultados de perdas de pressão distribuída e localizada para cada trecho da rede, calcula-se mediante soma a perda de pressão total por trecho.

$$
\Delta \mathrm{P}_{\mathrm{T}}=\Delta \mathrm{P}_{\mathrm{d}}+\Delta \mathrm{P}_{\mathrm{L}}
$$

Estes resultados são vinculados aos trechos que compõe a rede de distribuição de ar.

\subsection{SIMULAÇÃO DA REDE}

Para realizar o processo da simulação de escoamentos na rede são adotados os conceitos e relações apresentadas no tópico 3.3.3. O algoritmo para simulação da rede está baseado nas seguintes procedimentos:

- Utilização da 1a lei de Kirchoff: em um nó: a soma das vazões mássicas de entradas é igual à soma das vazões mássicas da saída.

- Utilização da resistência fluido-dinâmica, sendo que a diferença de pressão de um trecho é determinada a partir da somatória das suas resistências,

- É definido um caminho como um conjunto de trechos em série desde um nó até outro nó, ou até o elemento terminal.

- São estabelecidos os caminhos com a finalidade de determinar a diferença de pressão para cada um deles, e esta é calculada pela somatória da perda total de pressão dos trechos que o compõe. Este 
valor de perda total é atribuído ao nó que está na extremidade mais a montante do caminho.

- O processo de simulação parte dos nós mais próximos ao ambiente para chegar àqueles que estão junto ao ventilador.

\subsection{COMPARAÇÃO DE CAMINHOS}

A última etapa do algoritmo tem como objetivo determinar valores de diferenças de pressão que serão adotados no balanceamento da rede. Para tanto são comparados resultados de níveis de pressão calculados para pares de caminhos posicionados em paralelo na rede. Novamente os fundamentos do tópico 3.3.3 e do 3.3.5 definem as premissas e procedimentos a ser implementados, conforme segue:

- Utilização da $2^{\text {a }}$ lei de Kirchoff para o processo da comparação de caminhos em paralelo, estabelecendo que as perdas de pressão são iguais nos trechos em paralelo.

- Utilização do conceito de resistência fluido-dinâmica para caminhos em paralelo, sendo que a vazão mássica dos caminhos em paralelo é diferente para cada um deles e proporcional à resistência.

- São escolhidos caminhos dois a dois para ser feita a comparação, sempre que eles estejam em paralelo.

- O procedimento para determinar o primeiro caminho da rede, que é considerado na comparação, é feita partindo de um nó até outro nó ou até um elemento terminal.

- O segundo caminho, também considerado na comparação, é determinado adotando-se o mesmo nó do primeiro caminho até outro nó ou até um elemento terminal.

- A determinação da diferença de pressão de balanceamento é resultante do processo de comparação de caminhos. É calculada pela diferença de níveis de pressão para os caminhos em paralelo e associados ao nó inicial do caminho.

- A definição do trecho em que pode ser inserido uma resistência adicional, também é resultado da comparação dos níveis de pressão obtidos nos caminhos em paralelo. 


\section{DESENVOLVIMENTO DO PROGRAMA DOBAL}

\subsection{DEFINIÇÃO DO EDITOR BASE PARA A PROGRAMAÇÃO}

Considerando que a proposta deste trabalho tem como objetivo desenvolver um programa computacional, a escolha de um editor para ser a base para o desenvolvimento do programa, foi o primeiro passo adotado. Foram estabelecidos requisitos para selecionar qual o editor de programas deveria ser utilizado.

Em termos gerais de operacionalidade os requisitos foram: a possibilidade de criar telas, inserir imagens tais como menus, caixas de diálogo, botões e objetos.

Considerando as necessidades de programação exigidas no tratamento de parâmetros e dados relacionados a redes de distribuição de ar, os requisitos adotados como critérios eram que houvesse a possibilidade de:

- Inserir um conjunto de informações interligadas, para caracterização dos dutos, como também dos trechos seqüenciais de uma rede.

- Fazer cálculos de perdas para cada um dos trechos da rede.

- Simular os caminhos possíveis para o escoamento do ar.

- Fazer interface com um banco de dados que armazenasse um conjunto de informações, dados e resultados, de cada trecho de dutos.

- Gerar um programa executável de modo que o usuário não precisasse ter o editor de programa instalado no computador.

A pesquisa para a escolha do editor base considerou como alternativas 0 MatLab e o Visual Basic. Na comparação entre estes e considerando os critérios citados foi escolhido o Visual Basic 6.0. Ele possui a capacidade para executar as tarefas exigidas e as ferramentas necessárias para o desenvolvimento do programa.

Foi também verificada a necessidade de utilizar-se um banco de dados para armazenar, adicionar, modificar e excluir eletronicamente todos os dados do projeto em formato de arquivo. Para atender a essa demanda foi escolhido um banco de dados feito em Microsoft Access $^{\circledR}$ 97. Usando este aplicativo é criado um arquivo para registro e operação das informações através de tabelas.

Assim o programa foi desenvolvido em Visual Basic vinculando tabelas do Access, e seu arquivo executável foi denominado DOBAL.exe. 


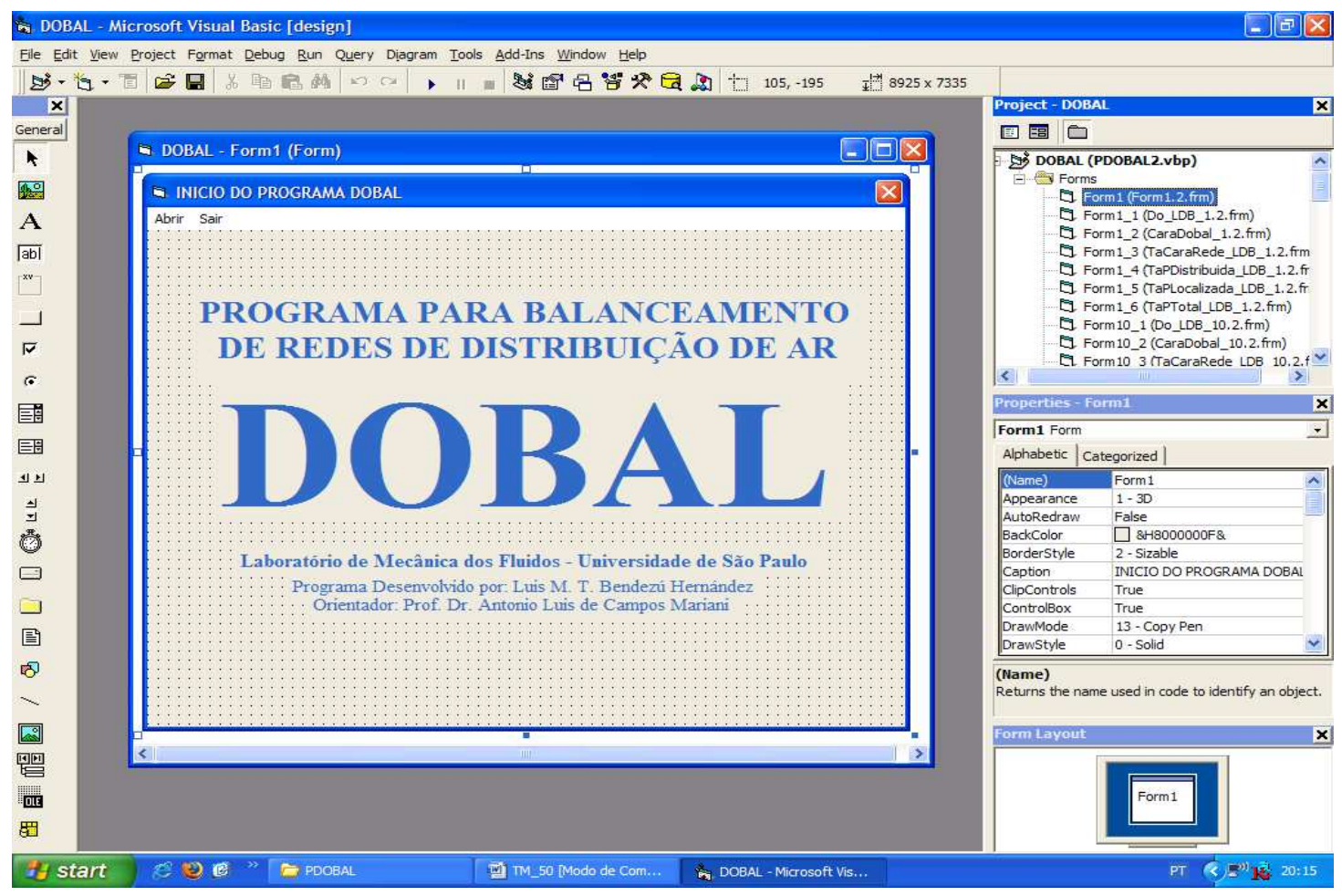

Figura 5.1 - Ambiente de programação do Visual Basic

\subsection{ESTRUTURAÇÃO DO PROGRAMA}

A estruturação do programa foi concebida considerando três partes relacionadas entre si, sendo que em cada uma delas são executadas as tarefas para operacionalizar o processo de balanceamento da rede. Estas partes são: "Identificação do Projeto", "Inserção de Dados e Cálculos" e "Tabela de Dados e Resultados". Conforme se pode observar na figura 5.2.

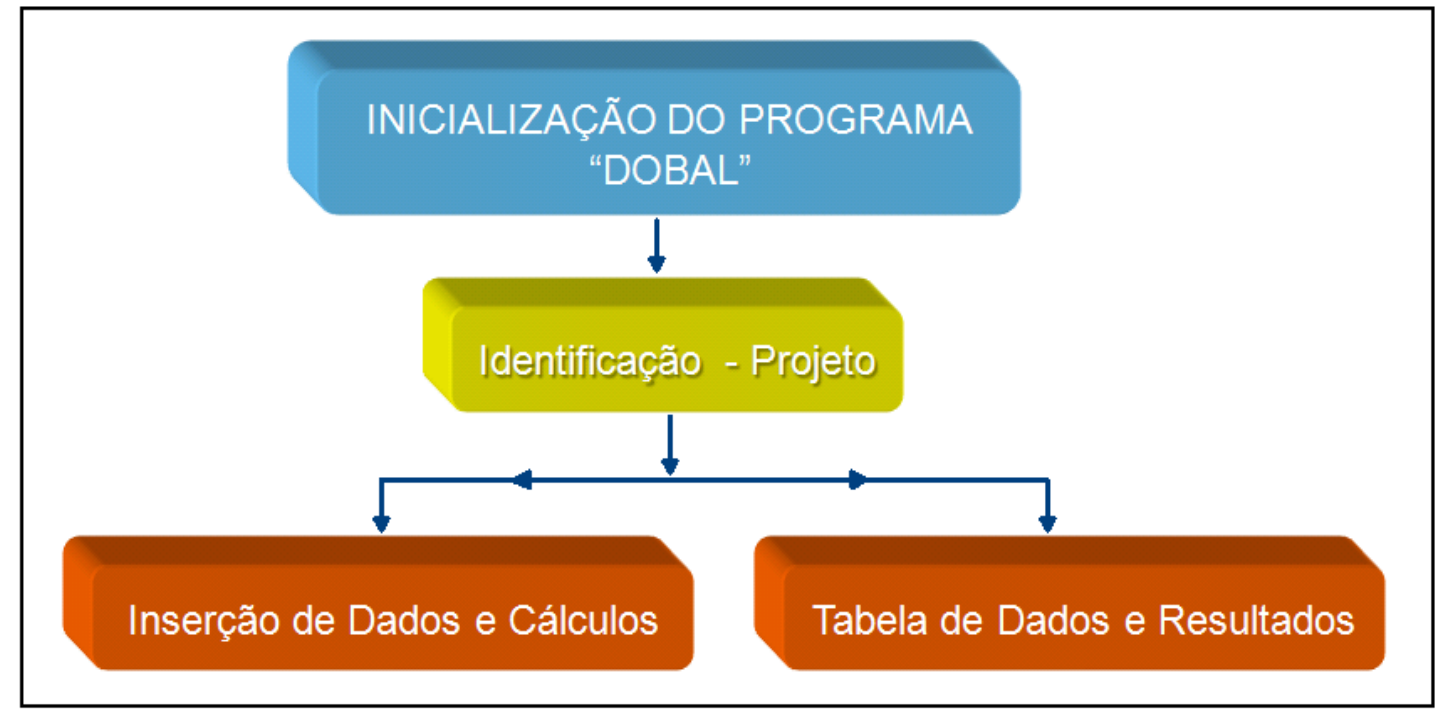

Figura 5.2 - Estrutura principal do programa 
As partes adotadas têm a finalidade de separar as três fases importantes que ocorrem durante o uso do programa, evitando o adensamento de informações tratadas em uma mesma fase, o que poderia inclusive congestionar a tela disponibilizada para o usuário.

A primeira parte que tem como função estabelecer a identificação do projeto e possui dois campos a serem preenchidos: "Nome Projeto" e "Nome do Usuário". Desta forma cada projeto está relacionado a uma tabela do banco de dados a partir da sua identificação. O conteúdo do campo "Nome Projeto" também é utilizado como identificador para todas as tabelas de resultados, ocupando a primeira coluna destas.

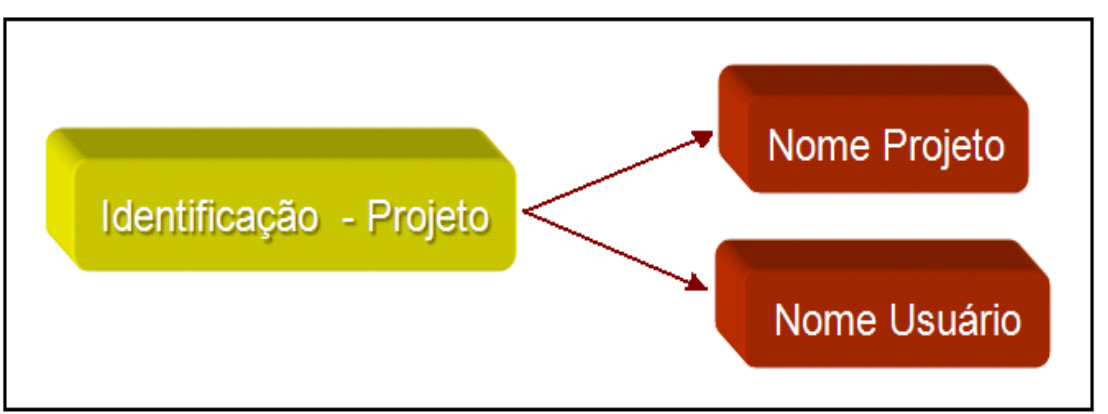

Figura 5.3 - Identificação do Projeto

A segunda parte do programa, identificada por "Inserção de Dados e Cálculos", tem como finalidade receber os dados e fazer os cálculos relativos à rede de distribuição de ar, executando as seis etapas descritas no algoritmo apresentado no capítulo 4, conforme ilustrado na figura 5.4 .

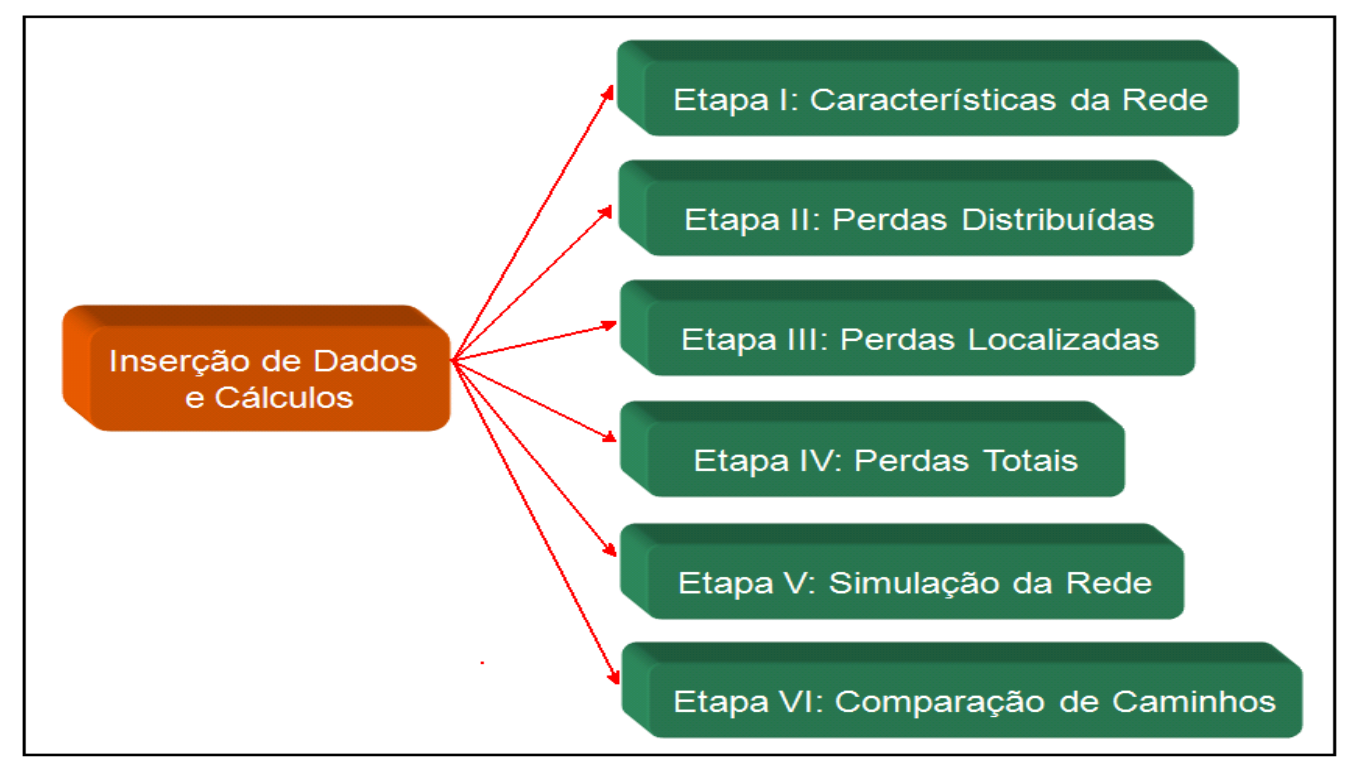

Figura 5.4 - Inserção de Dados e Cálculos 
A terceira parte, chamada "Tabela de Dados e Resultados", tem como objetivo organizar os dados e resultados na forma de tabelas para visualização e verificação destes. Há quatro categorias de tabelas que podem ser vistas na figura 5.5 .

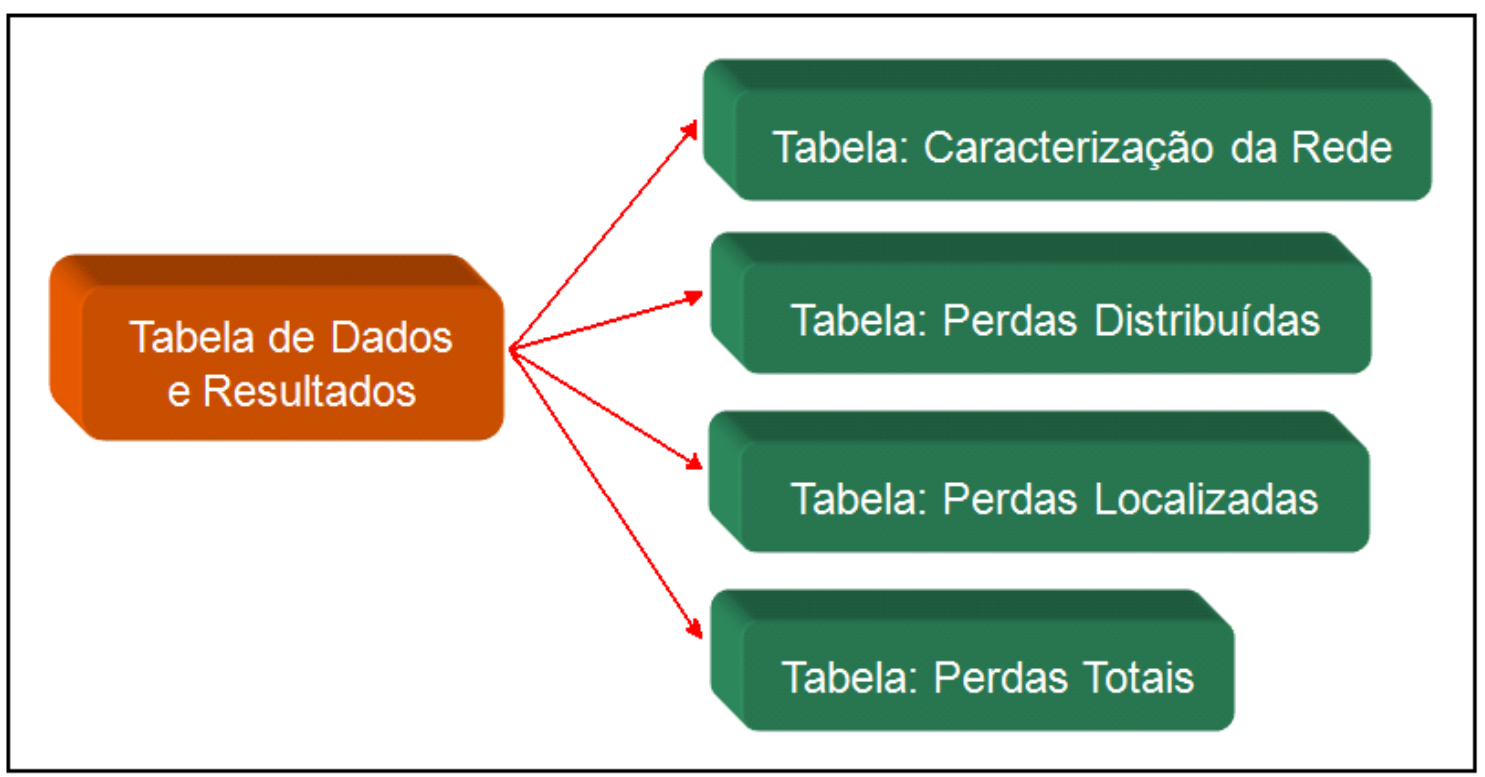

Figura 5.5 - Tabela de Dados e Resultados

\subsection{DETALHAMENTO DAS ETAPAS DO PROGRAMA PARA INSERÇÃO DE DADOS E ELABORAÇÃO DE CÁLCULOS}

Para implantar a lógica e as equações conforme estabelecido no algoritmo apresentado no capítulo 4, foram organizadas as 6 etapas já explicitadas. A programação destas etapas foi feita com conjuntos de comandos que executavam os procedimentos representados nos fluxogramas que estão a seguir.

As seis etapas foram programadas para serem executadas sequencialmente para cada trecho da rede.

\subsubsection{Etapa I: Características da rede}

A programação da primeira etapa seguiu a seqüência definida pelo fluxograma da figura 5.6. Nesta são encontrados dois elementos principais: Disposição de trechos e Geometria. No programa é feita a caracterização da rede para cadastrar os trechos e sua geometria, retangular ou circular, e sua disposição relativa aos outros. 


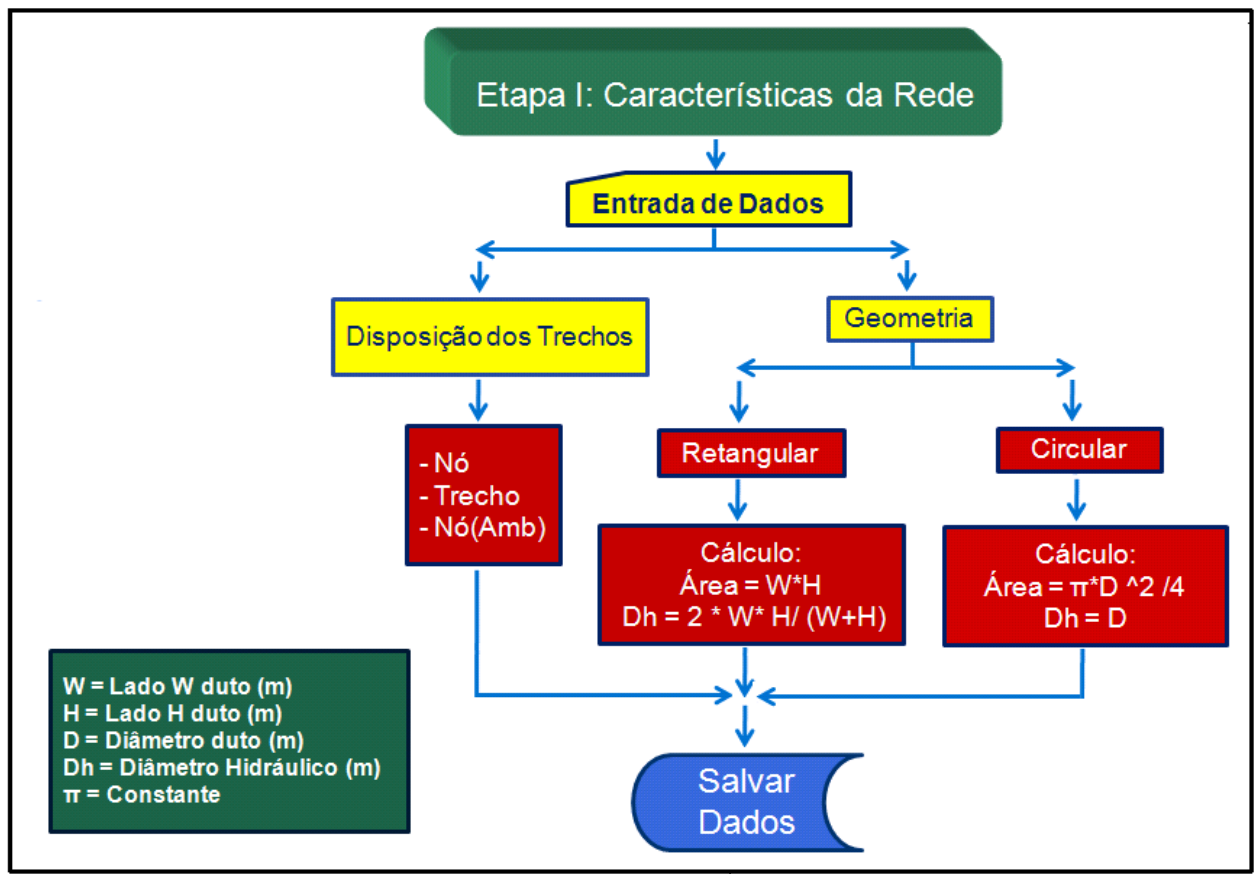

Figura 5.6 - Etapa I: Caracterização da Rede

\subsubsection{Etapa II: Perdas distribuídas}

Nesta etapa foram programados comandos para fazer o registro de todos os parâmetros do escoamento necessários para calcular as perdas distribuídas para cada trecho. O fluxograma da figura 5.7 indica os passos e principais equações para obter o código.

Tj = Número do Trecho $\mathbf{j}$.

$Q=\operatorname{Vazäo}\left(m^{\wedge} 3 / h\right)$

$\mathrm{L}=$ Comprimento $(\mathrm{m})$

$\rho=$ Massa especifica $\left(\mathrm{kg} / \mathrm{m}^{\wedge} 3\right)$

$V=$ Viscosidade cinemática $(m \wedge 2 / s)$

$\varepsilon=$ Rugosidade $(\mathrm{m})$

m =Vazáo mássica $(\mathrm{kg} / \mathrm{s})$

$\mathbf{G}=$ Velocidade mássica $\left(\mathrm{kg} / \mathrm{s} \mathrm{m} \mathbf{m}^{\wedge} \mathbf{2}\right)$

P. dina $=$ Pressão dinâmica $(\mathrm{Pa})$

$\mathbf{R e}=$ Número de Reynolds

$f=$ Fator de atrito

P. Distri. = Perda Distribuida $(\mathrm{Pa})$

\section{Etapa II: Perdas Distribuídas}

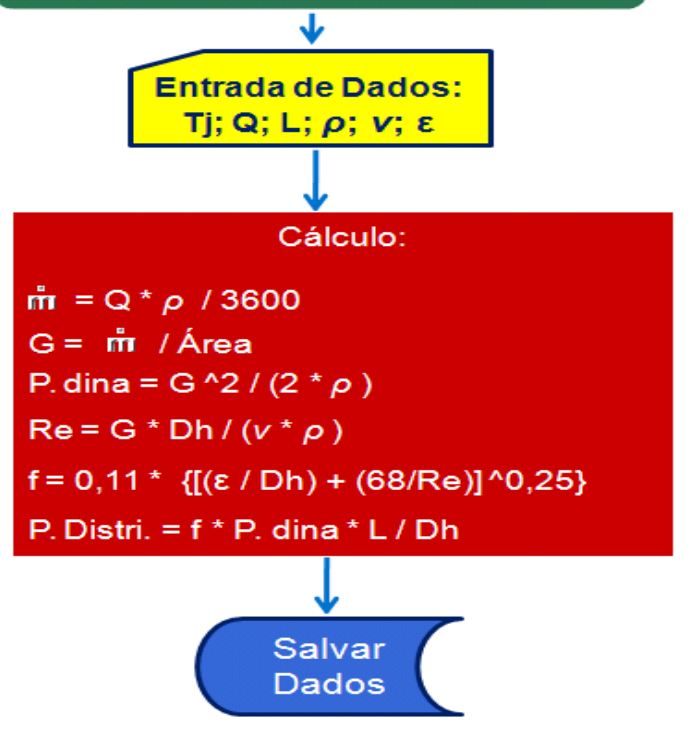

Figura 5.7 - Etapa II: Perdas Distribuídas 


\subsubsection{Etapa III: Perdas localizadas}

De modo similar ao descrito no item anterior, o programa deve calcular as perdas localizadas a partir dos coeficientes dos acessórios, e de valores diretamente fornecidos de perdas de pressão. Nas equações o programa adota variáveis do escoamento determinadas na etapa anterior, como a pressão dinâmica. As várias parcelas existentes para cada caminho são acumuladas em uma variável, conforme esquema da figura 5.8 .

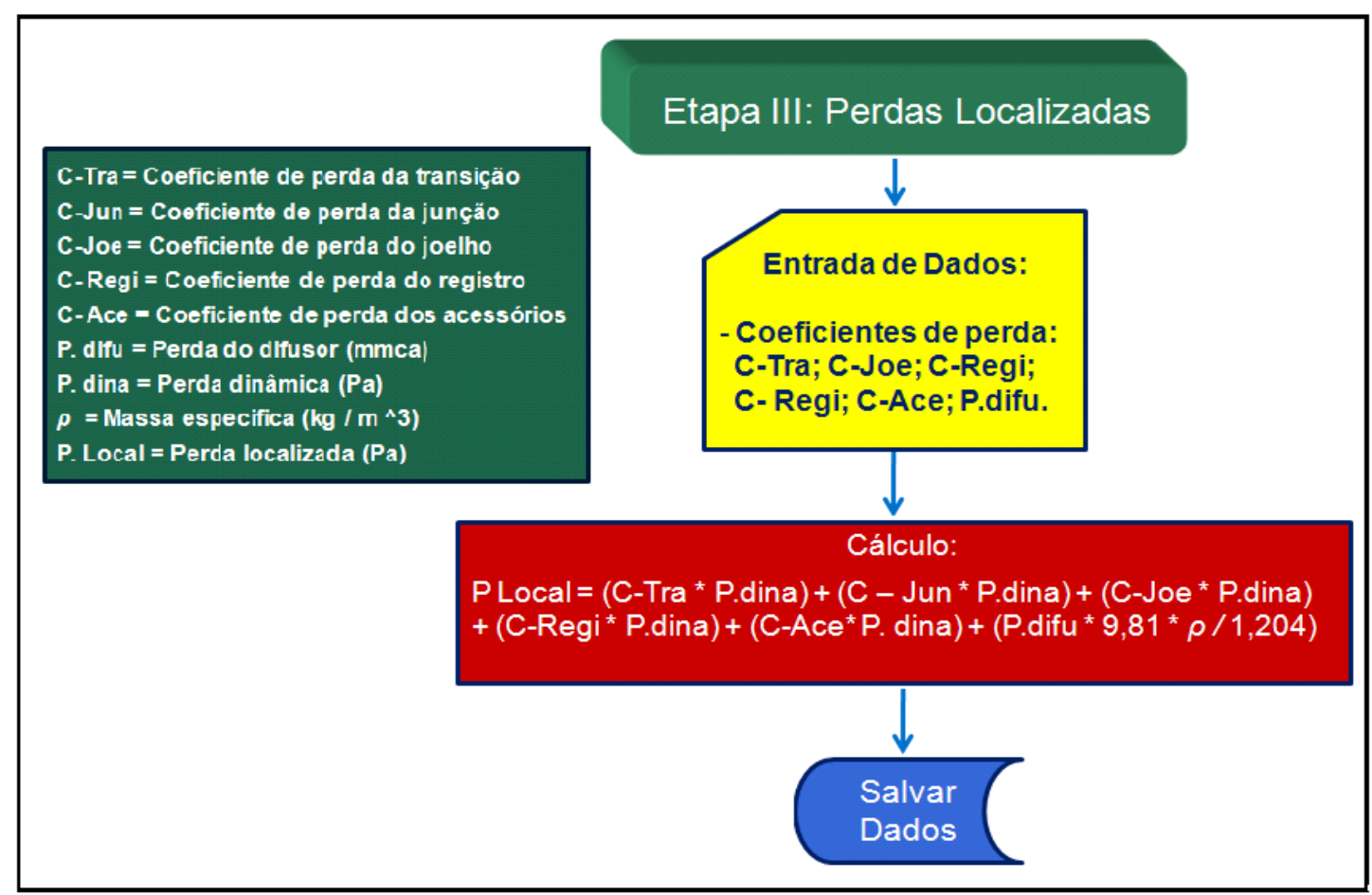

Figura 5.8 - Etapa III: Perdas Localizadas

\subsubsection{Etapa IV: Perda total}

A partir dos resultados das perdas distribuídas e localizadas de cada trecho já registrado, o programa calcula a perda de pressão total para cada um deles. $\mathrm{O}$ fluxograma está na figura 5.9. 


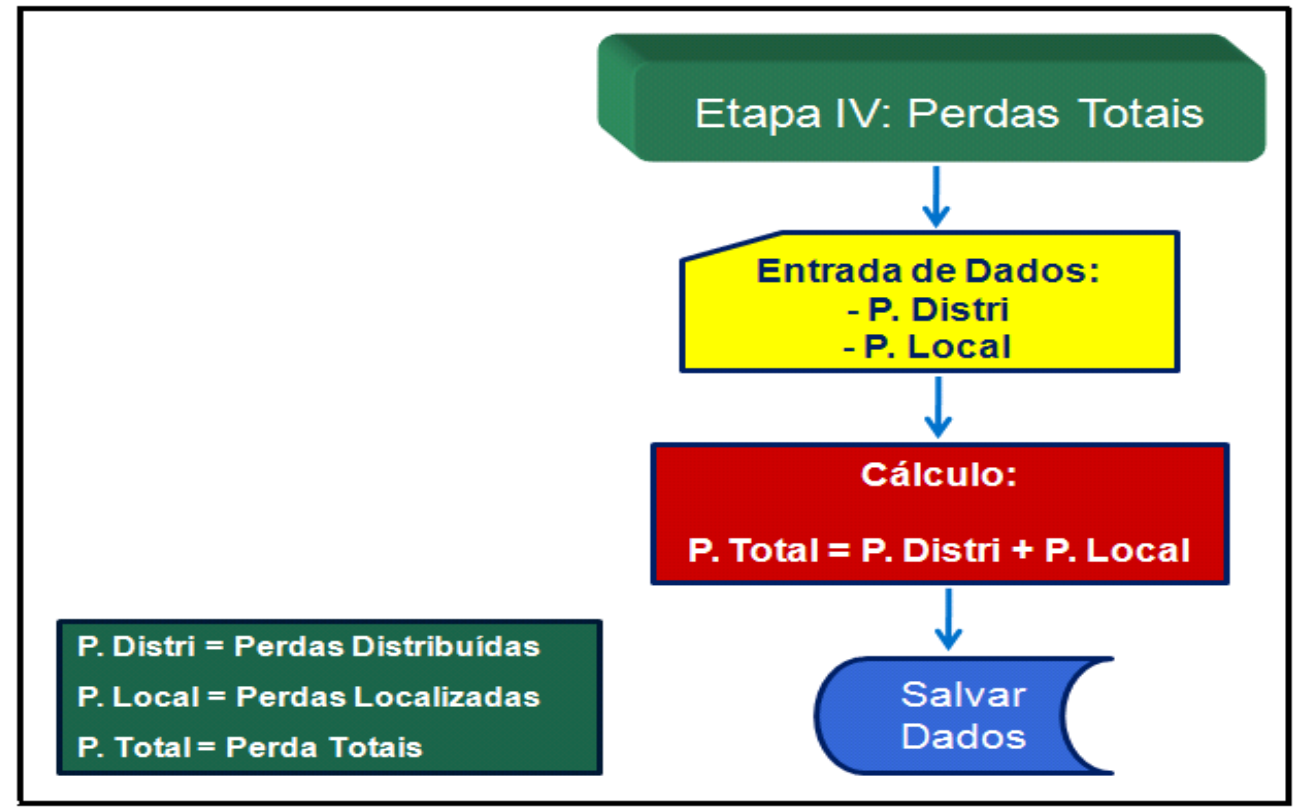

Figura 5.9 - Etapa IV: Perdas Totais

\subsubsection{Etapa V: Simulação da rede}

Nesta quinta etapa o programa faz a simulação dos escoamentos para todos os caminhos posicionados em paralelo, tomando os dois a dois. A definição de cada par de caminhos é feita a partir do mesmo nó e buscando o nó seguinte ou o ambiente como indicado na figura 5.10.

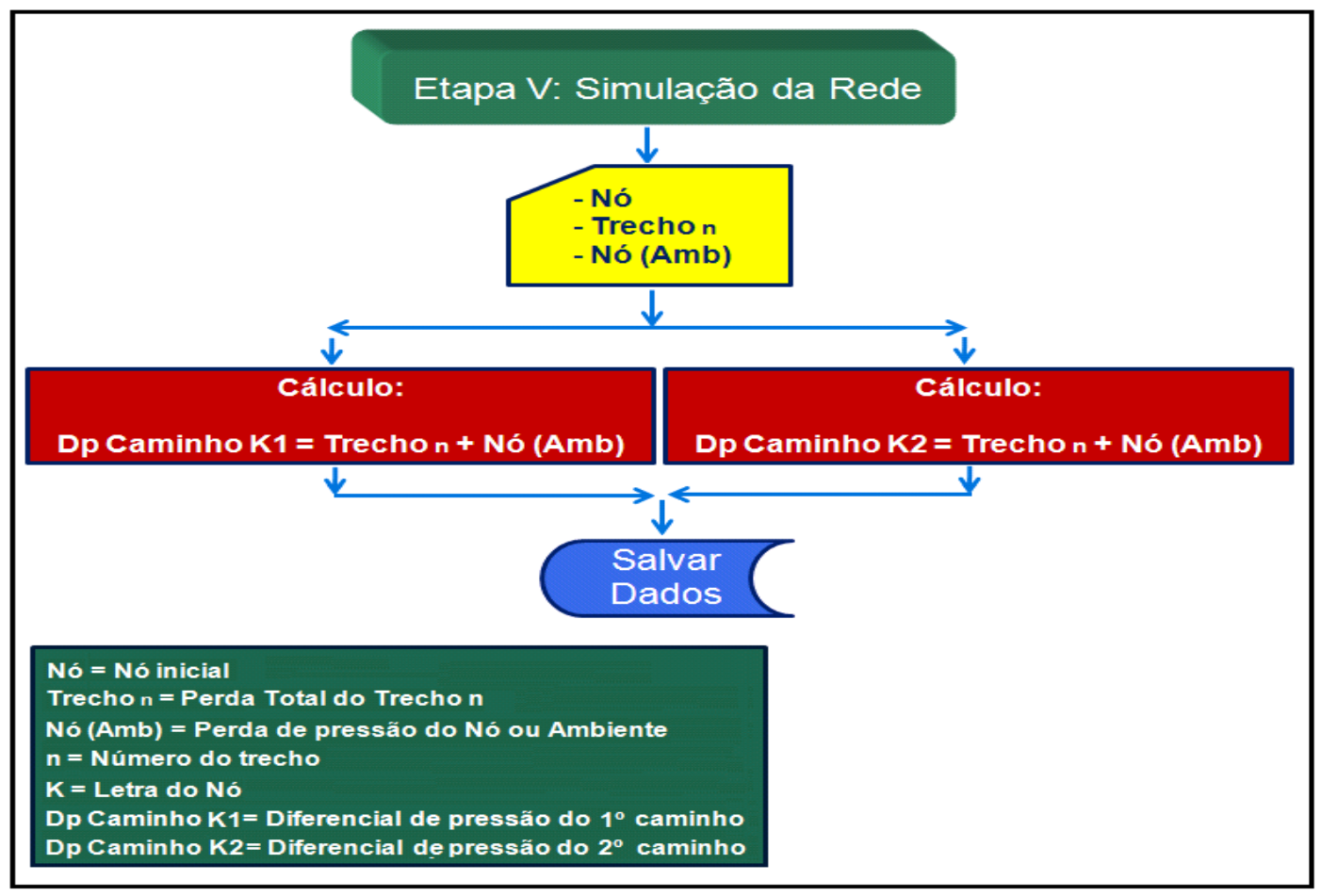

Figura 5.10 - Etapa V: Simulação da Rede 


\subsubsection{Etapa VI: Comparação de caminhos}

A última etapa do programa faz o cálculo da diferença de pressão entre pares de caminhos em paralelo, conforme escolhas adotadas na etapa $\mathrm{V}$. O resultado é a diferença de pressão a ser empregada para fazer o balanceamento. A comparação entre as perdas nos dois caminhos também informa qual deles possui menor resistência, e este é o recomendável para receber o regulador. O Fluxograma da Comparação de Caminhos é mostrado na figura 5.11.

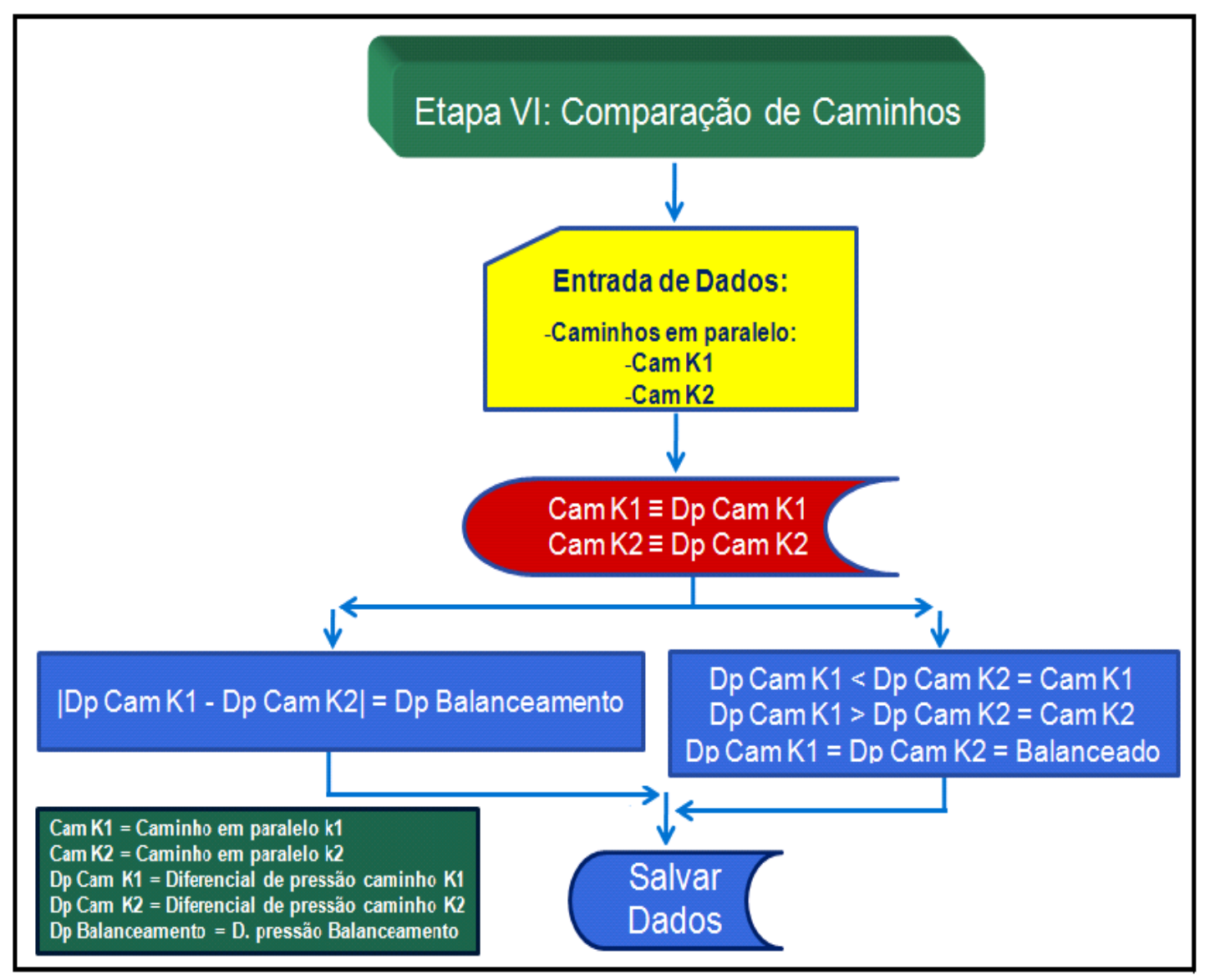

Figura 5.11 - Etapa VI: Comparação de Caminhos

\subsection{BANCO DE DADOS UTILIZADO NO PROGRAMA}

Em um banco de dados do aplicativo Microsoft Access $^{\circledR}$ 97, foram criadas tabelas com o nome de "Balance.mdb". A finalidade destas tabelas é visualizar e 
verificar os registros dos dados e resultados calculados nas diversas etapas do programa. Este banco de dados fornece ferramentas para imprimir os dados obtidos.

O banco de dados tem por nome "Balance.mdb e contém 10 pares de tabelas relacionadas, como é mostrada na figura 5.12 .

A primeira tabela, denominada Projeto \#, possui os dados da identificação

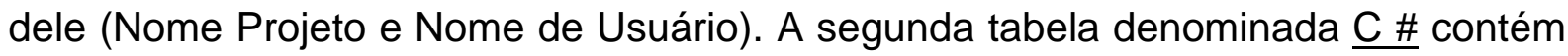
todos os dados inseridos e calculados no programa.

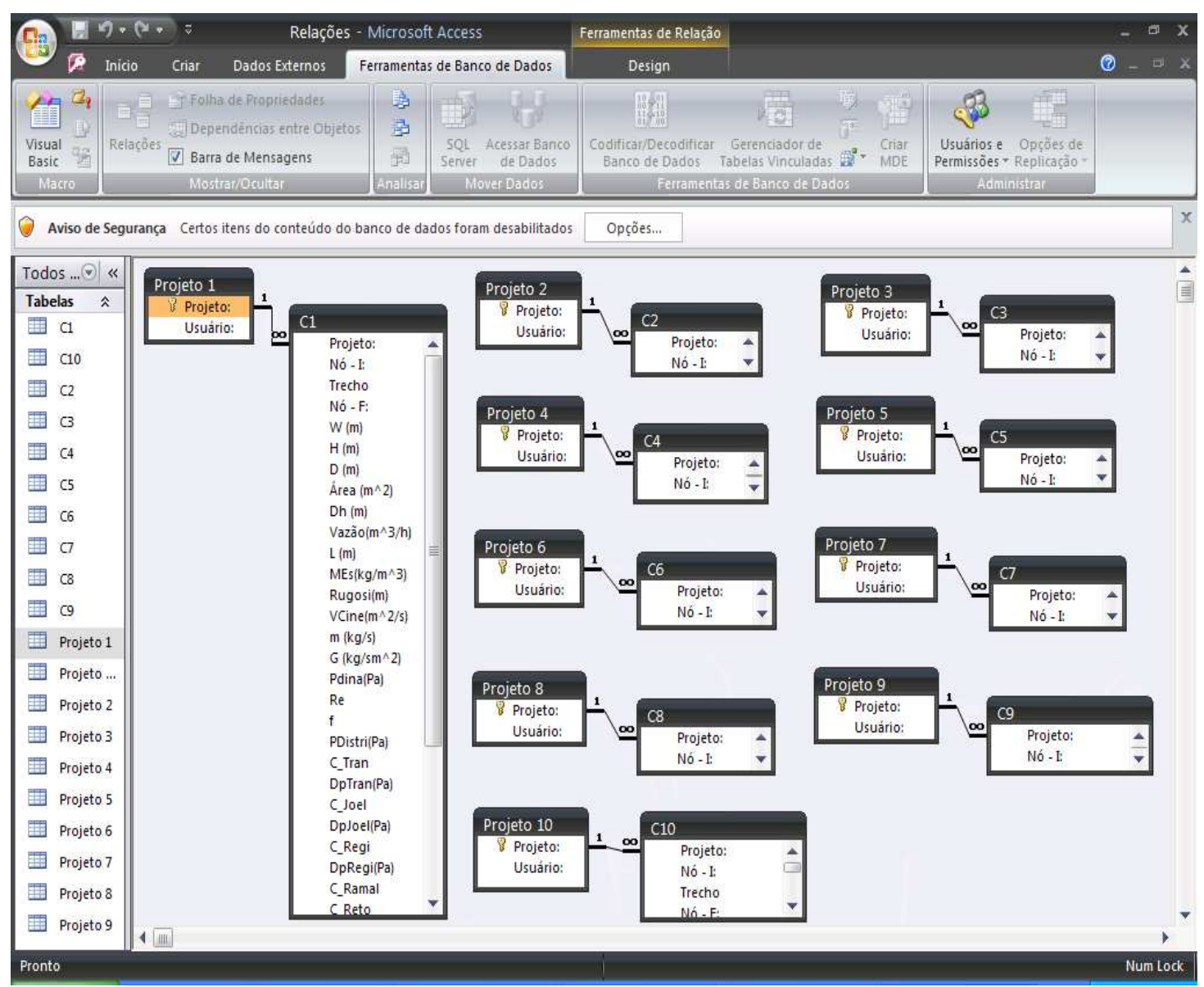

Figura 5.12 - Banco de dados Access: Balance.mdb 


\section{ESTUDO DE CASOS}

Para analisar a funcionalidade do programa desenvolvido foram adotados dois estudos de casos com redes de insuflação e retorno de ar. São situações típicas de instalações de ar condicionado, sendo que a diferença entre elas é que no caso II estão sendo considerados a tomada de ar exterior e o retorno vinculados à caixa de mistura. Destaca-se no caso II, a preocupação com o balanceamento que irá proporcionar a .garantia das vazões de ar externo de renovação.

\subsection{CASO I: CARACTERIZAÇÃO DA REDE DE DISTRIBUIÇÃO DE AR}

A instalação escolhida para este caso está apresentada pelo manual HVAC SYSTEMS DUCT DESIGN - SMACNA, Third Edition, 1990, conforme figura 6.1.

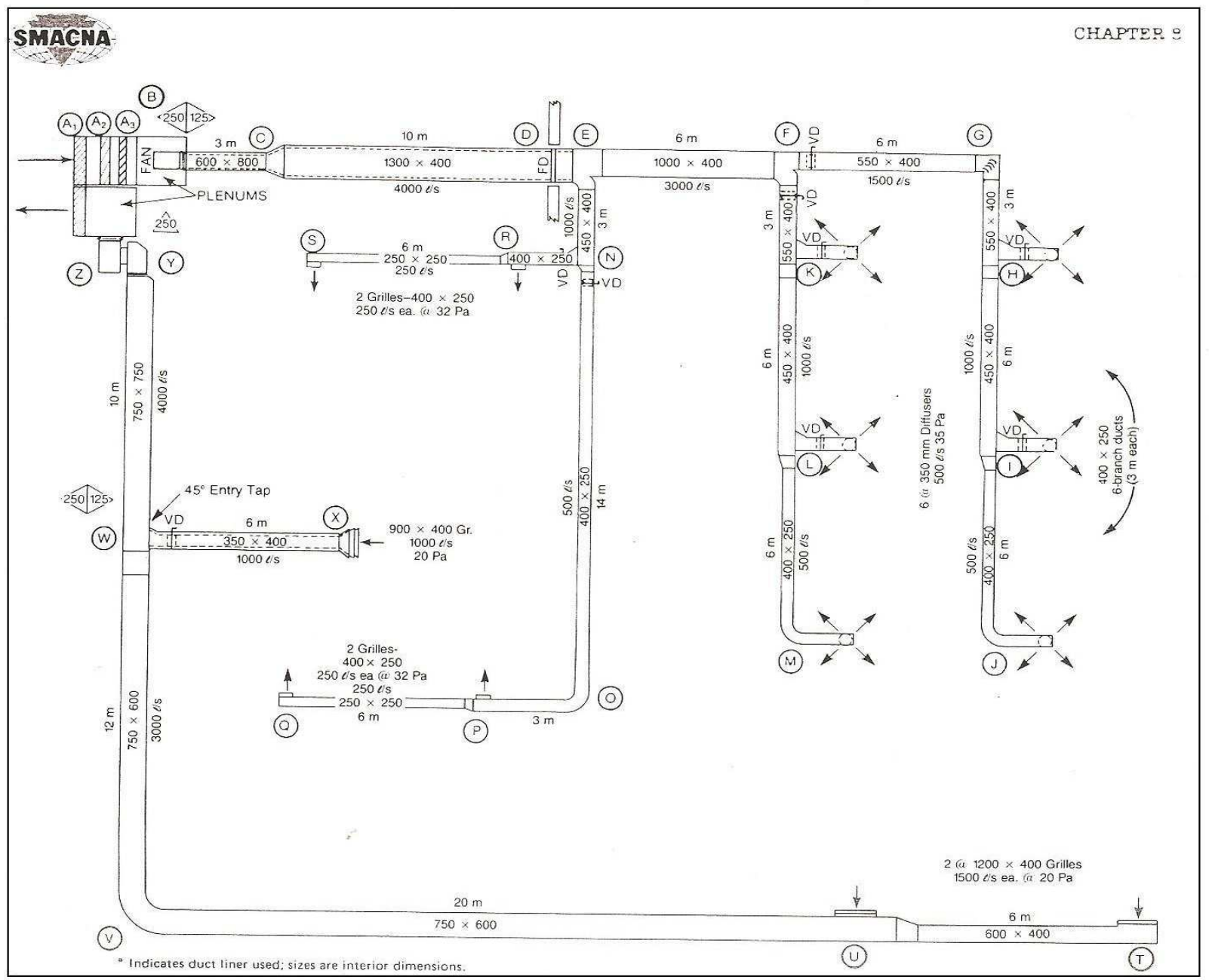

Figura 6.1 - Esquema do sistema simulado no programa (SMACNA, 1990) 
Neste caso o sistema de distribuição de ar é formado por 22 trechos considerando-se insuflação e retorno. A geometria de todos os dutos possui seções transversais de escoamento como retangulares.

As vazões volumétricas identificadas no esquema proposto pela SMACNA (1990) adotam massa específica de $1,204 \mathrm{~kg} / \mathrm{m}^{3}$, ou seja, condições padrão como referência. Isto possibilita determinar os valores de vazões mássicas correspondentes a cada trecho da rede. Para condições de pressão nos ambientes condicionados foram presumidos valores iguais a zero.

O projeto da rede de distribuição de ar foi executado em conformidade com a carga térmica dos ambientes e observando os critérios de máxima velocidade em cada trecho, de modo a manter o nível de ruído apropriado. O ventilador foi então dimensionado para movimentar $14400 \mathrm{~m}^{3} / \mathrm{h}$ de ar que será distribuído por grelhas e difusores.

Neste estudo do caso I, os difusores de insuflação, como também grelhas de insuflação e de retorno, possuem características de vazão e de perdas conforme está mostrado na tabela 6.1 .

Tabela 6.1 - Características de difusores e grelhas

\begin{tabular}{|c|c|c|c|}
\hline Descrição & $\mathbf{Q}_{\text {pad }}\left(\mathbf{m}^{\mathbf{3}} \mathbf{/ h}\right)$ & Perda (mmca) & Perda (Pa) \\
\hline Difusor - Insuflação & 1800 & 3,8 & 37 \\
\hline Grelha - Insuflação & 900 & 3,5 & 34 \\
\hline Grelha - Retorno & 3600 & 2,3 & 23 \\
\hline Grelha - Retorno & 5400 & 3,4 & 33 \\
\hline
\end{tabular}

Para ser feita a análise da rede projetada, tendo como meta obter-se 0 balanceamento da mesma e utilizando a metodologia escolhida, deve-se adotar as etapas apresentadas no capítulo 4.

Assim, inicialmente foi estabelecida a numeração para todos os trechos no sentido do ambiente para o ventilador. Também os nós receberam sua denominação com letras no mesmo sentido.

A figura 6.2 mostra a identificação dos trechos e nós no esquema da rede. 


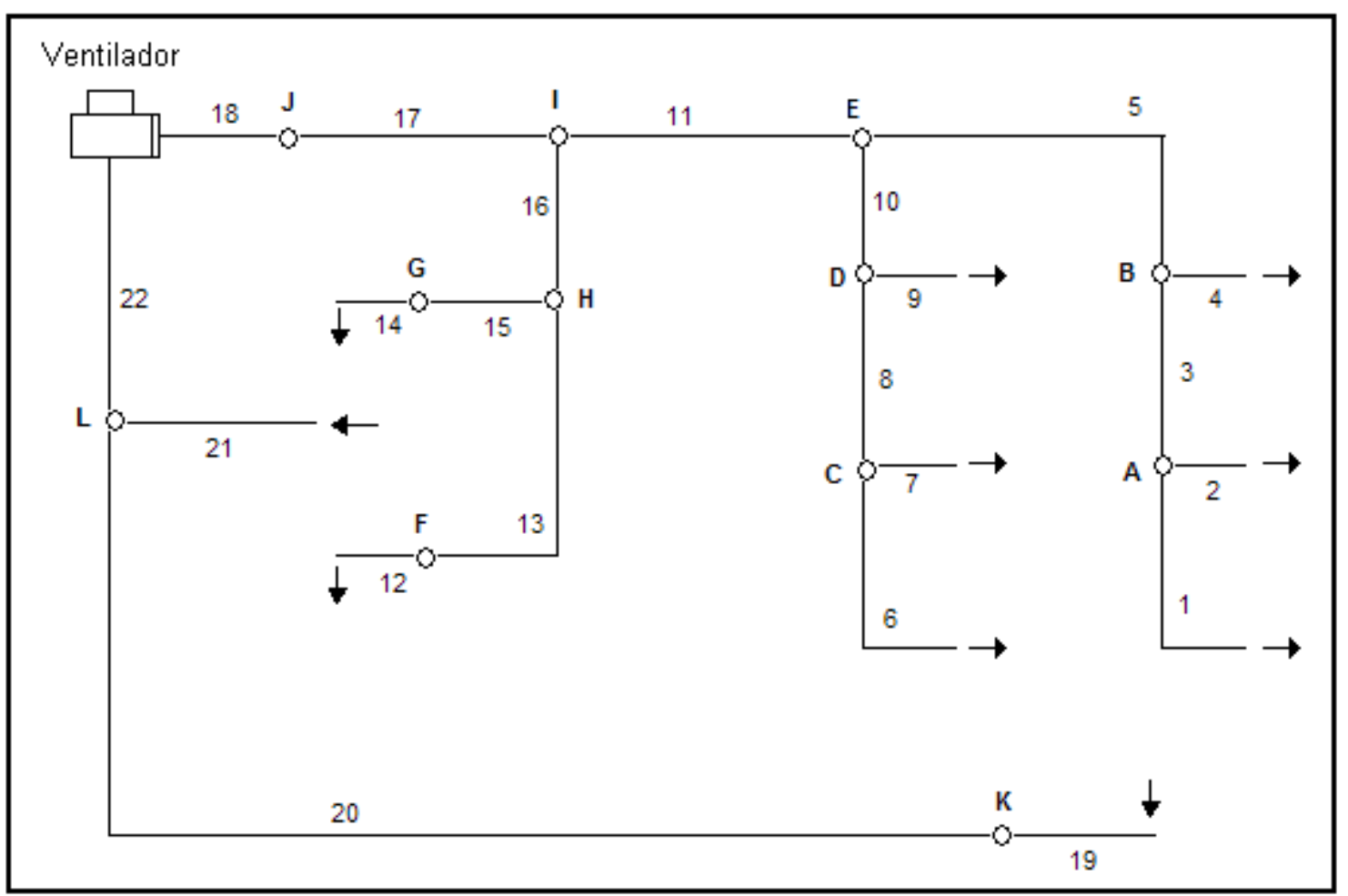

Figura 6.2 - Esquema da rede com identificação dos nós e trechos Caso I

Nesta análise não foram consideradas as vazões de ar externo e de exaustão, pois os dados não estavam disponíveis. Isto não prejudica o propósito de realizar o balanceamento da rede, inclusive porque uma solução possível é adotar dispositivos nos equipamentos de condicionamento de ar que realizem exaustão do ar de retorno e entrada de ar externo de modo equilibrado.

Outros parâmetros importantes para caracterizar a rede e aplicação do método neste projeto são:

- Para os trechos de dutos: dimensões das seções transversais (W e H), comprimento $(L)$, tipo de material e sua respectiva rugosidade $(\varepsilon)$.

- Para o escoamento: Vazões em cada trecho (Q), massa específica ( $\rho)$ e a viscosidade cinemática (v).

$\mathrm{Na}$ tabela 6.2 estão apresentados os valores numéricos para todos os parâmetros citados no parágrafo anterior relativos ao projeto em análise. 
Tabela 6.2 - Características geométricas e parâmetros nos trechos - Caso I

\begin{tabular}{|c|c|c|c|c|c|c|c|}
\hline Trecho & $\begin{array}{c}W \\
(m)\end{array}$ & $\begin{array}{c}\mathbf{H} \\
(\mathrm{m})\end{array}$ & $\begin{array}{c}Q \\
\left(m^{3} / h\right)\end{array}$ & $\begin{array}{l}\mathrm{L} \\
(\mathrm{m})\end{array}$ & $\begin{array}{c}\varepsilon \\
(\mathrm{m})\end{array}$ & $\begin{array}{c}\rho \\
\left(\mathrm{kg} / \mathrm{m}^{3}\right)\end{array}$ & $\begin{array}{c}v \\
\left(\mathrm{~m}^{2} / \mathrm{s}\right)\end{array}$ \\
\hline 1 & 0,40 & 0,25 & 1800 & 9,0 & $0,9^{*} 10^{-4}$ & 1,204 & $1,51 * 10^{-5}$ \\
\hline 2 & 0,40 & 0,25 & 1800 & 3,0 & $0,9^{*} 10^{-4}$ & 1,204 & $1,51 * 10^{-5}$ \\
\hline 3 & 0,45 & 0,40 & 3600 & 6,0 & $0,9^{*} 10^{-4}$ & 1,204 & $1,51 * 10^{-5}$ \\
\hline 4 & 0,40 & 0,25 & 1800 & 3,0 & $0,9^{*} 10^{-4}$ & 1,204 & $1,51 * 10^{-5}$ \\
\hline 5 & 0,55 & 0,40 & 5400 & 9,0 & $0,9^{*} 10^{-4}$ & 1,204 & $1,51^{*} 10^{-5}$ \\
\hline 6 & 0,40 & 0,25 & 1800 & 9,0 & $0,9^{*} 10^{-4}$ & 1,204 & $1,51 * 10^{-5}$ \\
\hline 7 & 0,40 & 0,25 & 1800 & 3,0 & $0,9^{*} 10^{-4}$ & 1,204 & $1,51 * 10^{-5}$ \\
\hline 8 & 0,45 & 0,40 & 3600 & 6,0 & $0,9 * 10^{-4}$ & 1,204 & $1,51 * 10^{-5}$ \\
\hline 9 & 0,40 & 0,25 & 1800 & 3,0 & $0,9^{*} 10^{-4}$ & 1,204 & $1,51 * 10^{-5}$ \\
\hline 10 & 0,55 & 0,40 & 5400 & 3,0 & $0,9^{*} 10^{-4}$ & 1,204 & $1,51^{*} 10^{-5}$ \\
\hline 11 & 0,10 & 0,40 & 10800 & 6,0 & $0,9^{*} 10^{-4}$ & 1,204 & $1,51 * 10^{-5}$ \\
\hline 12 & 0,25 & 0,25 & 900 & 6,0 & $0,9^{*} 10^{-4}$ & 1,204 & $1,51 * 10^{-5}$ \\
\hline 13 & 0,40 & 0,25 & 1800 & 17,0 & $0,9^{*} 10^{-4}$ & 1,204 & $1,51 * 10^{-5}$ \\
\hline 14 & 0,25 & 0,25 & 900 & 6,0 & $0,9^{*} 10^{-4}$ & 1,204 & $1,51 * 10^{-5}$ \\
\hline 15 & 0,40 & 0,25 & 1800 & 3,0 & $0,9^{*} 10^{-4}$ & 1,204 & $1,51 * 10^{-5}$ \\
\hline 16 & 0,45 & 0,40 & 3600 & 3,0 & $0,9^{*} 10^{-4}$ & 1,204 & $1,51 * 10^{-5}$ \\
\hline 17 & 0,13 & 0,40 & 14400 & 10,0 & $9,0 * 10^{-4}$ & 1,204 & $1,51 * 10^{-5}$ \\
\hline 18 & 0,60 & 0,80 & 14400 & 3,0 & $9,0 * 10^{-4}$ & 1,204 & $1,51 * 10^{-5}$ \\
\hline 19 & 0,60 & 0,40 & 5400 & 6,0 & $0,9^{*} 10^{-4}$ & 1,204 & $1,51 * 10^{-5}$ \\
\hline 20 & 0,75 & 0,60 & 10800 & 32,0 & $0,9^{*} 10^{-4}$ & 1,204 & $1,51 * 10^{-5}$ \\
\hline 21 & 0,35 & 0,40 & 3600 & 6,0 & $9,0^{*} 10^{-4}$ & 1,204 & $1,51^{*} 10^{-5}$ \\
\hline 22 & 0,75 & 0,75 & 14400 & 10,0 & $0,9^{*} 10^{-4}$ & 1,204 & $1,51 * 10^{-5}$ \\
\hline
\end{tabular}

Os acessórios empregados na rede também estão identificados e com seus dados apresentados vinculados ao trecho que pertencem.

Os dados para estas singularidades foram obtidos na forma de coeficientes de perda $(C)$ ou de valores de diferença de pressão $(\Delta P)$.

$\mathrm{Na}$ tabela 6.3, encontram-se os coeficientes de perda para transições, joelhos e registros, assim como os coeficientes relativos ao trecho reto e ao ramal de cada junção.

Nesta tabela estão ainda os valores de coeficientes ( $\mathrm{Ci}$ ) para outros acessórios e as diferenças de pressão $(\Delta \mathrm{P})$ para os difusores. 
Tabela 6.3 - Coeficientes e valores de perda para os trechos da rede - Caso I

\begin{tabular}{|c|c|c|c|c|c|c|c|c|c|c|}
\hline Trecho & $\begin{array}{c}\mathbf{C} \\
\text { Transição }\end{array}$ & $\begin{array}{c}\text { Coelho } \\
\text { Registro }\end{array}$ & $\begin{array}{c}\text { Ramal } \\
\text { Reto }\end{array}$ & $\begin{array}{c}\text { C1 } \\
\text { R2 }\end{array}$ & $\mathbf{C 3}$ & $\mathbf{C 4}$ & $\begin{array}{c}\Delta \text { P Difusor } \\
\text { (Pa) }\end{array}$ \\
\hline $\mathbf{1}$ & 0,05 & 0,17 & 0,04 & - & - & - & 1,20 & - & - & 37 \\
\hline $\mathbf{2}$ & 0,05 & - & 0,04 & - & - & - & - & - & - & 37 \\
\hline $\mathbf{3}$ & 0,05 & - & - & - & - & - & - & - & - & - \\
\hline $\mathbf{4}$ & 0,05 & - & 0,04 & - & - & - & - & - & - & 37 \\
\hline $\mathbf{5}$ & - & 0,15 & 0,04 & - & 0,06 & - & - & - & - & - \\
\hline $\mathbf{6}$ & 0,05 & 0,17 & 0,04 & - & - & - & - & - & 1,20 & 37 \\
\hline $\mathbf{7}$ & 0,05 & - & 0,04 & - & - & - & - & - & - & 37 \\
\hline $\mathbf{8}$ & 0,05 & - & - & - & - & - & - & - & - & - \\
\hline $\mathbf{9}$ & 0,05 & - & 0,04 & - & - & - & - & - & - & 37 \\
\hline $\mathbf{1 0}$ & - & - & 0,04 & 0,63 & - & - & - & - & - & - \\
\hline $\mathbf{1 1}$ & - & - & - & - & $-0,05$ & - & - & - & - & - \\
\hline $\mathbf{1 2}$ & 0,06 & 0,90 & - & - & - & - & - & - & - & 33 \\
\hline $\mathbf{1 3}$ & 0,05 & 0,12 & 0,04 & - & - & - & - & - & - & - \\
\hline $\mathbf{1 4}$ & 0,06 & 0,90 & - & - & - & - & - & - & - & 33 \\
\hline $\mathbf{1 5}$ & - & - & 0,04 & - & - & 0,74 & - & - & - & - \\
\hline $\mathbf{1 6}$ & - & - & - & 0,84 & - & - & - & - & - & - \\
\hline $\mathbf{1 7}$ & 0,25 & - & 0,38 & - & - & - & - & - & - & - \\
\hline $\mathbf{1 8}$ & - & - & - & - & - & - & - & - & - & - \\
\hline $\mathbf{1 9}$ & 0,25 & 1,80 & - & - & - & 0,53 & - & - & - & 23 \\
\hline $\mathbf{2 0}$ & 0,20 & 0,16 & - & - & - & 0,33 & - & - & - & - \\
\hline $\mathbf{2 1}$ & 0,30 & - & 1,88 & - & - & $-0,37$ & - & - & - & 23 \\
\hline $\mathbf{2 2}$ & 0,25 & - & - & - & - & 1,00 & - & - & - & - \\
\hline & & & & & & & & \\
\hline
\end{tabular}

\subsection{APLICAÇÃO DO PROGRAMA DOBAL PARA O PROJETO DO ESTUDO DE CASO I}

Para verificar o comportamento da rede do caso I e obter os valores de balanceamento foi utilizado o programa DOBAL aplicado ao esquema da rede apresentado na figura 6.2 e os parâmetros mostrados nas respectivas tabelas.

\subsubsection{Identificação do projeto - Caso I}

Em primeiro lugar foi feita a identificação no programa dos dados do projeto do estudo de caso que foi simulado e avaliado. 
Estes dados são apresentados na Tabela 6.4.

Tabela 6.4 - Nome do Projeto e Usuário - Caso I

\begin{tabular}{|c|c|}
\hline Projeto: & Usuário: \\
\hline USP-22Trechos & Lab. Mec. Flu. \\
\hline
\end{tabular}

\subsubsection{Inserção de dados, cálculos e resultados para o projeto- Caso I}

Após identificação do projeto foram inseridos os dados, realizados os cálculos e obtidos os resultados a partir das seis etapas, conforme proposta do programa DOBAL.

O detalhamento sobre as etapas de aplicação do programa DOBAL está ilustrado no Manual contido no Apêndice A. Nos tópicos seguintes, em que o programa é utilizado na rede do estudo de caso, as tabelas apresentadas trazem os resultados numéricos em formatos adequados a este texto, porém não exatamente ao que mostra na saída do programa.

\subsubsection{Etapa I: Parâmetros característicos da rede - Caso I}

Nesta primeira etapa os dados que relacionam os 22 trechos e nós estabelecem os vínculos conforme a disposição da rede. Estes dados foram obtidos do esquema da rede (Figura 6.2). Esta vinculação entre trechos e nós estabelece os caminhos que o ar percorre para simular seu escoamento.

A Tabela 6.5 mostra estes dados para o estudo de caso. 
Tabela 6.5 - Caracterização da rede com vinculação de trechos e nós - Caso I

\begin{tabular}{|c|c|c|}
\hline Nó & Trecho & Nó (Amb) \\
\hline A & 1 & 0 \\
\hline A & 2 & 0 \\
\hline B & 3 & A \\
\hline B & 4 & 0 \\
\hline C & 6 & 0 \\
\hline C & 7 & 0 \\
\hline D & 8 & C \\
\hline D & 9 & 0 \\
\hline E & 5 & B \\
\hline E & 10 & D \\
\hline F & 12 & 0 \\
\hline G & 14 & 0 \\
\hline H & 13 & F \\
\hline H & 15 & G \\
\hline I & 11 & E \\
\hline I & 16 & H \\
\hline J & 17 & I \\
\hline K & 19 & 0 \\
\hline L & 20 & K \\
\hline L & 21 & 0 \\
\hline VEN & 18 & J \\
\hline VEN & 22 & L \\
\hline & & \\
\hline & 19 & 0 \\
\hline
\end{tabular}

Convém observar que nas duas últimas linhas da tabela 6.5 encontra-se a denominação "VEN" na coluna dos nós. Esta denominação indica a posição do ventilador em relação aos trechos da rede vinculados à aspiração e à descarga deste equipamento.

Ainda nesta etapa foram inseridas as dimensões dos dutos e calculadas as áreas $(S)$ e diâmetro hidráulicos $\left(D_{h}\right)$ para cada um dos 22 trechos.

Estes valores estão na tabela 6.6. 
Tabela 6.6 - Dados e resultados para área e diâmetro hidráulico - Caso I

\begin{tabular}{|c|c|c|c|c|}
\hline Trecho & $\mathbf{W}(\mathbf{m})$ & $\mathbf{H}(\mathbf{m})$ & $\mathbf{S}\left(\mathbf{m}^{\mathbf{2}}\right)$ & $\mathbf{D}_{\mathbf{h}}(\mathbf{m})$ \\
\hline $\mathbf{1}$ & 0,40 & 0,25 & 0,10 & 0,31 \\
\hline $\mathbf{2}$ & 0,40 & 0,25 & 0,10 & 0,31 \\
\hline $\mathbf{3}$ & 0,45 & 0,40 & 0,18 & 0,42 \\
\hline $\mathbf{4}$ & 0,40 & 0,25 & 0,10 & 0,31 \\
\hline $\mathbf{5}$ & 0,55 & 0,40 & 0,22 & 0,46 \\
\hline $\mathbf{6}$ & 0,40 & 0,25 & 0,10 & 0,31 \\
\hline $\mathbf{7}$ & 0,40 & 0,25 & 0,10 & 0,31 \\
\hline $\mathbf{8}$ & 0,45 & 0,40 & 0,18 & 0,42 \\
\hline $\mathbf{9}$ & 0,40 & 0,25 & 0,10 & 0,31 \\
\hline $\mathbf{1 0}$ & 0,55 & 0,40 & 0,22 & 0,46 \\
\hline $\mathbf{1 1}$ & 1,00 & 0,40 & 0,40 & 0,57 \\
\hline $\mathbf{1 2}$ & 0,25 & 0,25 & 0,06 & 0,25 \\
\hline $\mathbf{1 3}$ & 0,40 & 0,25 & 0,10 & 0,31 \\
\hline $\mathbf{1 4}$ & 0,25 & 0,25 & 0,06 & 0,25 \\
\hline $\mathbf{1 5}$ & 0,40 & 0,25 & 0,10 & 0,31 \\
\hline $\mathbf{1 6}$ & 0,45 & 0,40 & 0,18 & 0,42 \\
\hline $\mathbf{1 7}$ & 1,30 & 0,40 & 0,52 & 0,61 \\
\hline $\mathbf{1 8}$ & 0,60 & 0,80 & 0,48 & 0,69 \\
\hline $\mathbf{1 9}$ & 0,60 & 0,40 & 0,24 & 0,48 \\
\hline $\mathbf{2 0}$ & 0,75 & 0,60 & 0,45 & 0,67 \\
\hline $\mathbf{2 1}$ & 0,35 & 0,40 & 0,14 & 0,37 \\
\hline $\mathbf{2 2}$ & 0,75 & 0,75 & 0,56 & 0,75 \\
\hline & & & & \\
\hline
\end{tabular}

\subsubsection{Etapa II: Cálculo das perdas distribuídas - Caso I}

Nesta etapa foram inseridos os dados para cada trecho de duto. A saber, vazão volumétrica, comprimento, rugosidade, massa específica e viscosidade cinemática. A partir destes dados foram calculados a vazão mássica $(\dot{\mathrm{m}})$, a velocidade mássica (G), a pressão dinâmica (Pdin), o número de Reynolds $(\mathbf{R e}), 0$ coeficiente de perda distribuída (f) e finalmente a perda distribuída de cada um dos trechos, utilizando as equações apresentadas no capitulo 4.

A tabela 6.7 traz os resultados para cada variável utilizada e para a perda distribuída em cada trecho. 
Tabela 6.7 - Perdas distribuídas para cada trecho - Caso I

\begin{tabular}{|c|c|c|c|c|c|c|}
\hline Trecho & $\begin{array}{c}\dot{\mathbf{m}} \\
(\mathbf{k g} / \mathbf{s})\end{array}$ & $\begin{array}{c}\mathbf{G} \\
\left(\mathbf{k g} / \mathbf{s} \cdot \mathbf{m}^{\mathbf{2}}\right)\end{array}$ & $\begin{array}{c}\mathbf{P d i n} \\
\mathbf{( P a})\end{array}$ & $\mathbf{R e}$ & $\mathbf{f}$ & $\begin{array}{c}\Delta \mathbf{P}_{\mathbf{d}} \\
\mathbf{( P a})\end{array}$ \\
\hline $\mathbf{1}$ & 0,60 & 6,02 & 15,05 & 102649 & $1,93 \mathrm{E}-02$ & 8 \\
\hline $\mathbf{2}$ & 0,60 & 6,02 & 15,05 & 102649 & $1,93 \mathrm{E}-02$ & 3 \\
\hline $\mathbf{3}$ & 1,20 & 6,69 & 18,59 & 154551 & $1,76 \mathrm{E}-02$ & 5 \\
\hline $\mathbf{4}$ & 0,60 & 6,02 & 15,05 & 102649 & $1,93 \mathrm{E}-02$ & 3 \\
\hline $\mathbf{5}$ & 1,81 & 8,21 & 27,99 & 207729 & $1,66 \mathrm{E}-02$ & 9 \\
\hline $\mathbf{6}$ & 0,60 & 6,02 & 15,05 & 102649 & $1,93 \mathrm{E}-02$ & 8 \\
\hline $\mathbf{7}$ & 0,60 & 6,02 & 15,05 & 102649 & $1,93 \mathrm{E}-02$ & 3 \\
\hline $\mathbf{8}$ & 1,20 & 6,69 & 18,59 & 154551 & $1,76 \mathrm{E}-02$ & 5 \\
\hline $\mathbf{9}$ & 0,60 & 6,02 & 15,05 & 102649 & $1,93 \mathrm{E}-02$ & 3 \\
\hline $\mathbf{1 0}$ & 1,81 & 8,21 & 27,99 & 207729 & $1,66 \mathrm{E}-02$ & 3 \\
\hline $\mathbf{1 1}$ & 3,61 & 9,03 & 33,86 & 283112 & $1,55 \mathrm{E}-02$ & 5 \\
\hline $\mathbf{1 2}$ & 0,30 & 5,02 & 10,47 & 69030 & $2,12 \mathrm{E}-02$ & 5 \\
\hline $\mathbf{1 3}$ & 0,60 & 6,02 & 15,05 & 102649 & $1,93 \mathrm{E}-02$ & 16 \\
\hline $\mathbf{1 4}$ & 0,30 & 5,02 & 10,47 & 69030 & $2,11 \mathrm{E}-02$ & 5 \\
\hline $\mathbf{1 5}$ & 0,60 & 6,02 & 15,05 & 102649 & $1,93 \mathrm{E}-02$ & 3 \\
\hline $\mathbf{1 6}$ & 1,20 & 6,69 & 18,59 & 154551 & $1,76 \mathrm{E}-02$ & 2 \\
\hline $\mathbf{1 7}$ & 4,82 & 9,26 & 35,61 & 310697 & $2,23 \mathrm{E}-02$ & 13 \\
\hline $\mathbf{1 8}$ & 4,82 & 10,03 & 41,78 & 380668 & $2,16 \mathrm{E}-02$ & 4 \\
\hline $\mathbf{1 9}$ & 1,81 & 7,53 & 23,55 & 198807 & $1,67 \mathrm{E}-02$ & 5 \\
\hline $\mathbf{2 0}$ & 3,61 & 8,03 & 26,78 & 295928 & $1,52 \mathrm{E}-02$ & 19 \\
\hline $\mathbf{2 1}$ & 1,20 & 8,60 & 30,71 & 175023 & $2,54 \mathrm{E}-02$ & 13 \\
\hline $\mathbf{2 2}$ & 4,82 & 8,60 & 30,71 & 354777 & $1,46 \mathrm{E}-02$ & 6 \\
\hline & & & & & & \\
\hline
\end{tabular}

\subsubsection{Etapa III: Cálculo das perdas localizadas - Caso I}

Nesta etapa foram realizados os cálculos para obtenção das perdas de pressão nos diferentes acessórios da rede, que são somados em cada trecho totalizando sua respectiva perda localizada.

$\mathrm{Na}$ tabela 6.8 estão os resultados das perdas para cada acessório presente nos trechos da rede e sua soma, resultando a perda localizada neste. 
Tabela 6.8 - Perdas localizadas para cada trecho - Caso I

\begin{tabular}{|c|c|c|c|c|c|c|c|c|}
\hline Trecho & $\begin{array}{c}\Delta \mathbf{P}_{\mathbf{1}} \\
\mathbf{( P a})\end{array}$ & $\begin{array}{c}\Delta \mathbf{P}_{\mathbf{2}} \\
\mathbf{( P a})\end{array}$ & $\begin{array}{c}\Delta \mathbf{P}_{\mathbf{3}} \\
\mathbf{( P a}\end{array}$ & $\begin{array}{c}\Delta \mathbf{P}_{\mathbf{4}} \\
\mathbf{( P a})\end{array}$ & $\begin{array}{c}\Delta \mathbf{P}_{\mathbf{5}} \\
\mathbf{( P a})\end{array}$ & $\begin{array}{c}\Delta \mathbf{P}_{\mathbf{6}} \\
\mathbf{( P a})\end{array}$ & $\begin{array}{c}\Delta \mathbf{P}_{\mathbf{7}} \\
\mathbf{( P a})\end{array}$ & $\begin{array}{c}\Delta \mathbf{P}_{\mathbf{L}} \\
\mathbf{( P a})\end{array}$ \\
\hline $\mathbf{1}$ & 0,75 & 2,56 & 0,60 & - & 18,06 & 3,80 & 37,28 & 59 \\
\hline $\mathbf{2}$ & 0,75 & - & 0,60 & - & - & 3,80 & 37,28 & 38 \\
\hline $\mathbf{3}$ & 0,93 & - & - & - & - & - & - & 1 \\
\hline $\mathbf{4}$ & 0,75 & - & 0,60 & - & - & 3,80 & 37,28 & 38 \\
\hline $\mathbf{5}$ & - & 4,20 & 1,12 & 1,68 & - & - & - & 7 \\
\hline $\mathbf{6}$ & 0,75 & 2,56 & 0,60 & - & 18,06 & 3,80 & 37,28 & 59 \\
\hline $\mathbf{7}$ & 0,75 & - & 0,60 & - & - & 3,80 & 37,28 & 38 \\
\hline $\mathbf{8}$ & 0,93 & - & - & - & - & - & - & 1 \\
\hline $\mathbf{9}$ & 0,75 & - & 0,60 & - & - & 3,80 & 37,28 & 38 \\
\hline $\mathbf{1 0}$ & - & - & 1,12 & 17,63 & - & - & - & 19 \\
\hline $\mathbf{1 1}$ & - & - & - & $-1,69$ & - & - & - & -2 \\
\hline $\mathbf{1 2}$ & 0,63 & 9,42 & - & - & - & 3,40 & 33,25 & 43 \\
\hline $\mathbf{1 3}$ & 0,75 & 1,81 & 0,60 & - & - & - & - & 3 \\
\hline $\mathbf{1 4}$ & 0,63 & 9,42 & - & - & - & 3,40 & 33,25 & 43 \\
\hline $\mathbf{1 5}$ & - & - & 0,60 & - & 11,14 & - & - & 12 \\
\hline $\mathbf{1 6}$ & - & - & - & 15,62 & - & - & - & 16 \\
\hline $\mathbf{1 7}$ & 8,91 & - & 13,53 & - & - & - & - & 22 \\
\hline $\mathbf{1 8}$ & - & - & - & - & - & - & - & 0 \\
\hline $\mathbf{1 9}$ & 5,89 & 42,39 & - & - & 12,48 & 2,30 & 22,56 & 83 \\
\hline $\mathbf{2 0}$ & 5,36 & 4,29 & - & - & 8,84 & - & - & 18 \\
\hline $\mathbf{2 1}$ & 9,21 & - & 57,74 & - & $-11,36$ & 2,30 & 22,56 & 78 \\
\hline $\mathbf{2 2}$ & 7,68 & - & - & - & 30,71 & - & - & 38 \\
\hline
\end{tabular}

Legenda:

$\Delta \mathrm{P}_{1}=$ Perda localizada em transições

$\Delta \mathrm{P}_{2}=$ Perda localizada em joelhos

$\Delta \mathrm{P}_{3}=$ Perda localizada em registros

$\Delta \mathrm{P}_{4}=$ Perda localizada em junções

$\Delta \mathrm{P}_{5}=$ Perda localizada em acessórios

$\Delta \mathrm{P}_{6}=$ Perda localizada em acessórios genéricos

$\Delta \mathrm{P}_{7}=$ Perda localizada em difusores

$\Delta \mathrm{P}_{\mathrm{L}}=$ Perda localizada total no trecho 
6.2.2.4 Etapa IV: Cálculo das perdas totais - Caso I

$\mathrm{Na}$ quarta etapa foram calculadas as perdas totais para os 22 trechos da instalação adotada como estudo de caso. Para cada trecho são somadas as perdas localizadas e distribuídas, obtidas a partir da imposição da vazão de projeto. Os resultados desta etapa estão mostrados na tabela 6.9.

Tabela 6.9 - Perdas totais para cada trecho - Caso I
\begin{tabular}{|c|c|c|c|}
\hline Trecho & $\begin{array}{c}\Delta \mathbf{P}_{\mathbf{d}} \\
(\mathbf{P a})\end{array}$ & $\begin{array}{c}\Delta \mathbf{P}_{\mathbf{L}} \\
\mathbf{( P a})\end{array}$ & $\begin{array}{c}\Delta \mathbf{P}_{\mathbf{T}} \\
\mathbf{( P a})\end{array}$ \\
\hline $\mathbf{1}$ & 8 & 59 & 67 \\
\hline $\mathbf{2}$ & 3 & 38 & 41 \\
\hline $\mathbf{3}$ & 5 & 1 & 6 \\
\hline $\mathbf{4}$ & 3 & 38 & 41 \\
\hline $\mathbf{5}$ & 9 & 7 & 16 \\
\hline $\mathbf{6}$ & 8 & 59 & 67 \\
\hline $\mathbf{7}$ & 3 & 38 & 41 \\
\hline $\mathbf{8}$ & 5 & 1 & 6 \\
\hline $\mathbf{9}$ & 3 & 38 & 41 \\
\hline $\mathbf{1 0}$ & 3 & 19 & 22 \\
\hline $\mathbf{1 1}$ & 5 & -2 & 3 \\
\hline $\mathbf{1 2}$ & 5 & 43 & 48 \\
\hline $\mathbf{1 3}$ & 16 & 3 & 19 \\
\hline $\mathbf{1 4}$ & 5 & 43 & 48 \\
\hline $\mathbf{1 5}$ & 3 & 12 & 15 \\
\hline $\mathbf{1 6}$ & 2 & 16 & 18 \\
\hline $\mathbf{1 7}$ & 13 & 22 & 35 \\
\hline $\mathbf{1 8}$ & 4 & 0 & 4 \\
\hline $\mathbf{1 9}$ & 5 & 83 & 87 \\
\hline $\mathbf{2 0}$ & 19 & 18 & 37 \\
\hline $\mathbf{2 1}$ & 13 & 78 & 91 \\
\hline $\mathbf{2 2}$ & 6 & 38 & 44 \\
\hline & & & \\
\hline
\end{tabular}

\subsubsection{Etapa V: Simulação da rede - Caso I}

Nesta etapa foram calculadas perdas de pressão total para o escoamento que percorre cada caminho definido a partir de um nó até o nó seguinte ou até 0 ambiente. 
A tabela 6.10 mostra o resultado para as perdas de pressão total presente nos caminhos definidos pelo fluxo de ar na instalação.

Tabela 6.10 - Caminhos da rede - Caso I

\begin{tabular}{|c|c|c|c|}
\hline Nó & Trecho & $\begin{array}{c}\text { Nó } \\
(\mathbf{A m b})\end{array}$ & $\begin{array}{c}\Delta \mathbf{P}_{\mathbf{T}} \text { caminho } \\
(\mathbf{P a})\end{array}$ \\
\hline A & 1 & 0 & 67 \\
\hline A & 2 & 0 & 41 \\
\hline B & 3 & A & 73 \\
\hline B & 4 & 0 & 41 \\
\hline C & 6 & 0 & 67 \\
\hline C & 7 & 0 & 41 \\
\hline D & 8 & C & 73 \\
\hline D & 9 & 0 & 41 \\
\hline E & 5 & B & 89 \\
\hline E & 10 & D & 95 \\
\hline F & 12 & 0 & 48 \\
\hline G & 14 & 0 & 48 \\
\hline H & 13 & F & 67 \\
\hline H & 15 & G & 63 \\
\hline I & 11 & E & 98 \\
\hline I & 16 & H & 85 \\
\hline J & 17 & I & 133 \\
\hline K & 19 & 0 & 88 \\
\hline L & 20 & K & 125 \\
\hline L & 21 & 0 & 91 \\
\hline
\end{tabular}

\subsubsection{Etapa VI: Comparação de caminhos - Caso I}

Esta última etapa traz os resultados em termos de diferença de pressão para obtenção do balanceamento. Foram comparados os valores da perda de pressão total nos caminhos em paralelo partindo de um nó até o ambiente ou até o nó seguinte, sendo que a diferença resultou no valor de perda de pressão a ser introduzida para efetivar o balanceamento (DpBalance). O processo de comparação de caminhos através do programa também oferece como resultado a indicação do trecho em que deve haver o acréscimo de perda de pressão para obtenção do balanceamento. 
Os resultados para o projeto do estudo de caso estão na tabela 6.11.

Tabela 6.11 - Resultados de diferenças de pressão para o balanceamento - Caso I

\begin{tabular}{|c|c|c|c|}
\hline Nó & $\begin{array}{c}\text { Perda Total } \\
\text { Nó }(\mathbf{P a})\end{array}$ & $\begin{array}{c}\text { DpBalance } \\
(\mathbf{P a})\end{array}$ & $\begin{array}{c}\text { Trecho } \\
\text { Balance }\end{array}$ \\
\hline A & 67 & 26 & 2 \\
\hline B & 73 & 32 & 4 \\
\hline C & 67 & 26 & 7 \\
\hline D & 73 & 32 & 9 \\
\hline E & 95 & 6 & 5 \\
\hline H & 67 & 4 & 15 \\
\hline I & 98 & 13 & 16 \\
\hline L & 125 & 34 & 21 \\
\hline
\end{tabular}

Nesta etapa também foi calculado o caminho crítico da rede e foram determinados os níveis de pressão total na descarga e aspiração do ventilador a partir das redes de insuflação e de retorno. Conforme está mostrado na tabela 6.12.

Tabela 6.12 - Níveis de pressão totais na descarga e aspiração do ventilador - Caso I

\begin{tabular}{|c|c|c|c|}
\hline Caminho $\mathbf{P}_{\text {Tdesc }}$ & $\mathbf{P}_{\text {Tdesc }}(\mathbf{P a})$ & Caminho $\mathbf{P}_{\text {Tasp }}$ & $\mathbf{P}_{\text {Tasp }}(\mathbf{P a})$ \\
\hline VEN - 18 - J & 137 & VEN - 22 - L & -169 \\
\hline
\end{tabular}

Este resultado permitiu calcular a pressão total exigida para selecionar o ventilador. Esta pressão é idêntica à perda de pressão total que ocorre no sistema.

O equacionamento para determinação da perda de pressão total no sistema é:

$$
\Delta \mathrm{p}_{\mathrm{T} \text { Ventilador }}=137-(-169)=306(\mathrm{~Pa})
$$




\subsection{CASO II: CARACTERIZAÇÃO DA REDE DE DISTRIBUIÇÃO DE AR}

A instalação escolhida neste segundo caso tem como objetivo analisar a situação na qual há dificuldade de balanceamento entre o retorno e a entrada de ar exterior. A instalação foi apresentada por Bolliger Jr. e Mariani (2002) e seu esquema está na figura 6.3.

Neste caso o sistema de distribuição de ar apresentado é formado por 14 trechos divididos em redes de insuflação e retorno. Assim, inicialmente foi estabelecida a numeração para todos os trechos no sentido do ambiente para o ventilador. Também os nós receberam sua denominação com letras no mesmo sentido.

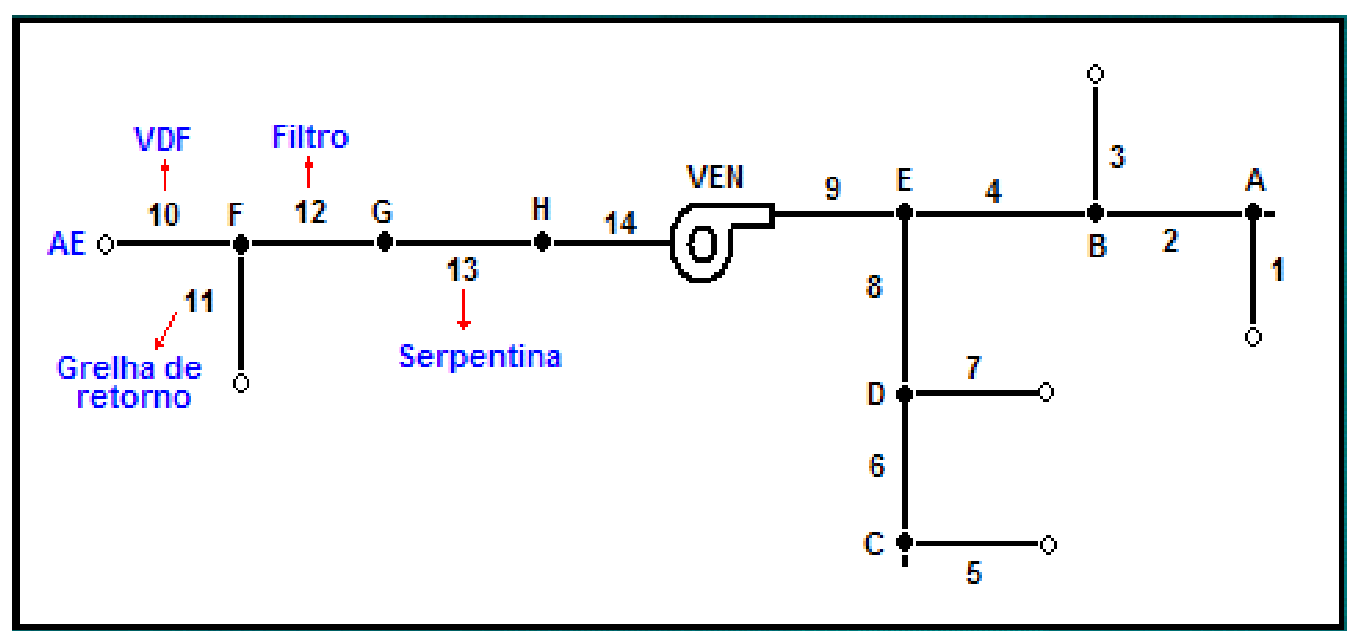

Figura 6.3 - Esquema da rede com identificação dos nós e trechos Caso II (SMACNA, 2002)

As vazões volumétricas identificadas no esquema proposto por Bolliger Jr e Mariani (2002) adotam massa específica para a rede de insuflação de $1,109 \mathrm{~kg} / \mathrm{m}^{3}$. Outros valores para massa específica estão na tabela 6.14. O ventilador foi então dimensionado para movimentar $5500 \mathrm{~m}^{3} / \mathrm{h}$ de ar que será distribuído por difusores. Neste estudo de caso, os difusores de insuflação, possuem características de vazão e de perdas conforme está mostrado na tabela 6.13.

Tabela 6.13 - Características de difusores

\begin{tabular}{|c|c|c|c|}
\hline Difusor & $\mathbf{Q}_{\mathbf{p a d}}\left(\mathbf{m}^{\mathbf{3}} \mathbf{/ h}\right)$ & Perda $(\mathbf{m m c a})$ & Perda (Pa) \\
\hline ADLK6 & 1000 & 5,9 & 53 \\
\hline ADLK7 & 1500 & 4,5 & 40 \\
\hline ADLK8 & 2000 & 6,9 & 62 \\
\hline
\end{tabular}


Nesta análise foram consideradas as vazões de ar externo e de exaustão, pois os dados foram disponíveis. Na tabela 6.14 estão apresentados os valores numéricos para todos os parâmetros relativos ao projeto em análise.

Tabela 6.14 - Características geométricas e parâmetros nos trechos - Caso II

\begin{tabular}{|c|c|c|c|c|c|c|c|c|}
\hline Trecho & $\begin{array}{c}W \\
(m)\end{array}$ & $\begin{array}{c}\mathrm{H} \\
(\mathrm{m})\end{array}$ & $\begin{array}{c}D \\
(m)\end{array}$ & $\begin{array}{c}Q \\
\left(m^{3} / h\right)\end{array}$ & $\begin{array}{l}\mathrm{L} \\
(\mathrm{m})\end{array}$ & $\begin{array}{c}\varepsilon \\
(\mathrm{m})\end{array}$ & $\begin{array}{c}\rho \\
\left(\mathrm{kg} / \mathrm{m}^{3}\right)\end{array}$ & $\begin{array}{c}v \\
\left(m^{2} / s\right)\end{array}$ \\
\hline 1 & - & - & 0,30 & 1500 & 1,0 & $1,5^{*} 10^{-4}$ & 1,109 & $1,51 * 10^{-5}$ \\
\hline 2 & 0,40 & 0,20 & & 1500 & 5,0 & $1,5^{\star} 10^{-4}$ & 1,109 & $1,51 * 10^{-5}$ \\
\hline 3 & - & - & 0,30 & 2000 & 2,0 & $1,5^{*} 10^{-4}$ & 1,109 & $1,51 * 10^{-5}$ \\
\hline 4 & 0,40 & 0,35 & - & 3500 & 10,0 & $1,5^{*} 10^{-4}$ & 1,109 & $1,51 * 10^{-5}$ \\
\hline 5 & - & - & 0,25 & 1000 & 3,0 & $1,5^{*} 10^{-4}$ & 1,109 & $1,51 * 10^{-5}$ \\
\hline 6 & 0,40 & 0,10 & - & 1000 & 5,0 & $1,5^{\star} 10^{-4}$ & 1,109 & $1,51 * 10^{-5}$ \\
\hline 7 & - & - & 0,25 & 1000 & 3,0 & $1,5^{*} 10^{-4}$ & 1,109 & $1,51 * 10^{-5}$ \\
\hline 8 & 0,40 & 0,20 & - & 2000 & 10,0 & $1,5^{*} 10^{-4}$ & 1,109 & $1,51 * 10^{-5}$ \\
\hline 9 & 0,40 & 0,55 & - & 5500 & 5,0 & $1,5^{\star} 10^{-4}$ & 1,109 & $1,51 * 10^{-5}$ \\
\hline 10 & 0,30 & 0,40 & - & 600 & 0,05 & $1,5^{*} 10^{-4}$ & 1,035 & $1,51^{*} 10^{-5}$ \\
\hline 11 & 0,10 & 1,03 & - & 4900 & 0,05 & $1,5^{*} 10^{-4}$ & 1,072 & $1,51^{*} 10^{-5}$ \\
\hline 12 & 0,53 & 1,00 & - & 5500 & 0,05 & $1,5^{\star} 10^{-4}$ & 1,067 & $1,51 * 10^{-5}$ \\
\hline 13 & 0,83 & 1,00 & - & 5500 & 0,05 & $1,5^{*} 10^{-4}$ & 1,088 & $1,51^{*} 10^{-5}$ \\
\hline 14 & 0,83 & 1,00 & - & 5500 & 0,05 & $1,5^{*} 10^{-4}$ & 1,109 & $1,51 * 10^{-5}$ \\
\hline
\end{tabular}

$\mathrm{Na}$ tabela 6.15, encontram-se os coeficientes de perda para transições, joelhos e registros, assim como os coeficientes relativos ao trecho reto e ao ramal de cada junção.

Tabela 6.15 - Coeficientes e valores de perda para os trechos da rede - Caso II

\begin{tabular}{|c|c|c|c|c|c|c|c|c|c|c|}
\hline Trecho & $\begin{array}{c}\mathbf{C} \\
\text { Transição }\end{array}$ & $\begin{array}{c}\mathbf{C} \\
\text { Joelho }\end{array}$ & $\begin{array}{c}\mathbf{C} \\
\text { Registro }\end{array}$ & $\begin{array}{c}\mathbf{C} \\
\text { Ramal }\end{array}$ & $\begin{array}{c}\mathbf{C} \\
\text { Reto }\end{array}$ & $\mathbf{C 1}$ & $\mathbf{C 2}$ & $\mathbf{C} 3$ & $\mathbf{C 4}$ & $\begin{array}{c}\Delta \mathbf{P} \text { Difusor } \\
(\mathbf{P a})\end{array}$ \\
\hline $\mathbf{1}$ & - & - & - & 1,60 & 0,31 & - & - & - & - & 40 \\
\hline $\mathbf{2}$ & - & - & - & - & 0,23 & - & - & - & - & - \\
\hline $\mathbf{3}$ & - & - & - & 1,60 & - & - & - & - & - & 62 \\
\hline $\mathbf{4}$ & - & - & - & - & - & - & - & - & - & - \\
\hline $\mathbf{5}$ & - & - & - & 2,24 & 0,60 & - & - & - & - & 53 \\
\hline $\mathbf{6}$ & - & - & - & - & 0,10 & - & - & - & - & - \\
\hline $\mathbf{7}$ & - & - & - & 2,24 & - & - & - & - & - & 53 \\
\hline $\mathbf{8}$ & - & - & - & - & - & - & - & - & - & - \\
\hline $\mathbf{9}$ & - & - & - & - & - & - & - & - & - & - \\
\hline
\end{tabular}




\subsection{APLICAÇÃO DO PROGRAMA DOBAL PARA O PROJETO DO ESTUDO DO CASO II}

\subsubsection{Identificação do projeto - Caso II}

Foram cadastrados no programa os dados que identificam o projeto do presente estudo de caso. Estes dados são apresentados na Tabela 6.16.

Tabela 6.16 - Nome do Projeto e Usuário - Caso II

\begin{tabular}{|l|l|}
\hline Projeto: & Usuário: \\
\hline Caso QAI & ASP-RET \\
\hline
\end{tabular}

\subsubsection{Inserção de dados, cálculos e resultados para o projeto - Caso II}

Em seguida foram inseridos os dados, realizados os cálculos e obtidos os resultados a partir das seis etapas, conforme proposta do programa DOBAL. A seguir são apresentados os resultados numéricos em formatos adequados em forma de tabelas.

\subsubsection{Etapa I: Parâmetros característicos da rede - Caso II}

A primeira etapa relaciona os dados para os 14 trechos e respectivos nós estabelecendo os vínculos conforme a disposição da rede. Estes dados foram obtidos do esquema da rede (Figura 6.3). Os caminhos percorridos pelo ar são estabelecidos permitindo realizar a simulação do escoamento.

A Tabela 6.17 mostra estes dados para o estudo de caso II. 
Tabela 6.17 - Caracterização da rede com vinculação de trechos e nós - Caso II

\begin{tabular}{|c|c|c|}
\hline Nó & Trecho & Nó (Amb) \\
\hline$A$ & 1 & 0 \\
\hline$B$ & 2 & $A$ \\
\hline$B$ & 3 & 0 \\
\hline$C$ & 5 & 0 \\
\hline$D$ & 6 & C \\
\hline D & 7 & 0 \\
\hline$E$ & 4 & B \\
\hline$E$ & 8 & $D$ \\
\hline VEN & 9 & $E$ \\
\hline$F$ & 10 & 0 \\
\hline$F$ & 11 & 0 \\
\hline$G$ & 12 & $F$ \\
\hline$H$ & 13 & G \\
\hline VEN & 14 & H \\
\hline & & \\
\hline
\end{tabular}

Ainda nesta etapa foram inseridas as dimensões dos dutos e calculadas as áreas $(S)$ e diâmetro hidráulicos $\left(D_{h}\right)$ para cada um dos 14 trechos.

Tabela 6.18 - Dados e resultados para área e diâmetro hidráulico - Caso II

\begin{tabular}{|c|c|c|c|c|c|}
\hline Trecho & $\mathbf{W}(\mathbf{m})$ & $\mathbf{H}(\mathbf{m})$ & $\mathbf{D}(\mathbf{m})$ & $\left.\mathbf{S} \mathbf{( m}^{\mathbf{2}}\right)$ & $\mathbf{D}_{\mathbf{h}}(\mathbf{m})$ \\
\hline $\mathbf{1}$ & - & - & 0,30 & 0,07 & 0,30 \\
\hline $\mathbf{2}$ & 0,40 & 0,20 & & 0,08 & 0,27 \\
\hline $\mathbf{3}$ & - & - & 0,30 & 0,07 & 0,30 \\
\hline $\mathbf{4}$ & 0,40 & 0,35 & - & 0,05 & 0,25 \\
\hline $\mathbf{5}$ & - & - & 0,25 & 0,04 & 0,16 \\
\hline $\mathbf{6}$ & 0,40 & 0,10 & - & 0,05 & 0,25 \\
\hline $\mathbf{7}$ & - & - & 0,25 & 0,14 & 0,37 \\
\hline $\mathbf{8}$ & 0,40 & 0,20 & - & 0,08 & 0,27 \\
\hline $\mathbf{9}$ & 0,40 & 0,55 & - & 0,22 & 0,46 \\
\hline $\mathbf{1 0}$ & 0,30 & 0,40 & - & 0,12 & 0,34 \\
\hline $\mathbf{1 1}$ & 0,10 & 1,03 & - & 0,55 & 0,70 \\
\hline $\mathbf{1 2}$ & 0,53 & 1,00 & - & 0,83 & 0,91 \\
\hline $\mathbf{1 3}$ & 0,83 & 1,00 & - & 0,83 & 0,91 \\
\hline $\mathbf{1 4}$ & 0,83 & 1,00 & - & 0,83 & 0,91 \\
\hline
\end{tabular}


6.4.2.2 Etapa II: Cálculo das perdas distribuídas - Caso II

Os dados para cada trecho da rede foram inseridos no programa. Relativos ao fluido são: vazão volumétrica, massa específica e viscosidade cinemática, e ao duto são comprimento e rugosidade. Foram calculadas a vazão mássica (m்), a velocidade mássica $(G)$, a pressão dinâmica (Pdin), o número de Reynolds $(R e)$, o coeficiente de perda distribuída (f) e a perda distribuída em cada um dos trechos. A tabela 6.19 traz os resultados para a perda distribuída em cada trecho.

Tabela 6.19 - Perdas distribuídas para cada trecho - Caso II

\begin{tabular}{|c|c|c|c|c|c|c|}
\hline Trecho & $\begin{array}{c}\dot{\mathbf{m}} \\
(\mathbf{k g} / \mathbf{s})\end{array}$ & $\begin{array}{c}\mathbf{G} \\
\left(\mathbf{k g} / \mathbf{s} \cdot \mathbf{m}^{\mathbf{2}}\right)\end{array}$ & $\begin{array}{c}\mathbf{P d i n} \\
\mathbf{( P a})\end{array}$ & $\mathbf{R e}$ & $\mathbf{f}$ & $\begin{array}{c}\Delta \mathbf{P}_{\mathbf{d}} \\
\mathbf{( P a})\end{array}$ \\
\hline $\mathbf{1}$ & 0,47 & 6,60 & 19,64 & 118238 & $1,99 \mathrm{E}-02$ & 1 \\
\hline $\mathbf{2}$ & 0,47 & 5,78 & 15,06 & 93193 & $2,08 \mathrm{E}-02$ & 6 \\
\hline $\mathbf{3}$ & 0,62 & 8,80 & 34,91 & 157650 & $1,92 \mathrm{E}-02$ & 4 \\
\hline $\mathbf{4}$ & 1,08 & 7,70 & 26,73 & 170131 & $1,85 \mathrm{E}-02$ & 13 \\
\hline $\mathbf{5}$ & 0,31 & 6,16 & 17,11 & 91962 & $2,10 \mathrm{E}-02$ & 4 \\
\hline $\mathbf{6}$ & 0,31 & 7.70 & 26,73 & 73570 & $2,28 \mathrm{E}-02$ & 19 \\
\hline $\mathbf{7}$ & 0,31 & 6,16 & 17,11 & 91962 & $2,10 \mathrm{E}-02$ & 4 \\
\hline $\mathbf{8}$ & 0,61 & 7,70 & 26,73 & 124149 & $2,20 \mathrm{E}-02$ & 20 \\
\hline $\mathbf{9}$ & 1,69 & 7,70 & 26,73 & 211514 & $1,75 \mathrm{E}-02$ & 5 \\
\hline $\mathbf{1 0}$ & 0,17 & 1,43 & 0,99 & 31125 & $2,49 \mathrm{E}-02$ & 0 \\
\hline $\mathbf{1 1}$ & 1,46 & 2,65 & 3,28 & 114650 & $1,85 \mathrm{E}-02$ & 0 \\
\hline $\mathbf{1 2}$ & 1,63 & 1,96 & 1,80 & 110702 & $1,84 \mathrm{E}-02$ & 0 \\
\hline $\mathbf{1 3}$ & 1,66 & 2,00 & 1,84 & 110781 & $1,84 \mathrm{E}-02$ & 0 \\
\hline $\mathbf{1 4}$ & 1,69 & 2,04 & 1,88 & 110857 & $1,84 \mathrm{E}-02$ & 0 \\
\hline
\end{tabular}

\subsubsection{Etapa III: Cálculo das perdas localizadas - Caso II}

Foram realizados os cálculos para obtenção das perdas de pressão nos diferentes acessórios da rede, e somados em cada trecho, totalizando a perda localizada neste.

A tabela 6.20 traz os resultados das perdas para cada acessório e seu respectivo trecho. 
Tabela 6.20 - Perdas localizadas para cada trecho - Caso II

\begin{tabular}{|c|c|c|c|c|c|c|c|c|}
\hline Trecho & $\begin{array}{c}\Delta \mathbf{P}_{\mathbf{1}} \\
\mathbf{( P a}\end{array}$ & $\begin{array}{c}\Delta \mathbf{P}_{2} \\
\mathbf{( P a})\end{array}$ & $\begin{array}{c}\Delta \mathbf{P}_{3} \\
\mathbf{( P a}\end{array}$ & $\begin{array}{c}\Delta \mathbf{P}_{\mathbf{4}} \\
\mathbf{( P a})\end{array}$ & $\begin{array}{c}\Delta \mathbf{P}_{5} \\
\mathbf{( P a})\end{array}$ & $\begin{array}{c}\Delta \mathbf{P}_{6} \\
\mathbf{( P a})\end{array}$ & $\begin{array}{c}\Delta \mathbf{P}_{\mathbf{7}} \\
(\mathbf{P a})\end{array}$ & $\begin{array}{c}\Delta \mathbf{P}_{\mathrm{L}} \\
\mathbf{( P a})\end{array}$ \\
\hline $\mathbf{1}$ & - & - & - & 31,73 & - & - & 40,66 & 78 \\
\hline $\mathbf{2}$ & - & - & - & 3,00 & - & - & - & 3 \\
\hline $\mathbf{3}$ & - & - & - & 55,86 & - & - & 62,35 & 118 \\
\hline $\mathbf{4}$ & - & - & - & - & - & - & - & 0 \\
\hline $\mathbf{5}$ & - & - & - & 38,93 & - & - & 63,31 & 102 \\
\hline $\mathbf{6}$ & - & - & - & 3,00 & - & - & - & 3 \\
\hline $\mathbf{7}$ & - & - & - & 38,33 & - & - & 53,31 & 92 \\
\hline $\mathbf{8}$ & - & - & - & - & - & - & - & 0 \\
\hline $\mathbf{9}$ & - & 6,41 & - & - & - & - & - & 6 \\
\hline $\mathbf{1 0}$ & - & - & - & - & - & 144,00 & - & 144 \\
\hline $\mathbf{1 1}$ & - & - & - & - & - & 10,39 & - & 10 \\
\hline $\mathbf{1 2}$ & - & - & - & - & - & 44,30 & - & 44 \\
\hline $\mathbf{1 3}$ & - & - & - & - & - & 180,00 & - & 180 \\
\hline $\mathbf{1 4}$ & - & - & - & - & - & - & - & 0 \\
\hline
\end{tabular}

Legenda:

$\Delta \mathrm{P}_{1}=$ Perda localizada em transições

$\Delta \mathrm{P}_{2}=$ Perda localizada em joelhos

$\Delta \mathrm{P}_{3}=$ Perda localizada em registros

$\Delta \mathrm{P}_{4}=$ Perda localizada em junções

$\Delta \mathrm{P}_{5}=$ Perda localizada em acessórios

$\Delta \mathrm{P}_{6}=$ Perda localizada em acessórios genéricos

$\Delta \mathrm{P}_{7}=$ Perda localizada em difusores

$\Delta \mathrm{P}_{\mathrm{L}}=$ Perda localizada total no trecho

6.4.2.4 Etapa IV: Cálculo das perdas totais - Caso II

$\mathrm{Na}$ presente etapa foram calculadas as perdas totais para os 14 trechos da instalação. Os resultados desta etapa estão mostrados na tabela 6.21. 
Tabela 6.21 - Perdas totais para cada trecho - Caso II

\begin{tabular}{|c|c|c|c|}
\hline Trecho & $\begin{array}{c}\Delta \mathbf{P}_{\mathbf{d}} \\
(\mathbf{P a})\end{array}$ & $\begin{array}{c}\Delta \mathbf{P}_{\mathbf{L}} \\
(\mathbf{P a})\end{array}$ & $\begin{array}{c}\Delta \mathbf{P}_{\mathbf{T}} \\
(\mathbf{P a})\end{array}$ \\
\hline $\mathbf{1}$ & 1 & 78 & 79 \\
\hline $\mathbf{2}$ & 6 & 3 & 9 \\
\hline $\mathbf{3}$ & 4 & 118 & 122 \\
\hline $\mathbf{4}$ & 13 & 0 & 13 \\
\hline $\mathbf{5}$ & 4 & 102 & 106 \\
\hline $\mathbf{6}$ & 19 & 3 & 22 \\
\hline $\mathbf{7}$ & 4 & 92 & 96 \\
\hline $\mathbf{8}$ & 20 & 0 & 20 \\
\hline $\mathbf{9}$ & 5 & 6 & 11 \\
\hline $\mathbf{1 0}$ & 0 & 144 & 144 \\
\hline $\mathbf{1 1}$ & 0 & 10 & 10 \\
\hline $\mathbf{1 2}$ & 0 & 44 & 44 \\
\hline $\mathbf{1 3}$ & 0 & 180 & 180 \\
\hline $\mathbf{1 4}$ & 0 & 0 & 0 \\
\hline
\end{tabular}

\subsubsection{Etapa V: Simulação da rede - Caso II}

As perdas de pressão total para o escoamento que percorre cada trecho estão apresentadas na tabela 6.22 .

Tabela 6.22 - Caminhos da rede - Caso II

\begin{tabular}{|c|c|c|c|}
\hline Nó & Trecho & $\begin{array}{c}\text { Nó } \\
(\mathbf{A m b})\end{array}$ & $\begin{array}{c}\Delta \mathbf{P}_{\mathbf{T}} \text { caminho } \\
(\mathbf{P a})\end{array}$ \\
\hline A & 1 & 0 & 79 \\
\hline B & 2 & $\mathrm{~A}$ & 88 \\
\hline B & 3 & 0 & 122 \\
\hline C & 5 & 0 & 106 \\
\hline D & 6 & C & 128 \\
\hline D & 7 & 0 & 96 \\
\hline E & 4 & B & 135 \\
\hline E & 8 & D & 148 \\
\hline F & 10 & 0 & 144 \\
\hline F & 11 & 0 & 10 \\
\hline G & 12 & F & 188 \\
\hline H & 13 & G & 368 \\
\hline VEN & 9 & E & 159 \\
\hline VEN & 14 & H & 368 \\
\hline
\end{tabular}




\subsubsection{Etapa VI: Comparação de caminhos - Caso II}

De modo similar ao caso I, nesta etapa são obtidos os resultados em termos de diferença de pressão para o balanceamento, a partir da comparação de caminhos. Também está apresentada a indicação do trecho em que deve haver o acréscimo de perda de pressão para obtenção do balanceamento. Os resultados estão na tabela 6.23 .

Tabela 6.23 - Resultados de diferenças de pressão para o balanceamento - Caso II

\begin{tabular}{|c|c|c|c|}
\hline Nó & $\begin{array}{c}\text { Perda Total } \\
\text { Nó }(\mathbf{P a})\end{array}$ & $\begin{array}{c}\text { DpBalance } \\
(\mathbf{P a})\end{array}$ & $\begin{array}{c}\text { Trecho } \\
\text { Balance }\end{array}$ \\
\hline B & 122 & 34 & 2 \\
\hline D & 128 & 32 & 7 \\
\hline E & 148 & 13 & 4 \\
\hline F & 144 & 134 & 11 \\
\hline
\end{tabular}

Pode-se observar que no nó $\mathrm{F}$ há significativa diferença de pressão entre os dois caminhos. Esta diferença foi obtida na simulação com as vazões de projeto no trecho relacionado ao ar de retorno, com perda de $10 \mathrm{~Pa}$, e no trecho do ar externo, com $144 \mathrm{~Pa}$, ambos ligados à caixa de mistura. Nesta situação a resistência fluidodinâmica no trecho que conduz o ar externo á caixa de mistura possui um valor muito maior que a resistência no trecho de retorno, e isto causa redução significativa de vazão no caminho de entrada de ar para renovação.

Estes resultados permitem determinar as necessidades de correção nas resistências para alcançar o balanceamento, e assim garantir que o sistema receba a vazão correta de ar exterior para renovação.

Foi calculado o caminho crítico da rede e determinados os níveis de pressão total na descarga e aspiração do ventilador mostrados na tabela 6.24 .

Tabela 6.24 - Níveis de pressão totais na descarga e aspiração do ventilador - Caso II

\begin{tabular}{|c|c|c|c|}
\hline Caminho $\mathbf{P}_{\text {Tdesc }}$ & $\mathbf{P}_{\text {Tdesc }}(\mathrm{Pa})$ & Caminho $_{\text {Tasp }}$ & $\mathbf{P}_{\text {Tasp }}(\mathrm{Pa})$ \\
\hline VEN - 9 - E & 159 & VEN - 14 - H & -368 \\
\hline
\end{tabular}

Por fim foi calculada a pressão total exigida para selecionar o ventilador, com equacionamento a seguir: 


$$
\Delta \mathrm{p}_{\mathrm{T} \text { Ventilador }}=159-(-368)=527(\mathrm{~Pa})
$$

\subsection{ANÁLISE COMPARATIVA DOS RESULTADOS DO PROGRAMA DOBAL COM PLANILHA ELETRÔNICA USANDO O CASO I}

Para fins de comparação e verificação dos resultados obtidos com 0 programa DOBAL no estudo de caso I foi implementado o método de balanceamento direto através de cálculos realizados em planilha do aplicativo Microsoft Excel ${ }^{\circledR}$. A planilha, detalhada no Apêndice $B$, avaliou a eficácia dos equacionamentos codificados no programa.

$\mathrm{Na}$ planilha desenvolvida foram inseridos os dados, obtendo-se os resultados das perdas distribuídas, localizadas e totais em todos os trechos de dutos da rede de insuflação e de retorno. A tabela 6.25 apresenta o resumo com resultados de perdas por trecho obtidos na planilha eletrônica.

Tabela 6.25 - Perdas distribuídas, localizadas e totais obtidas com planilha

\begin{tabular}{|c|c|c|c|}
\hline TRECHO & $\Delta \mathbf{P}_{\mathbf{d}}(\mathbf{P a})$ & $\Delta \mathbf{P}_{\mathbf{L}}(\mathbf{P a})$ & $\Delta \mathbf{P}_{\mathbf{T}}(\mathbf{P a})$ \\
\hline 1 & 8,5 & 59,3 & 67,8 \\
\hline 2 & 2,8 & 38,6 & 41,4 \\
\hline 3 & 4,6 & 0,9 & 5,5 \\
\hline 4 & 2,8 & 38,6 & 41,4 \\
\hline 5 & 9,0 & 7,0 & 16,0 \\
\hline 6 & 8,5 & 59,3 & 67,8 \\
\hline 7 & 2,8 & 38,6 & 41,4 \\
\hline 8 & 4,6 & 0,9 & 5,5 \\
\hline 9 & 2,8 & 38,6 & 41,4 \\
\hline 10 & 3,0 & 18,8 & 21,8 \\
\hline 11 & 5,5 & $-1,7$ & 3,8 \\
\hline 12 & 4,9 & 42,6 & 47,5 \\
\hline 13 & 16,1 & 3,2 & 19,3 \\
\hline 14 & 4,9 & 42,6 & 47,5 \\
\hline 15 & 2,8 & 11,7 & 14,5 \\
\hline 16 & 2,3 & 15,6 & 17,9 \\
\hline 17 & 13,0 & 22,4 & 35,4 \\
\hline 18 & 4,0 & 0 & 4,0 \\
\hline 19 & 4,9 & 83,2 & 88,1 \\
\hline 20 & 19,5 & 18,5 & 38,0 \\
\hline 21 & 12,5 & 78,2 & 90,7 \\
\hline 22 & 5,9 & 38,1 & 44,0 \\
\hline & & & \\
\hline
\end{tabular}


A tabela 6.26 traz valores de perda de pressão total para o escoamento do ar nos caminhos, comparados dois a dois, quando estão em paralelo.

Tabela 6.26 - Perdas de pressão total em Pa

\begin{tabular}{|c|c|c|c|c|c|c|c|c|}
\hline \multirow{2}{*}{ CAMINHOS } & \multicolumn{7}{|c|}{ NÖS } \\
\hline & A & B & C & D & E & H & I & L \\
\hline A-1-0 & 67,8 & & & & & & & \\
\hline A-2-0 & 41,4 & & & & & & & \\
\hline B-3-A & & 73,3 & & & & & & \\
\hline B-4-0 & & 41,4 & & & & & & \\
\hline C-6-0 & & & 67,8 & & & & & \\
\hline C-7-0 & & & 41,4 & & & & & \\
\hline D-8-C & & & & 73,3 & & & & \\
\hline D-9-0 & & & & 41,4 & & & & \\
\hline E-5-B & & & & & 89,3 & & & \\
\hline E-10-D & & & & & 95,1 & & & \\
\hline H-15-G-14-0 & & & & & & 62,0 & & \\
\hline H-13-F-12-0 & & & & & & 66,8 & & \\
\hline I-11-E & & & & & & & 98,9 & \\
\hline I-16-H & & & & & & & 84,7 & \\
\hline L-20-19-0 & & & & & & & & $\mathbf{1 2 6 , 1}$ \\
\hline L-21-0 & & & & & & & & 90,7 \\
\hline
\end{tabular}

Para finalizar foram calculadas as diferenças de pressão em cada nó para os caminhos em paralelo e obtidos valores de Dp para o balanceamento. A tabela 6.27 apresenta estes resultados e a identificação do trecho que deve ser modificado para obtenção do balanceamento.

Tabela 6.27 - Diferença de pressão (Dp) e identificação de trechos para o balanceamento

\begin{tabular}{|c|c|c|c|c|c|c|c|c|}
\hline NÓS & A & B & C & D & E & H & I & L \\
\hline $\begin{array}{c}\text { Dp Balance } \\
(\mathbf{P a})\end{array}$ & 26,4 & 31,9 & 26,4 & 31,9 & 5,8 & 4,8 & 14,2 & 35,4 \\
\hline $\begin{array}{c}\text { Posição } \\
\text { Regulador }\end{array}$ & $\begin{array}{c}\text { Trecho } \\
2\end{array}$ & $\begin{array}{c}\text { Trecho } \\
4\end{array}$ & $\begin{array}{c}\text { Trecho } \\
7\end{array}$ & $\begin{array}{c}\text { Trecho } \\
9\end{array}$ & $\begin{array}{c}\text { Trecho } \\
5,6 \text { ou } 7\end{array}$ & $\begin{array}{c}\text { Trecho } \\
14,12\end{array}$ & $\begin{array}{c}\text { Trecho } \\
4,2,1 \text { ou 14 }\end{array}$ & $\begin{array}{c}\text { Trecho } \\
21\end{array}$ \\
\hline
\end{tabular}

A comparação entre os resultados obtidos para as diferenças de pressão para balanceamento gerados no programa DOBAL e na planilha em Microsoft Exce ${ }^{\circledR}$, para cada nó do sistema, estão apresentadas graficamente na figura 6.4. 


\section{Comparação de resultados \\ DOBAL \& Excel}

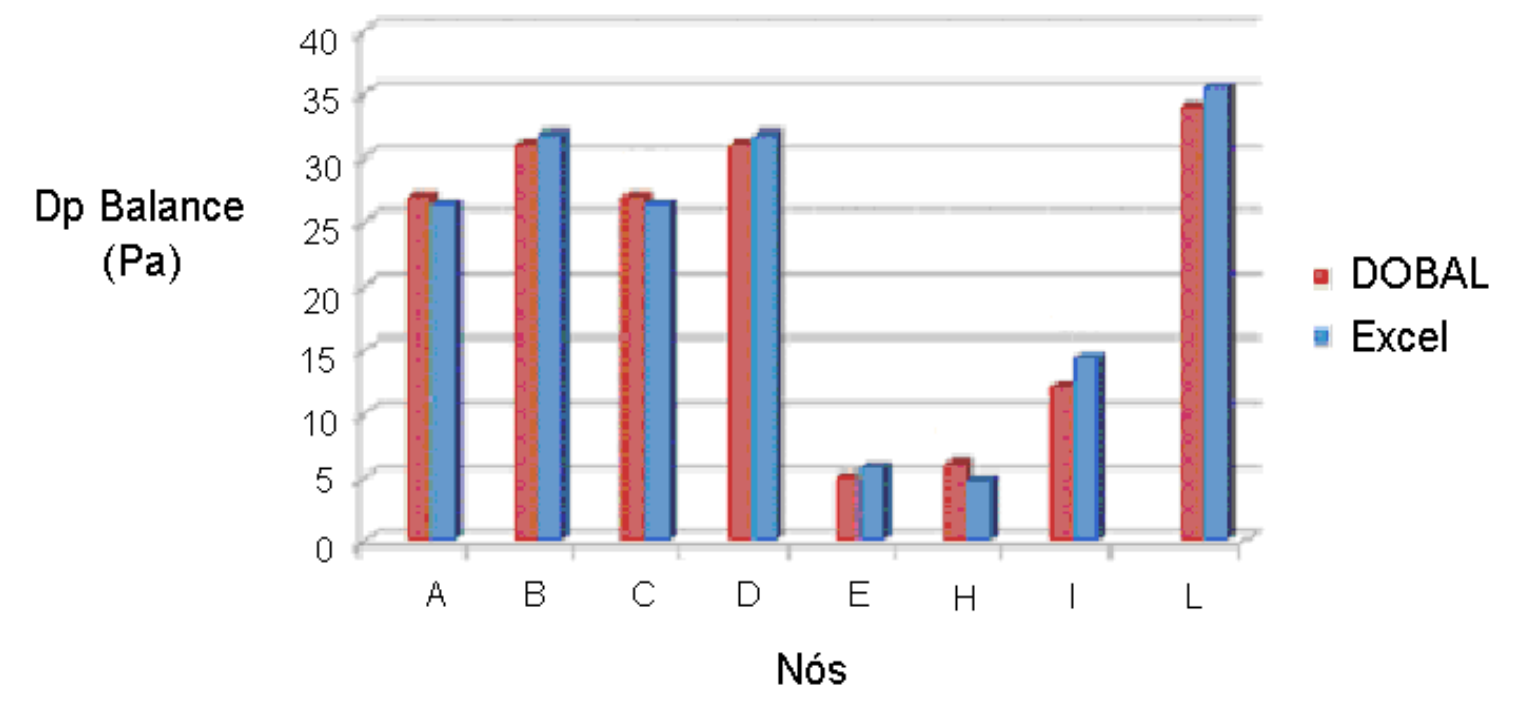

Figura 6.4 - Comparação de resultados Dobal \& Excel - caso I.

Comparando os resultados dos dois programas constata-se que em todos os nós as diferenças em termos absolutos são pequenas, da ordem de 0,5 Pa a 2,0 Pa. Por outro lado, considerando-se as diferenças dos resultados comparativos entre programas em relação às pressões exigidas para o balanceamento, podem-se encontrar valores em termos porcentuais significativos.

\subsection{ANÁLISE COMPARATIVA DOS RESULTADOS DO PROGRAMA DOBAL COM PROGRAMA T-DUCT USANDO CASO II}

Uma segunda análise comparativa do programa DOBAL foi realizada utilizando o programa T-Duct, desenvolvido por Robert Tsal. Este programa utiliza o método T para avaliar a necessidade de balanceamento, e foi aplicado para simular a rede proposta no estudo de caso II. No Apêndice C estão reproduzidas figuras com as telas resultantes do processo de simulação no programa T-Duct.

A análise compara os dois métodos estudados para realização do balanceamento a partir do sistema de distribuição de ar do Caso II. O método direto implementado no programa DOBAL e o método $\mathbf{T}$ que foi testado a partir do programa T-Duct. 
O programa T-Duct, na versão acadêmica disponível, tem como limite inserir 9 trechos da rede no máximo. Assim foram divididos os 14 trechos em 3 partes: uma primeira parte na rede de aspiração e duas partes para a rede de insuflação como é mostrada na figura 6.5 .

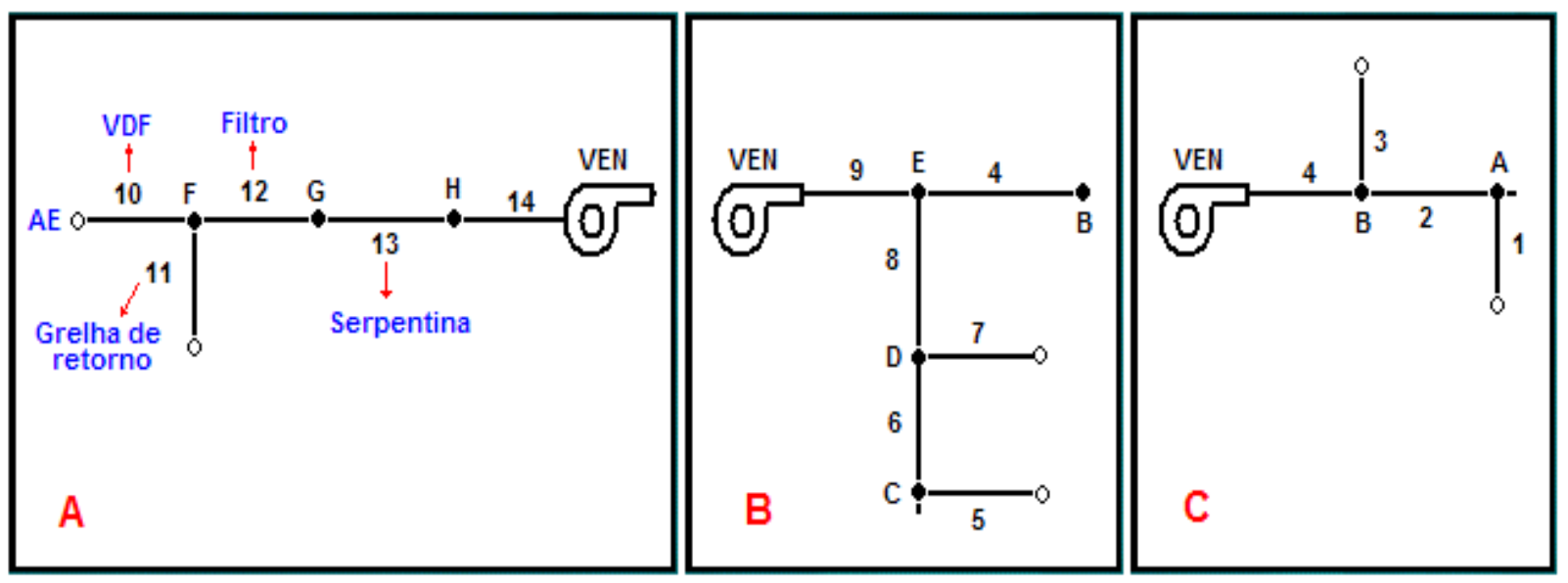

Figura 6.5 - Divisão da rede do Estudo de caso II

A parte "A" mostrada na figura 6.5 corresponde à rede de aspiração e contém 5 trechos. Cada um dos trechos foi inserido no programa T-Duct com suas respectivas características e parâmetros do escoamento. Com o processamento do programa é feira a simulação da rede, obtendo-se como resultados os valores percentuais de vazão "Q atual (\%)", em relação à vazão de projeto como mostra a tabela 6.28 .

Tabela 6.28 - Valores percentuais da vazão - Parte A

\begin{tabular}{|c|c|c|c|}
\hline TRECHO & $\mathbf{Q}_{\mathbf{~ p a d}}\left(\mathbf{m}^{\mathbf{3}} \mathbf{h} \mathbf{h}\right)$ & $\mathbf{Q}\left(\mathbf{m}^{\mathbf{3}} \mathbf{s}\right)$ & $\mathbf{Q}$ actual $(\%)$ \\
\hline 10 & 600 & 0,19 & 30 \\
\hline 11 & 4900 & 1,53 & 110 \\
\hline 12 & 5500 & 1,72 & 102 \\
\hline 13 & 5500 & 1,69 & 102 \\
\hline 14 & 5500 & 1,66 & 103 \\
\hline
\end{tabular}

Pela teoria apresentada anteriormente cada trecho encontra-se balanceado se o valor percentual é igual $\pm 5 \%$ da vazão do projeto. Analisando os resultados da tabela 6.28, observa-se que os trechos 10 e 11 possuem valores fora da faixa mencionada.

$\mathrm{Na}$ parte "B" da figura 6.5 foram inseridos no programa T-Duct 6 trechos, correspondente a rede de insuflação. A tabela 6.29 mostra os valores percentuais de vazão para cada um dos trechos após a simulação com este programa. 
Tabela 6.29 - Valores percentuais da vazão - Parte B

\begin{tabular}{|c|c|c|c|}
\hline TRECHO & $\mathbf{Q}$ pad $\left(\mathbf{m}^{\mathbf{3}} \mathbf{h}\right)$ & $\mathbf{Q}\left(\mathbf{m}^{\mathbf{3}} \mathbf{s}\right)$ & $\mathbf{Q}$ actual $(\%)$ \\
\hline 4 & 3500 & 1,06 & 99 \\
\hline 5 & 1000 & 0,30 & 92 \\
\hline 6 & 1000 & 0,30 & 92 \\
\hline 7 & 1000 & 0,30 & 107 \\
\hline 8 & 2000 & 0,60 & 100 \\
\hline 9 & 5500 & 1,66 & 99 \\
\hline
\end{tabular}

Com estes resultados verifica-se que os trechos que necessitam de intervenção são os trechos 5, 6 e 7.

Na parte "C" da figura 6.5 foram inseridos no programa T-Duct os últimos 4 trechos da rede de insuflação. A tabela 6.30 mostra os valores percentuais de vazão para cada um dos trechos, e podem ser observados quais deles precisam de intervenção para a obtenção do balanceamento. Eles são: trecho 1, 2 e 3.

Tabela 6.30 - Valores percentuais da vazão - Parte C

\begin{tabular}{|c|c|c|c|}
\hline TRECHO & $\mathbf{Q}$ pad $\left(\mathbf{m}^{\mathbf{3}} / \mathbf{h}\right)$ & $\mathbf{Q}\left(\mathbf{m}^{\mathbf{3}} \mathbf{s}\right)$ & $\mathbf{Q}$ actual $(\%)$ \\
\hline 1 & 1500 & 0,45 & 109 \\
\hline 2 & 1500 & 0,45 & 109 \\
\hline 3 & 2000 & 0,60 & 93 \\
\hline 4 & 3500 & 1,06 & 99 \\
\hline
\end{tabular}

Assim, considerando os resultados obtidos para as três partes, A, B e C, temse o resultado global para o estudo de caso II, utilizando o Método T. A falta de balanceamento foi verificada em diversos trechos das redes de insuflação e retorno, sendo mais crítico o trecho 10.

O método $\mathrm{T}$, como não determina diretamente a diferença de pressão exigida para balanceamento em cada trecho, necessita que sejam introduzidas modificações na rede, seguidas de nova simulação para avaliar os efeitos sobre o balanceamento. Optou-se por introduzir na simulação com o programa T-Duct, perdas adicionais com valores calculados a partir do programa DOBAL e aplica-las nos trechos que estavam desbalanceados, como está mostrado na tabela 6.23. 
Tabela 6.23 - Resultada de diferenças de pressão "Programa DOBAL"

\begin{tabular}{|c|c|c|c|}
\hline Nó & Perda Total Nó (Pa) & DpBalance (Pa) & Trecho Balance \\
\hline B & 122 & 34 & 2 \\
\hline D & 128 & 32 & 7 \\
\hline E & 148 & 13 & 4 \\
\hline F & 144 & 134 & 11 \\
\hline
\end{tabular}

Uma nova simulação com o programa T-Duct, após a adição das perdas adicionais, obteve resultados para a vazão em cada trecho conforme apresentado na coluna $Q_{C B}(\%)$ da tabela 6.31. Nesta mesma tabela há a comparação dos resultados antes do balanceamento e após este.

Tabela 6.31 - Resultados de balanceamento "Programa T-Duct"

\begin{tabular}{|c|c|c|}
\hline TRECHO & $\mathbf{Q}_{\mathrm{SB}}(\%)$ & $\mathbf{Q}_{\mathrm{CB}}(\%)$ \\
\hline 1 & 109 & 100 \\
\hline $\mathbf{2}$ & $\mathbf{1 0 9}$ & 99 \\
\hline 3 & 93 & 100 \\
\hline $\mathbf{4}$ & $\mathbf{9 9}$ & $\mathbf{9 9}$ \\
\hline 5 & 92 & 98 \\
\hline 6 & 92 & 98 \\
\hline $\mathbf{7}$ & $\mathbf{1 0 7}$ & $\mathbf{9 9}$ \\
\hline 8 & 100 & 99 \\
\hline 9 & 99 & 99 \\
\hline 10 & 30 & 103 \\
\hline $\mathbf{1 1}$ & $\mathbf{1 1 0}$ & $\mathbf{1 0 1}$ \\
\hline 12 & 102 & 102 \\
\hline 13 & 102 & 102 \\
\hline 14 & 92 & 103 \\
\hline
\end{tabular}

Legenda:

QSB $(\%)=$ Valores percentuais de vazão sem balanceamento.

$Q_{\mathrm{CB}}(\%)=$ Valores percentuais de vazão com balanceamento.

Comparando os dois programas, e por conseqüência os dois métodos, foram obtidos bons resultados de balanceamento da rede do caso II. Como foram introduzidos os valores de pressão obtidos no programa DOBAL (método direto) para realizar uma nova simulação da rede com o programa T-Duct, confirma-se que ambos os métodos convergem em resultados semelhantes. 


\section{CONCLUSÕES}

A revisão da evolução das instalações de ar condicionado mostra que no inicio do século $X X$ redes de dutos eram usadas para distribuir o ar nos ambientes, mas a preocupação com o balanceamento destas redes só teve inicio depois de 1965. A evolução de técnicas, o rigor nos procedimentos para obtenção do balanceamento só passa a existir nas últimas décadas de século passado.

A aplicação do balanceamento teve início como uma ciência prática, procurando estabelecer as vazões de projeto nos terminais das redes já instaladas. Faziam-se medições, atuando-se sobre reguladores em busca do acerto, fazendo tentativas em processos repetitivos.

Verificou-se que haviam conceitos, até os anos de 1980, entre os profissionais que atuavam na elaboração de projetos de ar condicionado, de que determinados métodos de dimensionamento de rede de dutos proporcionavam o balanceamento. Tsal e Behls em 1988 contestam este conceito em artigo publicado na ASHRAE. Nos anos seguintes apresentam novas propostas para análise de escoamento de ar em redes. No final dos anos 80 e início da década de 90 surgem propostas de simulação de redes de distribuição de ar através de modelos numéricos, e aplicações computacionais, como o Método T proposto por Tsal. A partir de então, são verificados casos em que projetos de redes de distribuição de ar passam a receber reguladores posicionados indicando preocupação com 0 balanceamento na fase de projeto.

Nos anos 80 e 90 o debate sobre a Qualidade do Ar em Ambientes Interiores (QAI) é intensificado e o balanceamento ganha maior valor neste contexto. A aplicação da análise do balanceamento em instalações existentes permite verificar causas de problemas relacionados com a QAI.

Há dois casos que são encontrados com freqüência em instalações de tratamento de ar. O primeiro ocorre para instalações com múltiplos ambientes, nas quais a má distribuição das vazões de ar afeta o ingresso da quantidade de ar de renovação em determinados ambientes. No outro caso há falta de vazão de ar externo no sistema como um todo. Neste exemplo, encontrado com freqüência em instalações com problemas de QAI, o problema é o balanceamento entre o retorno e o ar externo na caixa de mistura. Nesta situação a resistência fluido-dinâmica 
existente no trecho que conduz o ar externo à caixa de mistura possui valor muito acima da resistência do retorno, e isto causa redução significativa de vazão no caminho de entrada de ar para renovação.

A análise entre a rede de retorno e o caminho do ar externo através da metodologia proposta neste trabalho pode determinar quais as necessidades de correção nas resistências para alcançar o balanceamento. A obtenção deste equilíbrio garantirá que o sistema receba a vazão correta de ar exterior para renovação.

O programa DOBAL utilizou o método direto para avaliar as necessidades de balanceamento. Foi desenvolvido como um aplicativo computacional, possibilitando obter uma avaliação prévia e quantitativa das necessidades de intervenção na rede de distribuição de ar. Ele indica os possíveis caminhos críticos onde devem ser feitas modificações para que as vazões corretas de ar sejam obtidas.

O algoritmo definido para o processo da simulação do fluxo do ar através dos caminhos percorridos foi dividido em 6 etapas. Nestas são caracterizadas a rede e 0 escoamento, são calculadas as perdas de todos os trechos, são comparados dois a dois os caminhos simulando o escoamento desejado. E por fim são obtidas as resistências correspondentes às necessidades do balanceamento.

O editor de programas escolhido para desenvolvimento do aplicativo foi o Visual Basic, que atendeu satisfatoriamente as necessidades estabelecidas na implantação do algoritmo. As suas funções, telas, imagens e características especiais estabelecem boa interface entre o usuário e o aplicativo criado. Este aplicativo utilizou também um arquivo de banco de dados gerado no Microsoft Access ${ }^{\circledR}$ para organizar e armazenar valores relacionados aos parâmetros do escoamento do ar e da rede de dutos. O banco de dados facilita também o processo de impressão de tabelas com dados e resultados.

O uso do programa traz vantagens para o profissional de projeto já que com a simulação da rede de distribuição de ar há a determinação dos valores da diferença de pressão e dos trechos que necessitam de intervenção para fins de balanceamento. Assim é possível encontrar em catálogos de acessórios, ou manuais técnicos, o valor do coeficiente de perda que é adequado para a situação, e como o acessório deve ser utilizado. Outra solução possível é redimensionar os trechos para obtenção de valores exigidos pelo balanceamento. 
Para instalações já existentes, também pode ser aplicado o processo de simulação com o programa DOBAL para facilitar as atividades dos profissionais de $\mathrm{TAB}$, reduzindo o tempo na execução das suas atividades. Isto porque o processo de balanceamento será conduzido de modo direto, sem tentativas, fazendo-se a aplicação e posicionamento de reguladores que gerem as diferenças de pressão de balanceamento resultantes do uso do programa.

Com o objetivo de avaliar o desempenho do programa computacional desenvolvido foi adotada uma rede de distribuição de ar pré-dimensionada, sugerida no HVAC SYSTEMS DUCT DESIGN - SMACNA, 1990. Para esta rede, os escoamentos de ar foram avaliados utilizando-se o programa DOBAL aplicado a todos os trechos. Foram obtidos valores para as diferenças de pressão necessárias para o balanceamento e identificados os trechos onde estas devem ser introduzidas.

Em paralelo com o desenvolvimento do programa DOBAL, foi criada uma planilha através do aplicativo Microsoft $E x c e / \circledast$, para calcular as perdas distribuídas, localizadas, e totais de cada trecho da mesma rede. Foram também obtidos os valores de diferenças de pressão exigidos para o balanceamento. Os resultados foram comparados com aqueles apresentados pelo DOBAL e confirmam a eficácia do método e do programa.

Foi utilizado também o programa T-Duct para realizar a simulação do Estudo de caso II proposto por Bolliger Jr. e Mariani (2002) com a finalidade de comparar e avaliar os dois métodos para a obtenção do balanceamento. Os resultados do programa T-Duct foram comparados com aqueles apresentados pelo DOBAL e mostraram-se coerentes. A confirmação é verificada a partir da introdução dos valores de pressão obtidos no programa DOBAL (método direto) na realização de uma simulação com o programa T-Duct, e confirma-se que ambos os métodos solicitam valores iguais para que a rede esteja balanceada.

Com a aplicação do programa pretende-se garantir melhores resultados na distribuição de ar, fornecendo o conforto pleno para os ocupantes dos ambientes. Lembrando, ainda, que um sistema com melhor distribuição de ar possui um consumo de energia e custo operacional reduzido. 


\section{Sugestões para trabalhos futuros}

Visando o aprimoramento na aplicação do método através do programa computacional, são apresentadas algumas sugestões e recomendações que podem ser úteis em trabalhos posteriores:

- A utilização do banco de dados organizado neste trabalho em Microsoft Access 97 poderia ser substituído por outros disponíveis, tornando mais genérico e amplo o programa desenvolvido.

- O programa precisa de valores de coeficiente de perda de pressão relativo aos acessórios obtidos de manuais ou catálogos, podendo ser sugerido para um trabalho futuro, a organização de dados para estes coeficientes através de arquivos eletrônicos. 


\section{REFERÊNCIAS BIBLIOGRÁFICAS}

AABC - ASSOCIATED AIR BALANCE COUNCIL. National Standards for Testing and Balancing Heating, Ventilating, and Air Conditioning Systems, Washington, 1989.

ABNT - ASSOCIAÇÃO BRASILEIRA DE NORMAS TÉCNICAS. NBR 16401 Instalações de Ar Condicionado - Sistemas Centrais e Unitários, 3 partes. Rio de Janeiro, 2008.

ASHRAE - AMERICAN SOCIETY OF HEATING, REFRIGERATING AND AIR CONDITIONING ENGINEERS. Handbook of Fundamentals: Chapter 32 - Duct Design, SI Edition. Atlanta, 1993,1997, 2001.

ASHRAE - AMERICAN SOCIETY OF HEATING, REFRIGERATING AND AIR CONDITIONING ENGINEERS. Handbook of HVAC Applications Handbook: Chapter 36 - Testing, Adjusting and Balancing, SI Edition. Atlanta, 1999.

ASHRAE - AMERICAN SOCIETY OF HEATING, REFRIGERATING AND AIR CONDITIONING ENGINEERS. Handbook of HVAC Systems and Equipment, SI Edition. Atlanta, 1996.

ASHRAE - AMERICAN SOCIETY OF HEATING, REFRIGERATING AND AIR CONDITIONING ENGINEERS. Principles of Heating Ventilating and Air Conditioning. Atlanta, 1998.

ASHRAE - AMERICAN SOCIETY OF HEATING, REFRIGERATING AND AIR CONDITIONING ENGINEERS. Standard 111 - Practices for Measurement, Testing, Adjusting and Balancing of Building Heating, Ventilation, AirConditioning and Refrigeration Systems. Atlanta1988.

ALEXANDRE, C. S. Distribuição de ar. Nova Editorial. São Paulo, 2006.

ALEXANDRE, C. S. Qualidade do Ar Interior e a Economia de Energia. In: SEMINÁRIO QUALIDADE DO AR INTERIOR EM SISTEMAS DE AR CONDICIONADO. Instituto de Engenharia São Paulo, São Paulo, Novembro, 1999.

ASSY, T. M. Redes de distribuição de água: Cálculo numérico e analógico. Tese de livre docência apresentada à Escola Politécnica, São Paulo, 1959.

BESANT, R. W.; ASIEDU, Y. Sizing and balancing air duct systems. ASHRAE Journal, Vol. 42, n 12, pp. 24-36. Atlanta, December, 2000. 
BEVIRT, D. W. What engineers need to know about testing and balancing? ASHRAE Transactions, Vol. 100, Pt. 1, pp 705-714. Atlanta, 1994.

BOLLIGER JR., R.; MARIANI, A. L. C. Programa Smacna de educação continuada em tratamento de ar. SMACNA Chapter Brasil. São Paulo, 2002.

BROOKS, P. J. Duct design fundamentals. ASHRAE Journal, Vol. 37, n 4, pp. 6976. Atlanta, April, 1995.

CARRIER AIR CONDITIONING COMPANY. Manual de Aire Acondicionado. Editora McGraw Hill. Barcelona, 1976.

CHEONG. K. W. Airflow measurements for balancing of air distribution system tracer - gas technique as an alternative. Building and Environment. Vol. 36, pp. 955-964. Singapore, 2001.

COSTA, C. ENNIO. Física aplicada á construção - Conforto térmico. $4^{\mathrm{a}}$ Edição, Editora Edgar Blücher. São Paulo, 1998.

CREDER, H. Instalações de ar condicionado. 5aㅡ Edição, Editora Livros Técnicos e Científicos. Rio de Janeiro, 1996.

DOUGHERTY, FRED. W. Equal Friction Solution for Duct Sizing. ASHRAE Journal, Vol. 46, n 5, pp. 51-54. Atlanta, May, 2009.

ENERGY STAR PROGRAM. Supply Ventilation Systems - Mechanical Equipment Improvements. U.S. December, 2002

FOX, R. W.; MACDONALD, A. T. Introdução à Mecânica dos Fluidos. 4ª Edição. Rio de Janeiro, 1995.

GERDON, R. Testing air measuring stations. TAB Journal, pp 9-11, n. SUMMER. Washington, 1996.

HERRLIN, M. K.; ALLARD, F. Solution methods for the air balance in multizone buildings , Energy and Buildings, Vol. 18, pp. 159 -170. France, 1992.

HONEYWELL. Engineering manual of automatic control for commercial buildings. Heating Ventilating, Air Conditioning. SI Edition. Minneapolis, 1995.

HOWARD III, E. Indoor Air Quality. In: VI CONGRESSO BRASILEIRO DE REFRIGERAÇÃO, VENTILAÇÃO E CONDICIONAMENTO DO AR. São Paulo, 1999. 
HOWELL, TIMOTHY. Air distribution. TAB Journal, pp 12-13, n. WINTER. Washington, 1999.

JANU, G. J.; WENGER, J. D.; NESLER, C. G. Outdoor air flow control for VAV systems. ASHRAE Journal, Vol. 37, n 4, pp. 62-68. Atlanta, April, 1995.

KAUPP, C. W. Design and balancing with system diversity. TAB Journal, pp 7-9, n. FALL. Washington, 1998.

KLOOSTRA, LEON. How accurate are balancing hoods with various air flow patterns? TAB Journal, pp 2-4, n. SPRING. Washington, 2003.

KUMAR, A; ASHUTOSH, S. Optimum distribution of insulation over various components of an air - conditioned building. Building and Environment, Vol. 24, pp 169-178. India, 1989.

LAWSON, C. N., GERDON, R. W. Testing and balancing for the 1990s. ASHRAE Transactions, Vol. 100, Pt. 1, pp 720-724. Atlanta, 1994.

LEITE, B. C. C. Sistemas de ar condicionado com insuflamento pelo piso em ambientes de escritórios: Avaliação do conforto térmico e condições de operação. Tese de doutorado. EPUSP. São Paulo, 2003.

MARIANI, A. L. C. Estudo experimental de escoamentos turbulentos em passagens curtas com sensores multifuros multidirecionais. Tese de doutorado. EPUSP. São Paulo, 2000.

MARIANI, A. L. C. Análise e detalhamento da Portaria 3523/98 do Ministério da Saúde. In: SEMINÁRIO ECONOMIA DE ENERGIA COM QUALIDADE DO AR INTERIOR. São Paulo, anais, 1998.

MCLLVAINE, J. E. R.; BEAL, D.; FAIREY, P. W. Design and Construction of Interior Duct System. Florida Solar Energy Center. Florida, 2001.

MILEWSKI, L. The art of air balancing fan terminals. TAB Journal, pp 17-21, $\mathrm{n}$. SUMMER. Washington, 1998.

MONGER, S. Testing and balancing HVAC air and water systems. The Fairmont Press. USA, 1990.

NETSAL \& Associates, T - Method Duct System Simulator - User's Guide Version 2.0S. California, 1993. 
NIX, MIKE. Proportional balancing air handling systems. TAB Journal, pp 17-19, n. SUMMER. Washington, 2000.

NOLFO, A. P. A primer on testing, adjusting and balancing. ASHRAE Journal, Vol. 43, n 5, pp 19-25. Atlanta, May, 2001.

RICHARDSON, G. What should the design engineer expect the testing, adjusting, and balancing agency to do? ASHRAE Transactions, Vol. 100, Pt. 1, pp 715-719. Atlanta, 1994.

RICHARDSON, G. Testing and balancing underfloor systems. TAB Journal, pp 27, n. SUMMER. Washington, 2003.

SHILEI, L; NENG, Z; GUOHUI, F. Impact of phase change wall room on indoor thermal environment in winter, Energy and Buildings, Vol. 38, pp. $18-24$. France, 2005.

SMACNA - Sheet Metal and Air Conditioning Contractors' National Association. HVAC Systems Duct Design, 3ª Edition, U.S.A., 1990.

SMACNA - Sheet Metal and Air Conditioning Contractors' National Association. HVAC Systems, Testing, Adjusting and Balancing, $2^{a}$ Edition, U.S.A., 1993.

SMACNA - Sheet Metal and Air Conditioning Contractors' National Association. Tab Procedural Guide: Testing, Adjusting and Balancing Bureau (TAB), $1^{\mathrm{a}}$ Edition, U.S.A., 2003.

SMALL, MAURO. Non-iterative for balancing an air distribution system, Faculty of Virginia Polytechnic Institute and State University, Blacksburg - Virginia, 2002.

STOECKER, W. F.; JONES, J. W. Refrigeração e ar condicionado. Editora McGraw Hill, São Paulo, 1985.

SUN, T. Y. Air balance in a conditioned space and outdoor air flow control. HPAC Heating, Piping, Air Conditioning, Vol. 68, n 10, pp 73-75. Cleveland, October, 1996.

THATCHER, R. E. Balancing and commissioning. TAB Journal, pp 13-15, n. WINTER. Washington, 2003.

THOMAS, WILLIAM. Testing and balancing and existing occupied animal laboratory. TAB Journal, pp 21-22, n. WINTER. Washington, 1999. 
TSAL, R. J., ADLER, M. S. Evaluation of numerical methods for duct-work and pipeline optimization. ASHRAE Transactions, Vol. 93, Pt. 1, pp 17-34. Atlanta, 1987.

TSAL, R. J., BEHLS, H. F. Fallacy of the static regain duct design method. ASHRAE Transactions, Vol. 94, Pt. 2, pp 76-89. Atlanta, 1988a.

TSAL, R. J., BEHLS, H. F. T-method duct design, part I: Optimization theory, part II: Calculation procedure and economic analysis. ASHRAE Transactions, Vol. 94, Pt. 2, pp 90-111. Atlanta, 1988b.

TSAL, R. J., BEHLS, H. F., MANGEL, R. T-method duct design, part III: Simulation. ASHRAE Transactions, Vol. 94, Pt. 2. Atlanta, 1990.

TSAL, R. J., BEHLS, H. F., VARVAK, L. P. T-method duct design, part IV: Duct leakage theory. ASHRAE Transactions, Annual Meeting - Toronto, 1998a.

TSAL, R. J., BEHLS, H. F., VARVAK, L. P. T-method duct design, part V: Duct leakage calculation technique and economics. ASHRAE Transactions. Atlanta, 1998b.

WANG, J., OGILVIE, J. R. Airflow distributions at floor level in a slot-outlet and slot-inlet ventilated room. ASHRAE Transactions, Vol. 102, Pt. 2, pp 347-358. Atlanta, 1996.

WEISHEIMER, GUSTAVO. Avaliação de uma rede de difusores e dutos de ar condicionado. Departamento de Engenharia Mecânica da Escola de Engenharia da Universidade Federal do Rio Grande do Sul. Porto Alegre-2004.

WEISMAN, CHRISTIAN. Balancing exhaust systems with ductwork problems. TAB Journal, pp 21-23, n. SUMMER. Washington, 2003.

WHITE, F. M. Mecânica dos Fluidos. $4^{a}$ edição, Editora McGraw Hill, Rio de Janeiro, 2002.

YAMANE, E.; SAITO H. Tecnologia do condicionamento de ar. Editora Edgar Blücher Ltda, São Paulo, 1986. 


\section{APÊNDICES}




\section{APÊNDICE A}

\section{MANUAL DO PROGRAMA DOBAL}

\section{A.1 - INSTALAÇÃO DO PROGRAMA}

Dentro do CD de instalação existem duas pastas denominadas: "Balance" e "Instalacao". Selecione as pastas anteriormente mencionadas e acione o botão "copiar" do menu Editar, a seguir procure a unidade C e acione o botão "colar" do mesmo menu. Em resumo, todo o que usuário precisa fazer é colar as pastas "Balance e Instalacao" na unidade $\mathrm{C}$, para o funcionamento do programa. $\mathrm{Na}$ primeira pasta Balance encontra-se 0 arquivo Balance.mdb, nesse banco de dados serão inseridos todos os parâmetros e cálculos dos diferentes projetos. A seguinte pasta "Instalacao" se encontra o arquivo Setup.exe, com a execução dele se produz a instalação do programa. O computador também precisa apresentar um mínimo de $28 \mathrm{MB}$ de espaço em disco. O inicio do programa é feito acionando o arquivo DOBAL.exe ou pelo caminho criado no menu Iniciar do Windows.

\section{A.2 - UTILIZAÇÃO DO PROGRAMA}

Será mostrado a utilização do programa adotando como exemplo o estudo de caso apresentado no capitulo 6 deste trabalho.

\section{A.2.1 Inicialização do Programa}

O programa DOBAL inicia-se com a tela de abertura que está representada na figura A1.

No menu inicial do programa existem dois opções de botões:

O primeiro botão Abrir será utilizado para escolher um projeto com uma identificação numérica, (Encontram-se habilitados no programa 10 projetos).

Este projeto escolhido estará vinculado em uma área no banco de dados do Access que conterá os valores em formato de tabelas.

O segundo botão Sair será utilizado para sair do aplicativo DOBAL 


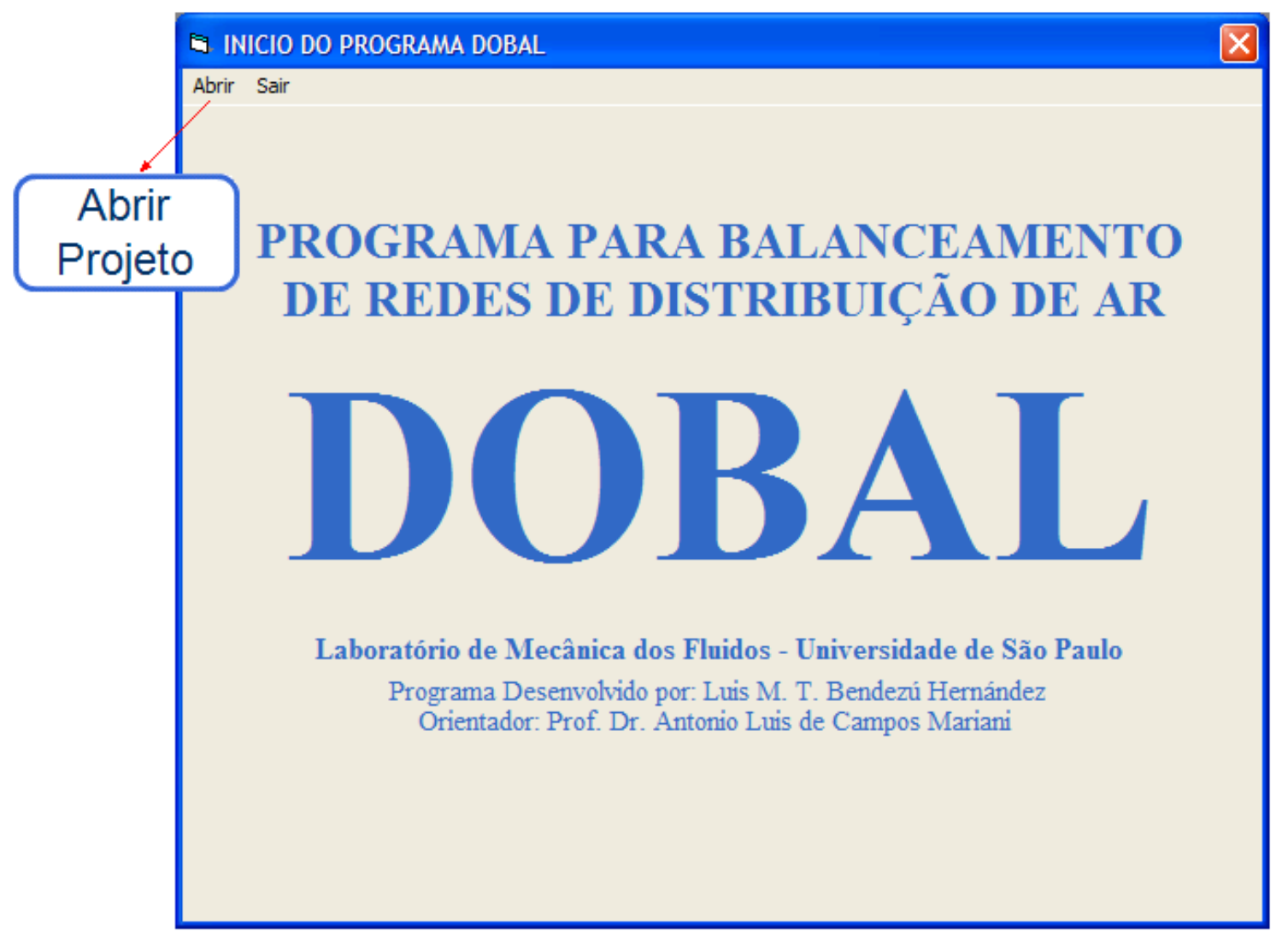

Figura A1 - Tela abertura do Programa DOBAL

Exemplo para inicialização do Programa DOBAL:

Acione o botão "Abrir" do menu principal e escolha o Projeto -1, a continuação o programa vinculará todos os dados e cálculos para a primeira tabela de nosso banco de dados do Access (balance.mdb).

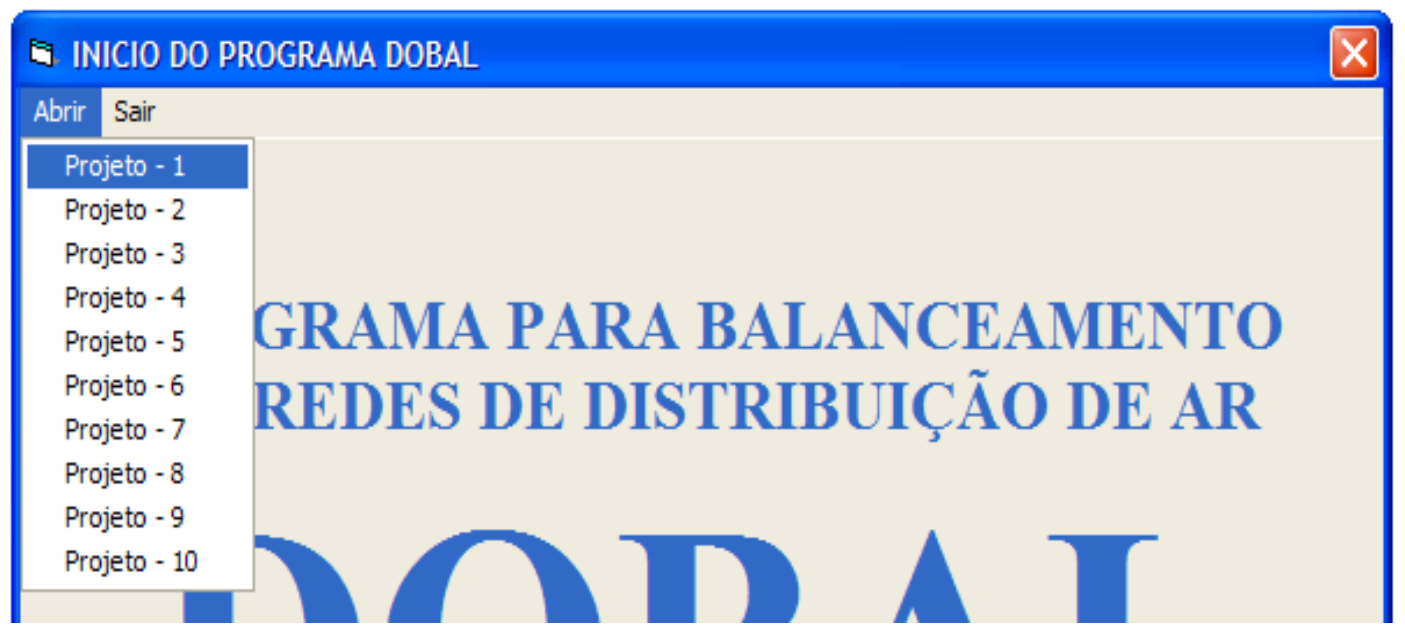

Figura A2 - Inicialização do Programa DOBAL 
Após a escolha do projeto será mostrada uma tela representada na figura A3, cuja finalidade é criar uma identificação do projeto, mediante as seguintes definições:

- Definir o Nome do Projeto e inserir no campo do mesmo nome.

- Definir o Nome do Usuário e inserir no campo específico.

Acionar o botão "Adicionar Projeto" para realizar a operação de inclusão dos dados anteriormente definidos, assim a identificação do projeto ficará no inicio das tabelas no arquivo do banco de dados.

A execução do botão "Excluir de Projeto" tem por finalidade excluir as definições anteriormente mencionadas como também os dados cadastrados e calculados do projeto selecionado.

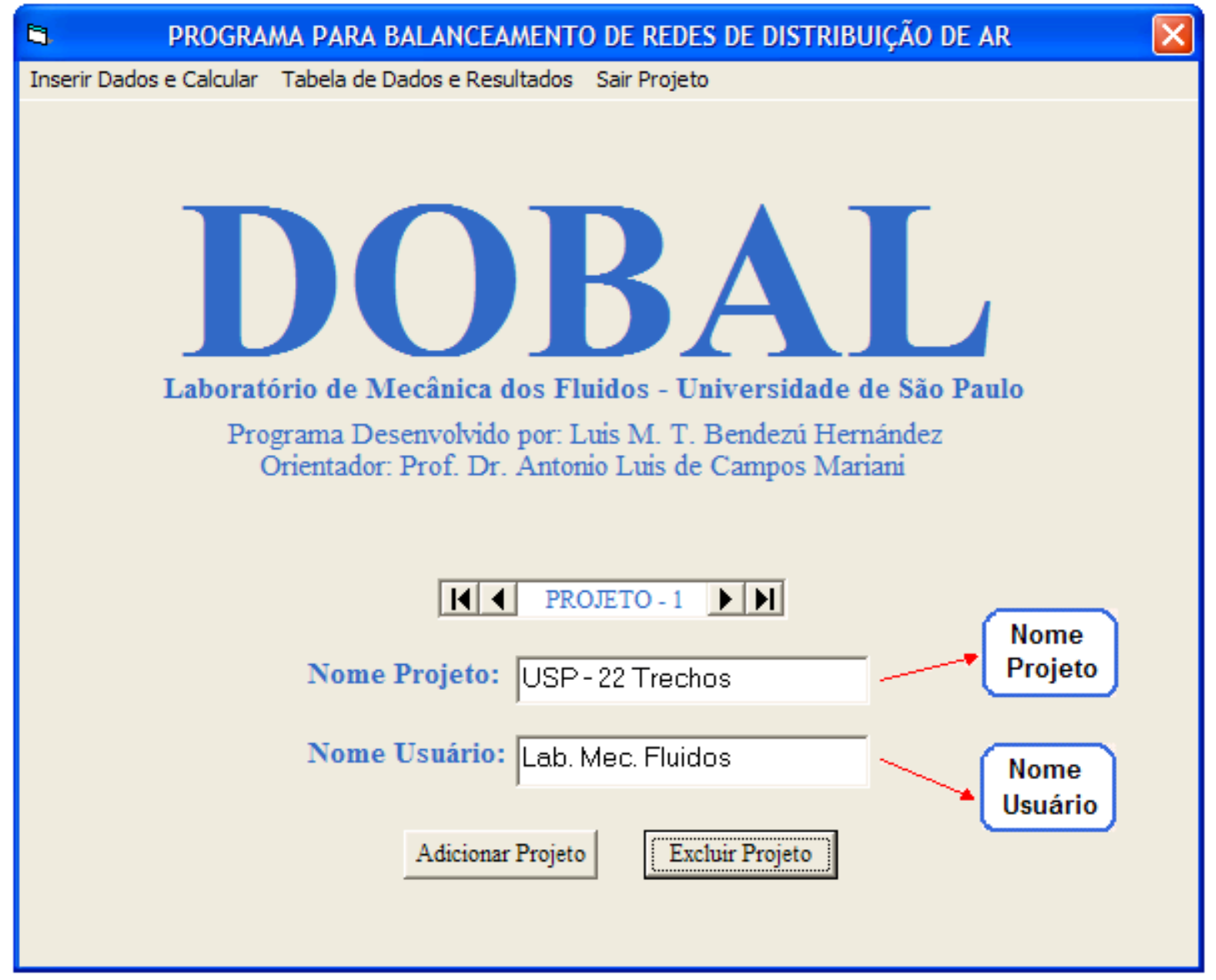

Figura A3 - Identificação do projeto

Para nosso caso será cadastrado:

- Nome do Projeto: USP - 22 Trechos

- Nome do Usuário: Lab. Mec. Fluidos. 
Nesta tela o menu oferece três opções que definem a seqüência de uso do programa, apresentado na figura A4 e são elas

- Inserir Dados e Calcular: Nesta opção o usuário irá executar diversas etapas realizando a inserção de dados e o calculo de resultados, obtendo inclusive os valores de balanceamento da rede.

- Tabela de Dados e Resultados: Nesta opção o usuário pode visualizar as tabelas com os registros dos dados e dos resultados calculados nas diversas etapas do programa, caso o usuário desejar imprimir estas tabelas, ele deve utilizar o aplicativo de banco de dados Access.

- Sair Projeto: Nesta opção o programa sai o projeto anteriormente selecionado, possibilitando escolher e carregar outro projeto.

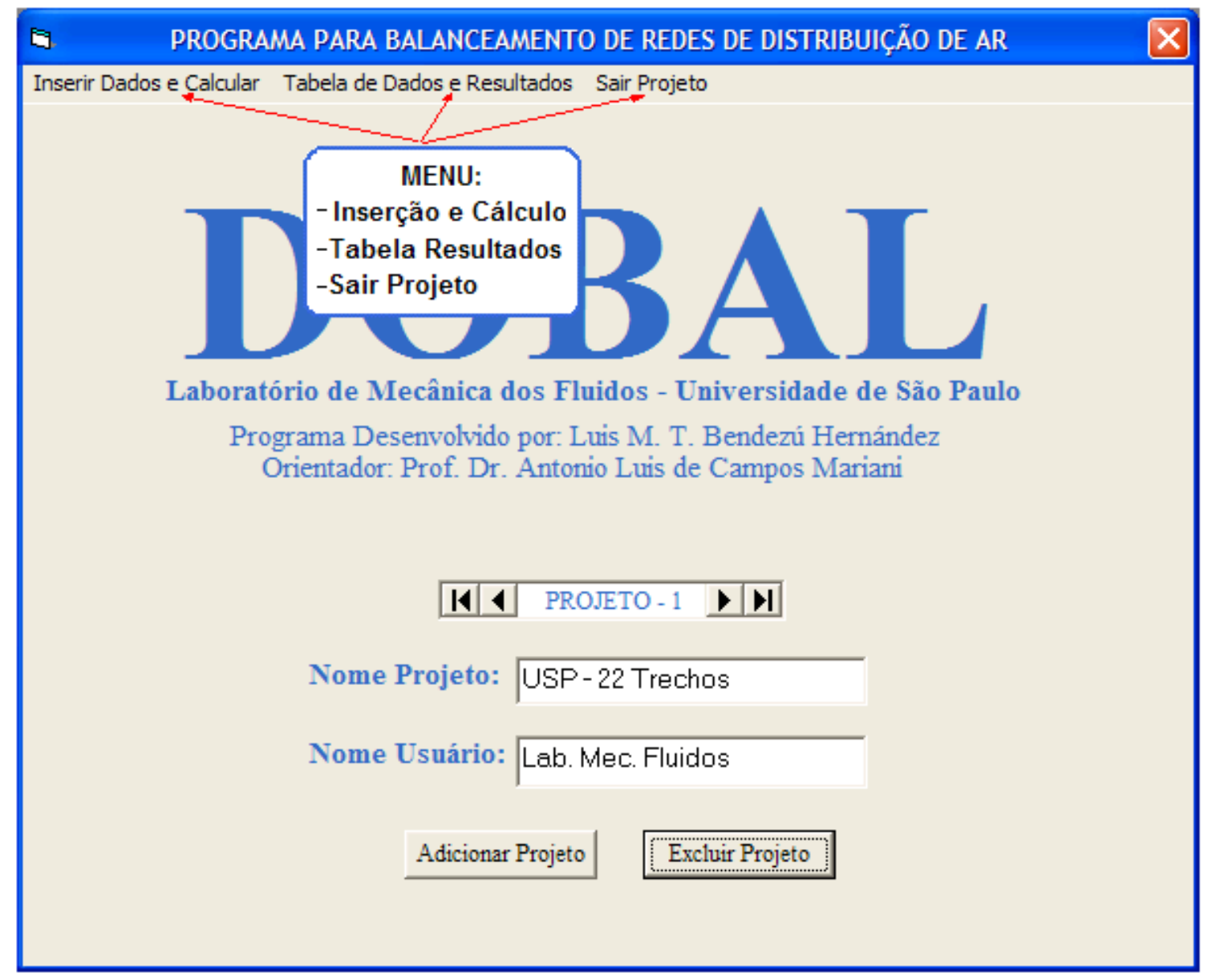

Figura A4 - Menu do projeto Inserido

\section{A.2.2 Inserção de dados e cálculos}

Estão definidas seis etapas para realizar o ingresso de dados, com cadastramento da rede e cálculos de resultados. É necessário ter o esquema da 
rede com a identificação de nós e trechos conforme metodologia estabelecida (veja item 4.1 - Caracterização da Rede), pois ele será a referência para a execução do programa.

Estas seis etapas são mostradas na figura A5, também se pode observar que na parte superior central desta tela se encontrará o nome do projeto cadastrado anteriormente.

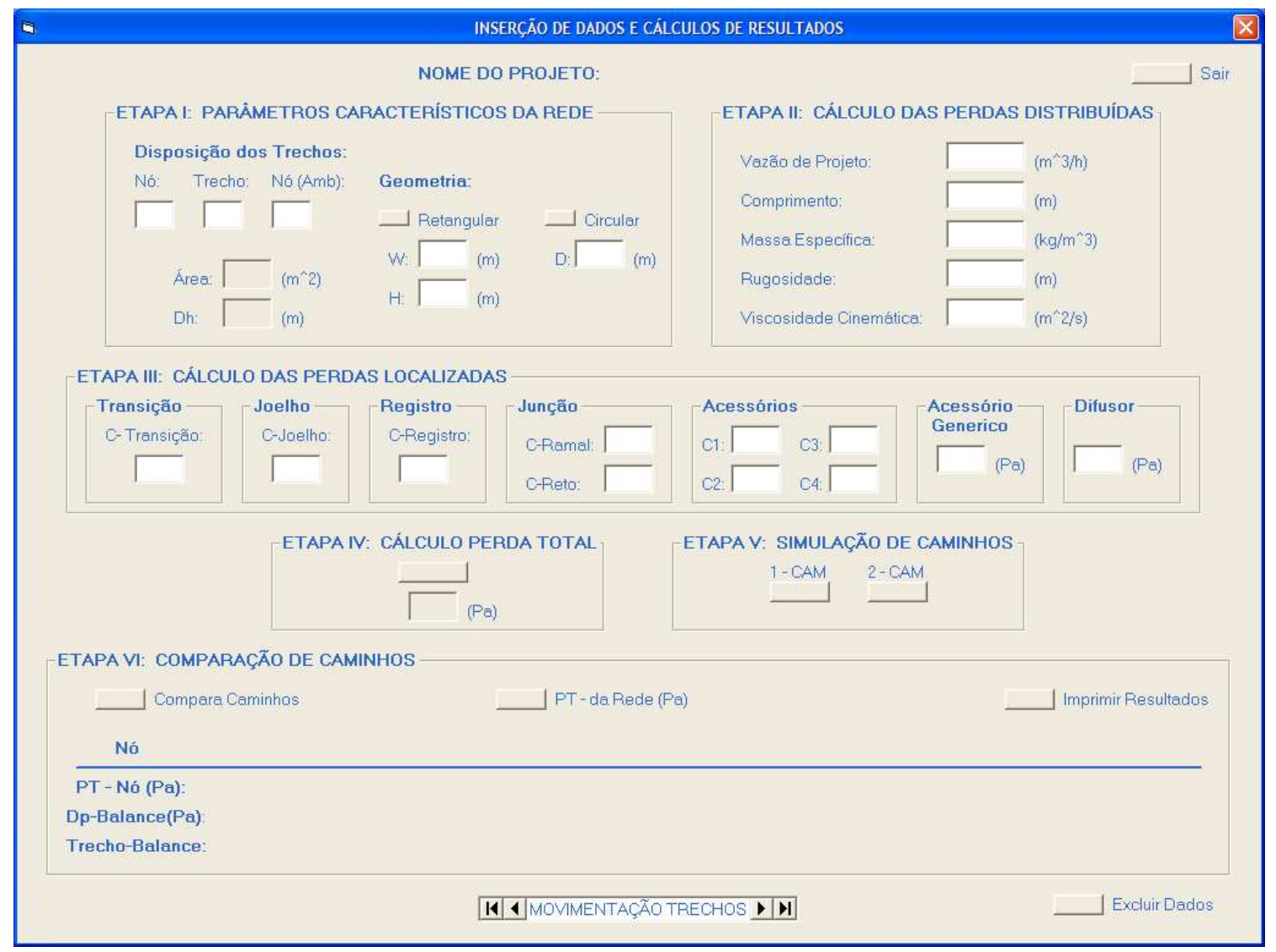

Figura A5 - Etapas do programa DOBAL

\section{A.2.2.1 Etapa I: Parâmetros característicos da rede}

Nesta etapa o usuário deve caracterizar a rede, informando para cada trecho as dimensões e os nós vinculados a ele. Esta informação dos nós auxilia o programa a relacionar os trechos, e os caminhos que o ar percorre. Na seqüência para executar esta etapa deve-se inserir dados nos campos a seguir:

a) Disposição dos Trechos: Utilizar o número atribuído a cada trecho e as letras dos nós nas extremidades. Caso uma das extremidades seja o ambiente cadastrar o número zero (0) na caixa "Nó (Amb)". 
b) Geometria: Cadastrar as dimensões do duto no trecho em questão. Para dutos circulares inserir o valor do diâmetro, e inserir o número zero (0) nas dimensões $\mathrm{W}$ e $\mathrm{H}$ da opção retangular. Para dutos retangulares fazer o inverso, lembrando de inserir o zero (0) no diâmetro D.

c) Cálculo da área e do diâmetro hidráulico: Acionar um dos botões "Circular" ou "Retangular" para realizar os cálculos para cada um dos trechos.

Pode se observar na figura A6, o preenchimento dos campos anteriormente definidos, utilizando os dados do estudo de caso (veja Capitulo Seis).

Na primeira caixa Nó, é colocada a primeira letra " $A$ " de nosso esquema, a continuação na caixa Trecho é inserido o número que esta vinculado a ele, nesse caso é o trecho número "1", e para finalizar o trecho esta vinculado ao ambiente então a caixa Nó (Amb) é cadastrado com o número "0".

Nas caixas da geometria pode-se observar que o duto número "1" tem dimensões retangulares, então o campo D, deve ser preenchido como "0".

\section{ETAPA I: PARÂMETROS CARACTERÍSTICOS DA REDE}

\section{Disposição dos Trechos:}

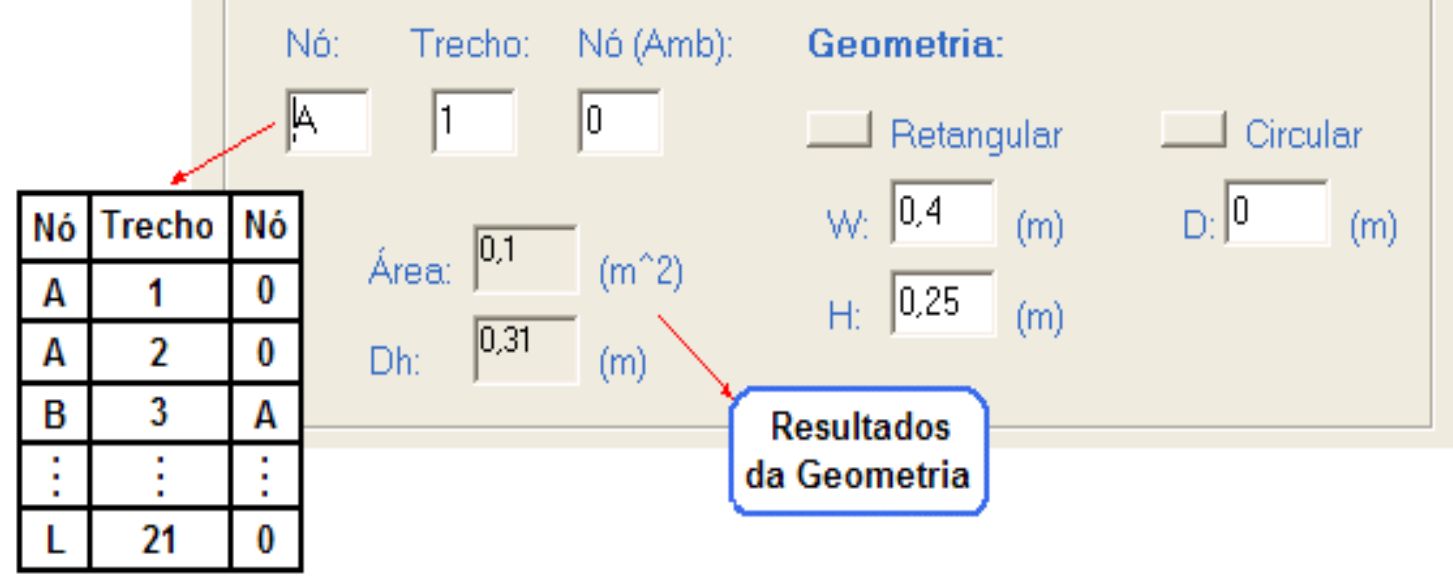

Figura A6 - Etapa I: Parâmetros Característicos

\section{A.2.2.2 Etapa II: Cálculo das perdas distribuídas}

Para o trecho registrado na Etapa I, devem ser informados nos respectivos campos alguns parâmetros do escoamento e dados preliminares do trecho.

São os seguintes:

- Vazão de projeto $\left(\mathrm{m}^{3} / \mathrm{h}\right)$. 
- Comprimento $(\mathrm{m})$.

- Massa Especifica $\left(\mathrm{kg} / \mathrm{m}^{3}\right)$

- Rugosidade (m).

- Viscosidade Cinemática $\left(\mathrm{m}^{2} / \mathrm{s}\right)$.

A figura $A 7$, mostra o preenchimento dos parâmetros do trecho número "1" utilizado como exemplo.

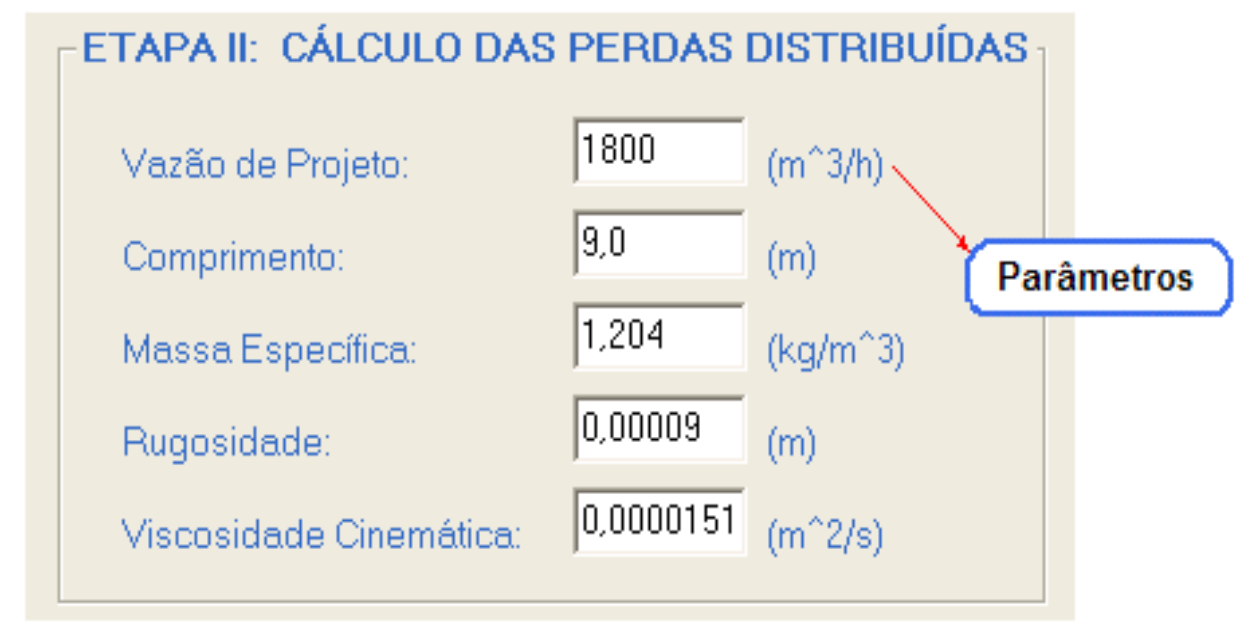

Figura A7 - Etapa II: Cálculo das Perdas Distribuídas

\section{A.2.2.3 Etapa III: Cálculo das perdas localizadas}

Para este mesmo trecho em questão, devem ser identificados todos os acessórios que produzem perdas localizadas. Há diversas opções de acessórios, sendo que para, transição, joelho, registro, junção e outros acessórios apresentados como $\mathrm{C} 1, \mathrm{C} 2, \mathrm{C} 3, \mathrm{C} 4$ o usuário deve inserir o coeficiente de perda adimensional respectivo. No caso de difusor, ou de outro acessório qualificado como genérico, os valores de perda devem ser informados em pascais. Todas as caixas devem ser preenchidas, adotando-se zero (0) para aquelas cujos acessórios não existem.

$\mathrm{Na}$ figura $\mathrm{A} 8$, representa os coeficientes que foram inseridos para o trecho número "1", nele se encontrão os adimensionais como também os acessórios em pascais. Os campos preenchidos com zeros são dados que não foram utilizados nesta etapa do programa. 


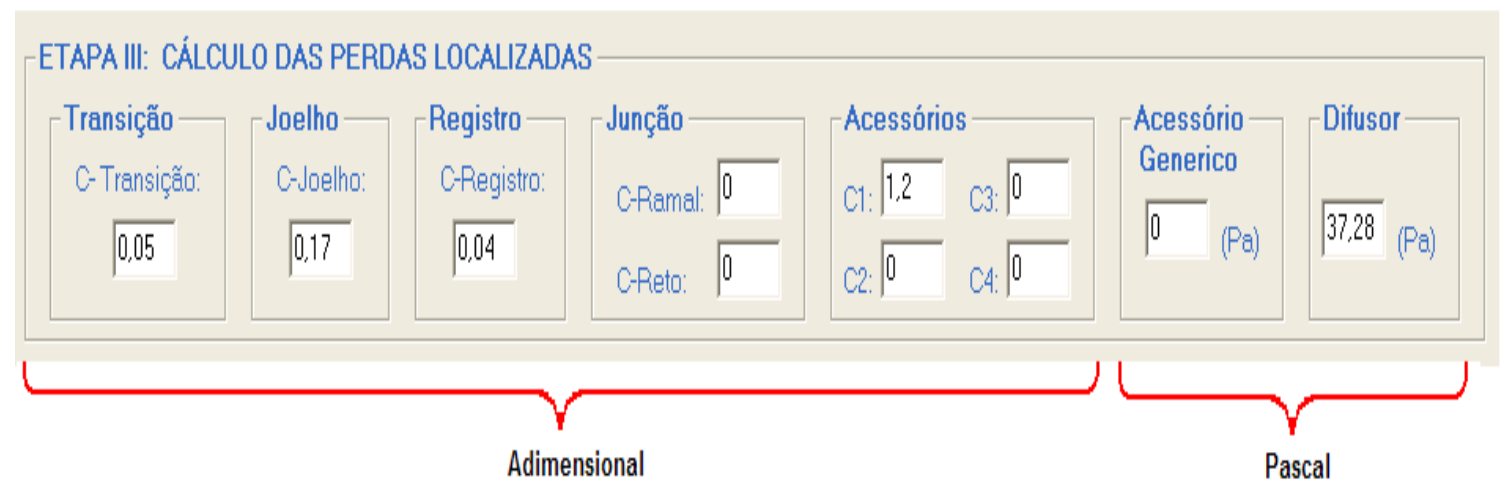

Figura A8 - Etapa III: Cálculo das Perdas Localizadas

\section{A.2.2.4 Etapa IV: Cálculo perda total}

Após serem inseridos os dados nas Etapas I, II e III, será acionado o botão desta etapa, para calcular a perda distribuída, localizada e total do trecho registrado anteriormente.

Para nosso caso será ilustrado na figura A9, o acionamento do botão e cálculo da perda total do trecho número "1".

\section{ETAPA IV: CÁLCULO PERDA TOTAL}

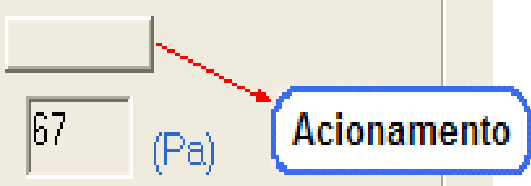

Figura A9 - Etapa IV: Cálculo das Perdas Totais

Pode-se adicionar que a configuração do programa DOBAL utiliza para inserção dos números a vírgula e não o ponto como separador das casas decimais.

\section{A.2.2.5 Etapa V: Simulação de caminhos}

Inseridos todos os dados, e executadas as etapas anteriores para o cálculo da perda total do trecho registrado, realiza-se a simulação dos caminhos.

Este procedimento é feito mediante ativação de um dos botões denominados como "1- CAM" ou "2 - CAM", ilustrada na figura A10. 


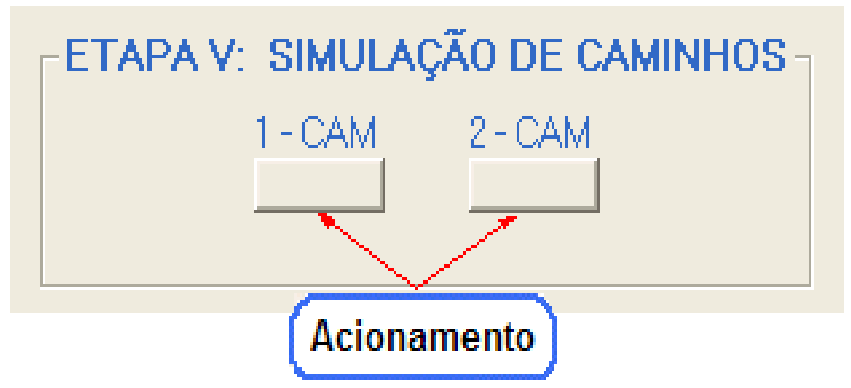

Figura A10 - Etapa V: Simulação de Caminhos

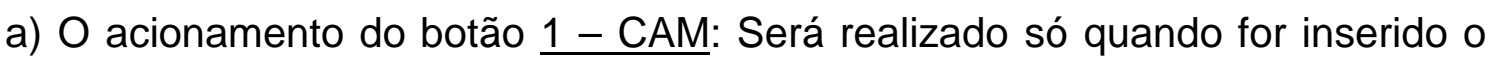
primeiro caminho, tendo como ponto de partida um nó do esquema da rede.

Utilizando o esquema da rede, do estudo de caso apresentado no capitulo seis, temos o primeiro caminho partindo do nó "A": A - 1 - 0, assim ficará definido o acionamento deste botão, ilustrado na figura $A 11$.

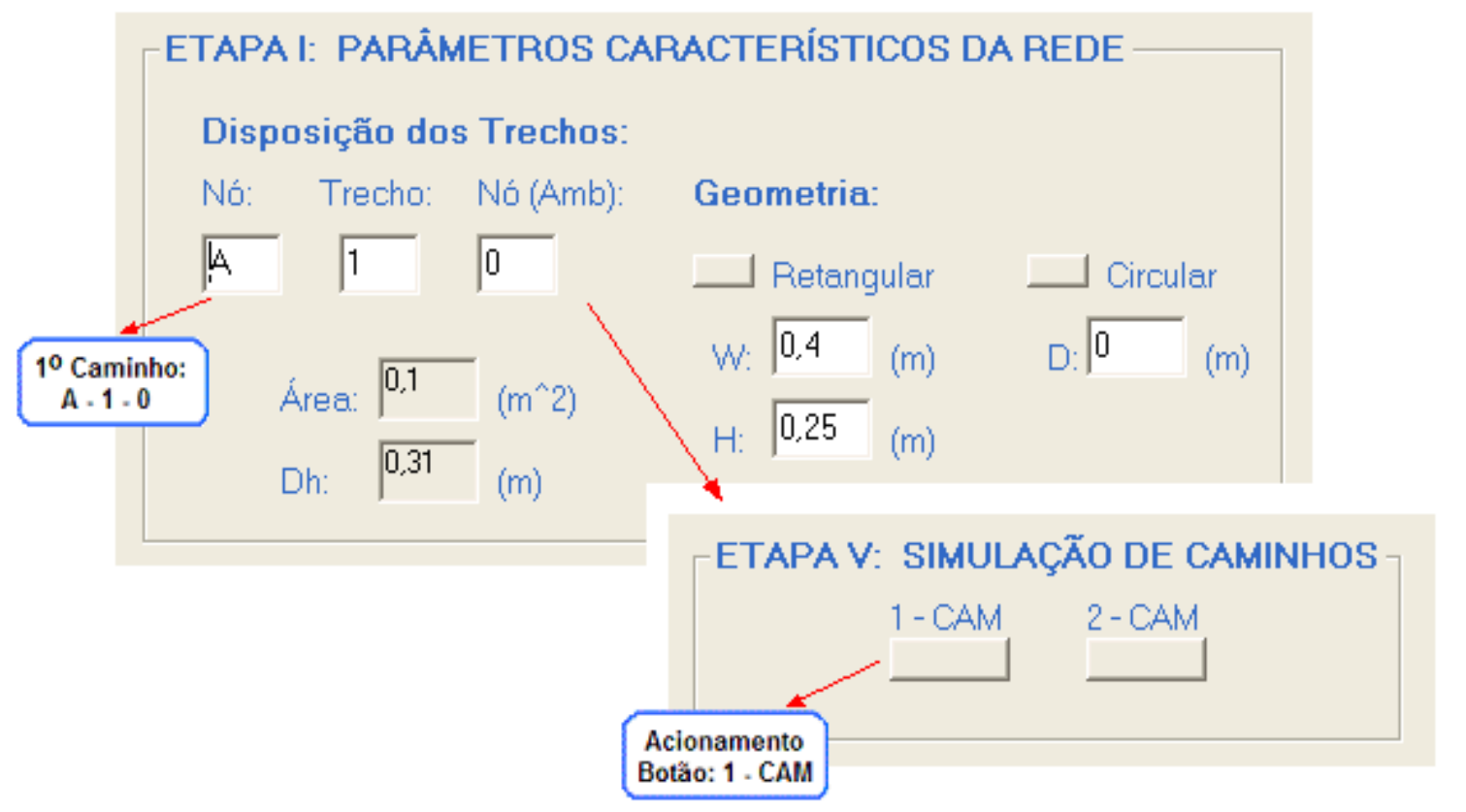

Figura A11 - Simulação do Primeiro Caminho.

b) $\mathrm{O}$ acionamento do botão $\underline{2}$ - CAM: Será realizado só quando for inserido o segundo caminho, tendo como ponto de partida o nó registrado anteriormente.

Utilizando o esquema da rede do estudo de caso apresentado no capitulo seis, temos o segundo caminho partindo do nó "A": A - $2-0$, assim será definido o acionamento deste botão, ilustrado na figura $A 12$. 


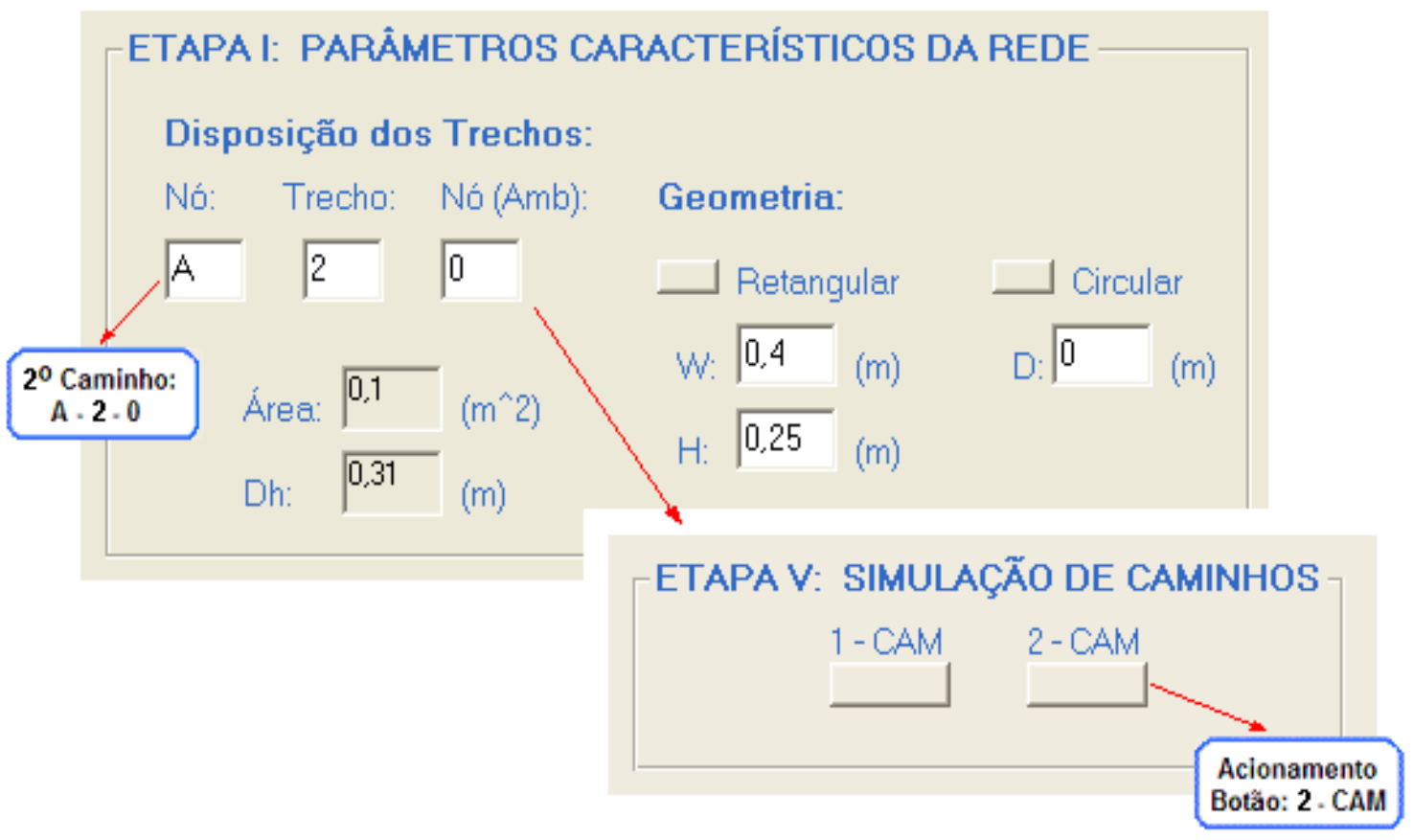

Figura A12 - Simulação do Segundo Caminho.

Outra função do botão 2 - CAM: É utilizado quando partindo de um nó, se tem um único caminho. Assim com o acionamento deste botão se produz a simulação do percorrido do ar.

De nosso estudo de caso, a rede de insuflação possui alguns nós que tem só um caminho, mostrado na figura A13.

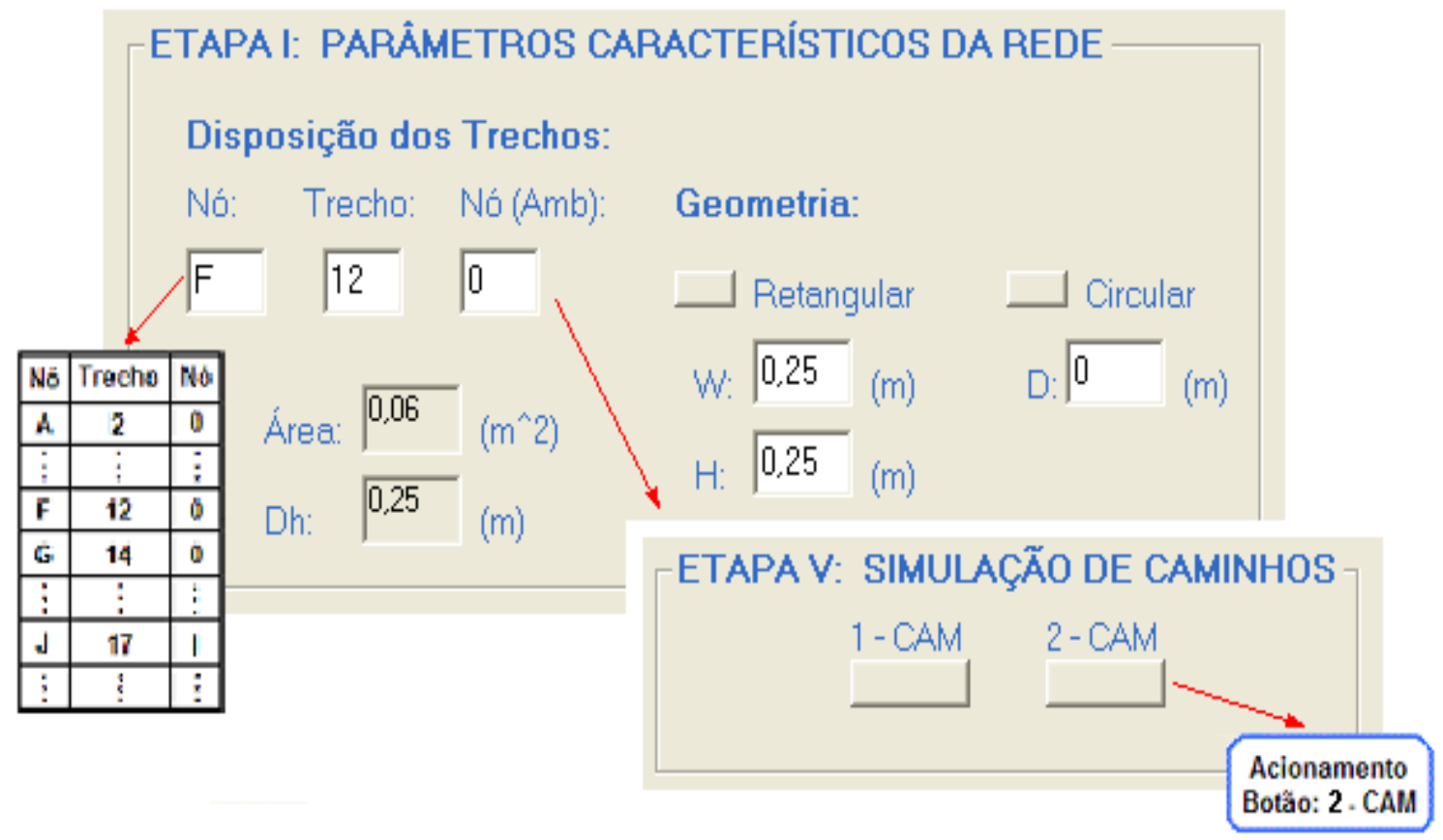

Figura A13 - Simulação de um só caminho. 


\section{A.2.2.6 Etapa VI: Comparação de caminhos}

Nesta etapa o usuário deve acionar alguns botões com a finalidade de obter os resultados do processo de balanceamento, como também o resultado da pressão total do sistema. Estas informações são mostradas em formato de tabela e poderá ser visualizado no programa e impresso no mesmo. Na seqüência para executar esta etapa é mostrada as definições de cada um deles:

a) Botão Compara Caminhos: Após ser executado o botão "2 - CAM" da etapa V aparecerá à letra do "Nó", que será comparado no programa. llustrada na figura A14. Nesse momento é realizado o acionamento do botão "Compara Caminhos" com a finalidade de calcular e mostrar os seguintes resultados:

- PT - Nó: Será mostrado o cálculo da pressão total do nó cadastrado.

- Dp - Balance: Nesta fila será mostrado o cálculo do diferencial de pressão de balanceamento entre dois caminhos em paralelo partindo de um mesmo nó, no caso de ter só um caminho, o programa colocará o diferencial de pressão com o mesmo valor da pressão total do nó.

- Trecho- Balance: Será mostrado o número do trecho vinculado ao caminho, com menor perda resultante no processo da simulação, é nele que poderá receber o regulador ou mudanças necessárias para determinação do balanceamento.

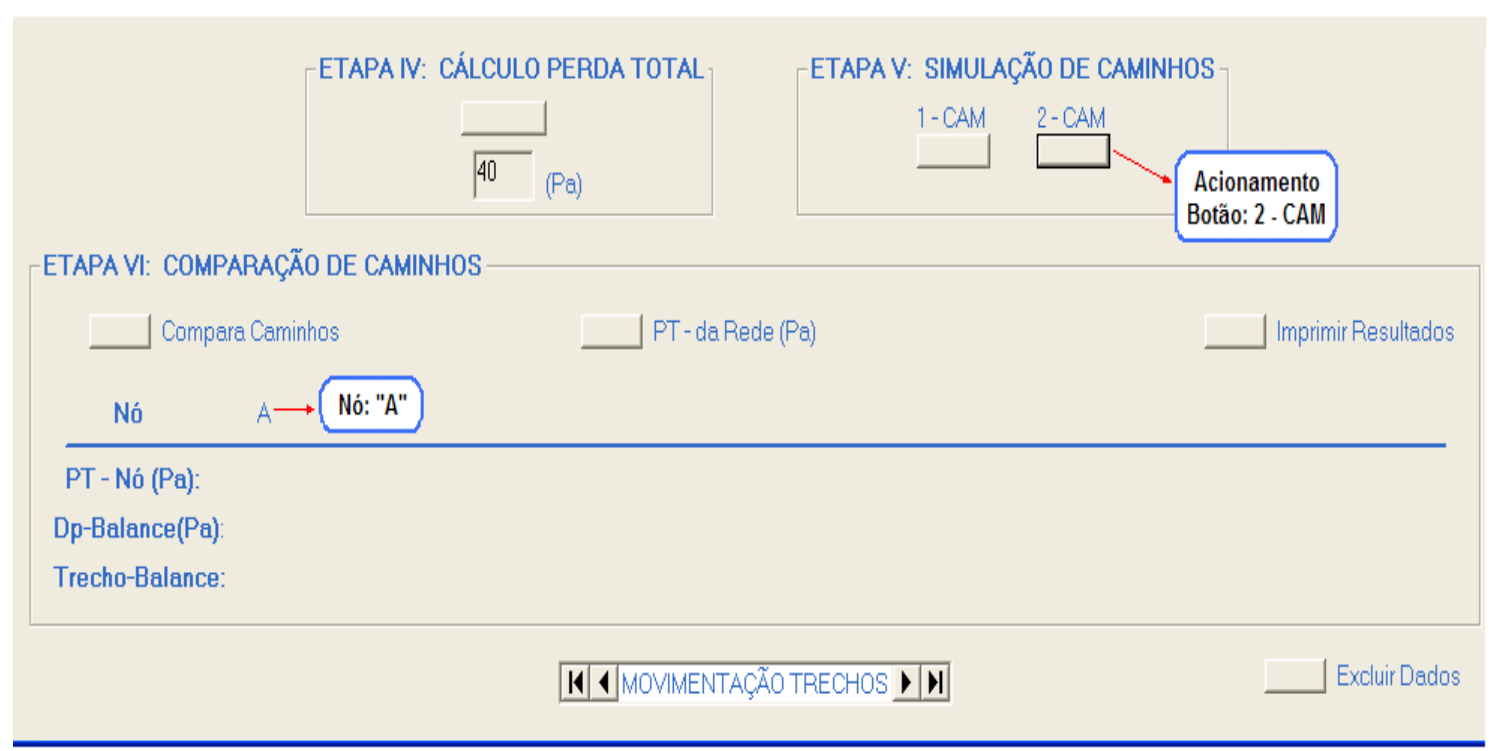

Figura A14 - Etapa VI: Comparação de Caminhos.

Para o exemplo usado nas etapas anteriores será mostrado na figura A15 o acionamento do botão "Compara Caminhos" para a obtenção dos resultados do nó 
"A". Este procedimento é repetido para cada um dos nós que se encontrem no esquema de rede.

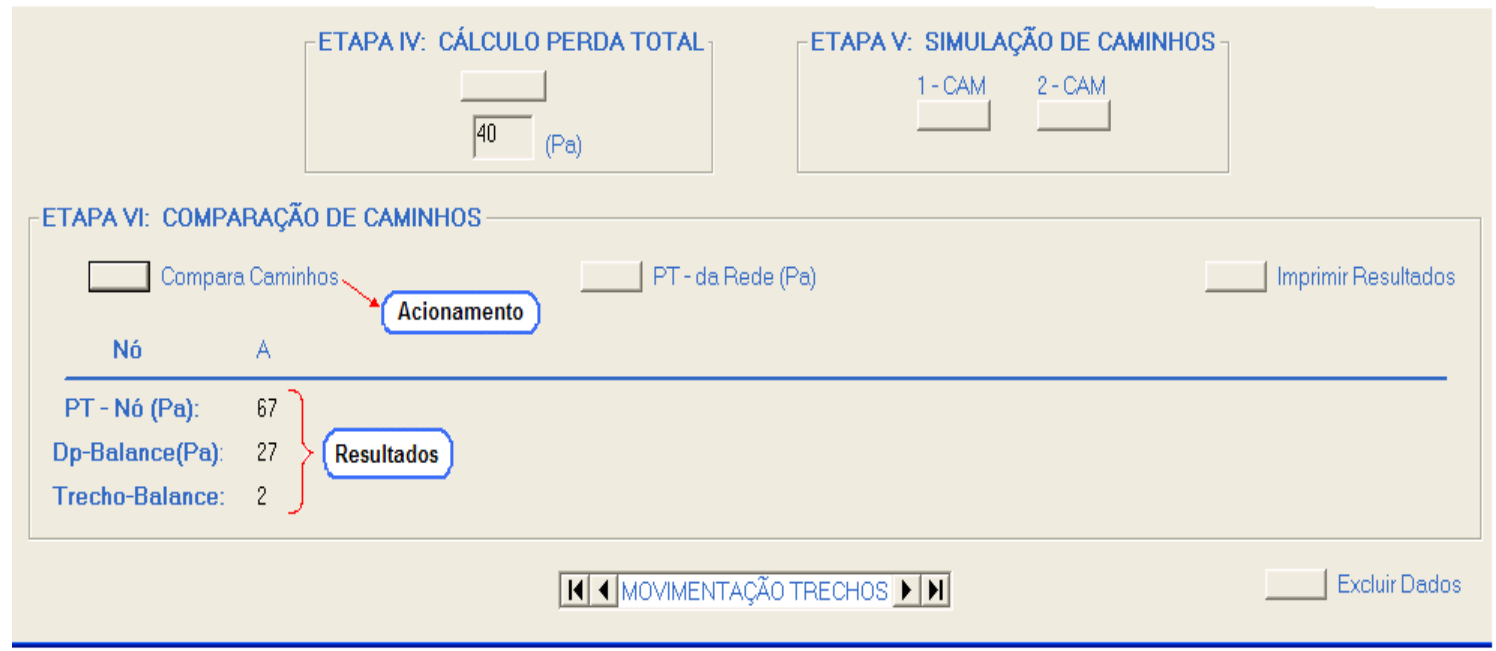

Figura A15 - Acionamento do botão "Compara Caminhos".

$\mathrm{Na}$ figura A16 se ilustra os resultados dos diferentes nós cadastrados e seus respectivos resultados.

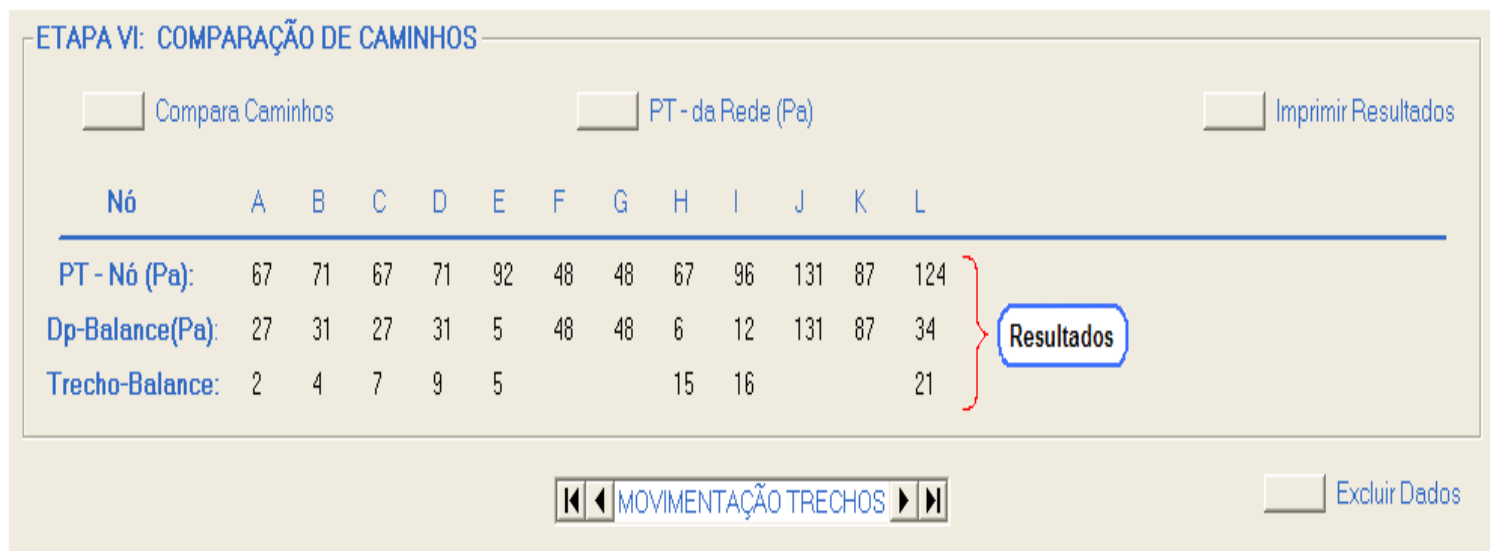

Figura A16 - Resultados da comparação dos caminhos.

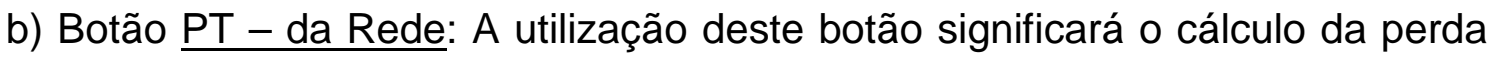
de pressão total no sistema, mediante ativação previa dos botões, "1-CAM" e "2CAM", o procedimento é explicado à continuação:

- Pressão na rede de insuflação: Para o cálculo da perda de pressão na descarga do ventilador será acionado o botão "ㅌ-CAM" e a Disposição dos Trechos será colocado da seguinte forma: VEN - \# Trecho - Nó, (VEN = representa o ventilador, \# Trecho = número do trecho que se encontra na saída do ar do ventilador, Nó = nó que se encontra depois do trecho inserido). 
A figura A17, ilustra os dados inseridos na "Disposição dos Trechos" e o acionamento do botão "1-CAM" para o cálculo da pressão total na descarga do ventilador.

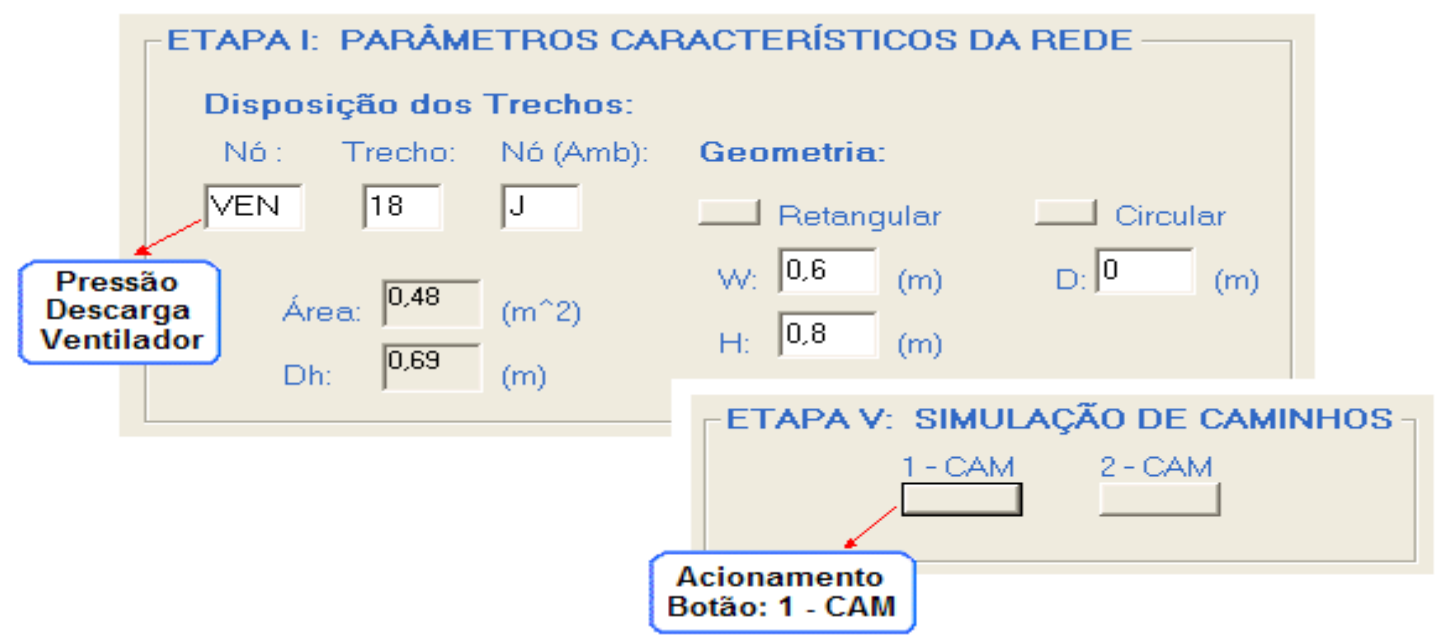

Figura A17 - Cálculo da pressão na descarga do ventilador

- Pressão na rede de retorno: Para o calculo da perda de pressão na aspiração do ventilador será acionado o botão "2-CAM" e a Disposição dos Trechos será colocado da seguinte forma: VEN - \#Trecho - Nó, (VEN = representa o ventilador, \#Trecho = número do trecho que se encontra na entrada do ventilador, Nó = nó que se encontra antes do trecho inserido).

A figura A18, ilustra os dados inseridos na "Disposição dos Trechos" e o acionamento do botão "2-CAM" para o cálculo da pressão total na aspiração do ventilador.

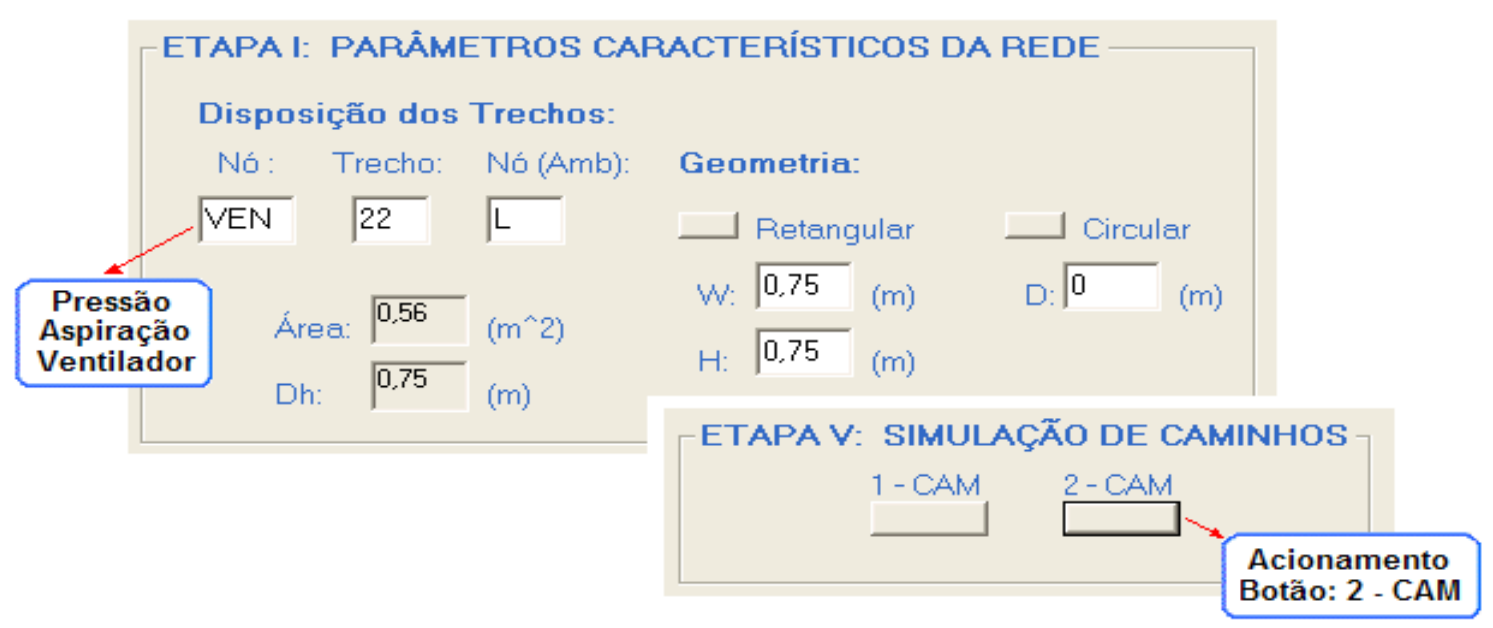

Figura A18 - Cálculo da pressão na aspiração do ventilador. 
Executados os procedimentos anteriores, é ativado o botão "PT- da Rede", para calcular a perda de pressão total, que foi consumida no sistema.

A figura A19 mostra a execução deste botão.

\begin{tabular}{|c|c|c|c|c|c|c|c|c|c|c|c|c|}
\hline \multicolumn{6}{|c|}{ Compara Caminhos } & & \multicolumn{5}{|c|}{ PT - da Rede (Pa) $\longrightarrow$ Acionamento } & \multirow{2}{*}{$\begin{array}{c}\text { Imprimir Resultados } \\
\text { VEN }\end{array}$} \\
\hline Nó & A & $B$ & c & $D$ & $E$ & $\mathrm{~F}$ & $G$ & $\mathrm{H}$ & । & J & $L$ & \\
\hline PT - Nó (Pa): & 67 & 71 & 67 & 71 & 92 & 48 & 48 & 67 & 96 & 131 & $87 \quad 124$ & 302 \\
\hline Dp-Balance(Pa): & 27 & 31 & 27 & 31 & 5 & 48 & 48 & 6 & 12 & 131 & $87 \quad 34$ & Resultado \\
\hline Trecho-Balance: & 2 & 4 & 7 & 9 & 5 & & & 15 & 16 & & 21 & nesulano \\
\hline
\end{tabular}

Figura A19 - Cálculo da perda de pressão total no sistema.

c) Botão Imprimir Resultados: A utilização deste botão enviará os resultados da etapa comparação de caminhos para uma impressora instalada no computador. Se a impressora não estiver pronta para imprimir, o usuário terá que salvar eles em um arquivo criado por ele.

A figura A20, representa a utilização do botão "Imprimir Resultados".

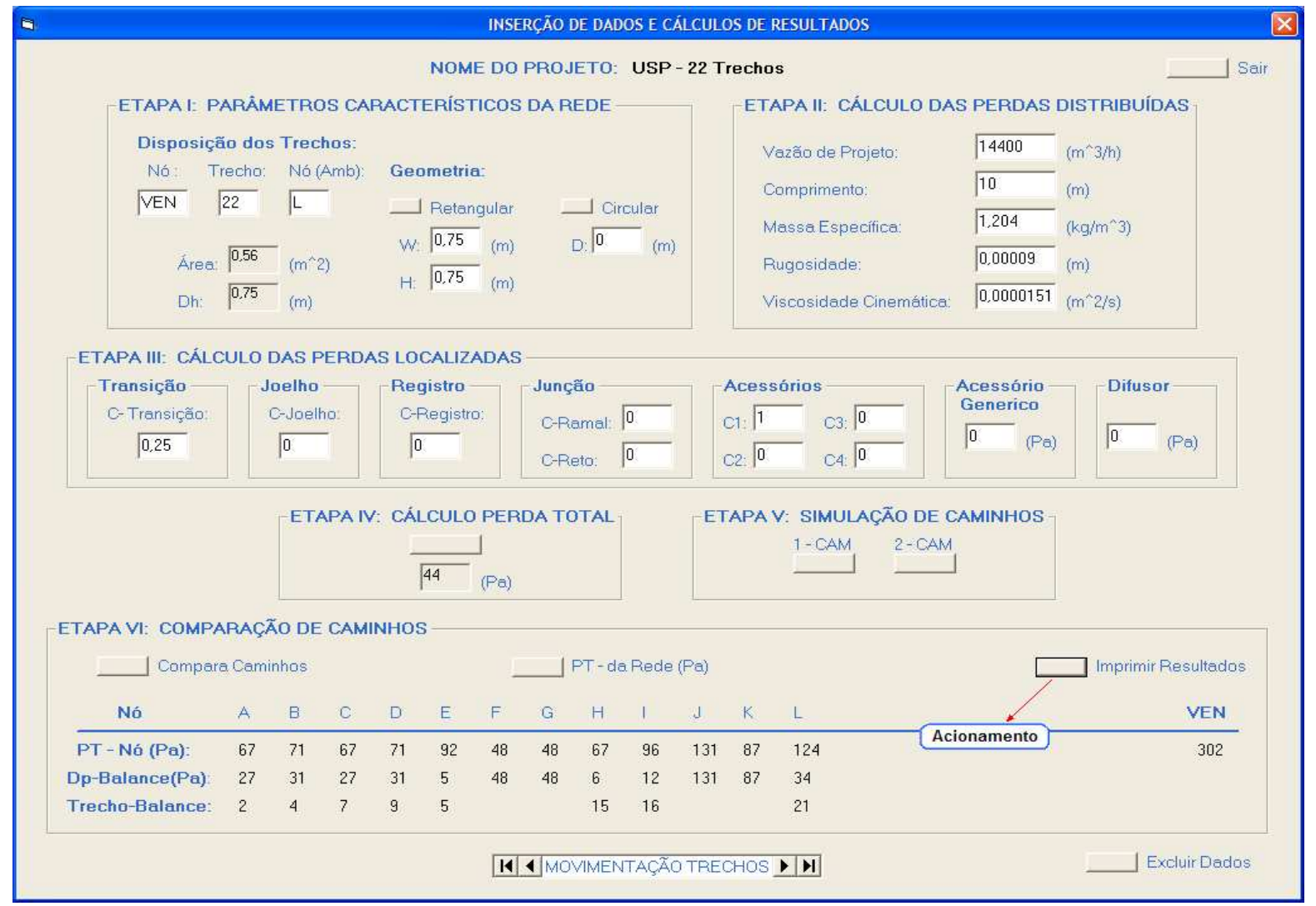

Figura A20 - Acionamento do botão "Imprimir Resultados". 
Outros itens a explicar para o correto funcionamento do programa DOBAL são:

- Botão "Movimentação Trechos": Cuja função é cadastrar cada um dos dados e parâmetros do trecho a ser inserido no programa. Para que isto ocorra deve ser acionada a seta à direita da parte interna do botão. Cada vez que sejam executados, os registros no banco de dados serão atualizados.

Se os dados inseridos estão corretamente colocados e não existe mudança alguma, o acionamento deste botão deixará em branco todos os campos para o ingresso de novos cadastros.

Se acionar a seta que se encontra na extremidade à direita do botão, pode-se visualizar o ultimo trecho cadastrado no programa.

A figura A21, mostra alguns dos caminhos cadastrados no programa, tendo em consideração que o botão é acionado para cada um dos trechos inseridos até a chegada no ventilador.

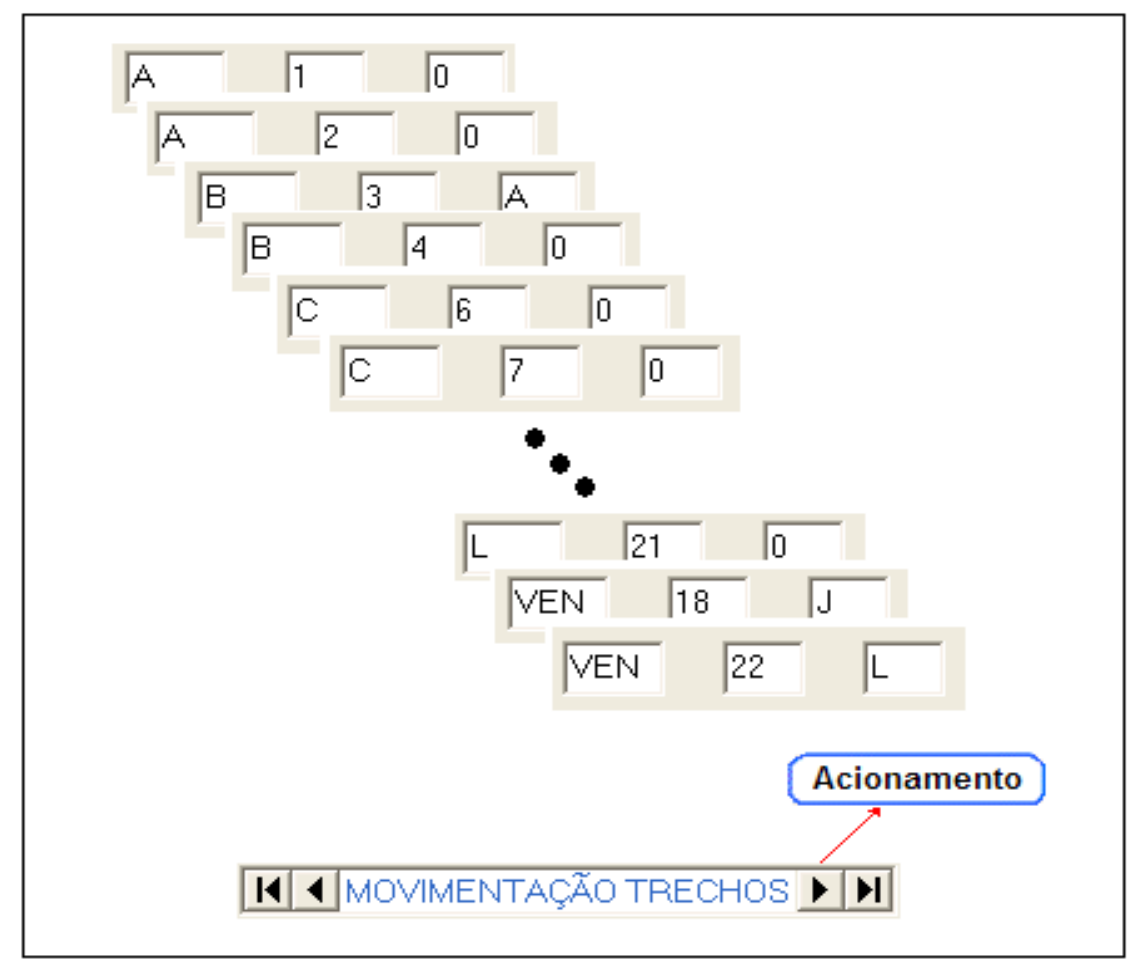

Figura A21 - Cadastros dos caminhos no programa.

- Botão "Excluir Dados": É utilizado para excluir os dados e cálculos de um determinado trecho no programa e no banco de dados do Microsoft Access ${ }^{\circledR}$, a escolha deste é feito mediante o acionamento do botão "Movimentação Trechos". 
- Botão "Sair": Nesta opção o programa sai da tela "Inserção de Dados e Cálculos de Resultados" e retorna para a tela onde se encontra a identificação do projeto.

\section{A.2.3 Tabela de dados e resultados}

Foram criadas quatro tabelas, cuja função é de resumir o conjunto de dados inseridos e calculados nas etapas mencionadas no item anterior, para um determinado projeto. A figura A22 mostra o acionamento desta opção.

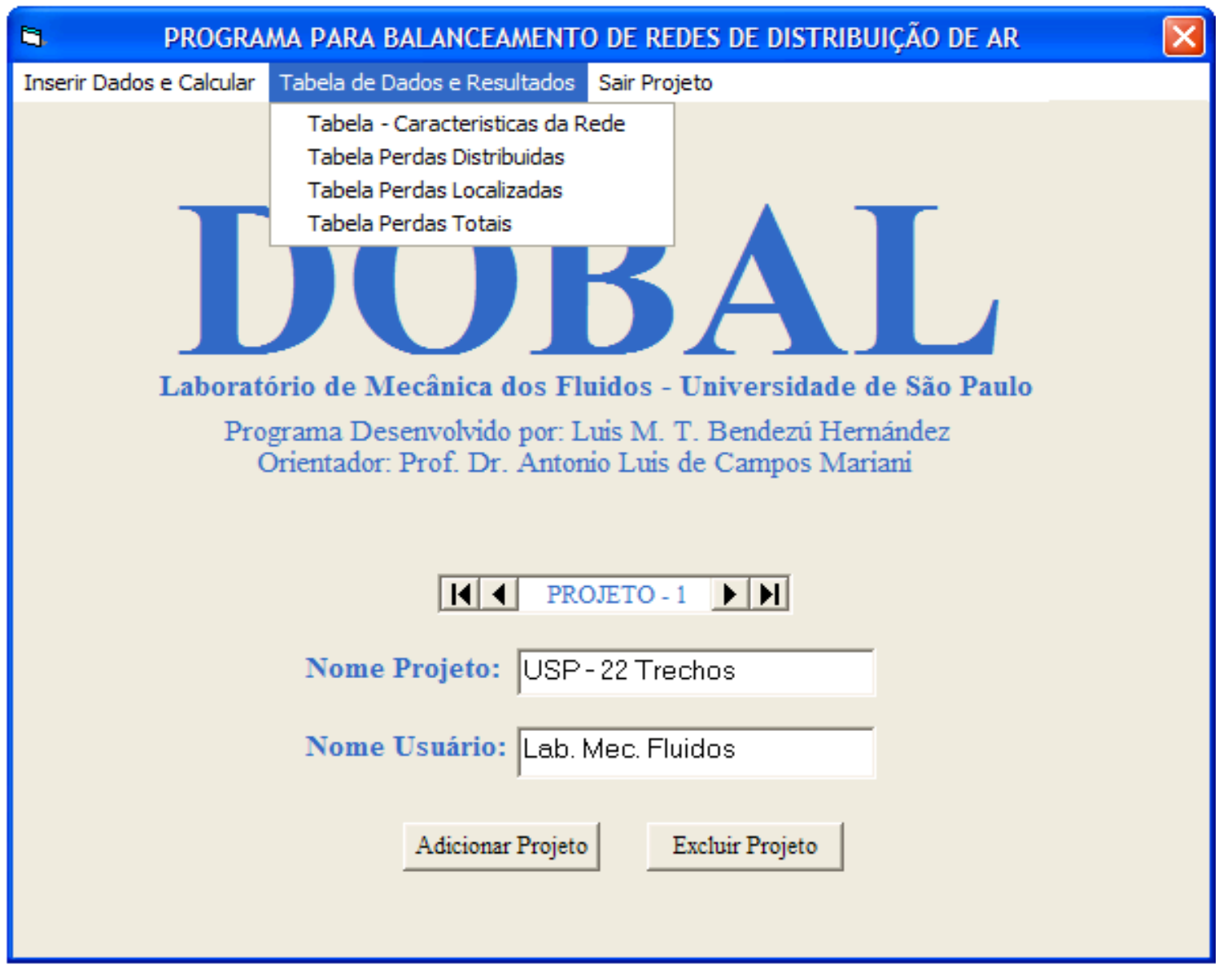

Figura A22 - Botão do Menu "Tabela e Dados e Resultados"

\section{A.2.3.1 Tabela - Características da Rede}

Esta tabela contém todos os dados inseridos e calculados, para cada um dos trechos cadastrados na primeira etapa do programa (Disposição dos trechos, Geometria, Área e Dh). O botão "Sair" é utilizado para fechamento da tela, possibilitando escolher uma nova tabela. A figura A23 ilustra o acionamento desta opção e mostra a tabela com dados. 


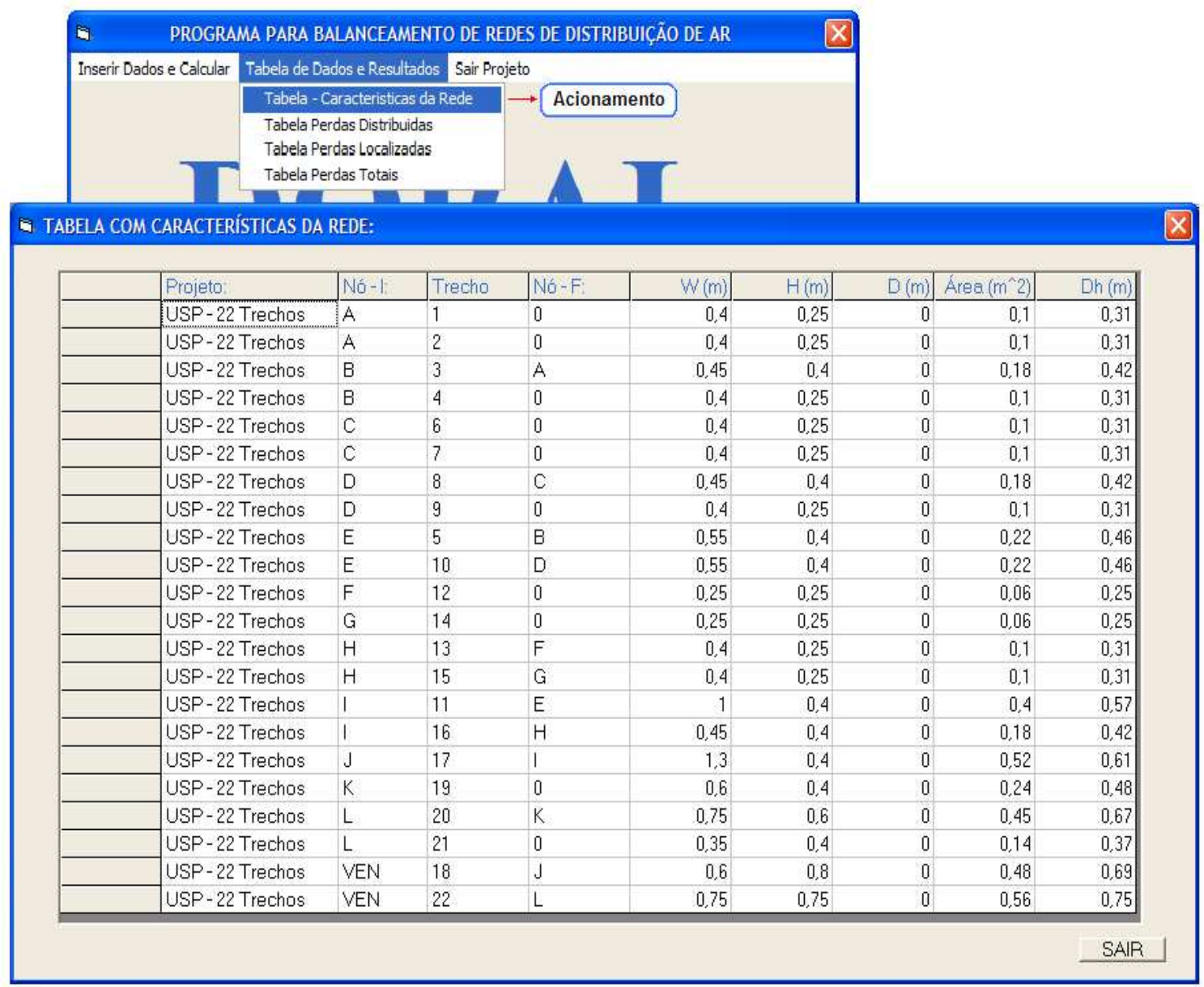

Figura A23 - Tabela Caracterização da Rede.

\section{A.2.3.2 Tabela Perdas Distribuídas}

O acionamento desta opção é mostrado na figura A24. Esta tabela contém os parâmetros do escoamento e dados preliminares, como também o cálculo da perda distribuída, para cada um dos trechos cadastrados na segunda etapa do programa. A figura A25 ilustra o conteúdo da tabela. O botão "Sair" tem a mesma função que a tabela anterior.

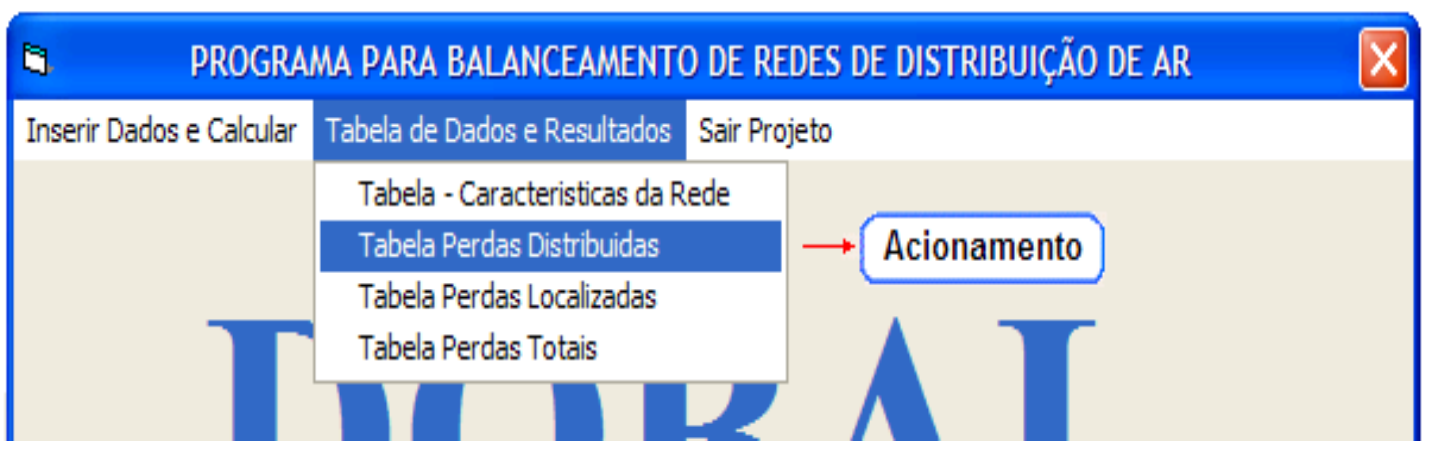

Figura A24 - Acionamento botão "Tabela Perdas Distribuídas". 


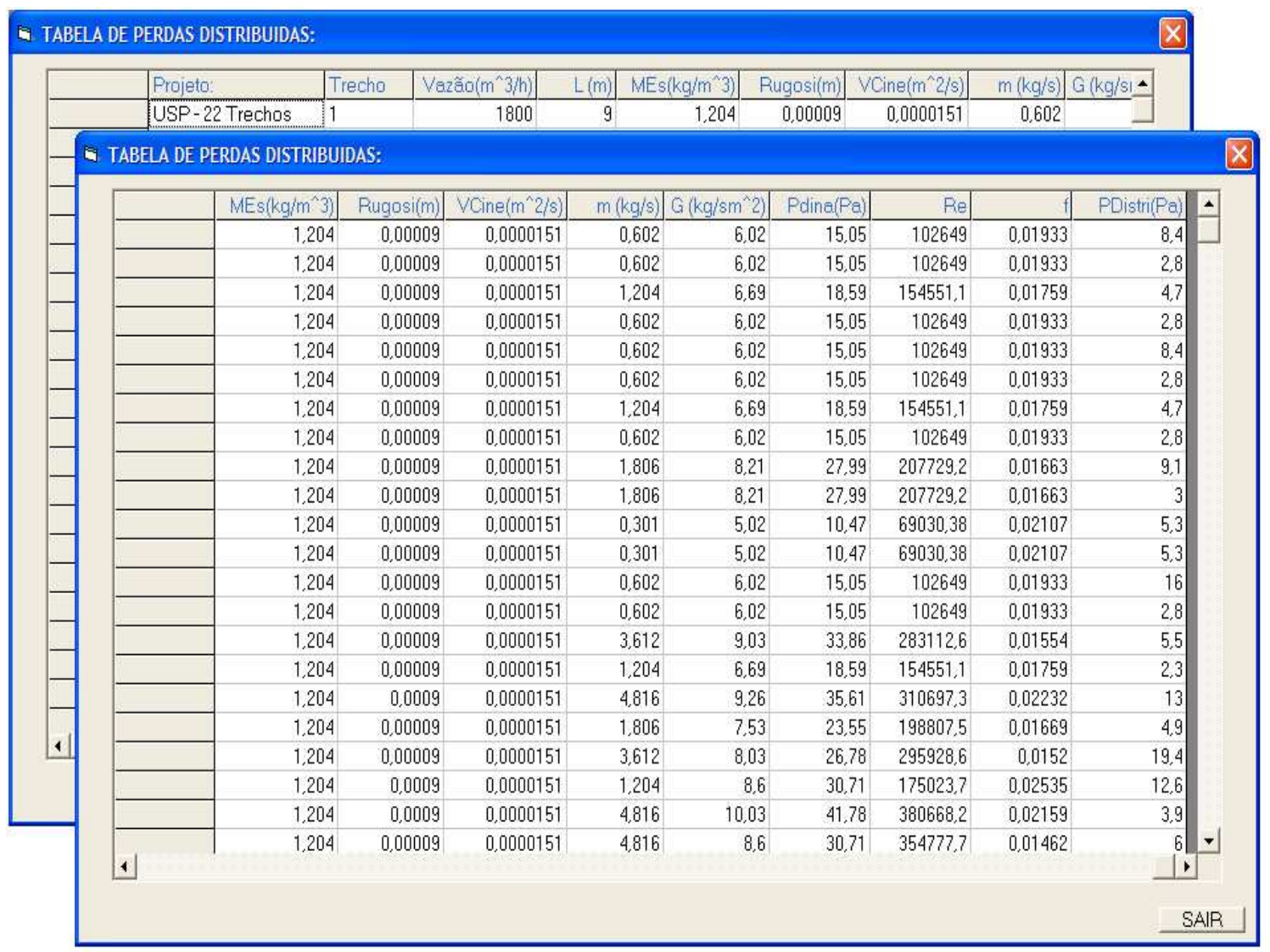

Figura A25 - Tabela de Perdas Distribuídas.

\section{A.2.3.3 Tabela Perdas Localizadas}

A seguinte tabela pode-se visualizar mediante acionamento do botão representado na figura A26. Nele se encontram os coeficientes de perda inseridos na terceira etapa e o resultado do cálculo da perda localizada para cada trecho registrado no programa. A figura A27 mostra a tabela com os dados e resultados.

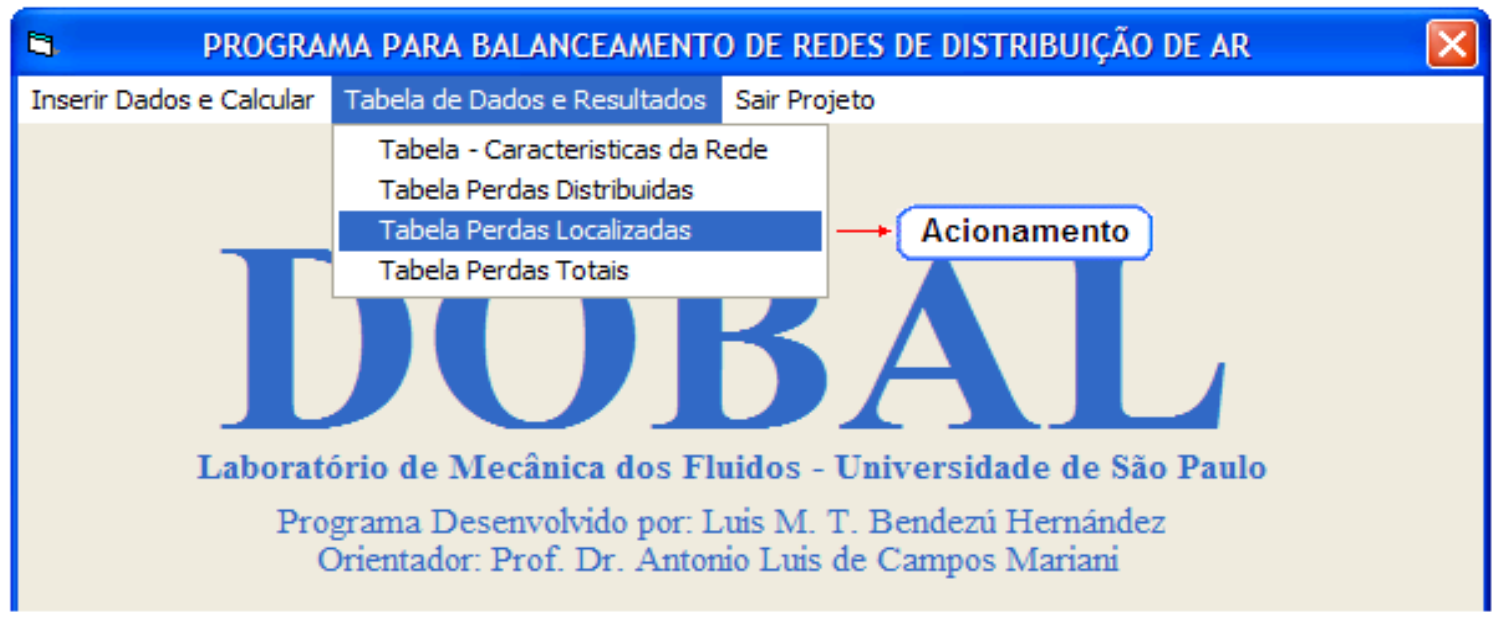

Figura A26 - Acionamento botão "Tabela Perdas Localizadas". 


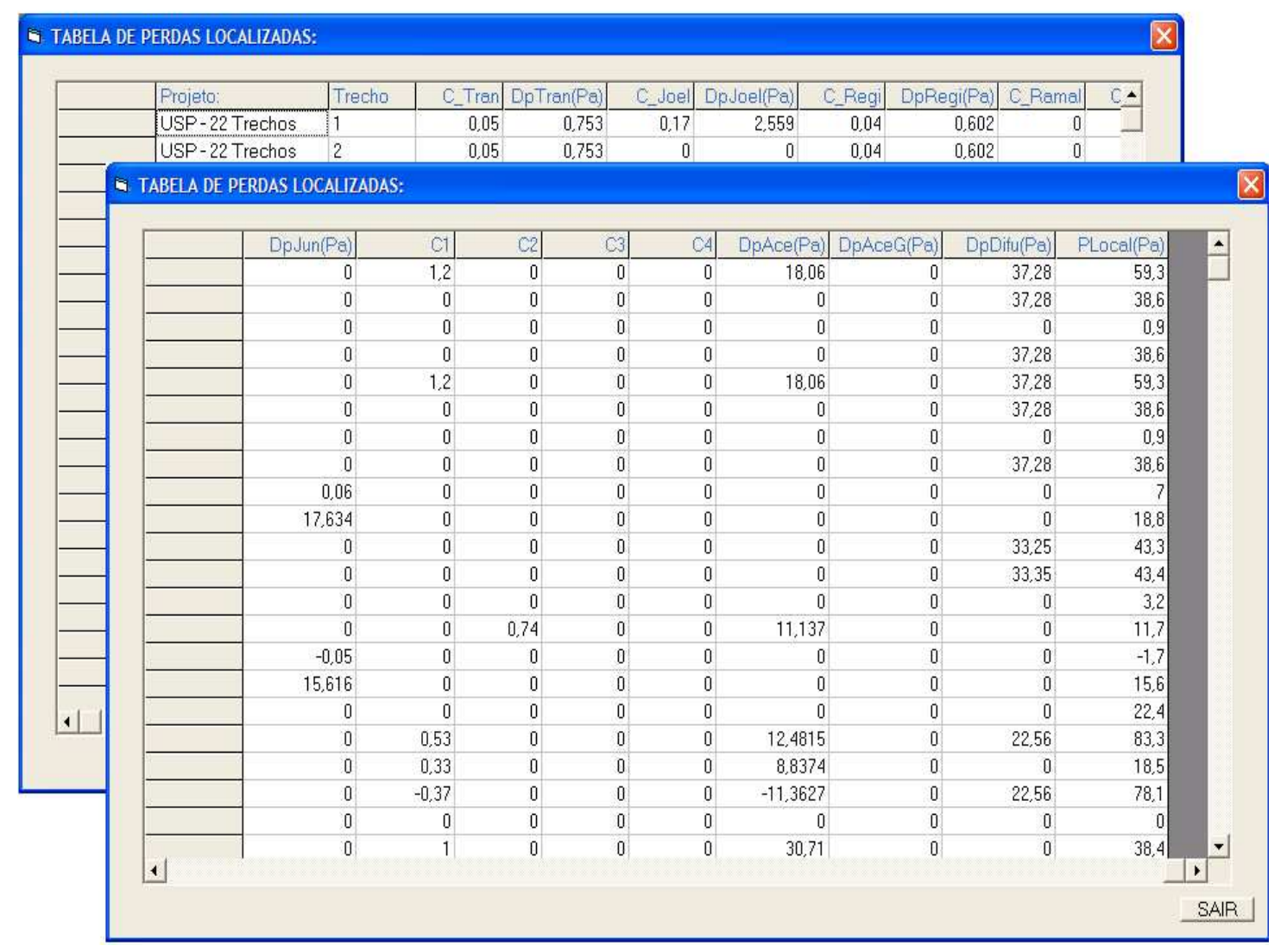

Figura A27 - Tabela de Perdas Localizadas.

\section{A.2.3.4 Tabela Perdas Totais}

Esta última tabela é acionada mediante a opção apresentada na figura A28. $\mathrm{Na}$ qual se pode encontrar um resumo dos resultados da perda distribuída, localizada e totais dos trechos registrados no programa DOBAL. A figura A29 mostra a tabela e os cálculos mencionados. O botão "Sair" é utilizado para fechamento da tela, possibilitando a escolha de novas tabelas no programa.

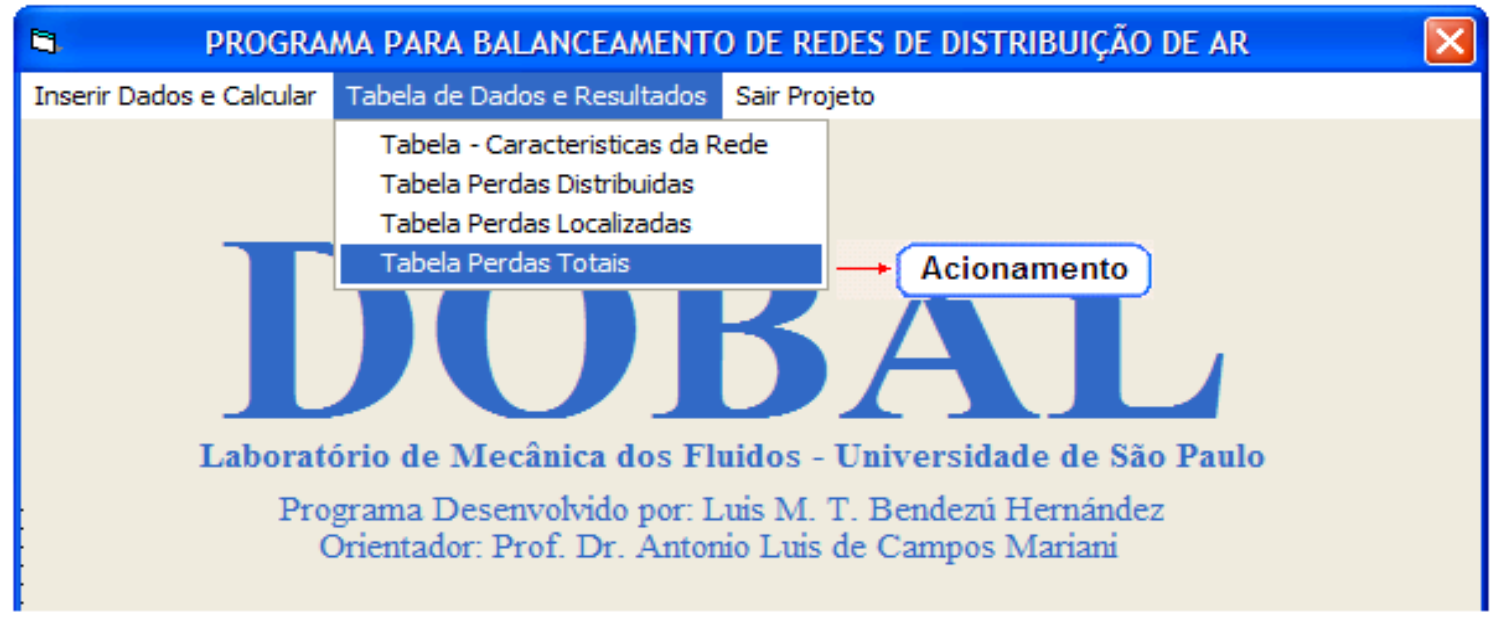

Figura A28 - Acionamento botão "Tabela Perdas Totais". 


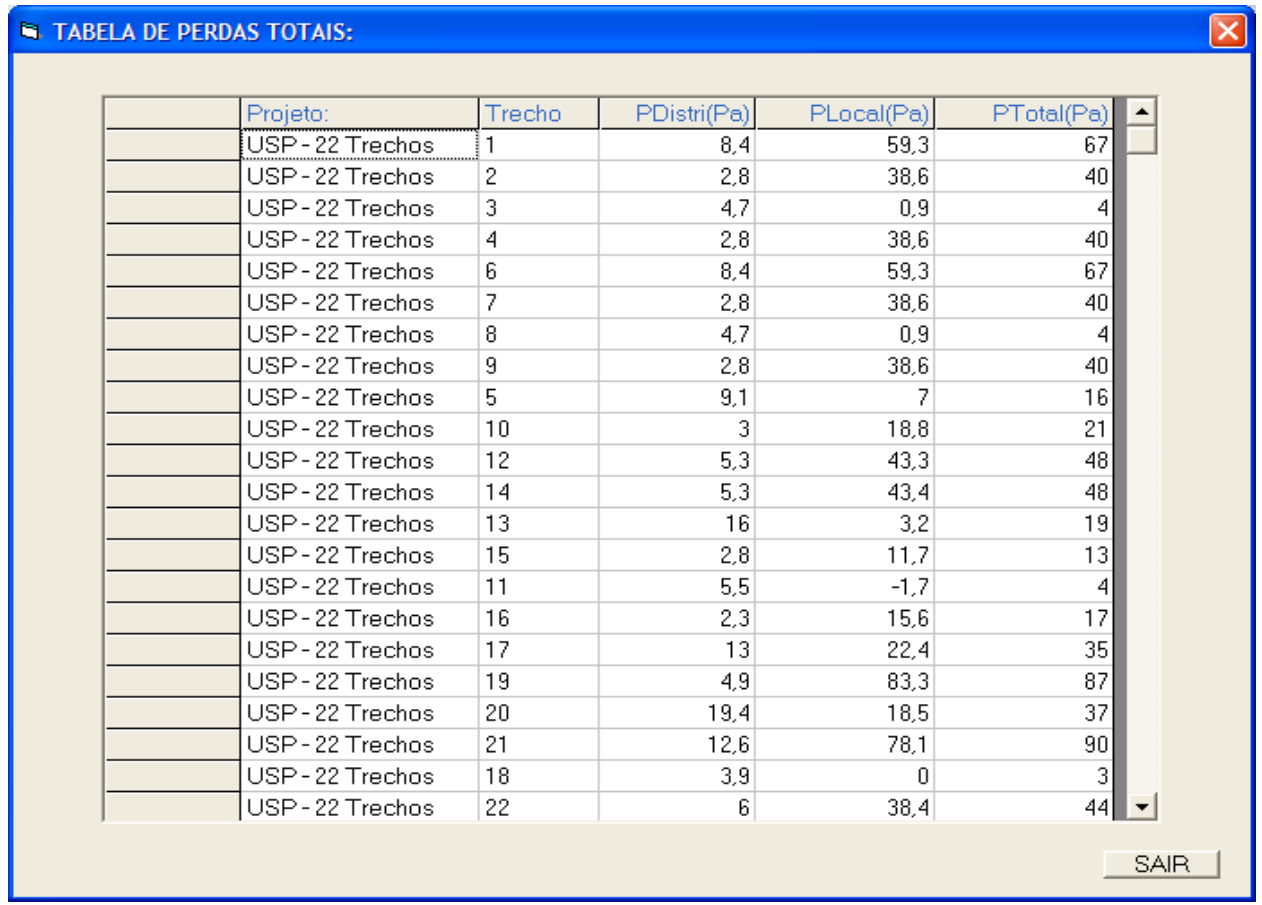

Figura A29 - Tabela de Perdas Totais.

A figura A30 mostra os resultados finais em formato de tabela, quando é acionado o botão "Imprimir Resultados" da etapa seis.

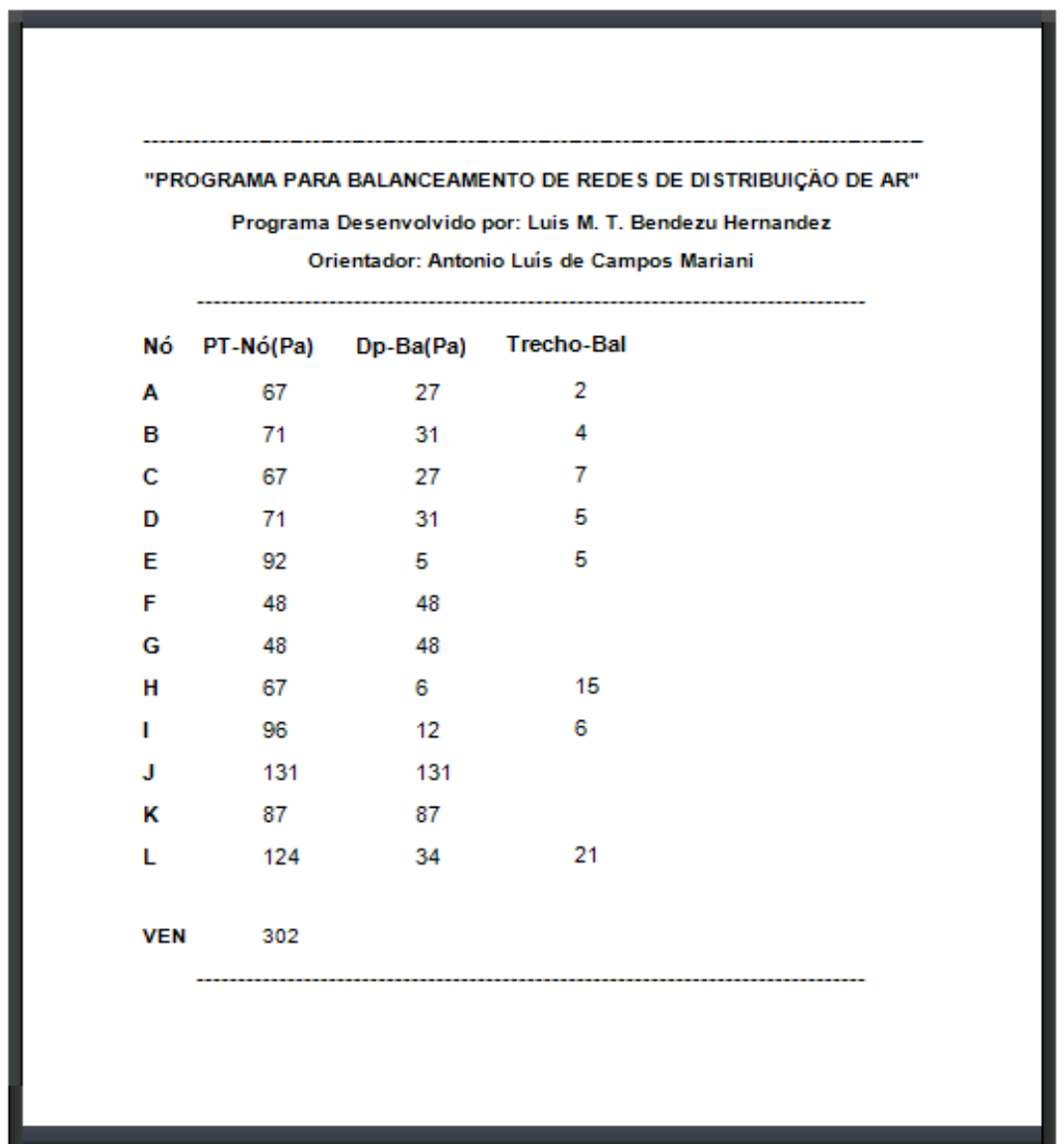

Figura A30 - Tabela de Resultados Finais. 
Para finalizar, as quatro tabelas definidas anteriormente permanecem com seus dados mesmo após fechamento do programa e podem ser abertas e impressas com auxilio do aplicativo Microsoft Access ${ }^{\circledR}$. 


\section{APÊNDICE B}

\section{ESTUDO DE CASO - PLANILHA ELETRÔNICA}

Como foi mencionado no capítulo seis, em paralelo com o desenvolvimento do programa DOBAL, foi criada no Microsoft Exce ${ }^{\circledR}$ uma planilha para calcular as perdas distribuídas, localizadas e totais de cada um dos trechos da rede simulando o escoamento com as vazões de projeto. Foi obtido o diferencial de pressão de balanceamento para os caminhos em paralelo.

A planilha desenvolvida tem por finalidade comparar os resultados nela calculados com os determinados pelo programa DOBAL. Assim pode-se avaliar se 0 algoritmo adotado no programa obtém bons resultados.

$\mathrm{Na}$ seguinte figura B1 estão apresentados os dados de entrada na planilha como propriedades do escoamento do ar dos dutos e dos difusores.

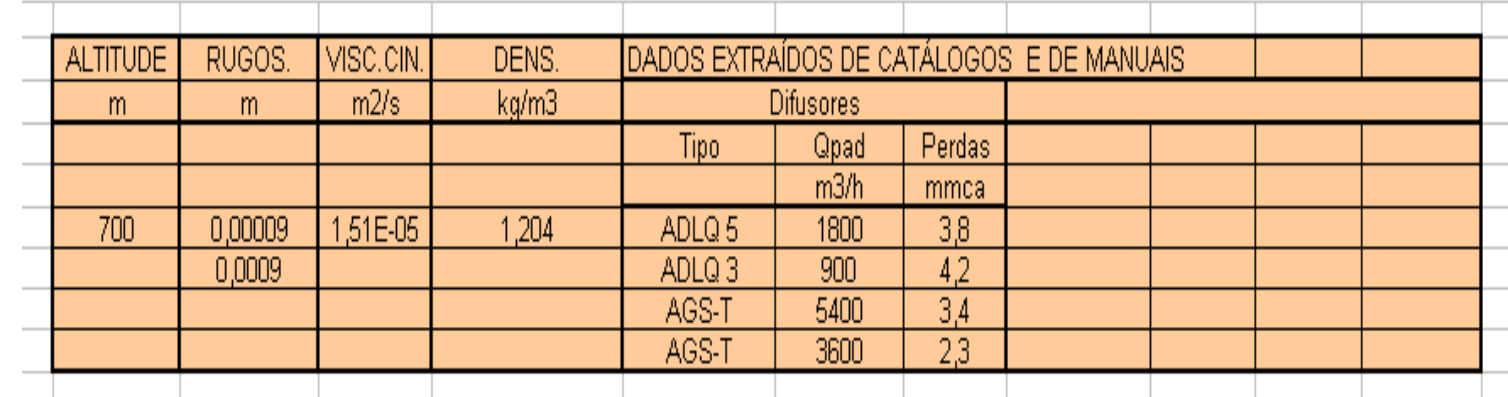

Figura B1: Propriedades para o ar e para dutos

Com os valores adotados para 0 ar, a planilha calcula a vazão mássica, velocidade mássica, pressão dinâmica, número de Reynolds, coeficiente de perda distribuída, e a perda distribuída de cada trecho. A figura B2 mostra a planilha com os valores. 
DETERMINACAO DAS PERDAS DISTRIBUIDAS

\begin{tabular}{|c|c|c|c|c|c|c|c|c|c|c|c|c|c|c|}
\hline TRECHO & a & $\bar{b}$ & Velocidade & $S$ & Pinolhado & $\overline{D h}$ & Opad & $\mathrm{m}$ & $\bar{G}$ & $\mathrm{pd}$ & NRE & f & L & Dp(distr. \\
\hline & $\mathrm{m}$ & $\mathrm{m}$ & $\mathrm{m} / \mathrm{s}$ & $m^{2}$ & $\mathrm{~m}$ & $\mathrm{~m}$ & $\mathrm{~m} 3 \mathrm{~h}$ & $\mathrm{~kg} / \mathrm{s}$ & $\mathrm{kg} / \mathrm{sm} 2$ & $P_{a}$ & & & $\mathrm{~m}$ & $\mathrm{~Pa}$ \\
\hline 1 & 0.4 & 0,25 & 5,00 & 0,1000 & 1,3 & 0,31 & 1800 & 0,602 & $\frac{6,02}{6,12}$ & 15,05 & 101885 & 0,01936 & 90 & 8,5 \\
\hline 2 & 0,40 & 0,25 & 5,00 & 0,1000 & 1,3 & 0,31 & 1800 & 0,602 & 6,02 & 15,05 & 101885 & 0,01936 & 30 & 28 \\
\hline 3 & 0,45 & 0,40 & 5,56 & 0,1800 & 1,7 & 0,42 & 3600 & 1,204 & 6,69 & 1858 & 155824 & 0,01756 & 60 & 46 \\
\hline 4 & 0,40 & 0,25 & 5,00 & 0,1000 & 1,3 & 0,31 & 1800 & 0,602 & 6,02 & 15,05 & 101885 & 0,01936 & 30 & 28 \\
\hline 5 & 0,55 & 0,40 & 6,82 & 0,2200 & 19 & 0,46 & 5400 & 1,806 & 8,21 & 27,99 & 209132 & 0,01661 & 90 & 90 \\
\hline 6 & 0,40 & 0,25 & 5,00 & 0,1000 & 1,3 & 0,31 & 1800 & 0,602 & 6,02 & 15,05 & 101885 & 0,01936 & 90 & 85 \\
\hline 7 & 0,40 & 0,25 & 5,00 & 0,1000 & 1,3 & 0,31 & 1800 & 0,602 & 6,02 & 15,05 & 101885 & 0,01936 & 30 & 28 \\
\hline 8 & 0,45 & 0,40 & 5,56 & 0,1800 & 1,7 & 0,42 & 3600 & 1,204 & 6,69 & 18,58 & 155824 & 0,01756 & 60 & 4,6 \\
\hline 9 & 0,40 & 0,25 & 5,00 & 0,1000 & 1,3 & 0,31 & 1800 & 0,602 & 6,02 & 15,05 & 101885 & 0,01936 & 30 & 28 \\
\hline 10 & 0,55 & 0,40 & 6,82 & 0,2200 & 19 & 0,46 & 5400 & 1,806 & 8,21 & 27,99 & 209132 & 0,01661 & 30 & 30 \\
\hline 11 & 1,00 & 0,40 & 7,50 & 0,4000 & 28 & 0,57 & 10800 & 3612 & 9,03 & 33,86 & 283822 & 0,01553 & 60 & 55 \\
\hline 12 & 0,25 & 0,25 & 4,00 & 0,0625 & 1 & 0,25 & 900 & 0,301 & 4,82 & 963 & 66225 & 0,02123 & 60 & 49 \\
\hline 13 & 0,40 & 0,25 & 5,00 & 0,1000 & 1,3 & 0,31 & 1800 & 0,602 & 6,02 & 15,05 & 101885 & 0,01936 & 170 & 16,1 \\
\hline 14 & 0,25 & 0,25 & 4,00 & 0,0625 & 1 & 0,25 & 900 & 0,301 & 4,82 & 9,63 & 66225 & 0,02123 & 6,0 & 49 \\
\hline 15 & 0,40 & 0,25 & 5,00 & 0,1000 & 1,3 & 0,31 & 1800 & 0,602 & 6,02 & 15,05 & 101885 & 0,01936 & 30 & 28 \\
\hline 16 & 0,45 & 0,40 & 5,56 & 0,1800 & 1,7 & 0,42 & 3600 & 1,204 & 6,69 & 1858 & 155824 & 0,01756 & 30 & 2,3 \\
\hline 17 & 1,30 & 0,40 & 7,69 & 0,5200 & 3,4 & 0,61 & 14400 & 4,816 & 9,26 & 35,62 & 311648 & 0,02230 & 100 & 130 \\
\hline 18 & 0,60 & 0,80 & 8,33 & 0,4800 & 28 & 0,69 & 14400 & 4,816 & 10,03 & 41,81 & 378430 & 0,02162 & 30 & 4,0 \\
\hline 19 & 0,60 & 0,40 & 6,25 & 0,2400 & 2 & 0,48 & 5400 & 1,806 & 7,53 & 23,52 & 198675 & 0,01669 & 6,0 & 49 \\
\hline 20 & 0,75 & 0,60 & 6,67 & 0,4500 & 27 & 0,67 & 10800 & 3,612 & 8,03 & 26,76 & 294334 & 0,01521 & 32,0 & 19.5 \\
\hline 21 & 0,35 & 0,40 & 7,14 & 0,1400 & 1,5 & 0,37 & 3600 & 1,204 & 8,60 & 30,71 & 176600 & 0,02529 & 60 & 12,5 \\
\hline 22 & 0,75 & 0,75 & 7,11 & 0,5625 & 3 & 0,75 & 14400 & 4,816 & 8,56 & 30,44 & 353201 & 0,01463 & 10,0 & 5,9 \\
\hline
\end{tabular}

Figura B2 - Planilha Excel: Perdas distribuídas

$\mathrm{Na}$ Tabela "Determinação das Perdas Localizadas", são inseridos os coeficientes e valores de perda para os acessórios localizados em cada trecho da rede, sendo totalizadas as perdas localizadas. Estes valores são apresentados na figura B3. 
DETERMINACAODAS PERDAS LOCALLZRDAS

\begin{tabular}{|c|c|c|c|c|c|c|c|c|c|c|c|c|c|c|c|c|c|c|c|c|}
\hline \multirow[t]{2}{*}{ TRECHO } & \multicolumn{3}{|c|}{ TRANASCSO } & \multicolumn{6}{|c|}{ JUNCOESONERGENTES } & \multicolumn{3}{|c|}{ JOELHOS } & Diflusores & \multicolumn{3}{|c|}{ REEGSTRO } & Dpplocol.1. & \multicolumn{3}{|c|}{$\triangle C E S \triangle O R I O S$} \\
\hline & $\mathrm{C}$ & pd & $D_{p}$ & $c b$ & $a$ & pds & Doptb & DoTs & Dpiunçós & c & $\mathrm{pd}$ & $D_{p}$ & & $\mathrm{C}$ & $p d$ & $D_{p}$ & & 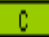 & $P d$ & $D_{p}$ \\
\hline & & $P_{s}$ & $P_{0}$ & & & $P_{0}$ & $P_{s}$ & $P_{0}$ & $P_{i}$ & & $p_{0}$ & $P_{0}$ & $P_{0}$ & & $P_{s}$ & $P_{0}$ & $P_{A}$ & & $P_{s}$ & $P_{s}$ \\
\hline 1 & 0,05 & 15,05 & 0,7525 & & & & & & & 0,17 & 15,05 & 25585 & 37,28 & 0,04 & 15,05 & 0,602 & 59,3 & 1,20 & 15,05 & 18,06 \\
\hline 2 & 0,05 & 15,05 & 0,1525 & & & & & & & & & & 37,28 & 0,04 & 15,05 & 0,602 & 38,6 & & & \\
\hline 3 & 0,05 & 18,58 & 0,9290 & & & & & & & & & & & & & & 0,9 & & & \\
\hline 4 & 0,05 & 15,05 & 0,7525 & & & & & & & & & & 37,28 & 0,04 & 15,05 & 0,602 & 38,6 & & & \\
\hline 5 & & & & & 0,06 & 22,99 & & 1,68 & 1,68 & 0,15 & 21,99 & 4,497830588 & & 0,04 & 21,99 & 1,11942 & 1,0 & & & \\
\hline 6 & 0,05 & 15,05 & 0,7525 & & & & & & & 0,17 & 15,05 & 25585 & 37,28 & 0,04 & 15,05 & 0,602 & 59,3 & 1,20 & 15,05 & 18,06 \\
\hline 1 & 0,05 & 15,05 & 0,7525 & & & & & & & & & & 37,28 & 0,04 & 15,05 & 0,602 & 38,6 & & & \\
\hline 8 & 0,05 & 18,88 & 0,92930 & & & & & & & & & & & & & & 0,9 & & & \\
\hline 9 & 0,05 & 15,05 & 0,7525 & & & & & & & & & & 31,28 & 0,04 & 15,05 & 0,602 & 38,6 & & & \\
\hline 10 & & & & 0,63 & & 21,99 & 10,6309 & & 10,63080884 & & & & & 0,04 & 27,99 & 1,11942 & 18,8 & & & \\
\hline 11 & & & & & $.0,05$ & 33,86 & & .16933125 & .1693125 & & & & & & & & 1,1, & & & \\
\hline 12 & 0,06 & 963 & 0,57792 & & & & & & & 0,9 & 9,63 & 8,6688 & 33,35 & & & & 426 & & & \\
\hline 13 & 0,05 & 15,05 & 0,7525 & & & & & & & 0,12 & 15,05 & 1,806 & & 0,04 & 15,05 & 0,602 & 3,2 & & & \\
\hline 14 & 0,06 & 963 & 0,57792 & & & & & & & 0,9 & 9,63 & 8,6668 & 33,35 & & & & 426 & & & \\
\hline 15 & & & & & & & & & & & & & & 0,04 & 15,05 & 0,602 & $111, ?$ & 0,74 & 15,05 & 11,14 \\
\hline 16 & & & & 0,84 & & 18,58 & 15,6074 & & 15,6074074 & & & & & & & & 156 & & & \\
\hline 17 & 0,25 & 35,62 & 8,9053 & & & & & & & & & & & 0,38 & 35,62 & 13,5361 & 224 & & & \\
\hline 18 & & & & & & & & & & & & & & & & & 0,0 & & & \\
\hline 19 & 0,25 & 23,52 & 588789 & & & & & & & 1,8 & 23,52 & 42,328125 & 2256 & & & & 83,2 & 0,53 & 23,52 & 12,46 \\
\hline 20 & 0,2 & 26,76 & 3,55311 & & & & & & & 0,16 & 26,76 & 4,280680880 & & & & & 18,5 & 0,33 & 26,76 & 8,83 \\
\hline 21 & 0,3 & 30,71 & 9,2142 & & & & & & & & & & 2256 & 1,88 & 30,71 & 50,1429 & 18,2 & $0,0,31$ & 30,71 & $.11,36$ \\
\hline 22 & 0,25 & 30,44 & 9,604 & & & & & & & & & & & & & & 38,1 & 1,00 & 30,44 & 30,44 \\
\hline
\end{tabular}

Figura B3 - Planilha Excel: Perdas Localizadas

Com os resultados das perdas distribuídas e das localizadas obtem-se as perdas totais para cada um dos trechos conforme apresentado na figura B4.

\begin{tabular}{|c|c|}
\hline TRECHO & DpT(trecho) \\
\hline & $\mathrm{Pa}$ \\
\hline 1 & 67,8 \\
\hline 2 & 41,4 \\
\hline 3 & 5,5 \\
\hline 4 & 41,4 \\
\hline 5 & 16,0 \\
\hline 6 & 67,8 \\
\hline 7 & 41,4 \\
\hline 8 & 5,5 \\
\hline 9 & 41,4 \\
\hline 10 & 21,8 \\
\hline 11 & 3,8 \\
\hline 12 & 47,5 \\
\hline 13 & 19,3 \\
\hline 14 & 47,5 \\
\hline 15 & 14,5 \\
\hline 16 & 17,9 \\
\hline 17 & 35,4 \\
\hline 18 & 4,0 \\
\hline 19 & 88,1 \\
\hline 20 & 38,0 \\
\hline 21 & 90,7 \\
\hline 22 & 44,0 \\
\hline
\end{tabular}

Figura B4 - Planilha Excel: Perdas Totais 
Como última etapa no uso da planilha obtem-se os níveis de pressão nos nós e as diferenças de pressão de balanceamento. Conforme apresentado na figura B5.

Nesta tabela são calculados os diferencias de pressão de balanceamento dos caminhos em paralelo tendo como inicio um determinado nó. Outro dado adicional é o coeficiente de balanceamento, com a finalidade de conhecer qual é o valor do coeficiente a ser mudado.

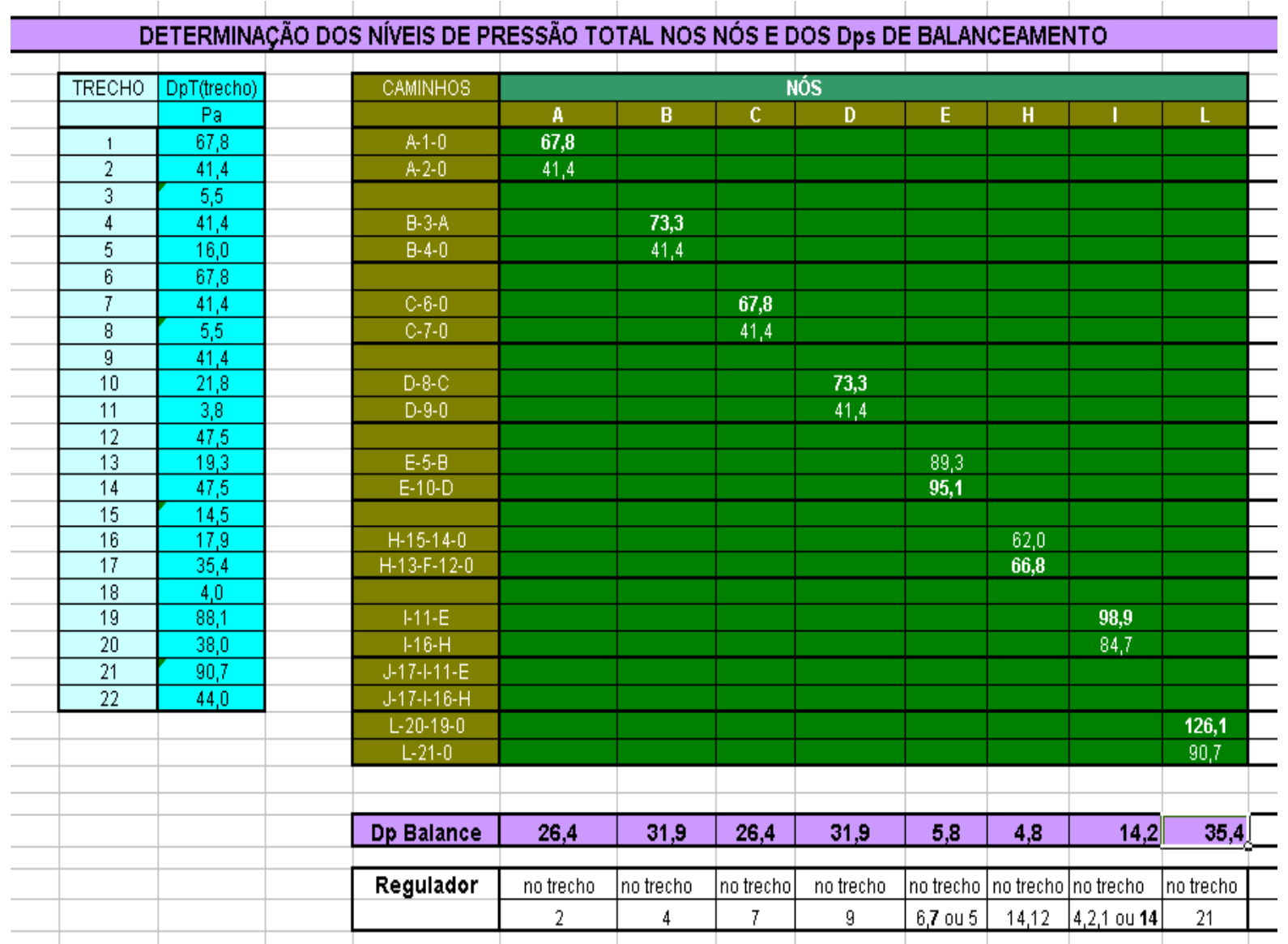

Figura B5 - Planilha Excel: Resultados para o balanceamento 


\section{APÊNDICE C}

\section{ESTUDO DE CASO II - PROGRAMA T DUCT}

Como foi mencionado no capítulo seis, em paralelo com o desenvolvimento do programa DOBAL, foi simulado no programa T-Duct para calcular o balanceamento dos trechos da rede simulando o escoamento com as vazões de projeto.

Foi obtido o valor percentual da vazão do projeto para cada um dos trechos com a finalidade de comparar os resultados calculados no programa T-Duct com os determinados pelo programa DOBAL. Assim pode-se avaliar se o algoritmo adotado no programa DOBAL obtém bons resultados.

$\mathrm{Na}$ seguinte figura $\mathrm{C} 1$ é apresentada a tela com a entrada dos primeiros dados no programa: Nome do Arquivo, Nome do projeto a ser simulado e Unidade que será utilizado no projeto, Nome da empresa, Nome do usuário da parte $C$ da figura 6.5 para o Estudo de Caso II.

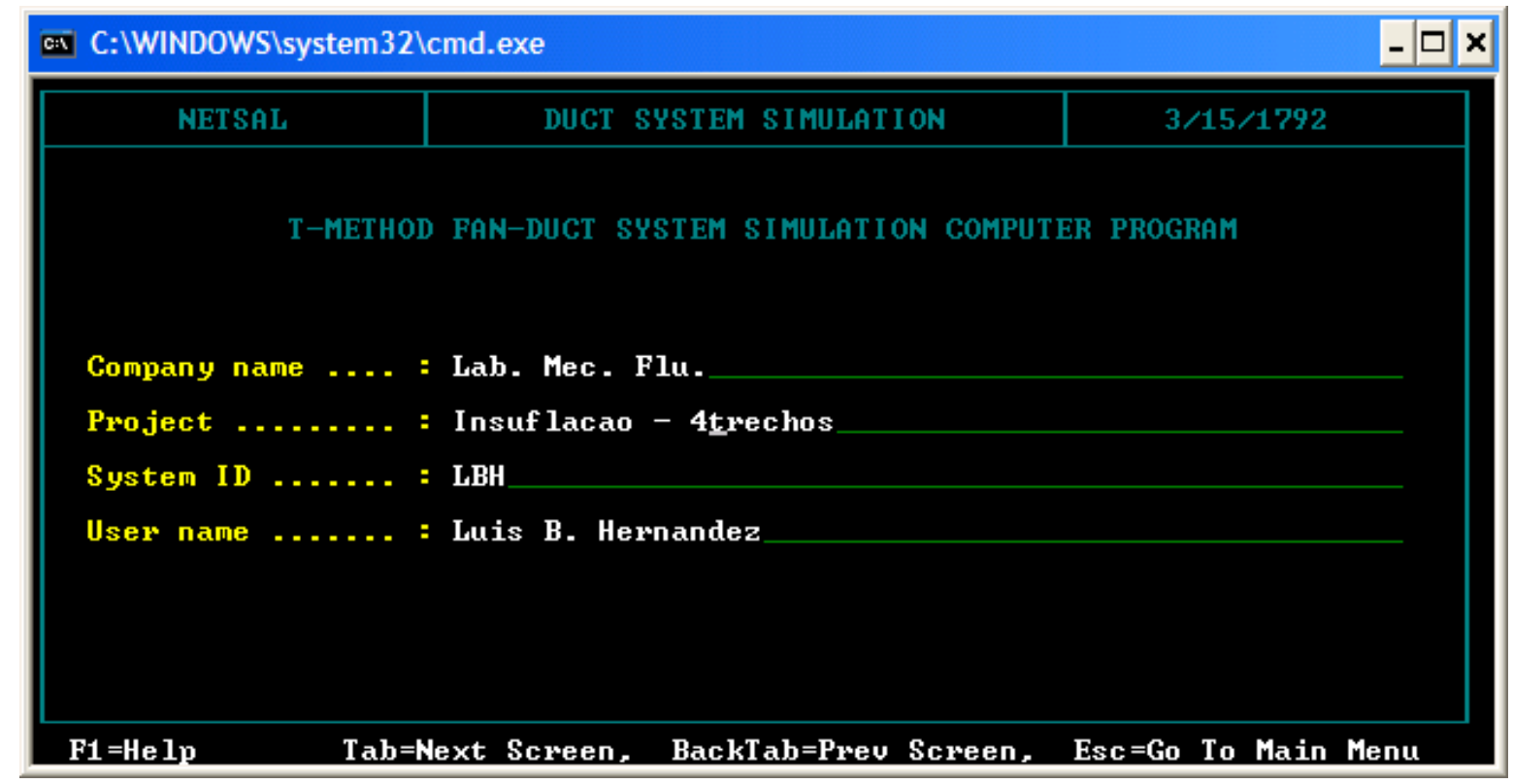

Figura C1 - Programa T-Duct : Identificação do projeto (Parte C) 
Na seguinte figura C2 é mostrada a vazão em valores percentuais na primeira simulação do programa com os 4 trechos da parte $C$

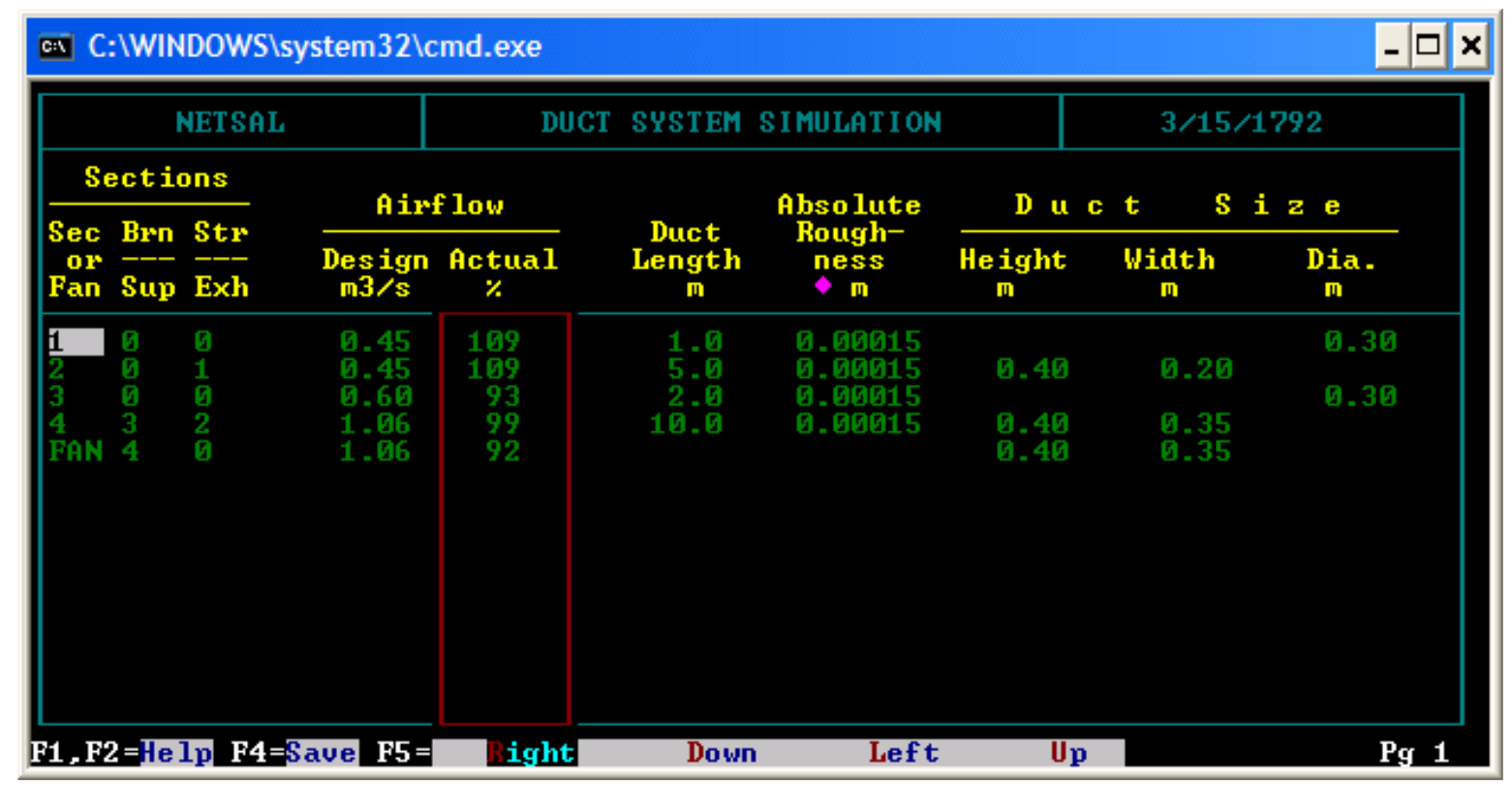

Figura C2 - Programa T-Duct : 1로 Simulação (Parte C)

$\mathrm{Na}$ seguinte figura C3 são mostrados os valores de perdas adicionais inseridos para a obtenção do balanceamento, estas perdas são os utilizados e calculados mediante o programa DOBAL, utilizado também o número do trecho proposto pelo mesmo aplicativo.

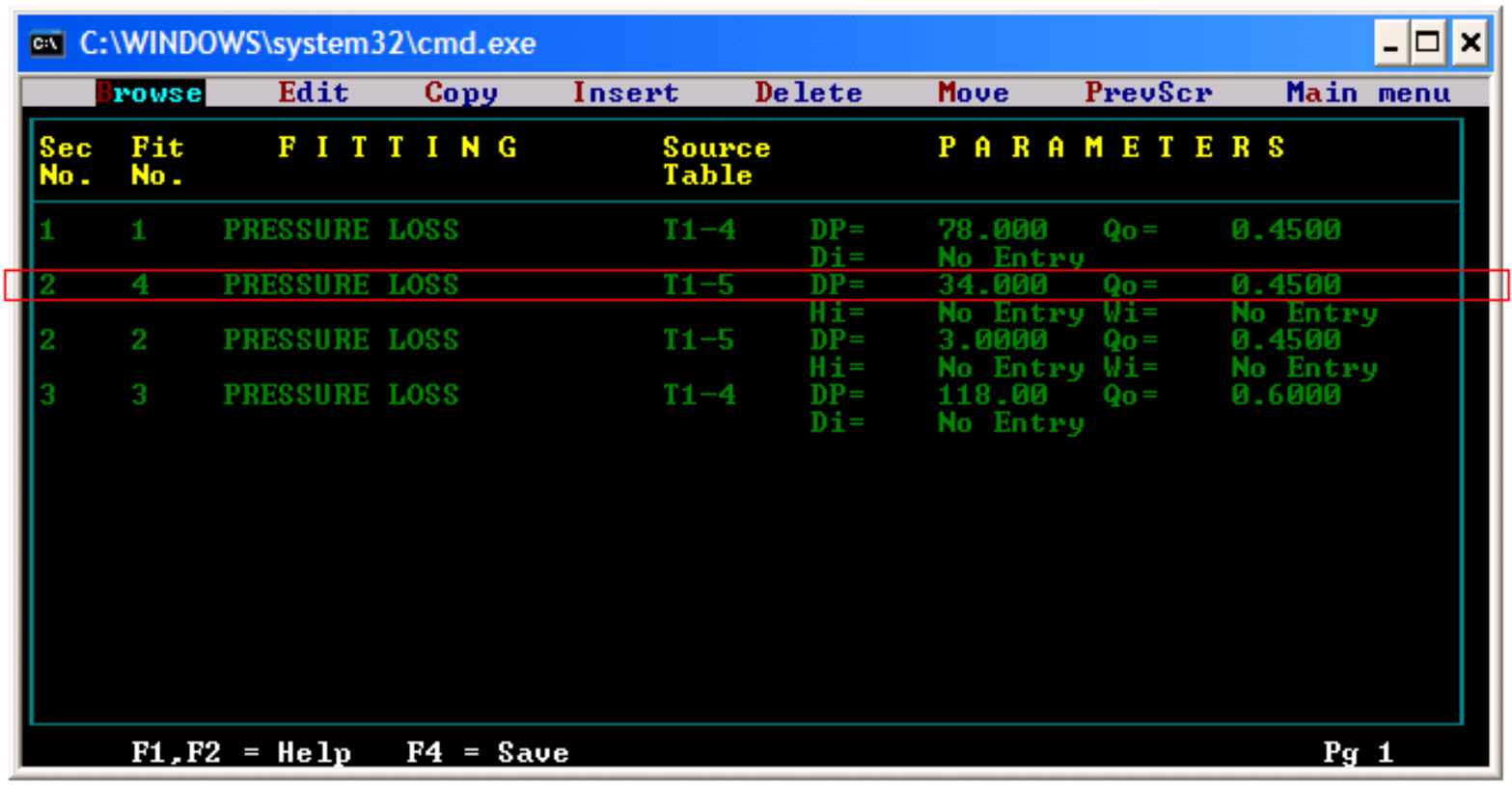

Figura C3 - Programa T-Duct : Perda adicional (Parte C) 
Após ser inserido este valor é feita a simulação e calculado mediante iterações os novos valores da parte $\mathrm{C}$ da rede de insuflação. A figura $\mathrm{C} 4$ mostra os valores calculados.

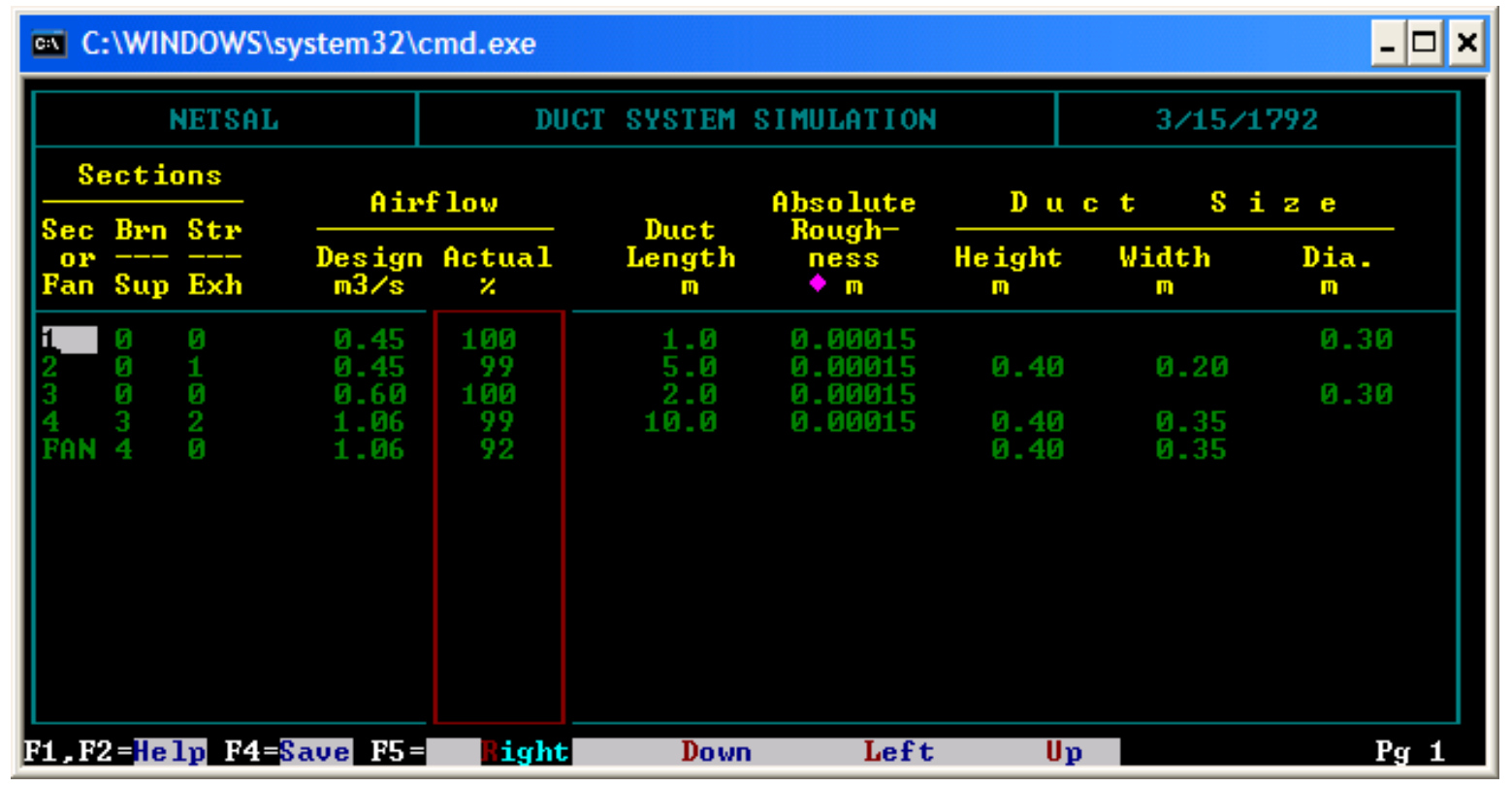

Figura C4 - Programa T-Duct : Balanceamento (Parte C)

A seguinte parte da rede de insuflação é a parte B que contem 6 trechos e é mostrado na figura $\mathrm{C} 5$.

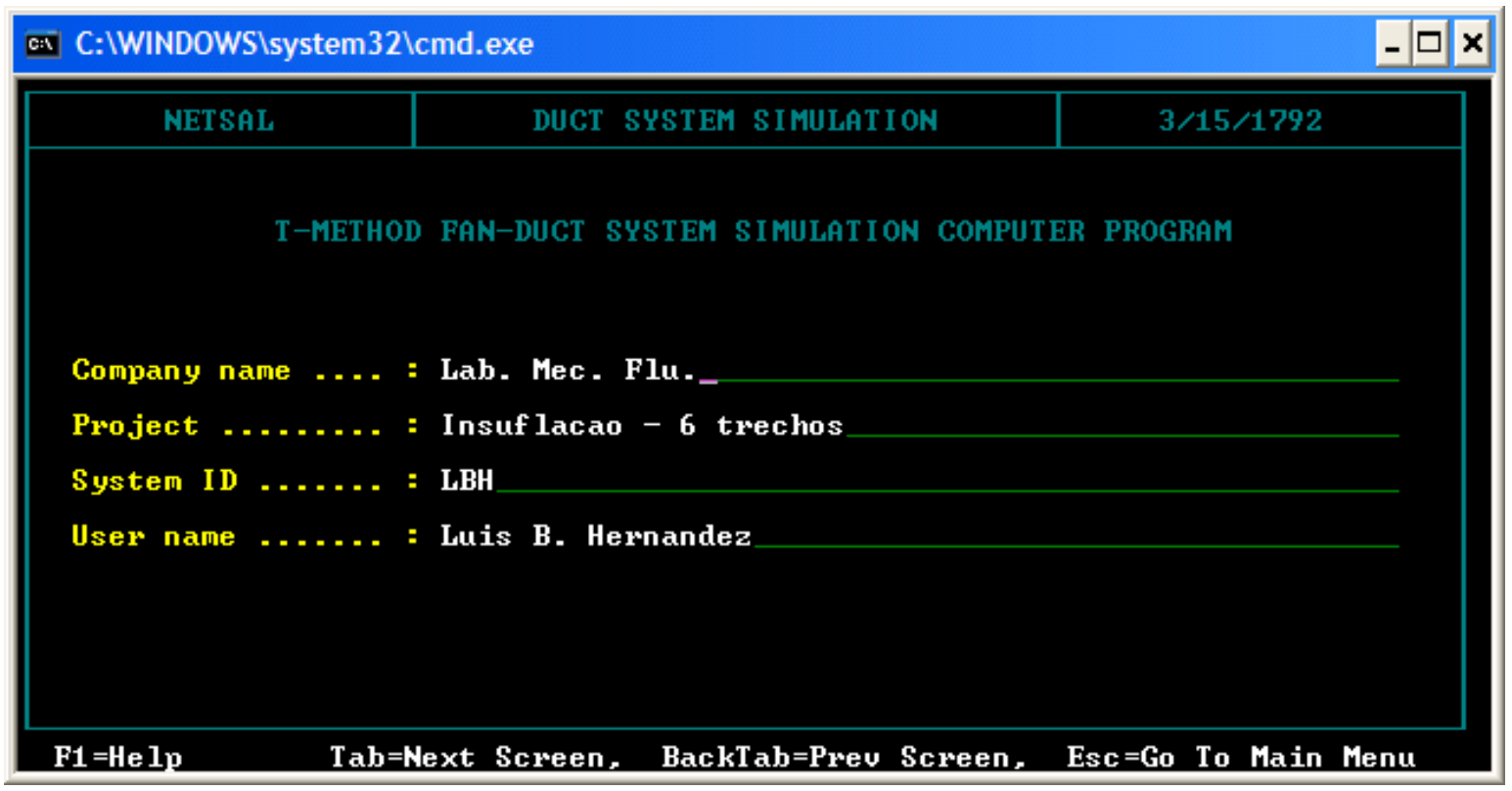

Figura C5 - Programa T-Duct : Identificação do projeto (Parte B) 
Na seguinte figura C6 é mostrada a vazão em valores percentuais na primeira simulação do programa com os 6 trechos da parte B.

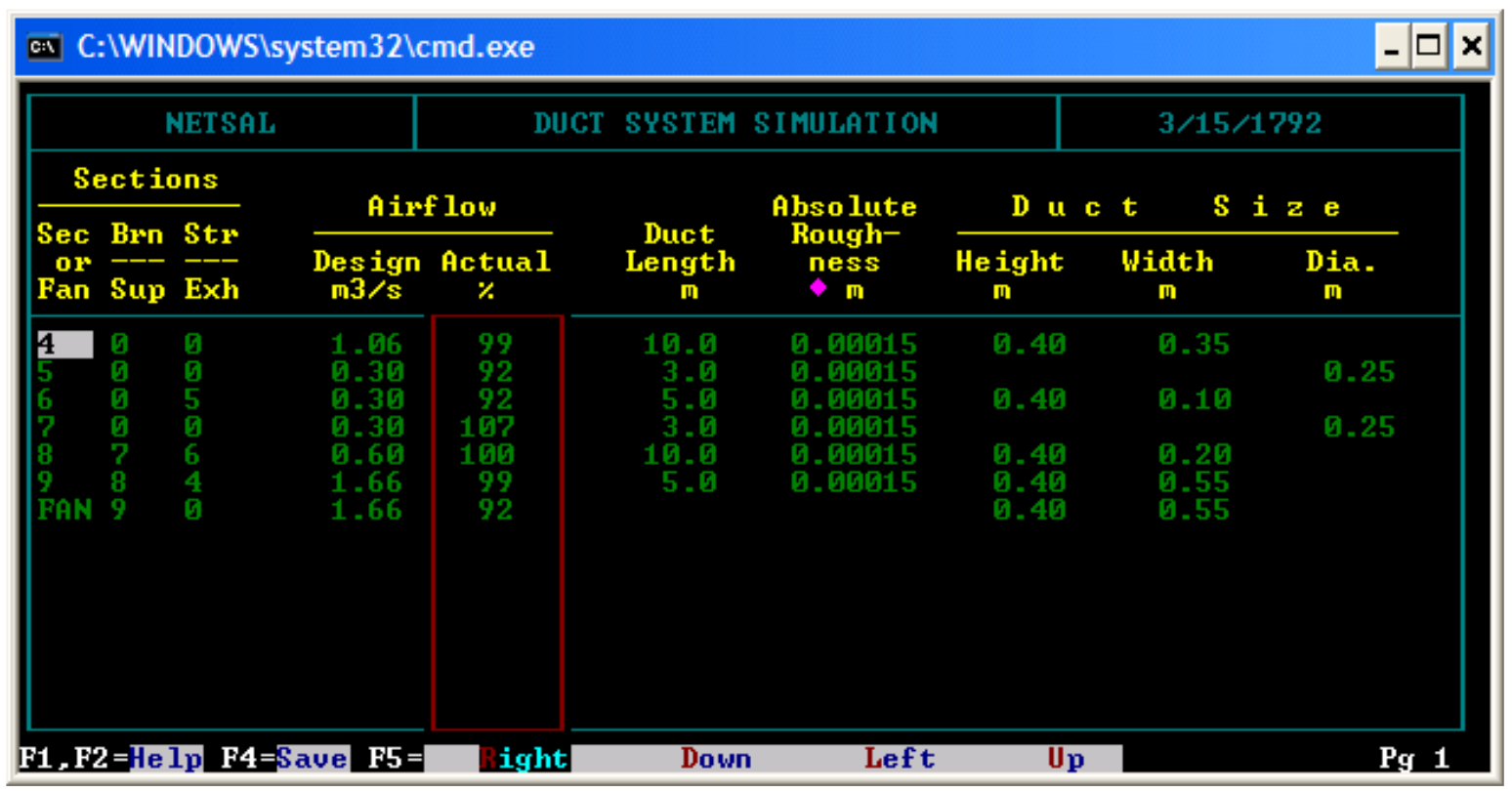

Figura C6 - Programa T-Duct : 1a Simulação (Parte B)

$\mathrm{Na}$ seguinte figura C7 são mostrados os valores de perdas adicionais inseridos para a obtenção do balanceamento, estas perdas são os utilizados e calculados mediante o programa DOBAL, utilizado também o número do trecho proposto pelo mesmo aplicativo.

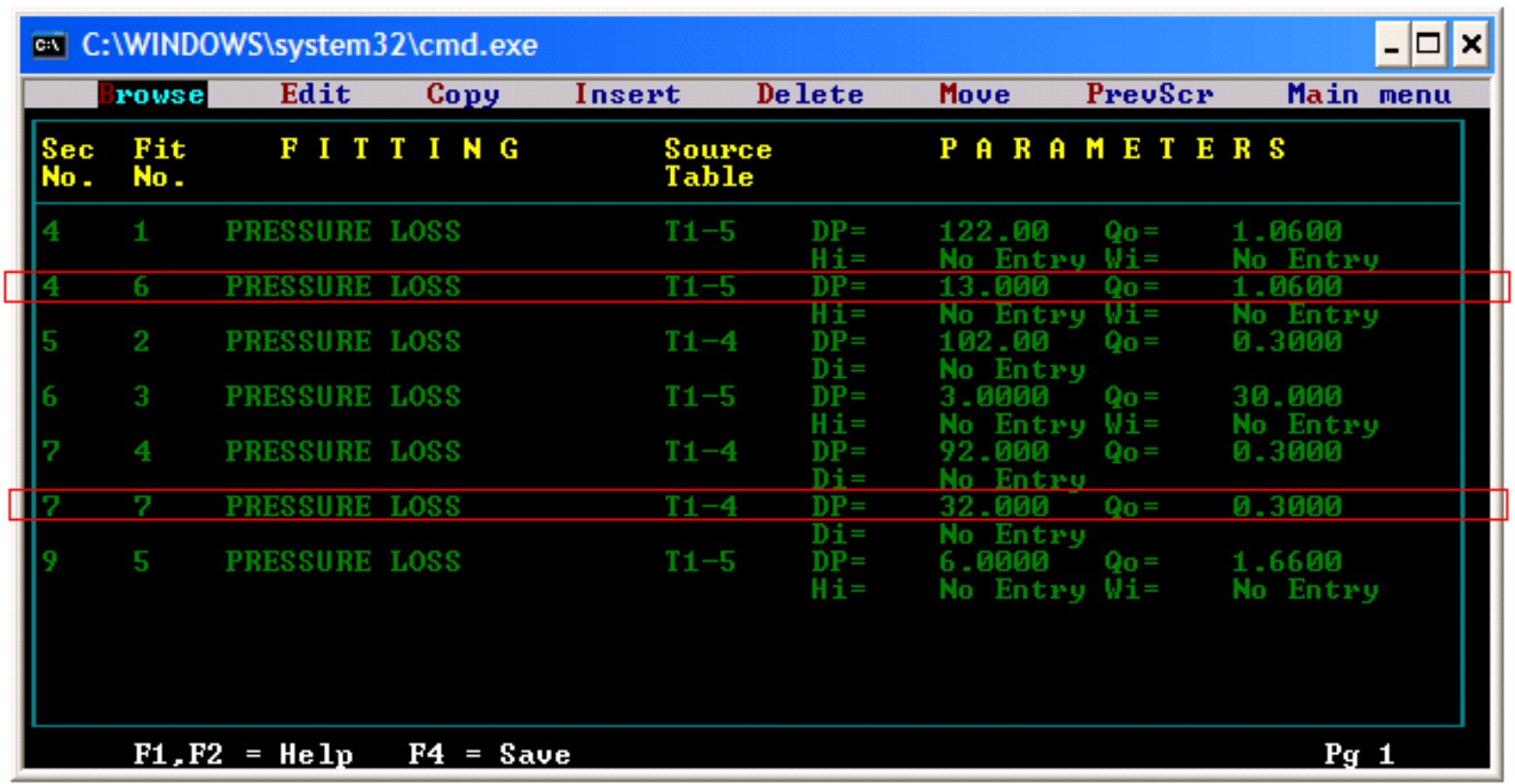

Figura C7 - Programa T-Duct : Perda adicional (Parte B) 
Após ser inserido estes valores nos trechos 4 e 7 é feita a simulação e calculado mediante iterações os novos valores da parte $B$ da rede de insuflação. $A$ figura C8 mostra os valores calculados.

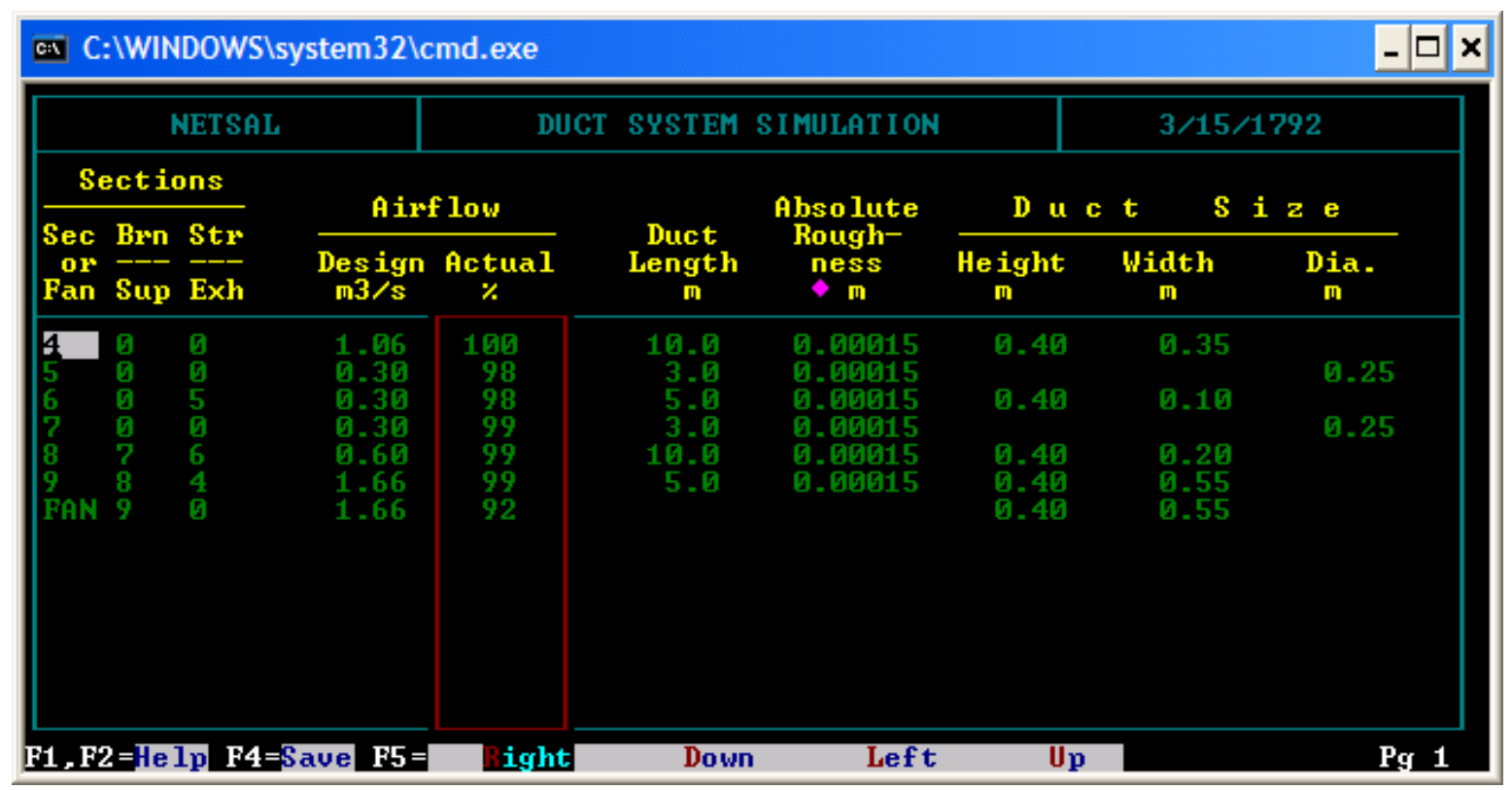

Figura C8 - Programa T-Duct : Balanceamento (Parte B)

A figura C9 mostra a rede de aspiração e sua identificação. Ele encontra-se na parte A da figura 6.5. Este sistema contém 5 trechos.

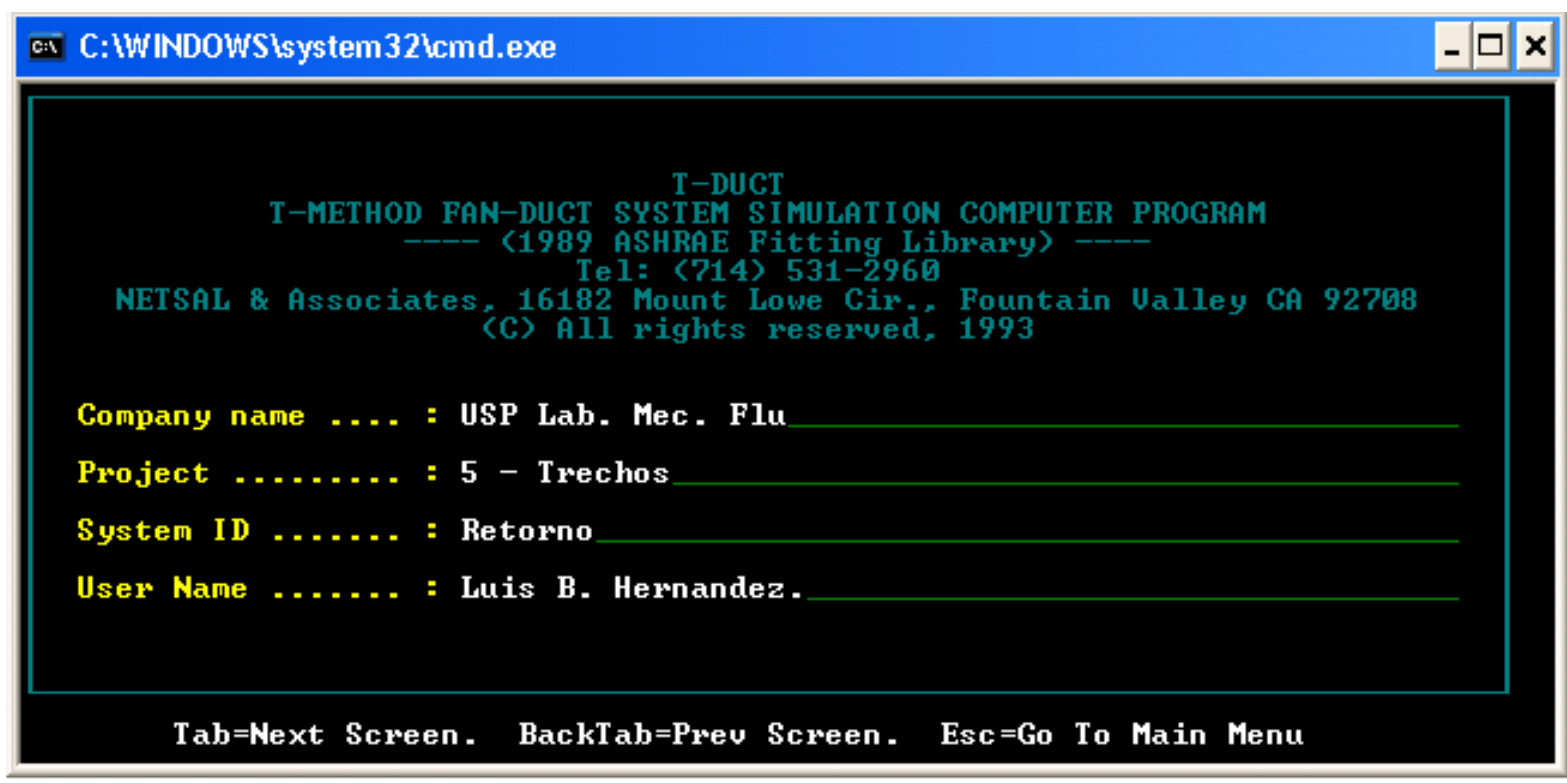

Figura C9- Programa T-Duct : Identificação do projeto (Parte A) 
$\mathrm{Na}$ seguinte figura C10 é mostrada a vazão em valores percentuais na primeira simulação do programa com os 5 trechos da parte A.

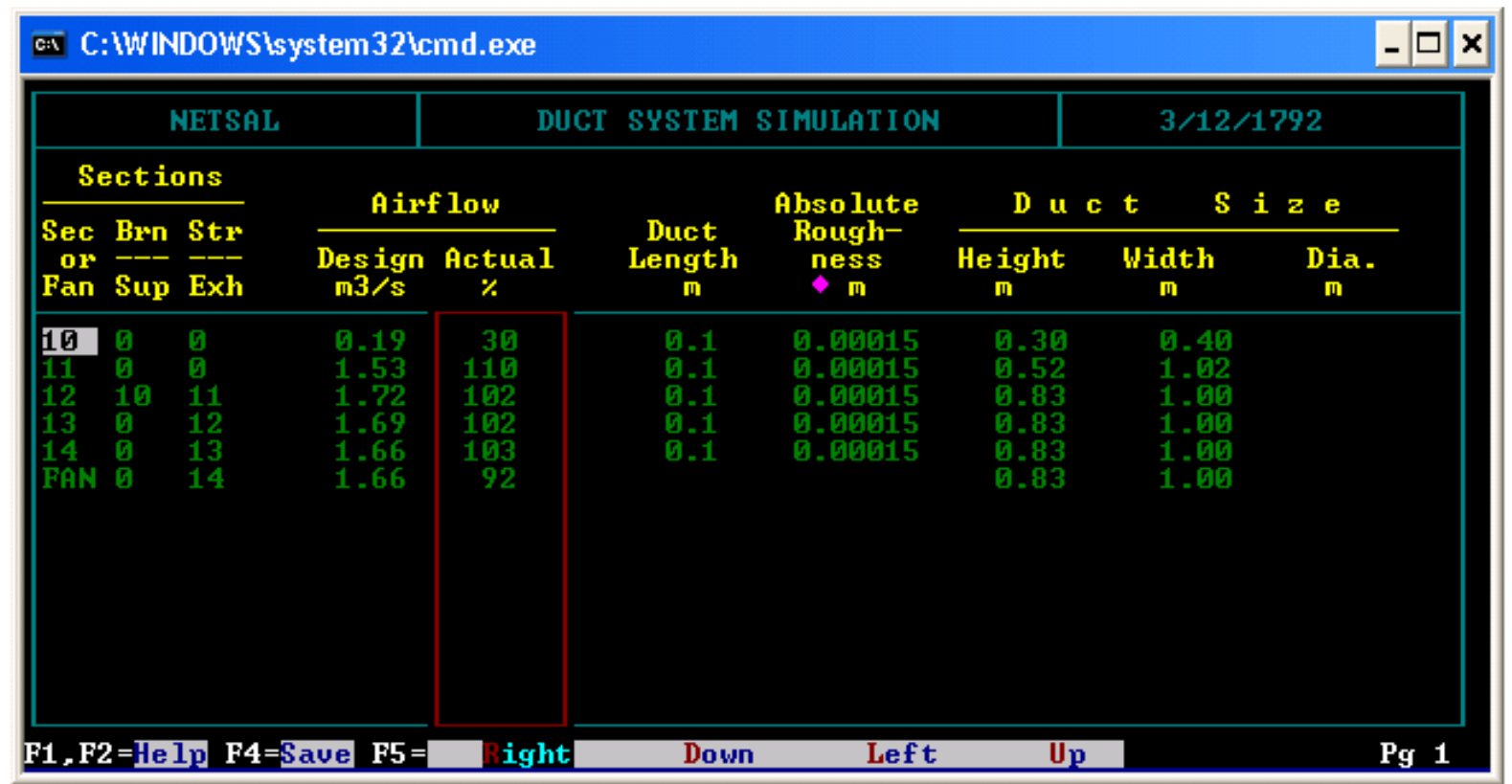

Figura C10 - Programa T-Duct : 1ª Simulação (Parte A)

$\mathrm{Na}$ seguinte figura C11 são mostrados os valores de perdas adicionais inseridos para a obtenção do balanceamento. Estes valores coincidem propositalmente com as necessidades de balanceamento obtidas no programa DOBAL.

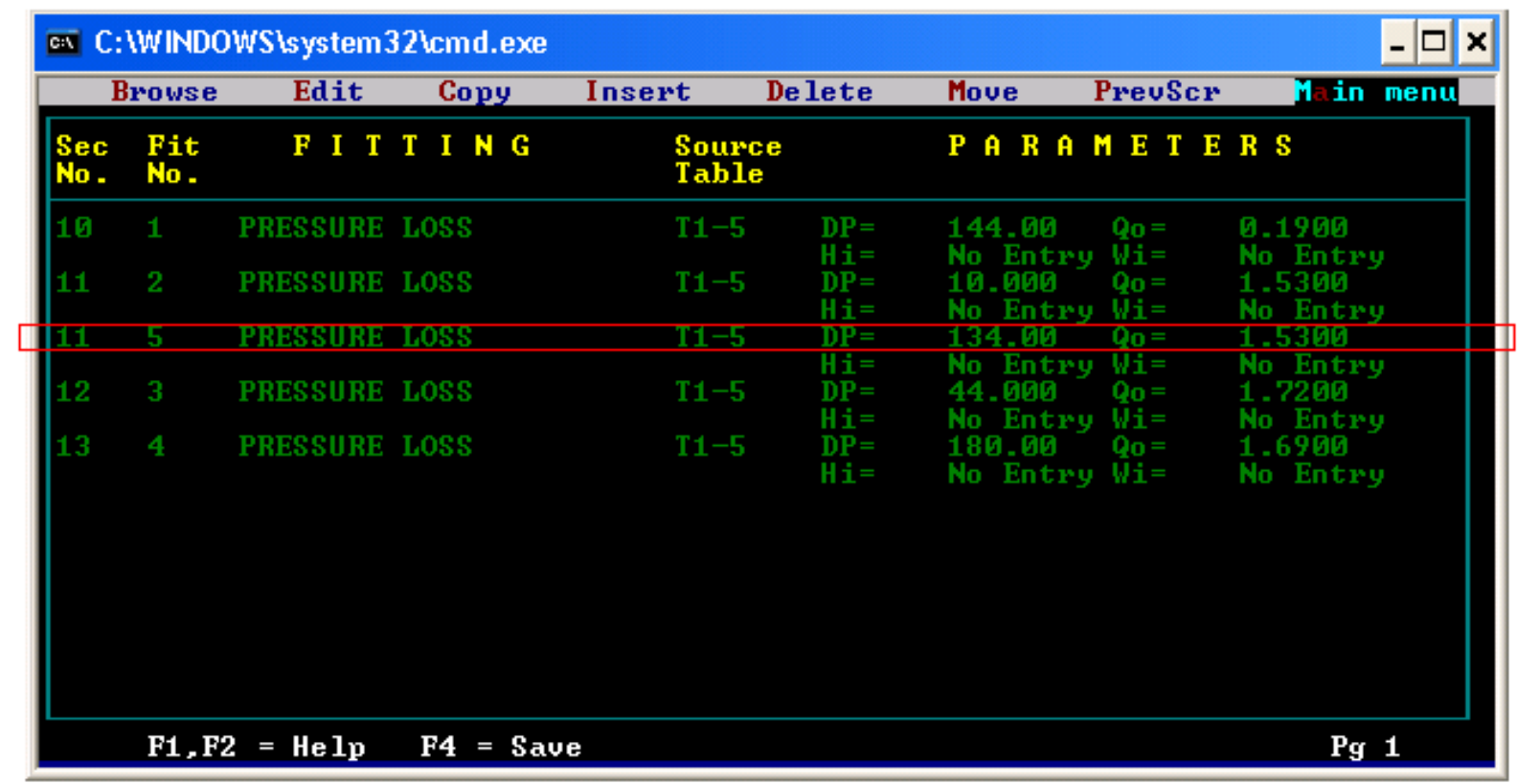

Figura C11 - Programa T-Duct : Perda adicional (Parte A) 
Após ser inserido este valor é feita a simulação e calculado mediante iterações os novos valores da parte A da rede de aspiração. A figura C12 mostra os valores calculados.

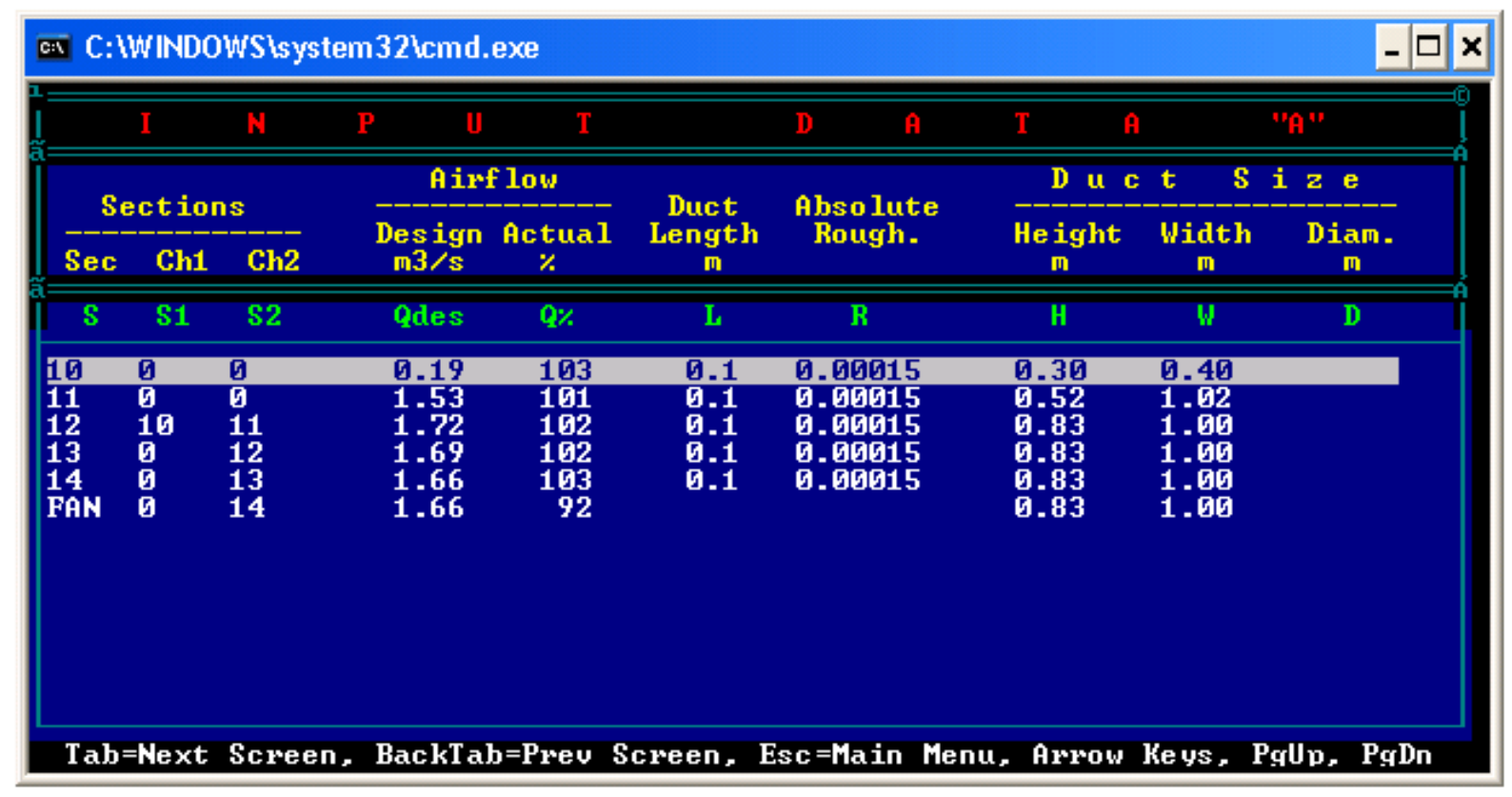

Figura C12 - Programa T-Duct : Balanceamento (Parte A) 